UNIVERSITAT POLITÈCNICA DE VALÈNCIA

DEPARTAMENTO DE QUÍMICA

INSTITUTO UNIVERSITARIO MIXTO DE TECNOLOGÍA QUÍMICA (UPV-CSIC)
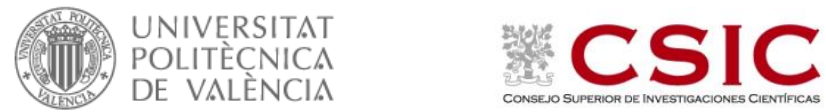

\title{
ELIMINACIÓN CATALÍTICA DE NITRATOS EN CONTINUO EN AGUAS NATURALES
}

\author{
TESIS DOCTORAL \\ Presentada por: \\ CRISTINA FRANCH MARTÍ \\ Dirigida por: \\ Dr. ANTONIO EDUARDO PALOMARES GIMENO
}

VALENCIA, 2011 



\title{
ELIMINACIÓN CATALÍTICA DE NITRATOS EN CONTINUO \\ EN AGUAS NATURALES
}

\author{
MEMORIA \\ Presentada por: \\ CRISTINA FRANCH MARTí
}

Dirigida por:

Dr. ANTONIO EDUARDO PALOMARES GIMENO

Para optar al título de:

DOCTOR

UNIVERSITAT POLITÈCNICA DE VALÈNCIA

DEPARTAMENTO DE QUÍMICA

INSTITUTO UNIVERSITARIO MIXTO DE TECNOLOGÍA QUÍMICA (UPV-CSIC)

VALENCIA, 2011 





\section{Agradecimientos/Agraïments}

En estes línees vull agrair tot el suport que m'han donat totes les persones que han estat al meu costat en estos sis anys que estic al ITQ.

En primer lloc vull donar les gràcies al Prof. Avelino Corma per haver-me donat l'oportunitat de realitzar la tesi al seu Institut, per espentar-me a fer-la i per estar sempre disponible per a donar idees científiques o per a donar suport moral.

Per suposat vull agrair al meu director de tesi, el Dr. Eduardo Palomares, per ensenyar-me tantes coses, per ser un bon jefe, un bon professor i millor persona, per deixar-me fer i desfer en tot lo que he volgut i per la seua ajuda i dedicació.

Agradecer a los participantes del proyecto MONACAT su inestimable ayuda y su dedicación durante todo el proyecto.

Gracias al personal investigador por tener siempre las puertas abiertas, en especial a Urbano por enseñarme tantas cosas acerca de las zeolitas, por su paciencia y sus consejos, y a Fernando por darme la oportunidad de trabajar en el sincrotrón.

También quiero dar las gracias a la gente de administración, taller e informática (en especial a Javi H.), por las horas que han perdido conmigo y por su paciencia. A Ma Amparo por tantas conversaciones. A la gente de la planta baja, no sólo por sus tareas de caracterización que tanta falta nos hacen, si no por compartir los primer años aquí en el ITQ, en especial a Adelina, Fani y Chusa por tantas risas.

Quiero agradecer a $\mathrm{M}$ a Jesús su grata compañía en mi "estancia” en la biblioteca y a Mạ Ángeles que siempre tiene algo que decir para sacarme una sonrisa, gracias también por tus consejos.

A mis compañeros de $\mathrm{NO}_{\mathrm{x}}$ : a José Prato (por tu biblia), a Álvaro (por tu amistad), a Neus, Pablo, Andrea, Javi y Ada por tener tanta paciencia conmigo en estos últimos meses, por quitarme faena para que pudiera escribir, por enseñarme a enseñar (he intentado hacerlo lo mejor posible) y por tantas risas. $Y$ a los que compartieron poquito tiempo conmigo: María, Mari Carmen, Eli y Andrés. A todos, muchas gracias. 
També agrair a la gent de la primera planta amb qui he compartit tants moments: Estefanía, Chelo, Pablo, Carmen, Pedro A. (gracias por tu inestimable ayuda con la conductividad) i Vicente Vert (ipodemos!).

Agradecer a toda la gente de síntesis con los que compartí unos meses: Manu, Vicent, Tomás, Raquel S. y por supuesto a Raquel P. (per estar tan loqueta i alegrar-nos els dies al ITQ).

Gracias a todos los de reacción por hacerme un sitio entre vosotros: Rut (la broncas), Víctor (el cantaor), Yannick (el franchute), Eva Briz (la dulce), Noemí, Cristina I., Javi, Salva, Roberto, Eva, Olga, Susi, María, Fran, Segundo, Diego y por supuesto a Tere P. y a Amada, mis compañeras de reacción 4.

Moltes gràcies a Esther per fer del laboratori ECO el millor del món, a Aroa per tots els consells i per sempre estar ahí, a les Isabels per tantes converses compartides, al meu Manolo per ser el millor, per escoltar-me i aconsellar-me i a la seua Ceci per ser tan dolça, a Ángel per ser el més Xungo i a Pedro pel seu bon humor.

I què dir de les meues Maris? Què han segut les Floretes que han alegrat l'estància al ITQ, per les seues rises, els menjars compartits (sobretot el xoco!!), per estar al meu costat en els bons moments però sobretot en els roïns i per tot el que ens queda per davant. A Amparo M. perquè juntes vam fundar el grup de les Maris, a Amparo F. per saber escoltar, a Inés per compartir la tasca d'escriure una tesi i per ser la més Xunga del grup, a Teresa que tanta companyia em va fer quan estàvem en síntesis, a Belén per prestar-me sa casa sempre que ho he necessitat, a Carlos per tindre sempre temes de conversa, a Rebe per les seues rises, a Selene per les xarraetes compartides i per l'ajuda amb l'ordinador (és que sóc nul·la), a Elena per les seues rises i els seus despistes, a la Xiqui (Imma) per tantes coses compartides i per tindre sempre un somriure, a Tania per la seua dolçor i la seua inestimable ajuda en temes de la tesi i a Gonza per sempre estar disposat a respondre les meues preguntes encara que foren les més xorra del món, a Manolo H. perquè he aprés a conèixer-te i perquè no eres tan roí com intentes demostrar, a Aarón per ser una Mari més, per tants kilòmetres compartits i per ser un bon amic, a Dolo perquè juntes hem aconseguit fer dos tesis, pels moments de tensió i per ensenyarme a veure sempre el costat bo de les coses, gràcies per ser una bona amiga. 
Moltes gràcies als meus amics de Moncofa i de Vilavella per comprendre que Cris està estudiant, en especial a les meues perletes Mer i Maria per ser les Tores i per sempre tindre un moment xat per a escoltar-me, açò s'ha de celebrar en una eixideta... A la Maru per tants bons moments.

Vull agrair per estar sempre al meu costat a tota la meua família de Moncofa i Vilavella, que no són pocs!! En especial als meus sogres, als meus cunyats (Luís, Jessi, Víctor i Lore), als meus germans, Yol i Vicen, per ser els millors i per fer una pinya, i sobretot als meus pares, Vicente i Vi, per donar-me la millor educació del món, per ensenyar-me sempre tots els camins que té la vida i per fer lo impossible per a que els tres sigam les millors persones possibles, vos vull molt!!

Als meus solets, Marta i Hugo, per il·luminar-me amb la seua alegria.

Gràcies a Àlex per caminar en mi sempre al meu costat en el llarg trajecte de la carrera i la tesi, per consentir-me fer lo que més m'agrada encara que supose no haver de fer coses junts, per ser la meua mitat, per tot el que hem viscut i pel que ens queda per viure junts, TV MIL!

A TOTS MIL GRÀCIES!!! VOS VULL SUPER MÉS DEL INFINITO!!!! 

Lo que sabemos es una gota de agua,

lo que ignoramos es el océano.

Isaac Newton 



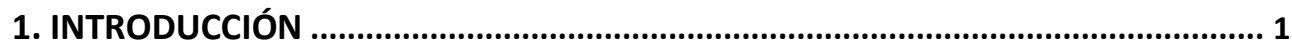

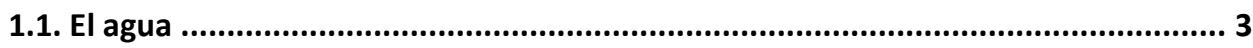

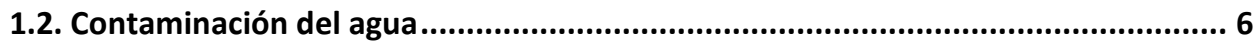

1.2.1. Clasificación de los contaminantes del agua ................................................. 7

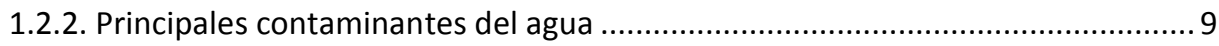

1.3. Contaminación del agua por nitratos ...........................................................10

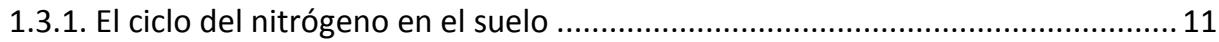

1.3.2. Fuentes de compuestos nitrogenados en las aguas naturales ........................ 13

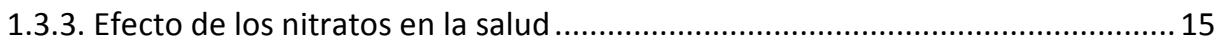

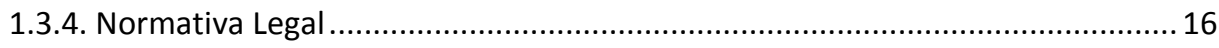

1.3.5. Los nitratos en las aguas subterráneas de la Unión Europea y España .............. 18

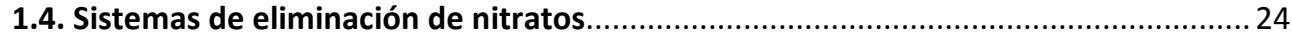

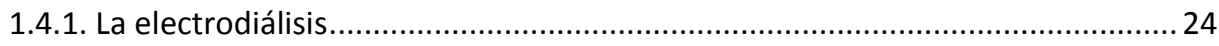

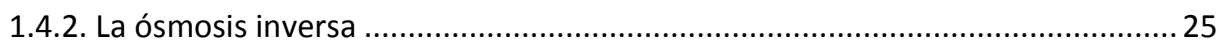

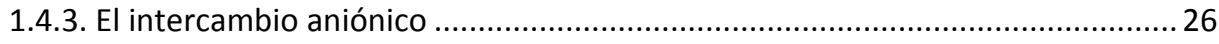

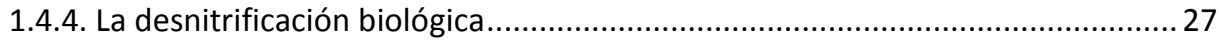

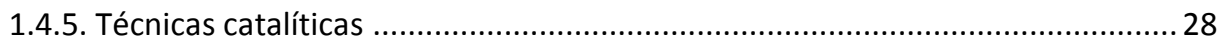

1.5. La reducción catalítica de nitratos............................................................31

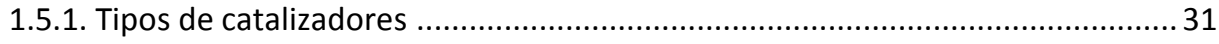

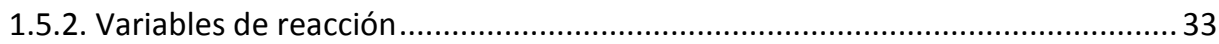

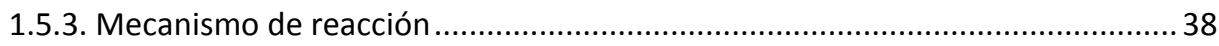

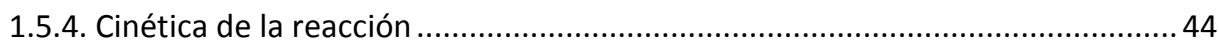

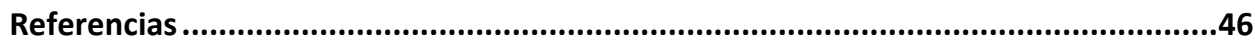

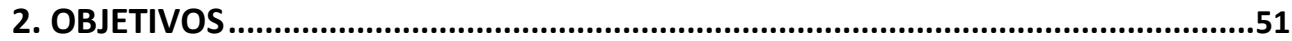

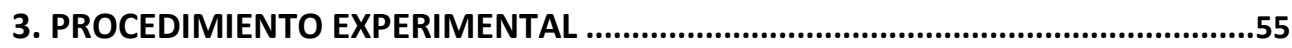

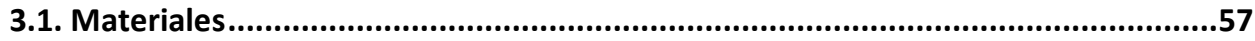

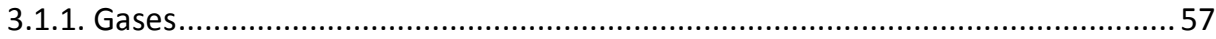

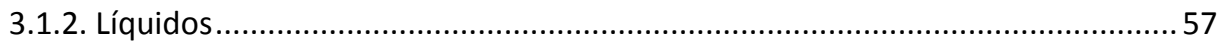

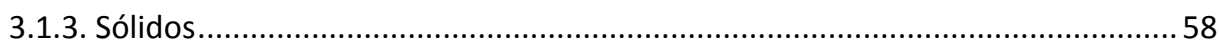

3.2. Síntesis de los soportes catalíticos ................................................................59 


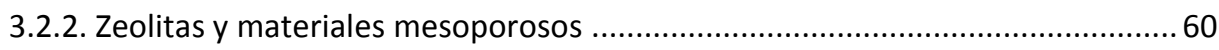

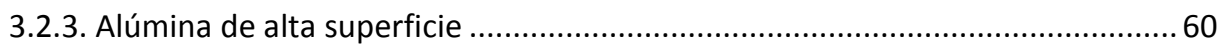

3.3. Preparación de los catalizadores .............................................................61

3.3.1. Catalizadores preparados por impregnación a volumen de poro .....................6 61

3.3.2. Catalizadores preparados por impregnación húmeda ...................................63 63

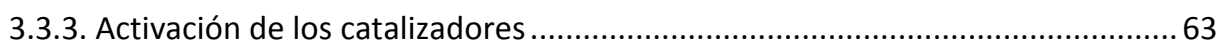

3.4. Técnicas de caracterización ....................................................................64

3.4.1. Análisis químico por Plasma de Acoplamiento Inductivo acoplado a un Espectroscopio Óptico de Emisión (ICP-OES) ........................................................... 64

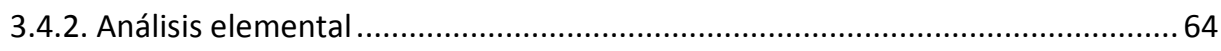

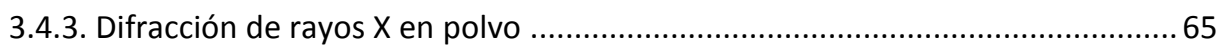

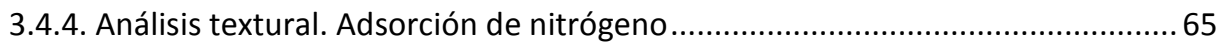

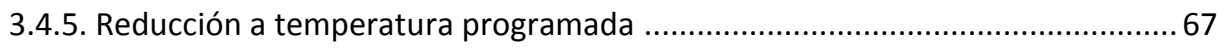

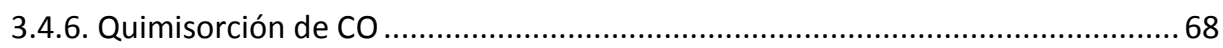

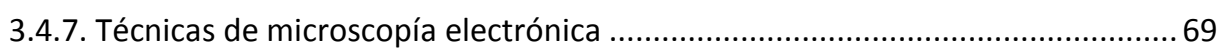

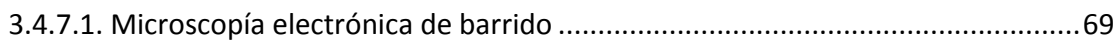

3.4.7.2. Microscopía electrónica de transmisión .......................................................70

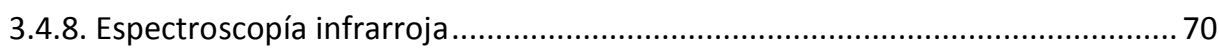

3.5. Ensayos catalíticos .........................................................................................71

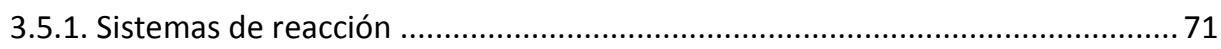

3.5.1.1. Reactor discontinuo de tanque agitado ........................................................... 71

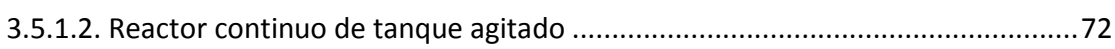

3.5.1.3. Reactor continuo de tanque agitado a presión.................................................73

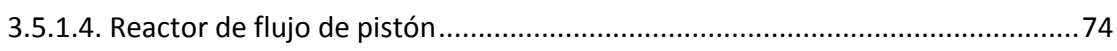

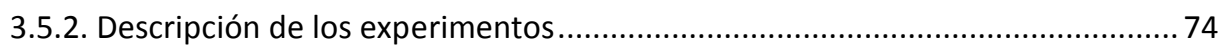

3.5.2.1. Reactor discontinuo de tanque agitado ......................................................... 75

3.5.2.2. Reactor continuo de tanque agitado ........................................................... 75

3.5.2.3. Reactor continuo de tanque agitado a presión................................................76

3.5.2.4. Reactor de flujo de pistón ..............................................................................76

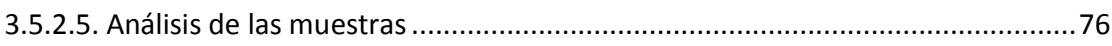

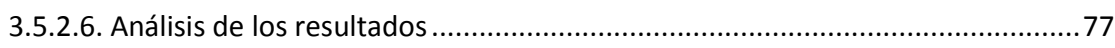

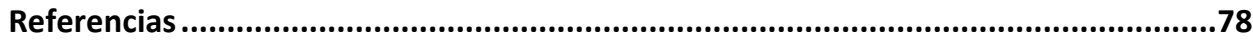


4. ESTUDIO DE LAS CONDICIONES DE REACCIÓN ..................................................79

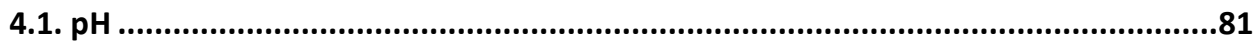

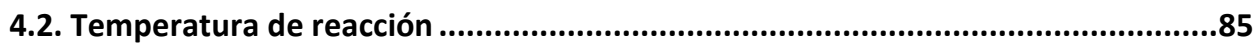

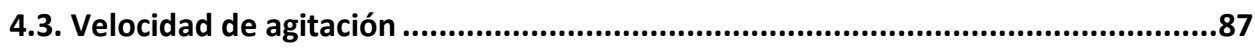

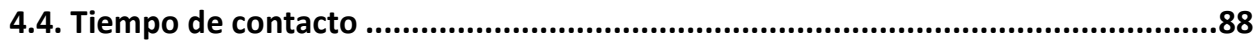

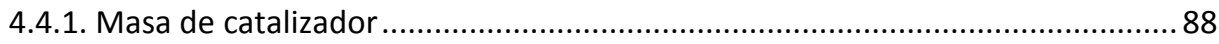

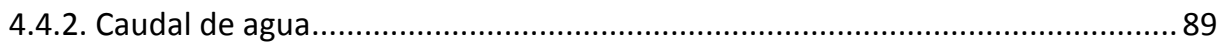

4.5. Hidrógeno en el medio............................................................................90

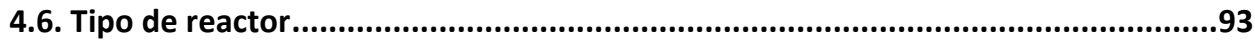

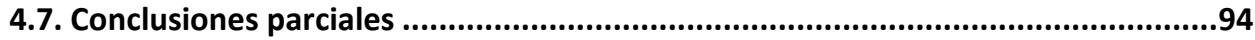

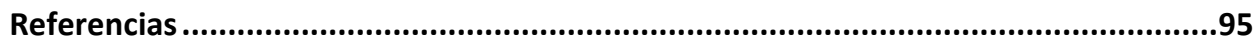

5. OPTIMIZACIÓN DE LA COMPOSICIÓN DEL CATALIZADOR Y DE SU PREPARACIÓN........97

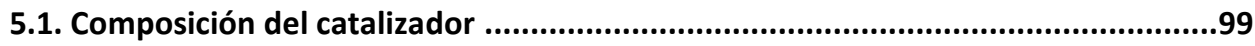

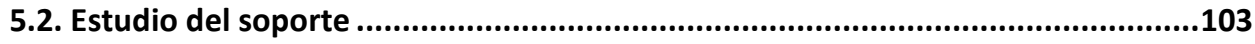

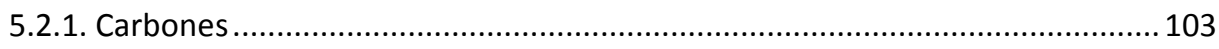

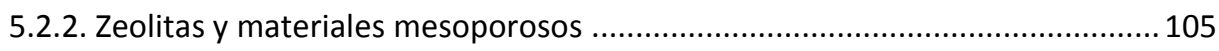

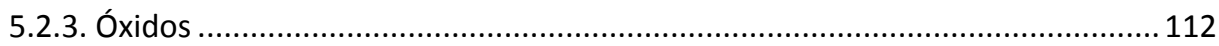

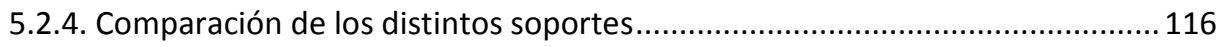

5.3. Estudio de la relación (Cu o Sn)/Pd ............................................................117

5.4. Comparación entre el catalizador $\mathrm{Sn} / \mathrm{Pd}$ y el catalizador $\mathrm{Cu} / \mathrm{Pd}$.......................120

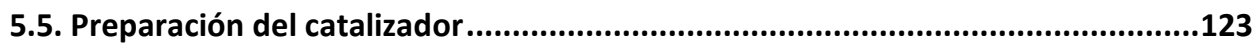

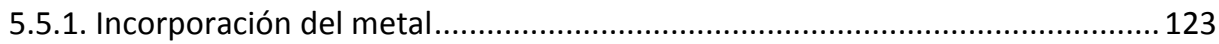

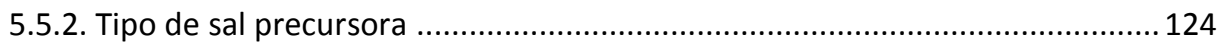

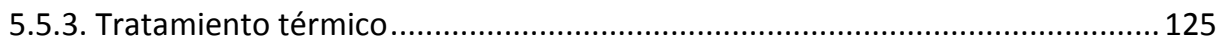

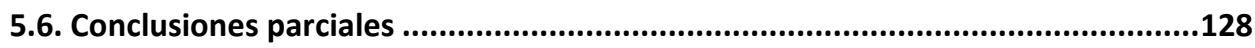

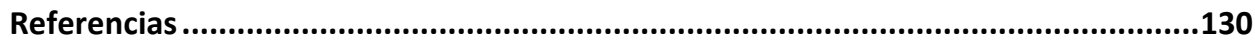

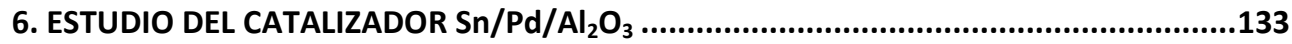

6.1. Estudios de desactivación y regeneración del catalizador ..................................135

6.1.1. Estudio de la desactivación del catalizador ................................................. 135

6.1.2. Estudio de la regeneración del catalizador ................................................. 140

6.2. Actividad del catalizador con distintos tipos de aguas contaminadas ...............146

6.3. Actividad del catalizador al variar el contenido en metales...............................147 


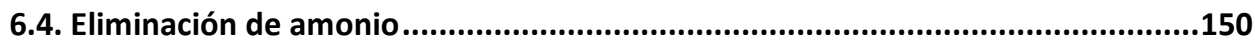

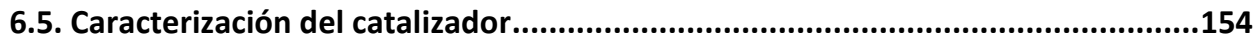

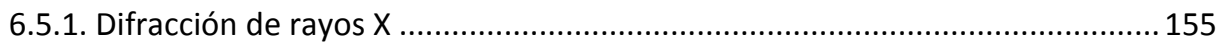

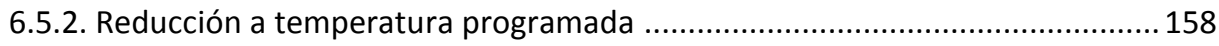

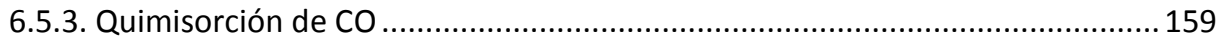

6.5.4. Microscopía electrónica de barrido y de transmisión .................................... 161

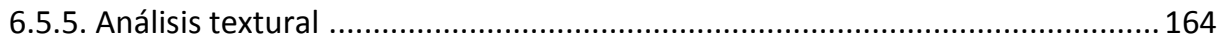

6.6. Mecanismo de la reacción .........................................................................164

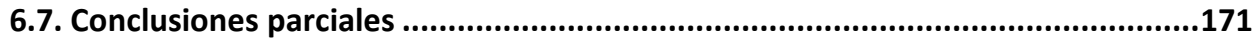

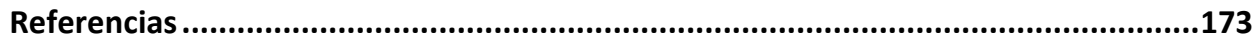

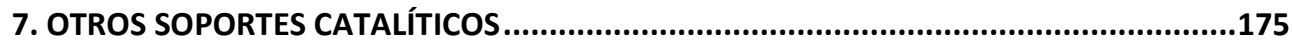

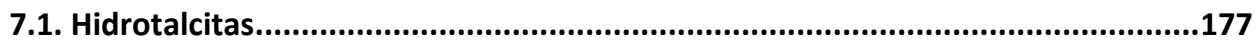

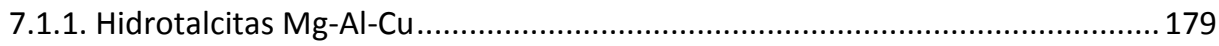

7.1.2. Hidrotalcitas Mg-Al-Cu impregnadas con Pd .............................................. 184

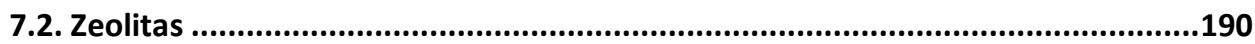

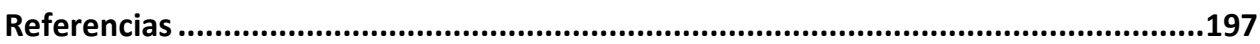

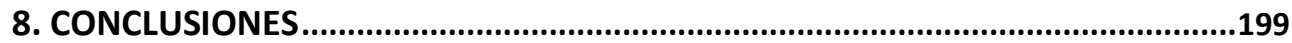

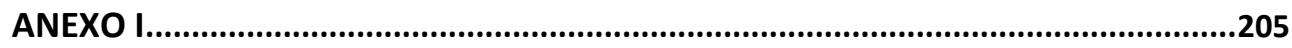

Índice de figuras.....................................................................................207

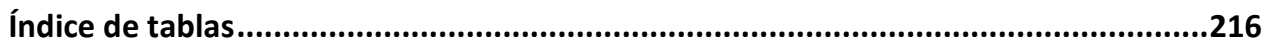

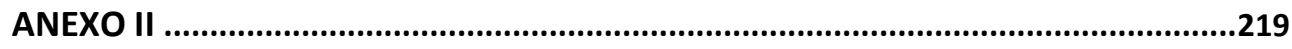

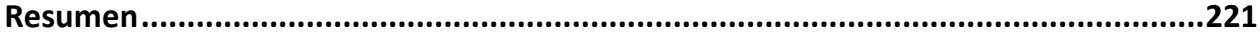

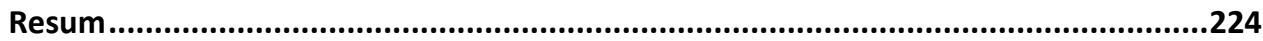

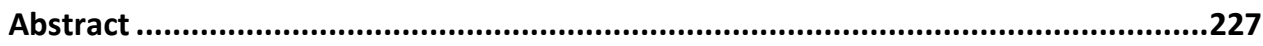

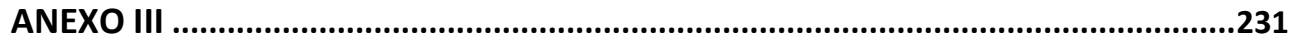

Curriculum obtenido durante el periodo de tesis doctoral 
1.

INTRODUCCIÓN 



\subsection{El agua}

El agua es uno de los componentes más abundantes de la Naturaleza y ha estado presente en la Tierra desde hace más de 3000 millones de años, ocupando tres cuartas partes de la superficie del planeta [1]. Es el constituyente mayoritario de los seres vivos, forma el $70 \%$ del peso humano y se encuentra en la mayor parte de los alimentos.

El volumen total del agua en la Tierra es de unos $1360 \cdot 10^{6} \mathrm{~km}^{3}$, distribuyéndose aproximadamente de la forma que se muestra en la figura 1.1 y en la tabla 1.1 [1-3]. Tal como se observa, la mayor parte del agua presente en el planeta es salada y se encuentra en los océanos, constituyendo el 97,2\% del total del agua presente en la Tierra. El 2,8\% restante es agua dulce, de la cual el $75 \%$ se encuentra en forma de hielo en los casquetes polares y glaciares, mientras que, del $25 \%$ que resta, el $24 \%$ está localizada en el suelo como agua subterránea y el resto se encuentra como agua continental en lagos, ríos y en el suelo.

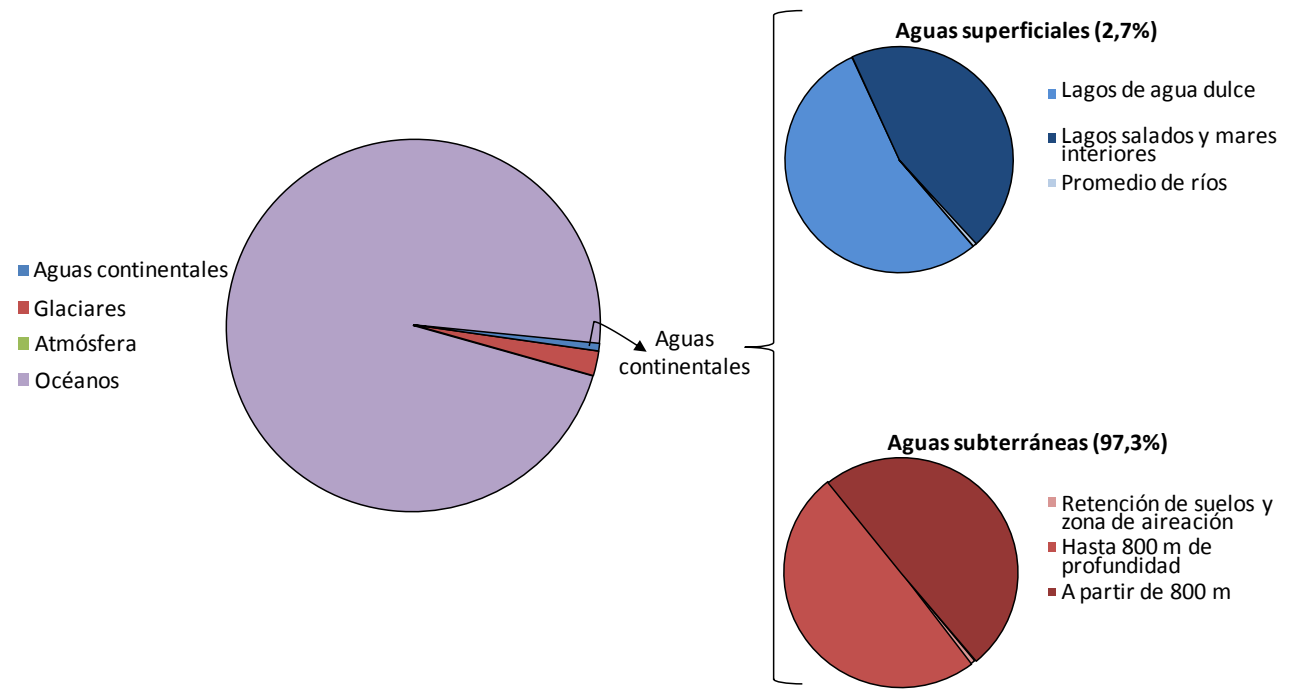

Figura 1. 1. Distribución del agua total de la Tierra. 
Tabla 1. 1. Localización del agua en la Tierra.

\begin{tabular}{lcc}
\hline \multicolumn{1}{c}{ Localización } & $\begin{array}{c}\text { Volumen agua } \\
\left(\mathbf{k m}^{\mathbf{3}} \mathbf{)}\right.\end{array}$ & $\begin{array}{c}\text { Porcentajes } \\
\mathbf{( \% )}\end{array}$ \\
\hline Aguas continentales & 8637250 & 0,6421 \\
Aguas superficiales & & \\
Lagos de agua dulce & 125000 & 0,009 \\
Lagos salados y mares interiores & 104000 & 0,008 \\
Promedio de ríos & 1250 & 0,0001 \\
Aguas subterráneas & & \\
Retención de suelos y zona de aireación & 67000 & 0,005 \\
Hasta 800 m de profundidad & 4170000 & 0,31 \\
A partir de 800 m & 4170000 & 0,31 \\
Glaciares & 29200000 & 2,15 \\
Atmósfera & 13000 & 0,001 \\
Océanos & 1322000000 & 97,2 \\
\hline
\end{tabular}

Esta distribución se mantiene constante por el ciclo hidrológico que consiste en una secuencia de fenómenos naturales que permiten un intercambio constante de agua entre la Tierra y la atmósfera, debido a la energía radiante del sol y a la fuerza de la gravedad (figura 1.2). El ciclo se inicia por la transferencia de agua desde la superficie de la Tierra hacia la atmósfera, en forma de vapor de agua, debido a la evaporación directa y a la transpiración de las plantas y animales, cuyo proceso conjunto se denomina evapotranspiración. El vapor de agua a medida que se eleva se enfría y se condensa dando lugar a la formación de nubes y nieblas, el agua posteriormente vuelve a la Tierra en forma de lluvia, nieve o granizo. Una parte del agua que llega a la Tierra es aprovechada por los seres vivos y la otra escurre por el terreno hasta llegar a un río, a un lago o a un océano. A este fenómeno se le conoce con el nombre de escorrentía. Otra parte del agua se filtra a través del suelo (proceso de percolación), formando capas de agua subterránea. Más tarde o más temprano, toda esta agua vuelve nuevamente a la atmósfera, debido principalmente a la evaporación, reiniciándose el ciclo hidrológico. 


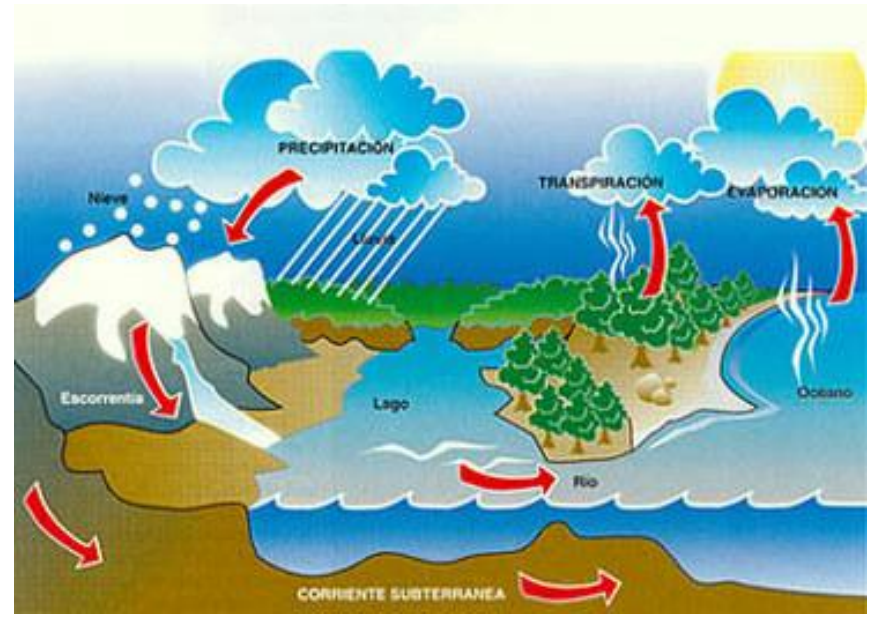

Figura 1. 2. Ciclo hidrológico del agua.

El origen del agua determina su composición y, por tanto, su calidad. Por un lado, al moverse el agua a través de distintas vías superficiales y subterráneas su calidad se ve alterada, de forma que la calidad del agua que sale de la zona de captación será diferente del agua que ha caído en ella. Por otro lado, aquella que discurre por la superficie tendrá distinta composición que la que lo hace por dentro de la tierra.

Las aguas superficiales se definen como cualquier tipo de agua que se encuentra discurriendo o estancada en la superficie, tales como arroyos, ríos, estanques, lagos y embalses. Su procedencia puede ser de escorrentía superficial, precipitación directa, exceso de humedad o descarga de la capa freática. La calidad y cantidad del agua superficial dependerá de una combinación entre el clima y factores geológicos. Por otra parte, las aguas subterráneas proceden de la percolación de las aguas superficiales, siendo su calidad, normalmente buena, aunque depende del terreno. Los factores de los que depende la calidad del agua subterránea son la naturaleza del agua de lluvia, el tiempo que esté el agua subterránea en el acuífero y la naturaleza del suelo a través del que se infiltra. En general no contiene sólidos en suspensión, ni contaminantes atmosféricos, ni bacterias, ni patógenos, y por contra presenta una elevada cantidad de iones de calcio, sodio y potasio, mientras que tiene poca cantidad de hierro y magnesio. Posee una 
elevada salinidad por efecto de los carbonatos, sulfatos y cloruros, siendo su conductividad muy elevada [3].

Según datos del Instituto Geológico y Minero de España (IGME), existen en nuestro país, excluidas las Islas Canarias que constituyen un gran acuífero volcánico, algo más de mil acuíferos, que ocupan casi la mitad de la superficie del país y proporcionan entre veinte y treinta mil millones de metros cúbicos anuales de agua. Se trata de una fuente cada vez más relevante de recursos hídricos en ciertas zonas y/o en ciertos períodos de tiempo $[4,5]$.

Los usos del agua a nivel mundial aparecen reflejados en la figura 1.3 donde se aprecia que la agricultura consume la mayor parte del agua, seguida de los procesos industriales. En España el consumo de agua en agricultura es el $80 \%$ del consumo total y el $20 \%$ que queda se reparte entre las aplicaciones en el sector industrial y el consumo doméstico.

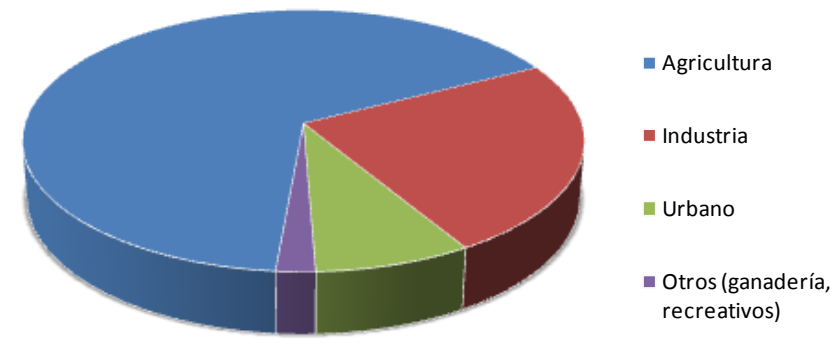

Figura 1. 3. Usos del agua a nivel mundial.

\subsection{Contaminación del agua}

La contaminación del agua se podría definir como un cambio en su calidad, que hace que el agua no sea adecuada para un determinado uso o que causa un efecto perjudicial sobre los organismos vivos $[5,6]$. Tan importante puede llegar a ser no tener agua, como que la calidad de los recursos disponibles no permita su uso. 
La calidad del agua ha de definirse en función de su uso y según su composición natural. Para evaluar los cambios en su calidad se utilizan los llamados indicadores de calidad, que pueden ser parámetros físicos, químicos o biológicos. Los indicadores físicos son el color, la turbidez, la conductividad, la temperatura, el gusto y el olor. Mientras que los indicadores químicos son el $\mathrm{pH}$, la dureza, la alcalinidad y el residuo seco. Otros indicadores, aparte de los anteriores, pueden ser los indicadores de contaminación orgánica (COT, DBO, DQO, nitrógeno, NTK) o el indicador de radiactividad [3].

El concepto de calidad del agua está estrechamente ligado al uso al que se encuentre destinada. Los objetivos de calidad ofrecen diferentes niveles de exigencia, de manera que, por ejemplo, son mucho más exigentes en el caso de las aguas destinadas al consumo humano, que si se trata de aguas para el riego de cultivos [5]. Así, desde la publicación de la Directiva Marco del Agua, el enfoque ha cambiado hacia la integración de los usos antrópicos con la función del agua dentro de los ecosistemas: el uso del agua por parte de la sociedad ha de permitir la existencia de ecosistemas saludables, regulando los usos en función de la capacidad receptora de los ecosistemas [4].

Los principales fenómenos causantes de la contaminación del agua están relacionados con el crecimiento de los núcleos de población, que aumentan la cantidad de aguas residuales; con los suelos contaminados; con el cultivo intensivo de la tierra, debido a que el exceso de nutrientes es arrastrado por las aguas de lluvia o riego y llega hasta los acuíferos; con la ganadería, que genera importantes cantidades de purines; con la generación de aguas contaminantes por la industria [3] y con la contaminación de los acuíferos por la intrusión marina [4].

\subsubsection{Clasificación de los contaminantes del agua}

Los contaminantes del agua se pueden clasificar atendiendo a su naturaleza o de acuerdo a su origen. Según su naturaleza los contaminantes del agua se pueden clasificar en tres grupos:

- Los contaminantes de tipo físico: como la contaminación térmica, la turbidez o el color. 
- Los contaminantes de tipo biológico: son todos los seres vivos que causan enfermedades (patógenos), pueden ser bacterias, virus, protozoos y helmintos.

- Los contaminantes de tipo químico: que a su vez pueden dividirse en:

o Orgánicos: disolventes, fenoles, compuestos orgánicos biodegradables, plaguicidas, etc.

o Inorgánicos: sales, metales, etc.

o Nutrientes: nitratos y fosfatos.

Según su fuente de producción, los contaminantes se pueden dividir en:

- Contaminantes de origen agrario: las actividades agrícolas producen compuestos no biodegradables y acumulación de nutrientes debido principalmente al uso de abonos y plaguicidas. Estos contaminantes a largo plazo pueden contaminar las aguas subterráneas. Los contaminantes agrícolas se distinguen por su carácter no puntual sino difuso y sus efectos se extienden sobre zonas muy amplias.

- Contaminantes de origen urbano: son básicamente las aguas residuales urbanas, las cuales se caracterizan por ser disoluciones acuosas complejas que contienen una gran variedad de componentes orgánicos e inorgánicos, tanto disueltos como en suspensión. Este tipo de aguas también contiene microorganismos, principalmente bacterias.

- Contaminantes de origen industrial: las fuentes industriales de contaminación pueden variar mucho en función del tamaño, del tipo y del lugar donde se encuentre la industria. En los países desarrollados los vertidos industriales están rigurosamente controlados, mientras que en muchos países en vías de desarrollo tales vertidos se realizan a veces sin ningún control. Las fuentes de contaminación debidas a la industria son, en su mayor parte, de tipo puntual, es decir, se encuentran localizadas en un área generalmente reducida. 


\subsubsection{Principales contaminantes del agua}

Los principales contaminantes que pueden aparecer en el agua son:

- Compuestos orgánicos biodegradables. Son aquellas sustancias que se oxidan en presencia de oxígeno debido a la actividad bacteriana. Como consecuencia de ello se produce una disminución de la concentración de oxígeno disuelto en el agua, lo que da lugar a efectos perjudiciales sobre la vida acuática y a la aparición de malos olores. Los compuestos orgánicos biodegradables pueden provenir en gran parte de las industrias del sector agroalimentario y de la actividad humana (restos de comida, materia fecal, etc.).

- Compuestos orgánicos no biodegradables. Se trata de compuestos orgánicos que se encuentran en una concentración muy pequeña y que son demasiado estables para ser degradados por los microorganismos y la naturaleza. Proceden generalmente de las industrias de plásticos, carburantes, disolventes, pinturas, plaguicidas, detergentes, aditivos alimentarios, productos farmacéuticos, etc. En este grupo también se incluyen los hidrocarburos y otros derivados del petróleo que pueden aparecer en el medio acuático por accidentes o vertidos incontrolados.

- Metales pesados. Los más importantes son las sales de mercurio y el plomo. Otros metales contaminantes son el vanadio, arsénico, níquel, zinc, cobalto, cobre, cadmio, manganeso, selenio, berilio y cromo. Algunos de estos elementos metálicos son micronutrientes, es decir, son necesarios para muchos animales y plantas, pero a partir de determinadas concentraciones son tóxicos. Una característica particular de la contaminación metálica es su persistencia en el ambiente y su acumulación en la cadena trófica.

- Los sedimentos. La mayor cantidad de contaminantes del agua son sedimentos o materiales en suspensión. Éstos son producidos principalmente por procesos naturales de erosión de la tierra y por los vertidos domésticos o industriales. Los sedimentos enturbian el agua y reducen la fotosíntesis; también alteran las redes de alimentos acuáticos y transportan plaguicidas, bacterias y otras sustancias 
perjudiciales. Los sedimentos destruyen el alimento y las zonas de desove de los peces.

- La salinidad. La cantidad de sales disueltas limita las aplicaciones de un agua. Los problemas más importantes suelen aparecer en los acuíferos cerca de la costa que pueden sufrir este tipo de contaminación por fenómenos de intrusión marina.

- Elementos patógenos. Son aquellos organismos capaces de producir enfermedades. Ejemplos de patógenos asociados con las aguas son algunos tipos de virus como la hepatitis, bacterias como la legionela, protozoos como los que producen disentería y algunos helmintos.

- Nutrientes. Son los elementos químicos esenciales para el crecimiento de los seres vivos. Además de carbono se necesitan fundamentalmente $\mathrm{N}$ y P. Los nutrientes son contaminantes cuando sus concentraciones son tan elevadas que producen un crecimiento excesivo de las plantas acuáticas, principalmente las algas. Este proceso se denomina eutrofización y se debe principalmente al aumento de fosfatos y nitratos en las aguas. Además, la presencia de cantidades importantes de nitratos en las aguas, impide su utilización para redes de abastecimiento público. En la presente tesis se tratará sobre la eliminación de los nitratos en aguas naturales y por ello los efectos de este contaminante se amplían en el siguiente apartado.

- Contaminación térmica. Este tipo de contaminación se debe a la utilización del agua como refrigerante en numerosos procesos industriales, de tal manera que parte de esta agua vuelve a su origen con algunos grados más de temperatura. El aumento de la temperatura disminuye la solubilidad del oxígeno en el agua y aumenta la velocidad de las reacciones metabólicas $[2,6]$.

\subsection{Contaminación del agua por nitratos}

La contaminación por nitratos es una de las causas más comunes de deterioro de la calidad de las aguas, siendo un problema compartido por toda la Unión Europea. Esta 
contaminación tiene su origen, en la mayoría de las ocasiones, en fuentes difusas y se debe sobre todo al uso de fertilizantes agrícolas y a las explotaciones ganaderas. En los últimos años se ha potenciado una agricultura intensiva basada en la disponibilidad de fertilizantes sintéticos de alto rendimiento y en el cultivo de especies vegetales de rápido crecimiento y de creciente rentabilidad para el agricultor. Este rápido e intenso desarrollo agrícola, ha generado una serie de efectos nocivos con implicaciones medioambientales negativas. También en lo referente a la ganadería, el volumen y el número de actividades ha aumentado de forma considerable, constituyendo una fuente potencial de contaminación de aguas superficiales y subterráneas [7].

\subsubsection{El ciclo del nitrógeno en el suelo}

Los compuestos nitrogenados del suelo pueden estar en forma mineral como $\mathrm{NO}_{3}{ }^{-}$, $\mathrm{NO}_{2}^{-}$y $\mathrm{NH}_{4}^{+}$o en forma orgánica como aminoácidos, proteínas o aminoazúcares, entre otros.

El ciclo del nitrógeno en los suelos, comprende un conjunto de transformaciones y procesos de transporte que unido al conjunto de variables que introducen las actividades desarrolladas en la superficie del terreno, la naturaleza de la zona, el espesor, el tipo de riego y otras variables, van a determinar la incorporación de compuestos de nitrógeno en mayor o menor volumen al flujo subterráneo del agua. 


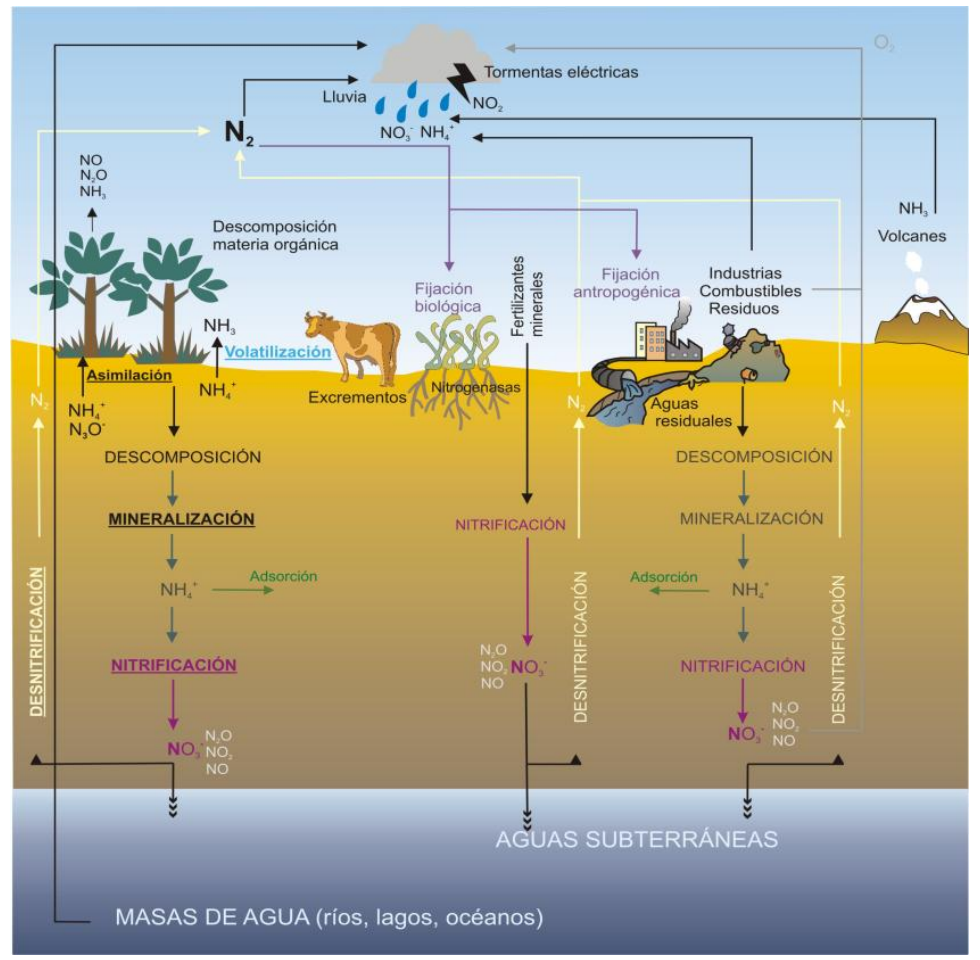

Figura 1. 4. Ciclo del nitrógeno en el suelo.

De forma sintética, los principales procesos que tienen lugar en el ciclo del nitrógeno (figura 1.4) son los que se describen a continuación:

$\checkmark$ Deposición atmosférica y fijación antropogénica, el nitrógeno que en distintas formas $\left(\mathrm{N}_{2}, \mathrm{NO}, \mathrm{N}_{2} \mathrm{O}, \mathrm{NO}_{2}, \mathrm{NH}_{3}\right)$ contiene la atmósfera pasa de forma natural (lluvia, fijación biológica) o antropogénica (fábrica de abonos nitrogenados) al suelo.

$\checkmark$ Asimilación de nitrógeno, los compuestos nitrogenados que han pasado al suelo son parcialmente asimilados por las plantas, pudiendo algunas de ellas incluso asimilarlo del aire.

$\checkmark$ Mineralización, al descomponerse las plantas y la materia orgánica del suelo, los compuestos orgánicos nitrogenados que contenían se transforman en amonio debido a la acción de los microorganismos. El amonio formado es adsorbido por el suelo. 
$\diamond$ Volatilización, parte del amonio del suelo se volatiliza y pasa a la atmósfera en forma de amoniaco gaseoso.

$\checkmark$ Nitrificación, el amonio del suelo se transforma en nitrito y posteriormente en nitrato debido a la acción de bacterias aerobias.

$\diamond$ Desnitrificación, el proceso anterior es reversible y otro tipo de microorganismos convierten el nitrato del suelo en nitrógeno gaseoso, o en óxidos de nitrógeno.

$\checkmark$ Lixiviación, el nitrato no aprovechado por debajo de la zona radicular y arrastrado por la lluvia o el agua de riego puede atravesar la capa freática produciendo la contaminación de las aguas subterráneas.

\subsubsection{Fuentes de compuestos nitrogenados en las aguas naturales}

Atendiendo a su origen y distribución espacial, las fuentes de compuestos nitrogenados se agrupan en dos tipos: las puntuales, asociadas a actividades industriales y urbanas, y las difusas, asociadas a las actividades de origen agrario.

Concretamente, los aportes de compuestos nitrogenados a las aguas subterráneas pueden venir de $[8,9]$ :

- Los compuestos nitrogenados de origen atmosférico, especialmente importante en áreas industriales.

- Los vertidos inadecuados de las actividades industriales o el almacenamiento de materias primas sin el debido control.

- Los vertidos a cauces superficiales, o directamente al suelo, de efluentes urbanos con o sin tratamiento previo.

- La inadecuada gestión de lixiviados procedentes de vertederos de residuos sólidos urbanos.

- El excedente de nitrógeno procedente de fertilizantes, no asimilado por los cultivos y lixiviado a los acuíferos a través de la zona no saturada.

- Los efluentes originados en las explotaciones ganaderas intensivas, por acumulación e incorrecta eliminación de los mismos. 
La literatura científica considera de forma generalizada que las prácticas agropecuarias son las principales responsables de la contaminación por nitratos en las aguas subterráneas. Esto se sustenta, entre otros argumentos, en la relación existente entre el incremento del contenido en nitratos en las aguas y el aumento de la superficie del suelo agrícola, el aumento del consumo de fertilizantes y la aparición de explotaciones de ganadería intensiva [8, 9].

El empleo de fertilizantes inorgánicos en agricultura se remonta al último cuarto del siglo XIX, aunque su producción masiva no se inicia hasta después de la segunda guerra mundial (1945). El máximo crecimiento en el consumo anual de fertilizantes corresponde al periodo de 1950-1975, durante el cual se multiplicó por seis en la mayor parte de países europeos (15 a 95 millones de toneladas). La aplicación de la fertilización nitrogenada puede ocasionar problemas, cuando la cantidad de nitrógeno aplicado excede la dosis crítica adecuada para cada tipo de cultivo. Entonces aumenta rápidamente la lixiviación de nitratos y por tanto el riesgo de su incorporación a las aguas subterráneas, mientras que la producción agrícola apenas se incrementa.

Otra de las variables a tener en cuenta es la forma química en la que el compuesto nitrogenado está en el abono. Aquellos fertilizantes que contienen nitratos, moléculas de elevada movilidad, son fácilmente arrastrados por el agua de infiltración, mientras que los amoniacales tardan más ya que estas moléculas tienen una menor movilidad. No obstante, el paso de la urea y de los compuestos amoniacales a nitratos se produce con rapidez, siempre que se den las condiciones de temperatura y humedad adecuadas, lo que aumentará el riesgo de contaminación. Por último están los abonos orgánicos, en los que el nitrógeno se presenta en forma orgánica (no asimilable por las plantas pero que se transforma en mineral por la acción de los microorganismos del suelo) y mineral. Éstos se han aplicado tradicionalmente como abono en las áreas de cultivo, pero su aplicación ha disminuido claramente con la aparición de fertilizantes sintéticos y por la especialización de la actividad agraria.

Hay que considerar también que la lluvia y el riego ejercen un papel importante como vehículo de transporte de los compuestos de nitrógeno a través de la zona no saturada. Por ello es del máximo interés optimizar la eficiencia y uniformidad del riego 
para conseguir que las infiltraciones de los compuestos nitrogenados en los acuíferos sean mínimas.

Otro factor importante relacionado con la contaminación por nitratos es la producción de estiércol. En España, el estiércol generado por animales que se encuentran en establos, es de 76 millones de toneladas anuales de las cuales 30 corresponden a estiércol sólido y 46 a líquido o semi-pastoso. El gran volumen de estiércol líquido, sobre todo el porcino, generado en zonas de ganadería intensiva está dando problemas importantes de contaminación por nitratos en las aguas subterráneas, ya sea por su inadecuado aprovechamiento para la agricultura o por su incorrecto tratamiento o depuración.

A esto hay que añadir que durante los últimos cincuenta años, han disminuido los pastos permanentes y zonas "tampón" (zanjas, setos, humedales), lo que favorece la erosión, la escorrentía y el paso más rápido de nutrientes a las aguas subterráneas. En España se han perdido un $60 \%$ de las zonas húmedas en el último siglo, debido al drenaje del suelo para cultivo, la plantación de árboles y el desarrollo urbano. Estas zonas húmedas podían llegar a eliminar del agua hasta $2 \mathrm{~kg} \mathrm{~N} /$ ha/día, por lo que es evidente que su pérdida va en detrimento de la calidad de las aguas [8].

\subsubsection{Efecto de los nitratos en la salud}

El nitrato, como sustancia de origen natural, se encuentra como componente de los alimentos en los productos cárnicos, lácteos, verduras, cereales y frutas, y a excepción de algunos tipos de verduras (remolacha, apio, lechugas y espinacas entre otras), las concentraciones en las que se presenta son muy bajas. En la actualidad la recomendación de FAO/OMS es que la cantidad máxima de nitratos que se debe ingerir es de 0-3,7 mg $\mathrm{NO}_{3}{ }^{-} / \mathrm{kg}$ de peso corporal.

La toxicidad de los nitratos proviene de su conversión en nitritos y de la posible formación endógena de nitrocompuestos, considerándose muchos de ellos cancerígenos. Los nitratos por sí solos son relativamente poco tóxicos para los adultos, pues son fácilmente absorbidos y eliminados por su organismo. No obstante, la alta concentración 
de nitratos en el agua potable puede causar la metahemoglobinemia en bebés. La metahemoglobinemia es un aumento de la metahemoglobina en la sangre. Ésta es una hemoglobina modificada (oxidada) incapaz de fijar el oxígeno y que provoca limitaciones en su transporte hacia los tejidos. Para que ésta se produzca es necesario primero una reducción del nitrato a nitrito, el cual se combina con la hemoglobina de la sangre y forma la metahemoglobina que es incapaz de transportar oxígeno a las células [5, 8, 10-12]. Por otro lado, los estudios realizados para determinar la relación directa nitratos-cáncer no son demasiado precisos aunque varios de ellos concluyen que es probable que exista dicha relación [8]. La cantidad letal para los humanos adultos es de 4 a $50 \mathrm{~g}$ de nitrato y de 1,6 a 9,5 g para nitritos $[8,9]$.

\subsubsection{Normativa Legal}

La máxima concentración permitida de nitratos en las aguas de consumo público en los países de la UE es de $50 \mathrm{mg} / \mathrm{L}$, por lo que todas las medidas legales y actuaciones técnicas que se encuentran en desarrollo, se dirigen a impedir que se superen los niveles permitidos por la legislación [8, 11, 13]. Esto se regula en la Directiva 676/1991 relativa a nitratos. El objetivo de la Directiva, adoptada por el Consejo el 12 de diciembre de 1991, es reducir la contaminación de las aguas, atribuible de modo directo o indirecto a los nitratos de origen agrario, y prevenir su extensión. La Directiva persigue la aplicación de una serie de medidas y actuaciones que se resumen en:

- La determinación de las aguas afectadas por la contaminación o que podrían verse afectadas de no tomarse medidas.

- La designación de zonas vulnerables, que corresponderán a aquellas superficies del territorio cuya escorrentía provoque o pueda provocar la contaminación por nitratos de las aguas contempladas en el apartado anterior.

- La elaboración de uno o más códigos de buenas prácticas agrarias.

- El establecimiento de programas de acción, que se aplicarán durante los cuatro años siguientes a su elaboración en las zonas vulnerables designadas y contendrán obligatoriamente las medidas recogidas en el Anexo II y las 
dispuestas por los Estados miembros en sus códigos de buenas prácticas agrarias.

- La presentación de un informe cuatrienal a la Comisión.

Esta Directiva se traspuso al ordenamiento jurídico español mediante el Real Decreto 261/1996 de 16 de febrero y su aplicación tanto en España como en la mayoría de los países de la UE no es todo lo eficaz que se desearía, siendo el mayor problema, la realización y puesta en marcha de los programas de acción cuatrienales que constituyen el núcleo de la norma. Posteriormente, el 23 de octubre de 2000 se publicó la Directiva 2000/60/CE, conocida como Directiva Marco del Agua (DMA), por la que se establece un marco comunitario de actuación en el ámbito de la política de aguas, como norma general integradora de las actuaciones en materia de aguas. La DMA contempla medidas de coordinación de las restantes normativas comunitarias en materia de agua. Así, en su art. 11.3 dispone que entre las "medidas básicas" que debe contener el programa de medidas a establecer por los Estados miembros para cada demarcación hidrográfica, figurarán necesariamente las medidas exigidas en virtud de otras normas comunitarias relacionadas en el art. 10 y el Anexo VI, entre ellas la Directiva 91/676/CEE. Así, la Directiva Marco del Agua considera como zonas protegidas, que deben ser objeto de un registro especial a incluir en los planes hidrológicos de cuenca, las zonas declaradas vulnerables en virtud de lo previsto en el art. 3.2 de la Directiva 91/676/CEE.

De conformidad con la Directiva Marco de Agua (DMA), la Directiva 2006/118/CE, de 12 de diciembre de 2006, relativa a la protección de las aguas subterráneas contra la contaminación y el deterioro, establece medidas específicas para prevenir y controlar la contaminación de las aguas subterráneas y los criterios para valorar el buen estado químico de las aguas subterráneas.

La política del agua desarrollada en España en el año 2009 continúa poniendo de relieve la importancia económica, social y medioambiental de este recurso. El Real Decreto 1383/2009, de 28 de agosto determina la nueva composición, estructura orgánica y funcionamiento del Consejo Nacional del Agua. Ese año se aprobó también el Real Decreto 1514/2009, de 2 de octubre, que traspone la Directiva 2006/118/CEE, por el que 
se regula la protección de las aguas subterráneas contra la contaminación y el deterioro. Este Real Decreto también incorpora los apartados 2.3, 2.4 y 2.5 del anexo $\mathrm{V}$ de la Directiva 2000/60/CE, relativos al estado químico de las aguas subterráneas y establece los criterios y las medidas específicas para prevenir y controlar la contaminación de las aguas subterráneas $[4,8,14]$.

\subsubsection{Los nitratos en las aguas subterráneas de la Unión Europea y de España}

La Unión Europea considera que la presencia de nitratos en las aguas subterráneas representa uno de los factores de riesgo más importantes para su calidad, tanto por el número de acuíferos afectados o amenazados, como por el hecho de que compromete uno de sus usos más sensibles: el consumo humano. Pese a los esfuerzos realizados hasta el presente para controlarlos, el problema persiste y, en algunas regiones, se espera que aún pueda incrementarse.

Si bien suelen ser necesarios años o, incluso décadas, para que los nitratos alcancen las aguas subterráneas, teniendo en cuenta que la edad promedio de las aguas destinadas a abastecimiento en la UE es de 40 años, se estima que la mayor parte del exceso de nitrógeno aportado principalmente por los fertilizantes se encuentra ya en estos acuíferos.

Los tratamientos para reducir el contenido de nitratos en las aguas potables son caros. En el caso del Reino Unido, el gasto anual en desnitrificación de aguas potables es del orden de 30 millones de euros, y se prevé que en las dos próximas décadas alcance un valor 10 veces superior. Por este motivo, es frecuente que se opte por diluirlas con aguas superficiales de mejor calidad y diferente origen. Naturalmente, tal opción no siempre se encuentra disponible, como ocurre en ciertas zonas de España donde los recursos subterráneos constituyen la única alternativa de suministro.

La UE considera que las medidas preventivas resultan más económicas que las correctoras. Según sus estimaciones, el coste de modificar las prácticas de cultivo para reducir la aportación de nitratos, representa para el agricultor del orden de 50-150 EUR por hectáreas y año, un valor muy inferior al que se requiere para desnitrificar las aguas 
subterráneas contaminadas. Además, estas medidas permitirían trasladar la responsabilidad de la contaminación al causante de la misma y no al consumidor, al que viene imputándose hasta ahora el coste del tratamiento.

La distribución de las concentraciones medias de nitratos en las aguas subterráneas en los diferentes países de Europa aparece reflejada en la figura 1.5. De los 31 países estudiados en 2008, 15 poseían aguas subterráneas con concentraciones de nitratos por encima del nivel límite permitido. Generalmente, los países con la mayor cantidad de zonas agrarias y la mayor densidad de población presentan mayores concentraciones de nitratos, lo que refleja el importante impacto de la agricultura en la contaminación de las aguas subterráneas por nitratos [8, 9, 15-17].
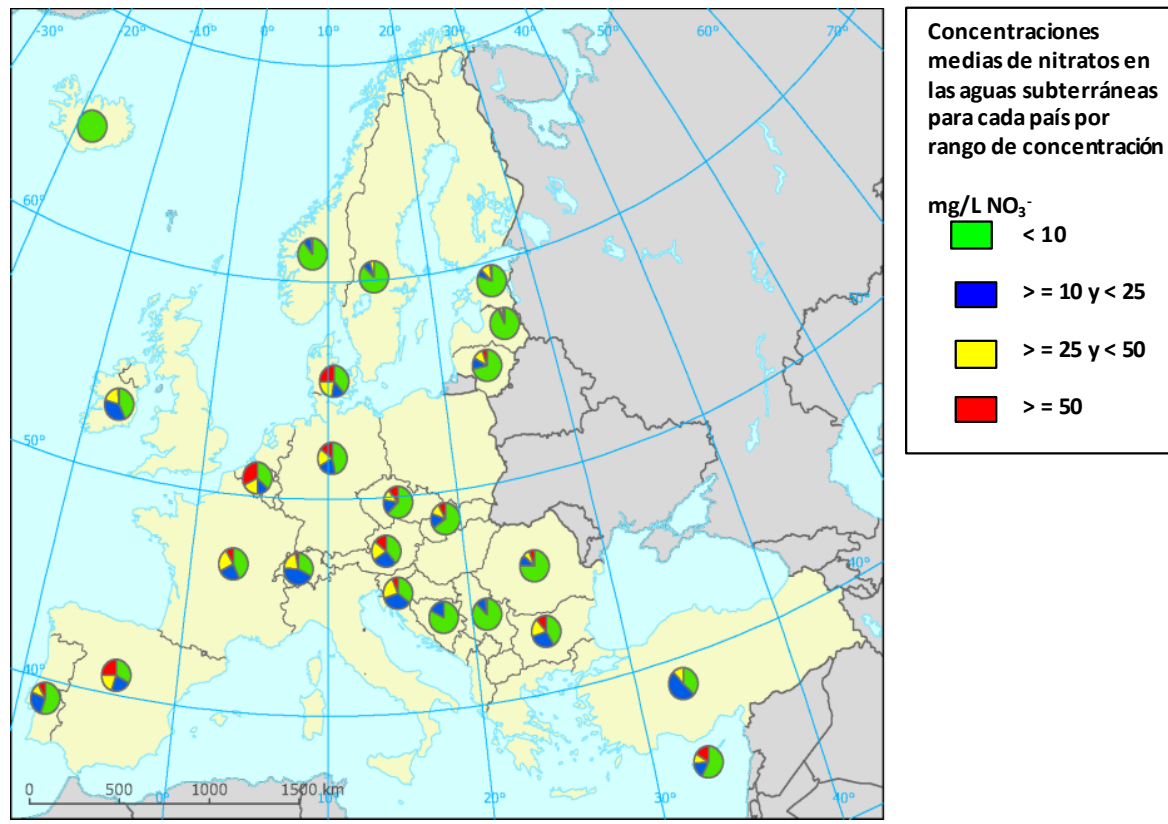

Figura 1. 5. Concentraciones medias de nitratos en los países de la Unión Europea (2008).

Respecto a la concentración de nitratos que presentan las aguas subterráneas en España, existen datos muy dispares en función de la demarcación hidrográfica de que se trate. En la tabla 1.2 se muestra la evolución del porcentaje de estaciones con concentración de nitratos superior a $50 \mathrm{mg} / \mathrm{L}$. Estos datos ponen de manifiesto una situación muy desigual entre las distintas demarcaciones hidrográficas, reflejando el buen 
estado químico de las demarcaciones de las Cuencas del Norte frente al resto de demarcaciones. De acuerdo con estos datos, las Demarcaciones del Tajo, Segura, Guadiana y Guadalquivir presentarían la peor situación.

Por otra parte, en el mapa adjunto (figura 1.6) aparecen las estaciones de la red de control de las aguas subterráneas en las que se han medido concentraciones superiores a $50 \mathrm{mg} / \mathrm{L}$ de nitratos en el año 2008, estos datos se corresponden con los observados en la tabla $1.2[8,14]$.

Tabla 1. 2. Porcentaje de estaciones con concentración de nitratos superior a $50 \mathrm{mg} / \mathrm{L}$.

\begin{tabular}{lccc}
\hline Demarcación hidrográfica & $\mathbf{2 0 0 6}$ & $\mathbf{2 0 0 7}$ & $\mathbf{2 0 0 8}$ \\
\hline Galicia Costa & SD & $0 \%$ & $2,44 \%$ \\
Miño-Sil & SD & $9 \%$ & $0 \%$ \\
Cantábrico & $0 \%$ & $0 \%$ & $1,88 \%$ \\
Cuencas Internas del País Vasco & $0 \%$ & $0 \%$ & $0 \%$ \\
Duero & $12,78 \%$ & $10,19 \%$ & $12,17 \%$ \\
Tajo & $25,32 \%$ & $25,62 \%$ & $23,66 \%$ \\
Guadalquivir & $29,76 \%$ & $27,54 \%$ & SD \\
Guadiana & $27,67 \%$ & $29,16 \%$ & $26,55 \%$ \\
Segura & $22,68 \%$ & $26,88 \%$ & SD \\
Júcar & $20,13 \%$ & $20,20 \%$ & $19,27 \%$ \\
Ebro & $18,70 \%$ & $20,47 \%$ & SD \\
\hline
\end{tabular}




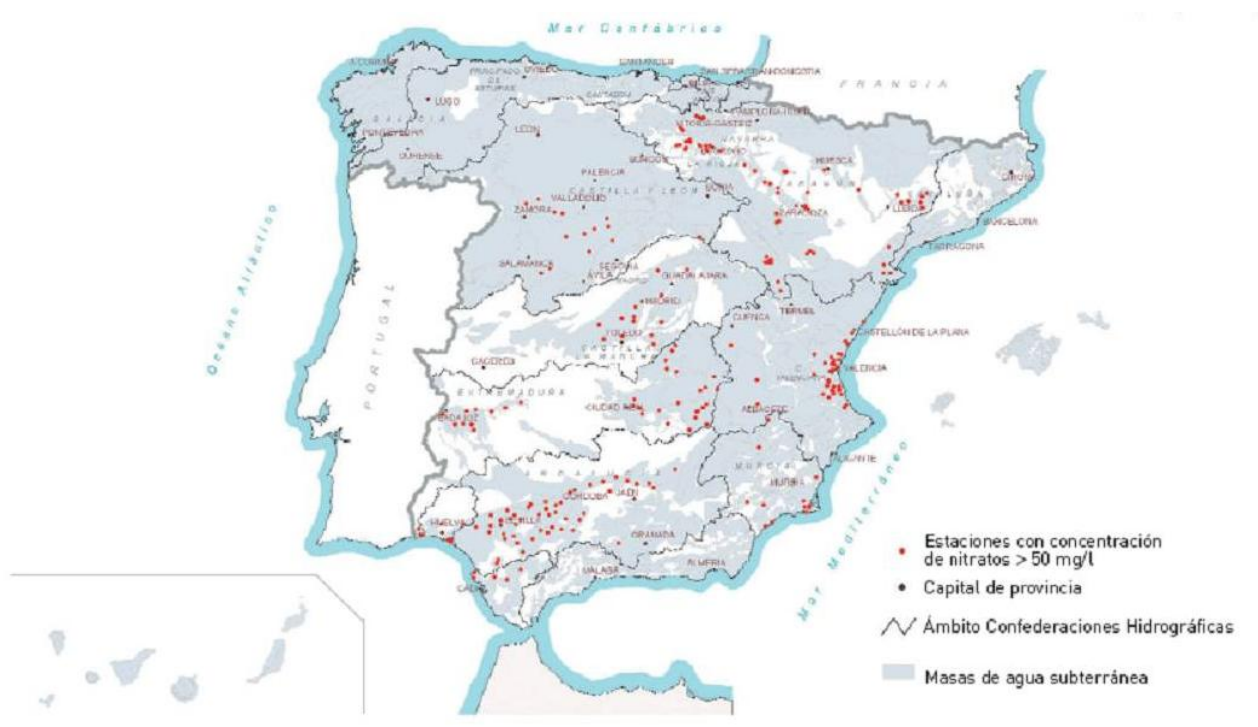

Figura 1. 6. Estaciones con concentración de nitratos superior a 50 mg/L en 2007.

Paralelamente, Fernández Ruiz [8] realizó un estudio de la presencia de nitratos en las aguas subterráneas de las Comunidades Autónomas españolas. Éste se llevó a cabo a partir de los análisis más recientes de este compuesto incluidos en la base de datos EQMAS, elaborada por el IGME (Instituto Geológico y Minero de España) y que recoge información correspondiente a datos analíticos procedentes del IGME, Confederaciones Hidrográficas y Comunidades Autónomas. Se seleccionaron un total de 2903 puntos de agua, pertenecientes a 521 masas de agua. De acuerdo con las directrices de la UE, los análisis de nitratos se clasificaron en cuatro intervalos de concentración: $\leq 10 \mathrm{mg} / \mathrm{L},>10$ $\leq 25 \mathrm{mg} / \mathrm{L},>25-\leq 50 \mathrm{mg} / \mathrm{L} \mathrm{y}>50 \mathrm{mg} / \mathrm{L}$. El primero corresponde a las aguas cuyo contenido en nitratos puede clasificarse como de fondo natural; el segundo comprende aquéllas que si bien poseen nitratos de origen antropogénico, no superan el valor de 25 $\mathrm{mg} / \mathrm{L}$ considerado como indicador de calidad; el tercer intervalo corresponde a aguas contaminadas, pero que no superan el límite máximo admisible para el consumo humano; las que sí lo superan estarían en el último de los intervalos citados.

En lo que respecta al porcentaje de muestras de contenido inferior a $10 \mathrm{mg} / \mathrm{L} \mathrm{NO}_{3}{ }^{-}$, la mayor parte están en las Comunidades del norte de la Península y en Castilla y León (figura 1.7). En el extremo opuesto se encuentran las comunidades que presentan un 
mayor porcentaje de muestras con un contenido en nitratos superior a $50 \mathrm{mg} / \mathrm{L}$. Éstas son La Rioja, Navarra, Extremadura y la Comunidad Valenciana $[18,19]$.

\section{DISTRIBUCIÓN EN INTERVALOS DEL CONTENIDO DE NITRATOS}

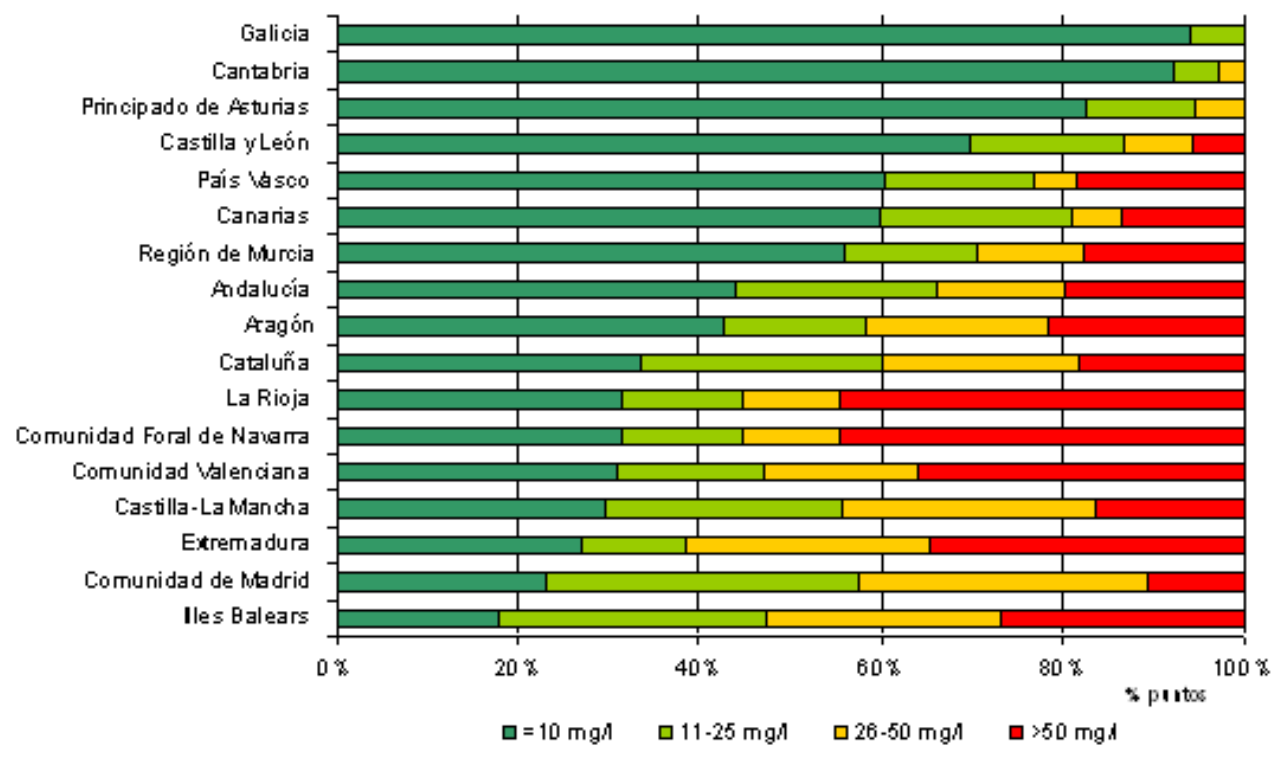

Fre It: Base de Dats EQ MAS 2006 (GME)

Figura 1. 7. Distribución del contenido en nitratos de los acuíferos de las CCAA.

A través de los resultados obtenidos en cada una de las Comunidades Autónomas, España ha designado hasta el momento un total de 57 zonas vulnerables (figura 1.8) en su territorio (un $12,7 \%$ de su superficie) y ha elaborado diversos códigos de buenas prácticas agrarias aplicable en las mismas, iniciativas enmarcadas en la Directiva 91/676/CEE [4, 8]. 


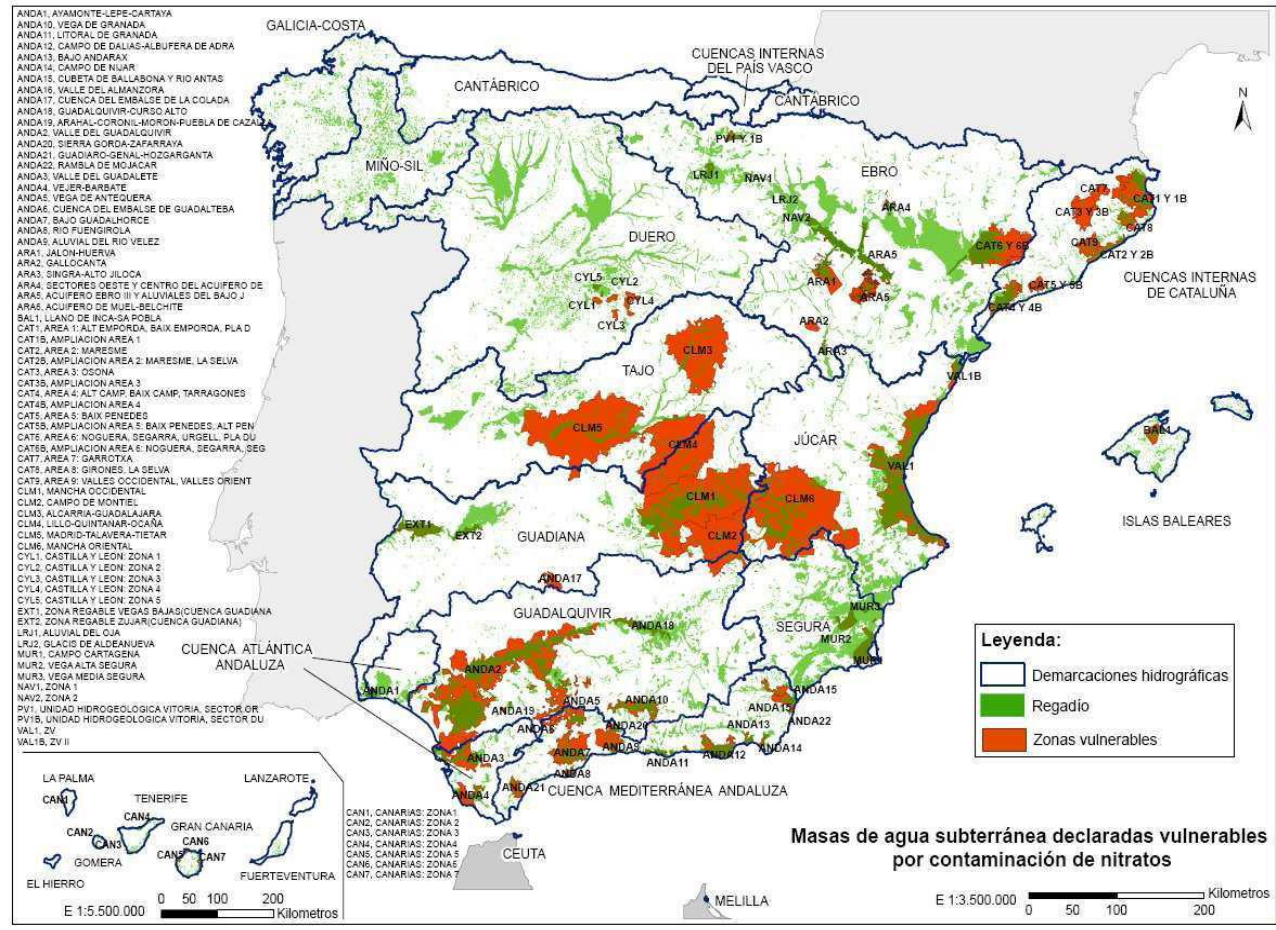

Figura 1. 8. Mapa de zonas vulnerables a la contaminación por nitratos.

En lo relativo a la evolución temporal, según las conclusiones del último informe cuatrienal remitido por el Ministerio de Medio Ambiente a la Comisión Europea correspondiente al período 2000-03, el porcentaje de puntos cuyo contenido promedio de nitratos superó en este período el umbral de $50 \mathrm{mg} / \mathrm{L}$ era del $24,7 \%$ frente al $21 \%$ del período 1996-99. Asimismo, el citado informe señalaba que, en el $44,1 \%$ de los puntos citados, la concentración de nitratos manifestaba una tendencia creciente, mientras que en el $24,2 \%$ se mantenía estable y disminuía en el resto. En tales circunstancias, cabe esperar que la puesta en marcha de las medidas asociadas a los códigos de buenas prácticas agrarias logre frenar, en un plazo razonable, este deterioro progresivo [8].

En el caso concreto de la Comunidad Valenciana [18], existe un número importante de acuíferos que excede el límite de nitratos permitido por la Unión Europea, los cuales representan alrededor del $8 \%$ del total de acuíferos de la Comunidad Valenciana. 


\subsection{Sistemas de eliminación de nitratos}

Las aguas contaminadas por nitratos se deben tratar antes de su uso. Para ello existen varias técnicas, las cuales se dividen en técnicas de separación y técnicas de transformación. Las técnicas de separación concentran los nitratos en un segundo desecho que habría que tratar o almacenar en un depósito, en este grupo están la electrodiálisis, la ósmosis inversa y las resinas aniónicas. Por otra parte, se encuentran las técnicas de transformación, las cuales transforman los nitratos en otros compuestos químicos, éstas son la eliminación biológica y la reducción catalítica.

\subsubsection{La electrodiálisis}

La electrodiálisis es un proceso de separación electroquímico que se basa en el transporte selectivo de iones como consecuencia de la aplicación de un campo eléctrico a través de un sistema de membranas de intercambio cargadas. El sistema consiste en una serie de membranas selectivas de aniones y cationes, dispuestas de forma alternativa y limitadas por separadores, formando compartimentos independientes, situados entre dos electrodos cargados (figura 1.9). La agrupación de dos membranas forma una celda. Al aplicar una diferencia de potencial eléctrico entre los electrodos, los cationes de la disolución emigran hacia el electrodo negativo, pasando a través de las membranas que son selectivas a los cationes y siendo bloqueados en aquéllas que no lo son. Al mismo tiempo los aniones, como por ejemplo los nitratos, se mueven en sentido contrario, hacia el electrodo positivo, pasando a través de las membranas selectivas a aniones, y son bloqueados por las que no lo son. De esta forma se produce un aumento de la concentración salina en las disoluciones de unos compartimentos respecto de sus inmediatos vecinos. Los compartimentos en los que no hay sales, desembocan en un canal donde se recoge el agua desmineralizada, mientras que los compartimentos con la disolución salina van a parar a un conducto de desecho, parte de cuyo contenido se suele llevar a la entrada del sistema (recirculación), al objeto de obtener un mayor rendimiento.

La ventaja de este método es que para llevar a cabo la eliminación no es necesario el uso de productos químicos, además el proceso de operación y mantenimiento de una 
planta de electrodiálisis es muy simple y completamente automático. Por el contrario, el principal inconveniente del sistema, además de no eliminar los nitratos (sólo los concentra), es su alto coste $[6,9,20]$.

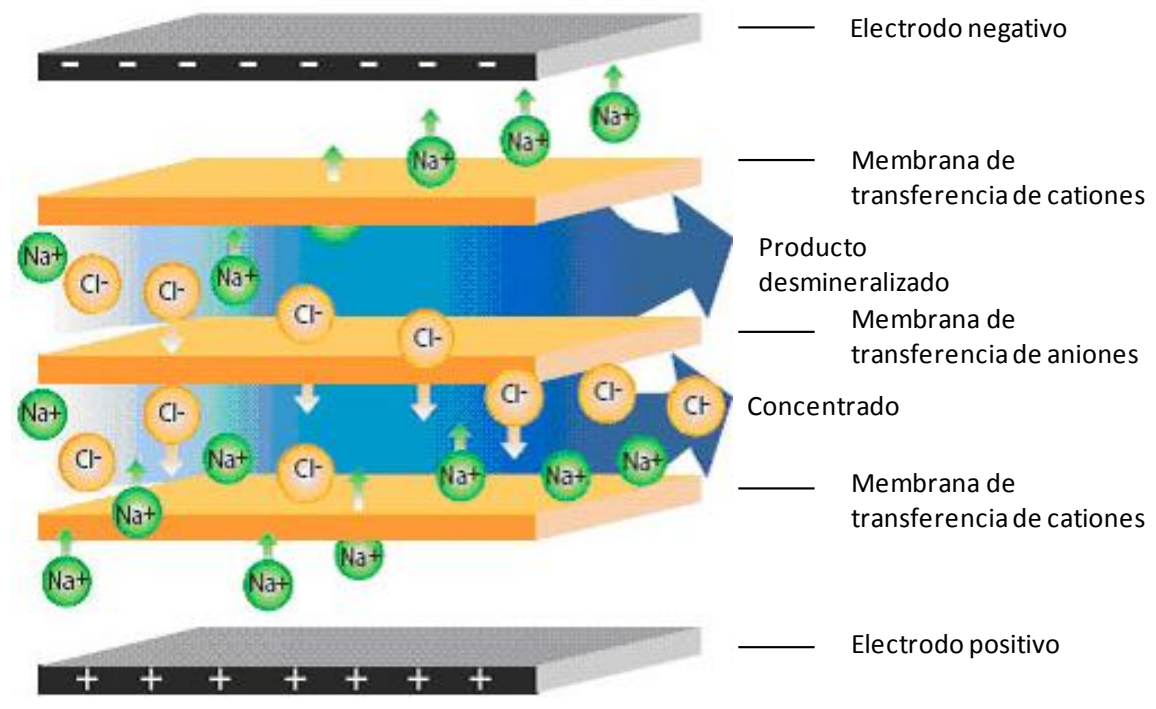

Figura 1. 9. Esquema del proceso de electrodiálisis.

\subsubsection{La ósmosis inversa}

La ósmosis inversa es un proceso en el cual las especies iónicas presentes en el agua se eliminan forzando al agua a pasar a través de una membrana semipermeable [9]. Se basa en el proceso de ósmosis, que es un fenómeno natural por el cual dos soluciones con distintas concentraciones salinas puestas en contacto a través de una membrana semipermeable tienden a igualar sus concentraciones. La figura 1.10 da un esquema simplificado del proceso de ósmosis inversa: al aplicar una presión superior a la presión osmótica se produce el fenómeno de ósmosis inversa, de forma que si se hace pasar a esa presión una corriente de agua a través de una membrana semipermeable, el agua pura fluirá desde la parte más concentrada a la menos concentrada, quedando retenidas las sales por la membrana [21, 22]. La ósmosis inversa es una técnica que permite alcanzar un alto grado de pureza del agua, además permite eliminar pesticidas y otras impurezas orgánicas. Sin embargo, al obtener un grado de pureza tan elevado, se debe mezclar con 
agua sin tratar para conseguir una composición apta para el consumo humano. La ósmosis inversa también presenta problemas por deposición de sustancias en la superficie de la membrana, ataque químico y exposición al cloro, lo que obliga a un pretratamiento de la membrana, ajuste del flujo, etc. Pese a esto, el principal problema son las elevadas necesidades energéticas del proceso.

No obstante, hay que señalar que tanto la ósmosis inversa como la electrodiálisis son los tratamientos comerciales actuales más utilizados para eliminar los nitratos de las aguas naturales $[6,9]$.

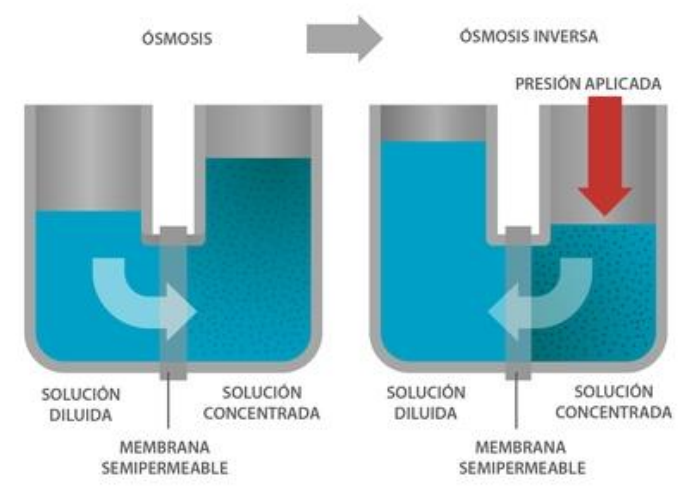

Figura 1. 10. Esquema del proceso de ósmosis inversa.

\subsubsection{El intercambio aniónico}

El uso de una resina de intercambio aniónico es otro de los procesos empleados para la eliminación de los nitratos. Se basa en el intercambio de iones de una solución (el agua contaminada) por un número químicamente equivalente de iones asociado con el material de intercambio (la resina). La técnica consiste en hacer pasar el agua contaminada a través de una resina de modo que los nitratos ( $\mathrm{y} / \mathrm{o}$ sulfatos) presentes en el agua se intercambien con los cloruros de la resina, obteniéndose el agua tratada. El problema de esta técnica es que cuando la resina se agota debe ser regenerada con una disolución concentrada de sales (figura 1.11), generándose una salmuera que debe ser tratada, además la mayoría de las resinas son más selectivas para atrapar los sulfatos que los nitratos, y suelen ser costosas. 
TRATAMIENTO

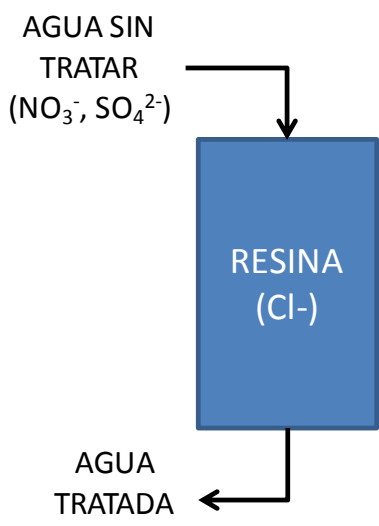

$\left(\mathrm{Cl}^{-}\right)$

\section{REGENERACIÓN}

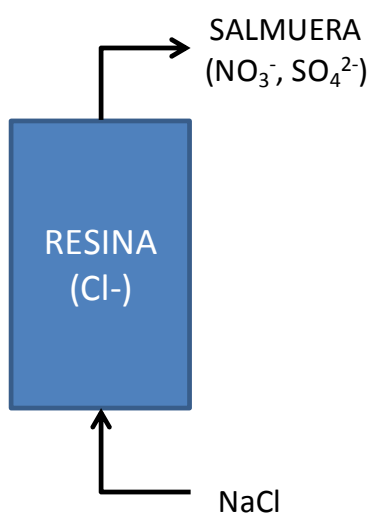

Figura 1. 11. Esquema del sistema de intercambio iónico.

Recientemente han aparecido varios trabajos en los que algunos autores proponen combinar el intercambio iónico, para eliminar los nitratos del agua a tratar, con la utilización de biomembranas para tratar los nitratos presentes en la salmuera formada al regenerar la membrana. El sistema pretende eliminar biológicamente los nitratos de la salmuera en presencia de otras sales, de forma que el nitrato se transforme en nitrógeno y $\mathrm{CO}_{2}$ con ayuda de los cultivos microbianos anóxicos. Esto permitiría que la solución salina pueda volver a utilizarse para regenerar la resina saturada [23-25] y reduciría la formación de salmuera, el consumo de $\mathrm{NaCl}$ para regenerar y las pérdidas de producto tratado. No obstante, este proceso no está del todo optimizado y aún no es de aplicación industrial.

\subsubsection{La desnitrificación biológica}

Los procesos de desnitrificación biológica se suelen utilizar en el tratamiento de las aguas residuales e industriales, dando resultados muy satisfactorios en las depuradoras de aguas residuales urbanas. Sin embargo, esta tecnología no se ha desarrollado en el sector de las aguas potables porque tiene el peligro de la contaminación bacteriana y de la presencia de residuos orgánicos tras el tratamiento del agua. Existen dos tipos de 
desnitrificación biológica, los procesos autótrofos y los procesos heterótrofos. La desnitrificación autótrofa utiliza $\mathrm{H}_{2} \mathrm{CO}_{3}$ como fuente de carbono e hidrógeno y azufre como fuente energética. La desnitrificación heterótrofa es más común y más simple y en ella la digestión de la bacteria se produce añadiendo un compuesto orgánico (metanol, etanol o ácido acético) que sirve tanto de fuente de carbono como de fuente energética. El tratamiento consiste en combinar en un reactor biológico una zona anóxica con una zona aireada. En la zona anóxica se desarrollan algunos tipos de bacterias que reducen los nitratos a nitrógeno con el fin de obtener la energía suficiente para su metabolismo cuando les falta el oxígeno molecular $[2,6]$. En algunos casos, se debe situar después del tratamiento biológico un post-tratamiento para eliminar el exceso de carbono orgánico añadido, como puede ser una adsorción con carbón activo [26-28].

Una alternativa a estos procesos es la utilización de biorreactores de membrana, en los cuales el agua contaminada por nitratos fluye a través de unas membranas microporosas y los nitratos difunden a través de los poros de las membranas. La desnitrificación tiene lugar en el interior de las membranas, creando una fuerza impulsora que facilita la transferencia de masa. Las membranas microporosas tienen una alta permeabilidad al nitrato, mientras que no dejan pasar los compuestos orgánicos y la biomasa, con los que estos se separan del agua tratada, aún así, los contenidos de estas dos especies en el agua de salida pueden llegar a ser bastante elevados [23, 29, 30].

Recientemente, algunos investigadores han propuesto el uso de un reactor bioelectroquímico en el cual los microorganismos de desnitrificación autótrofa son directamente inmovilizados en la superficie del cátodo. El proceso es altamente selectivo para la reducción de nitrato a nitrógeno gas. Sin embargo, este proceso genera subproductos como nitritos y $\mathrm{NO}_{x}[31,32]$.

\subsubsection{Técnicas catalíticas}

Existen varias técnicas catalíticas para la eliminación de los nitratos del agua:

- La reducción catalítica de nitratos a nitrógeno. Ésta es una nueva y atractiva manera de desnitrificar el agua, pues es un proceso en el que el nitrato es 
reducido a una sustancia inerte como el nitrógeno y no se genera ningún residuo que deba ser tratado. Esta es la técnica estudiada en esta tesis y por ello se describirá con más detalle en el siguiente apartado.

- La electrocatálisis que consiste en la utilización de un electrodo de carbono soportado con un metal activo para la reducción de los nitratos presentes en el agua. Sin embargo, este proceso presenta eficiencias bastante bajas en comparación con el uso de la reducción catalítica [33-35].

- La fotocatálisis, utilizada para la eliminación de nitratos de aguas residuales, en este caso se usa metanol como agente reductor, obteniendo conversiones de nitrato inferiores al 5\% [36]. En este proceso es necesaria la optimización de factores como el tiempo de irradiación, el pH de la disolución, la naturaleza del agente reductor y la naturaleza del metal depositado sobre el catalizador [37], lo que hace muy difícil su utilización para la potabilización del agua.

A modo de resumen, en la siguiente tabla se han comparado las principales características de las distintas técnicas utilizadas para la eliminación de nitratos del agua (tabla 1.3) [38]. 
Tabla 1. 3. Comparación de las técnicas para la eliminación de nitratos.

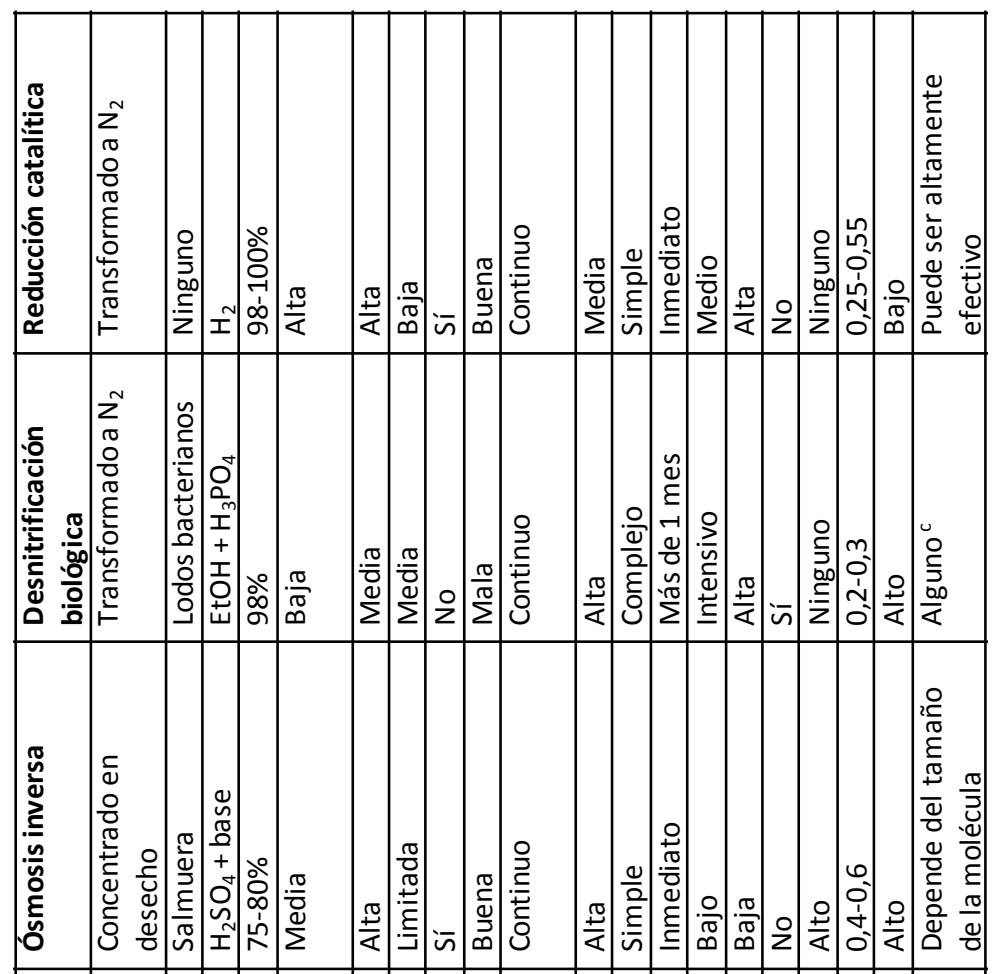

\begin{tabular}{|c|c|c|c|c|c|c|c|c|c|c|c|c|c|c|c|c|c|}
\hline 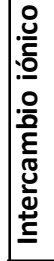 & 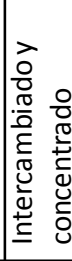 & 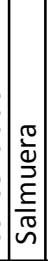 & 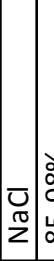 & 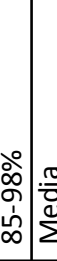 & $\frac{\pi}{\frac{\pi}{\pi}}$ & $\frac{\pi}{\pi}$ & 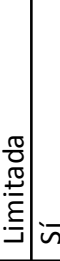 & 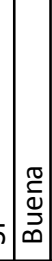 & 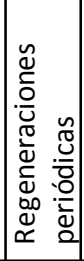 & $\frac{\pi}{2}$ & 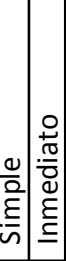 & 을. & $\frac{\widetilde{\sigma}}{\widetilde{\sigma}}$ & a & & & \\
\hline 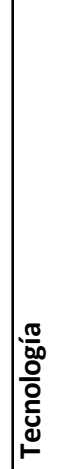 & 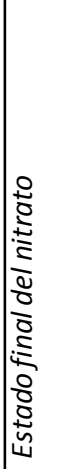 & 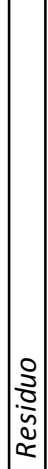 & & 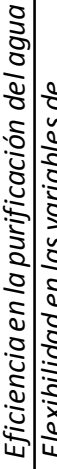 & 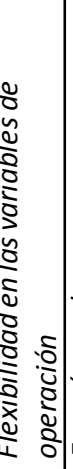 & 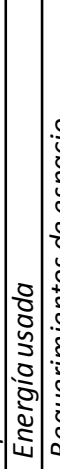 & 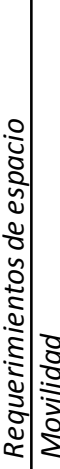 & 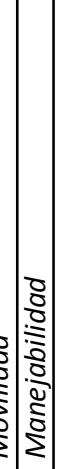 & 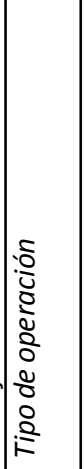 & 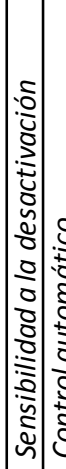 & 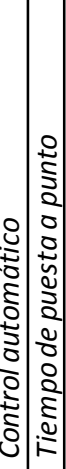 & 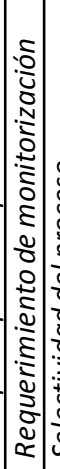 & 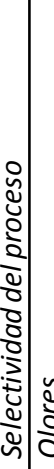 & $\stackrel{0}{0}$ & & 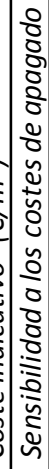 & 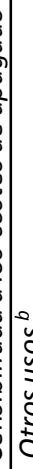 \\
\hline
\end{tabular}

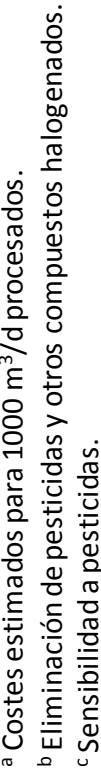




\subsection{La reducción catalítica de nitratos}

La eliminación catalítica de nitratos utilizando hidrógeno como agente reductor fue descrita por primera vez en 1989 por Vorlop y col. [39] y consiste en la reducción de los nitratos por el hidrógeno transformándolos en nitrógeno y agua mediante un catalizador sólido. Sin embargo, durante la reacción se pueden producir también nitritos como producto intermedio y amonio como subproducto, tal como muestran las ecuaciones siguientes [40].

$$
\begin{aligned}
& 2 \mathrm{NO}_{3}^{-}+5 \mathrm{H}_{2} \rightarrow \mathrm{N}_{2}+4 \mathrm{H}_{2} \mathrm{O}+2 \mathrm{OH}^{-} \quad \text { Ec. } 1.1 \\
& \mathrm{NO}_{3}{ }^{-}+\mathrm{H}_{2} \rightarrow \mathrm{NO}_{2}^{-}+\mathrm{H}_{2} \mathrm{O} \text { Ec. } 1.2 \\
& 2 \mathrm{NO}_{2}^{-}+3 \mathrm{H}_{2} \rightarrow \mathrm{N}_{2}+2 \mathrm{H}_{2} \mathrm{O}+2 \mathrm{OH}^{-} \quad \text { Ec. } 1.3 \\
& \mathrm{NO}_{2}^{-}+3 \mathrm{H}_{2} \rightarrow \mathrm{NH}_{4}^{+}+2 \mathrm{OH}^{-} \quad \text { Ec. } 1.4 \\
& \mathrm{NO}_{3}{ }^{-}+4 \mathrm{H}_{2} \rightarrow \mathrm{NH}_{4}^{+}+\mathrm{H}_{2} \mathrm{O}+2 \mathrm{OH}^{-} \quad \text { Ec. } 1.5
\end{aligned}
$$

Las ecuaciones anteriores se pueden resumir en las siguientes, que representan las reacciones generales de reducción catalítica de nitratos utilizando $\mathrm{H}_{2}$ como agente reductor.

$$
\begin{array}{ll}
2 \mathrm{NO}_{3}^{-}+5 \mathrm{H}_{2} \rightarrow \mathrm{N}_{2}+2 \mathrm{OH}^{-}+4 \mathrm{H}_{2} \mathrm{O} & \text { Ec. } 1.6 \\
2 \mathrm{NO}_{3}^{-}+8 \mathrm{H}_{2} \rightarrow 2 \mathrm{NH}_{4}^{+}+4 \mathrm{OH}^{-}+2 \mathrm{H}_{2} \mathrm{O} & \text { Ec. } 1.7
\end{array}
$$

Existen muchas variables que afectan a estas reacciones desde el tipo de catalizador hasta las condiciones de reacción; siendo los catalizadores empleados en esta reacción mayoritariamente catalizadores bimetálicos constituidos por una combinación entre un metal noble y un metal no noble [41-47]. En los siguientes apartados se abordan los estudios más relevantes sobre la reducción catalítica de nitratos de aguas desde distintas perspectivas.

\subsubsection{Tipos de catalizadores}

Se han descrito diversos tipos de catalizadores activos para esta reacción, ofreciendo diferentes resultados en función del metal utilizado, del soporte y de las condiciones de reacción. 
Como se ha indicado anteriormente, la mayor parte de los catalizadores utilizados son catalizadores bimetálicos que combinan un metal noble y un metal no noble. Las combinaciones de metales utilizadas han sido numerosas, empleando como metal noble $\mathrm{Pt}, \mathrm{Pd}, \mathrm{Ru}, \mathrm{Rh}, \mathrm{Ir}$, y como metal no noble $\mathrm{Ge}, \mathrm{Co}, \mathrm{Sn}, \mathrm{In}, \mathrm{Bi}, \mathrm{Au}, \mathrm{Fe}, \mathrm{Co}, \mathrm{Ni}, \mathrm{Ag}, \mathrm{Cu}, \mathrm{Sn}[42$, $44,48-52]$, obteniendo los mejores resultados con relaciones metal noble/metal no noble de 1 y 2 [37, 48, 53]. De todas ellas las combinaciones de Pd o Pt con Cu o Sn [49, 54-68] han sido las más estudiadas y las que mejores resultados presentaban.

Estos metales se han soportado sobre distintos materiales como óxidos, carbones y materiales laminares. Así se ha estudiado el uso de alúmina $[63,68,69], \mathrm{SiO}_{2}$ [64], $\mathrm{TiO}_{2}$ [70, 71], $\mathrm{CeO}_{2}$ [72], $\mathrm{ZrO}_{2}$ [73], $\mathrm{SnO}_{2}$ [74], carbón activo [48, 53-55, 75, 76], hidrotalcitas [56-58, 77], zeolitas [62], resinas acrílicas [59, 78, 79], fibras de vidrio [80], piedra pómez [81] y polímeros aniónicos $[60,61]$.

Entre todos ellos, los óxidos son los más usados como soportes. Algunos autores estudiaron la influencia de la preparación del material [69], la acidez del mismo [68] y su tamaño de partícula [63], indicando que los soportes más adecuados son los que tienen propiedades ácidas y un tamaño de grano y de cristal pequeños. El soporte más utilizado entre los óxidos es la alúmina, aunque se han utilizado otros soportes como el $\mathrm{TiO}_{2}$, el $\mathrm{SnO}$ o el $\mathrm{CeO}_{2}$. Estos últimos presentan un cambio en su estado de oxidación en el transcurso de la reacción, lo que indicaría que actúan no sólo como soportes sino como fase activa en las condiciones de reacción estudiadas [50, 70, 71].

Otros soportes estudiados son los carbones activos. Se han descrito diversos tipos de carbón como soporte: Norit Rox 0.8, Norit GAC 1240 PLUS, telas de carbón activo, nanotubos de carbono de pared múltiple comerciales Nanocyl-3100, etc., los cuales se han usado para soportar distintos metales, obteniendo los mejores resultados con combinaciones de Pd, Pt o Ru con Cu o Sn [53-55, 75].

Los materiales laminares como las hidrotalcitas también se han utilizado como soportes catalíticos en esta reacción. Así se ha estudiado el uso de hidrotalcitas con distintas relaciones $\mathrm{Mg} / \mathrm{Al}$ y con distintos metales, obteniéndose los mejores resultados con las hidrotalcitas de $\mathrm{Mg} / \mathrm{Al}$ de relación 4 e impregnadas con Cu y $\mathrm{Pd}[56-58,77]$. 


\subsubsection{Variables de reacción}

Varios autores han estudiado la influencia de determinadas variables de reacción en la actividad catalítica de algunos de los catalizadores descritos en el apartado anterior. Estos trabajos se han centrado principalmente en el estudio de la influencia del $\mathrm{pH}$, la concentración de hidrógeno, la temperatura, el tipo de reactor y la presencia de otras especies en el medio.

El efecto del pH en la reacción de hidrogenación catalítica de nitratos se ha estudiado en numerosos trabajos [37, 82-85]. Así, Sakamoto y col. [86] describieron que un aumento del pH de la solución llevaba a que los nitratos se redujeran totalmente a nitritos, de acuerdo con la ecuación 1.2, pero impedían que continuase la reacción. Según estos autores (figura 1.12) al aumentar el $\mathrm{pH}$ los iones hidroxilo compiten con los nitritos por los centros catalíticos, adsorbiéndose preferentemente los $\mathrm{OH}^{-}$sobre ellos, de forma que no continúa la reacción consecutiva de reducción de nitritos a nitrógeno (ecuaciones 1.3 y 1.4). Resultados similares han sido descritos por otros autores $[42,49,87]$.

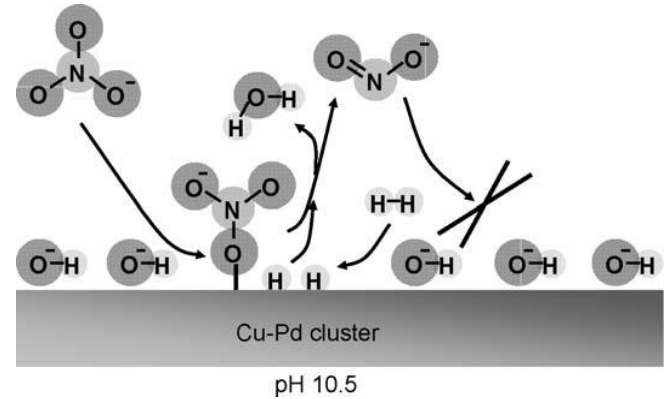

Figura 1. 12. Mecanismo de reacción propuesto en la superficie del catalizador sobre las partículas de Cu-Pd a pH 10,5 [86].

Además de influir sobre la actividad del catalizador, el aumento del $\mathrm{pH}$ se ha descrito que también afecta a la selectividad del mismo, aumentando la selectividad del catalizador a amonio [74].

De acuerdo con estos estudios, sería interesante controlar el $\mathrm{pH}$ del medio de reacción, evitando que éste aumente al aumentar la concentración de iones hidroxilo en el medio de reacción. Estos iones se forman por las reacciones descritas en las ecuaciones 
$1.1,1.3,1.4$ y 1.5 y un control del pH del medio permitiría su neutralización y disminución a medida que se van formando. Sin embargo, D'Arino y col. [40] indicaron que en estas reacciones con control del $\mathrm{pH}$ hay problemas de transferencia de masa en los poros del catalizador (figura 1.13). Según estos autores éste es el paso limitante en la reacción, siendo especialmente difícil el control del pH en las zonas cercanas a la fase activa, es decir, en los poros del soporte donde se produce la reacción de hidrogenación, ya que los iones hidroxilo formados sólo pueden ser neutralizados después de su difusión hacia el seno de la solución. Esto implica que no hay un control efectivo del pH en estos poros siendo éste más elevado en ellos que en el medio de reacción, lo que conlleva una mayor formación de subproductos no deseados: nitritos y amonio. Por este motivo, las propiedades intrínsecas de la selectividad de cada catalizador estarían, en principio, enmascaradas por el fenómeno de transferencia de masa.

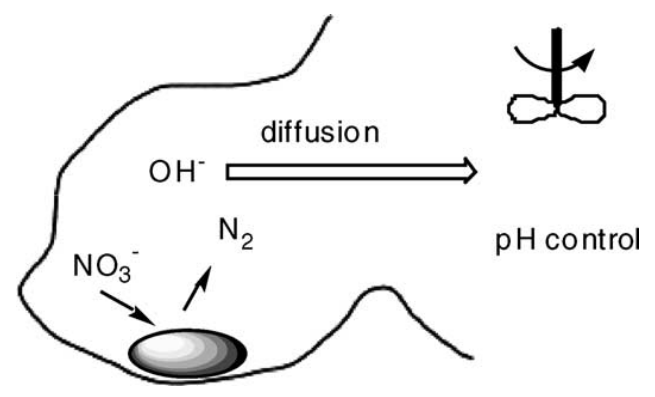

Figura 1. 13. Esquema representativo de la reducción de nitratos en el poro del catalizador.

Con el fin de evitar estos problemas se han propuesto varios métodos para el control del $\mathrm{pH}$ de la reacción como la adición continua de $\mathrm{HCl}, \mathrm{CO}_{2}$ o acetato al medio de reacción o la utilización de ácido fórmico en lugar de hidrógeno como agente reductor [83]. El uso de ácido fórmico se basa en que en el transcurso de la reacción éste se descompone en $\mathrm{H}_{2}$ y $\mathrm{CO}_{2}$, el cual puede tamponar el medio de reacción, inhibiendo el problema del aumento del pH y aumentando la actividad del catalizador [42, 49]. Resultados similares se obtienen mediante la adición continua de $\mathrm{CO}_{2}$ al medio de reacción, el cual neutraliza los iones hidroxilo que se van formando de una forma simple y efectiva manteniendo el $\mathrm{pH}$ de la solución constante. Estos trabajos $[42,49]$ muestran que 
la selectividad a amonio disminuye al añadir $\mathrm{CO}_{2}$ al medio de reacción, sin modificar la conversión obtenida con el catalizador.

No obstante, cuando se usa como soporte una resina acrílica [59] se observa que al añadir $\mathrm{CO}_{2}$ al medio de reacción la reacción es más lenta y se forma la misma cantidad de amonio. Esto se debe a la presencia de pares $\mathrm{COOH} / \mathrm{COO}^{-}$en la propia resina que actúan como tampón para controlar el pH (figura 1.14). En este caso, la adición de $\mathrm{CO}_{2}$ al medio inhibe la formación de este tampón, dificultando la reacción.

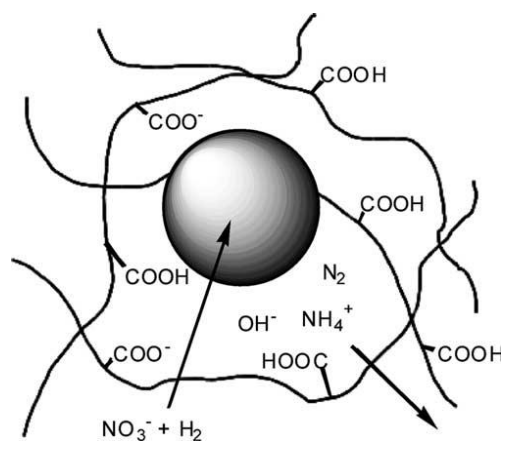

Figura 1. 14. Efecto tampón de las especies $\mathrm{COOH} / \mathrm{COO}^{-}$en las resinas acrílicas.

Otro aspecto estudiado la modificación de la actividad de un catalizador al variar la presión parcial de hidrógeno. En este sentido, Pintar y col. [83] observaron una clara diferencia tanto en la actividad como en la selectividad a amonio al modificar la relación $\mathrm{H}_{2} / \mathrm{CO}_{2}$, de modo que al aumentar la presión parcial de hidrógeno aumentaban ambas. Esta relación de la presión parcial de hidrógeno con la selectividad fue observada también por otros autores que estudiaron la reducción de nitritos [88] y de nitratos [87]. Estos resultados se han relacionado con que un aumento de la concentración de hidrógeno en el medio de reacción aumenta la probabilidad de que se produzca la reacción 1.7 frente a la 1.5 con lo que la selectividad a amonio aumenta.

Constantinou y col. [89] estudiaron el efecto de añadir aire al flujo de $\mathrm{H}_{2}$ utilizado como reductor, observando que a medida que aumentaba la cantidad de $\mathrm{O}_{2}$ añadido, se mantenía la actividad del catalizador, pero la formación de amonio disminuía considerablemente. Sugerían que este efecto se debe a que la superficie cubierta por hidrógeno disminuye con la presencia de $\mathrm{O}_{2}$ que se adsorbe sobre los mismos centros, por 
lo que existen menos átomos de $\mathrm{H}$ disponibles para formar $\mathrm{NH}_{4}^{+}$, favoreciendo la formación de $\mathrm{N}_{2}$.

En cuanto a la influencia de la temperatura de reacción en la eliminación catalítica de nitratos en aguas, los resultados presentados en la bibliografía muestran diferentes conclusiones. Por una parte, Wang y col. [85] observaron que cuando se usaban hidrotalcitas como soporte, tanto la adsorción como la actividad aumentaban con el aumento de la temperatura. En cambio, al utilizar un catalizador de Pd-Sn depositado en resinas acrílicas, Roveda y col. [59] obtuvieron que al aumentar la temperatura de reducción, la actividad disminuía considerablemente, mientras que la formación de amonio se mantenía. Estos distintos resultados indican que el efecto de la temperatura sobre la reacción depende en gran medida del catalizador utilizado.

La mayoría de los estudios realizados relativos a la eliminación de nitratos de aguas se basan en la utilización de reactores en discontinuo. No obstante, el uso de reactores de flujo continuo permite mejorar los problemas de transferencia de masa en el sistema de reacción disminuyendo la generación de amonio. Así, se ha descrito [90] que con el uso de un reactor trifásico trickle-bed, se pueden obtener altas conversiones a nitratos con una elevada selectividad a nitrógeno, al emplear una presión parcial de hidrógeno baja $(0,1$ bar) y caudales volumétricos de líquido mayores a $7 \mathrm{~mL} / \mathrm{min}$. Pintar y Batista $[90,91]$ desarrollaron otro sistema de reacción basado en la combinación de una resina de intercambio iónico y la reducción catalítica. En este sistema, primero se eliminan los nitratos mediante una resina de intercambio. Cuando ésta está agotada, se burbujea $\mathrm{H}_{2} \mathrm{a}$ una solución de $\mathrm{NaCl}$ hasta su completa saturación, y posteriormente esta solución se hace pasar por la columna de intercambio para regenerar la resina. La salmuera formada, saturada con $\mathrm{H}_{2}$, pasa a través del reactor catalítico y el nitrato que contenía se reduce a nitrógeno o amonio.

Por último, otra variable a estudiar es la presencia de otras especies en el medio de reacción. La mayoría de los estudios realizados se han efectuado utilizando agua desionizada o destilada añadiendo una sal inorgánica como fuente de iones nitrato. Esto representa una aproximación simplificada pero no un medio real. Pintar y col. [83] estudiaron el efecto de la dureza del agua y de las sales disueltas en ella en la eliminación 
catalítica de nitratos. Demostraron que la desaparición de los nitratos era más lenta al usar agua del grifo que al usar agua destilada con nitratos, debido a la presencia de otros iones en el agua que competían con los nitratos por los centros activos del catalizador. Asimismo, encontraron que el catión usado en la sal como fuente de nitratos influye en la velocidad de eliminación de los mismos, de forma que la velocidad de eliminación crece en el orden: $\mathrm{K}^{+}<\mathrm{Na}^{+}<\mathrm{Ca}^{2+}<\mathrm{Mg}^{2+}<\mathrm{Al}^{3+}$. Esto indicaría que la constante aparente de velocidad de la reacción superficial cambia proporcionalmente con el potencial de ionización del catión presente en la solución acuosa. Además se observó que la máxima concentración de iones nitrito acumulada disminuía en el orden: $\mathrm{K}^{+}>\mathrm{Na}^{+}>\mathrm{Ca}^{2+}>\mathrm{Mg}^{2+}>$ $\mathrm{Al}^{3+}$, disminuyendo en el mismo orden la formación de amonio. Esto se atribuía a que los cationes con elevada capacidad de polarización, permitían una rápida regeneración de la superficie del catalizador al aumentar la velocidad de desorción de los iones hidroxilo formados, aumentando la superficie accesible a nitratos y nitritos y la velocidad de reacción.

Se ha estudiado también la influencia de otros aniones en el medio de reacción sobre la actividad catalítica de un catalizador $\mathrm{Pd}-\mathrm{Cu} / \mathrm{Al}_{2} \mathrm{O}_{3}$ [83]. Los resultados obtenidos indican que la presencia de $\mathrm{Cl}^{-}$o $\mathrm{SO}_{4}{ }^{2-}$ aumenta la velocidad de desaparición de los nitratos y disminuye la selectividad a amonio. Esto se debe según estos autores a que estos iones, debido a sus características electronegativas, aumentan la concentración y fortaleza de los centros ácidos Brönsted del catalizador, los cuales neutralizan parcialmente los iones hidroxilo formados regenerando la superficie del catalizador.

Al estudiar el efecto del ión $\mathrm{HCO}_{3}{ }^{-}$se observó una disminución de la velocidad de reacción por la presencia de este anión en el medio de reacción. El efecto inhibidor de este ión se explicó por una competencia en la adsorción del $\mathrm{NO}_{3}^{-}$y el $\mathrm{HCO}_{3}{ }^{-}$sobre los centros activos del catalizador ya que ambos iones son estructuralmente parecidos [83]. En este sentido, la hidrogenación catalítica se va a ver principalmente influenciada por las especies iónicas estructuralmente similares a los iones nitrato presentes en el medio de reacción. 


\subsubsection{Mecanismo de reacción}

Se han propuesto dos posibles mecanismos para la eliminación catalítica de nitratos en aguas utilizando catalizadores bimetálicos. La principal diferencia entre ambos estriba en el papel que juegan los distintos metales en la reducción de los nitratos.

El primer mecanismo fue propuesto en uno de los primeros trabajos que trataba sobre la eliminación catalítica de nitratos en aguas por Vorlop y col. [39]. El mecanismo propuesto se muestra en la figura 1.15 [42]. En este esquema se propone que inicialmente los nitratos se reducen a nitritos por un agente reductor, sobre los centros activos de PdMe (siendo Me un metal no noble), mientras que los nitritos formados se reducen en los centros de metal noble (Pd). El nitrito al reducirse se transforma en NO, el cual puede pasar a $\mathrm{N}_{2}$ directamente, o reducirse en $\mathrm{N}_{2} \mathrm{O}$ que se transforma posteriormente en $\mathrm{N}_{2}$, O reducirse a amonio. Este mecanismo ha sido apoyado por varios autores [92, 93], los cuales además indicaron que el paso de nitritos a nitrógeno o amonio se llevaba a cabo tanto en los centros de Pd como en los centros Pd-Me.

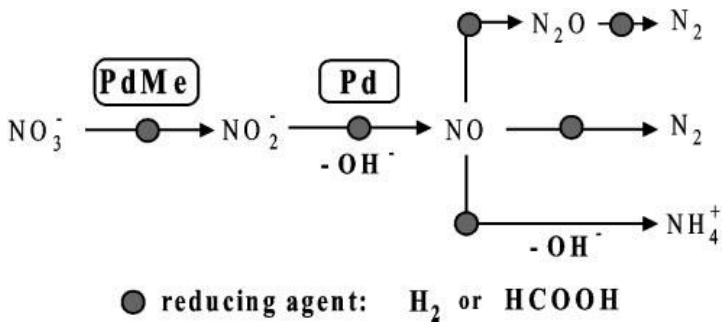

Figura 1. 15. Esquema de reacción propuesto por Vorlop y col. [42].

Este mecanismo fue completado unos años después por Prüsse y Vorlop [42] estableciendo además que era necesario que el hidrógeno se adsorbiera sobre el Pd, donde se activaba y entonces reducía el nitrato adsorbido a nitrito sobre los centros de Pd-Me. Los nitritos se reducían sobre los centros de Pd y la selectividad de la reacción venía determinada por la relación entre las especies nitrogenadas y de reductor presentes en la superficie de los centros monometálicos de paladio.

Warna y col. [94] propusieron un mecanismo similar descrito en las ecuaciones 1.8 a 1.20. Según este esquema, el $\mathrm{H}_{2}$ sufre una adsorción disociativa sobre los centros de paladio (ecuación 1.8). El hidrógeno adsorbido $\left(\mathrm{H}^{*}\right)$ reacciona con los iones $\mathrm{NO}_{3}{ }^{-}$presentes 
en el medio acuoso, formando una molécula de $\mathrm{NO}_{2}{ }^{*}$ (ecuación 1.9). El $\mathrm{NO}_{2}$ puede desorberse y sufrir una reacción de desproporcionación para dar $\mathrm{NO}_{2}^{-}$y $\mathrm{NO}_{3}^{-}$(ecuación 1.11). $\mathrm{El} \mathrm{NO}_{2}{ }^{-}$se reduce por un átomo de $\mathrm{H}^{*}$ formando $\mathrm{NO}^{*}$ (ecuaciones 1.12 y 1.13 ), el cual por adiciones de $\mathrm{H}^{*}$ forma $\mathrm{NH}$ (ecuación 1.14) que puede evolucionar a la formación de $\mathrm{N}_{2}$ (ecuación 1.15) o seguir adicionando $\mathrm{H}$ para formar $\mathrm{NH}_{3}$ (ecuaciones 1.16 a 1.18). En este esquema el paso más importante es la formación de NO*.

$$
\begin{array}{ll}
\mathrm{H}_{2}+2^{*} \rightarrow 2 \mathrm{H}^{*} & \text { Ec. } 1.8 \\
\mathrm{NO}_{3}{ }^{-}+\mathrm{H}^{*} \rightarrow \mathrm{NO}_{2}{ }^{*}+\mathrm{OH}^{-} & \text {Ec. } 1.9 \\
\mathrm{NO}_{2}{ }^{*} \leftrightarrow \mathrm{NO}_{2}{ }^{*} & \text { Ec. } 1.10 \\
2 \mathrm{NO}_{2}+2 \mathrm{OH}^{-} \rightarrow \mathrm{NO}_{2}{ }^{-}+\mathrm{NO}_{3}{ }^{-}+\mathrm{H}_{2} \mathrm{O} & \text { Ec. } 1.11 \\
\mathrm{NO}_{2}{ }^{-}+\mathrm{H}^{*} \rightarrow \mathrm{NO}^{*}+\mathrm{OH}^{-} & \text {Ec. } 1.12 \\
\mathrm{NO}_{2}{ }^{*}+\mathrm{H}^{*} \rightarrow \mathrm{NO}^{*}+\mathrm{OH}^{*} & \text { Ec. } 1.13 \\
\mathrm{NO}^{*}+2 \mathrm{H}^{*} \rightarrow \mathrm{NH}^{*}+\mathrm{OH}^{*}+{ }^{*} & \text { Ec. } 1.14 \\
2 \mathrm{NH}^{*} \rightarrow \mathrm{N}_{2}+2 \mathrm{H}^{*} & \text { Ec. } 1.15 \\
\mathrm{NH}^{*}+\mathrm{H}^{*} \rightarrow \mathrm{NH}_{2}{ }^{*}+{ }^{*} & \text { Ec. } 1.16 \\
\mathrm{NH}_{2}{ }^{*}+\mathrm{H}^{*} \rightarrow \mathrm{NH}_{3}{ }^{*}+{ }^{*} & \text { Ec. } 1.17 \\
\mathrm{NH}_{3}{ }^{*} \rightarrow \mathrm{NH}_{3}+{ }^{*} & \text { Ec. } 1.18 \\
\mathrm{NH}_{3}+\mathrm{H}_{2} \mathrm{O} \rightarrow \mathrm{NH}_{4}{ }^{*}+\mathrm{OH}^{-} & \text {Ec. } 1.19 \\
\mathrm{OH}^{*}+\mathrm{H}^{*} \rightarrow \mathrm{H}_{2} \mathrm{O}+2^{*} & \text { Ec. } 1.20
\end{array}
$$

Un esquema parecido fue propuesto por Sá y col. [50]. Según éste el NO* se disocia para dar $\mathrm{N}^{*}$ y $\mathrm{O}^{*}$. El $\mathrm{N}^{*}$ puede reaccionar con otro $\mathrm{N}^{*}$ para formar $\mathrm{N}_{2}$ o volver a reaccionar con el $\mathrm{NO}$ para dar $\mathrm{N}_{2} \mathrm{O}$. De forma alternativa, el $\mathrm{N}^{*}$ puede reaccionar con un átomo de $\mathrm{H}^{*}$, proveniente del $\mathrm{H}_{2}$ disociado, para dar $\mathrm{NH}_{3}$, según se muestra en las siguientes ecuaciones de reacción:

$$
\begin{aligned}
& \mathrm{NO}^{*} \rightarrow \mathrm{N}+\mathrm{O}^{*} \\
& 2 \mathrm{~N}^{*} \rightarrow \mathrm{N}_{2} \\
& \mathrm{NO}^{*}+\mathrm{N}^{*} \rightarrow \mathrm{N}_{2} \mathrm{O} \\
& \mathrm{N}^{*}+3 \mathrm{H}^{*} \rightarrow \mathrm{NH}_{3}
\end{aligned}
$$




$$
\begin{array}{ll}
\mathrm{O}^{*}+2 \mathrm{H}^{*} \rightarrow \mathrm{H}_{2} \mathrm{O} & \text { Ec. } 1.25
\end{array}
$$

Según Sá y col. [50], y como también defendían Warna y col. [94], la formación de NO y su hidrogenación son pasos claves para determinar la selectividad total de la reacción.

Basándose en este modelo, Yoshinaga y col. [92] explicaron la variación de la selectividad en un catalizador Pd-Cu/carbón al aumentar la cantidad de Cu en el mismo. Así, siguiendo el modelo de Prüsse [42], proponen que inicialmente los nitratos son reducidos a nitritos sobre los centros de $\mathrm{Pd}-\mathrm{Cu}$, mientras que los nitritos son reducidos sobre los centros de Pd. Sin embargo, Yoshinaga y col. [92] indican que no todos los centros de Pd tienen la misma capacidad reductora. Los centros de Pd situados en los bordes y las esquinas de los microcristales de paladio poseen una alta capacidad para la hidrogenación, lo que favorece una intensa hidrogenación del nitrito, llevando a la formación de amonio. Por otra parte, el nitrógeno se forma principalmente en los centros de paladio situados en las terrazas de los microcristales de $\mathrm{Pd}$, debido a que tienen una capacidad de hidrogenación más suave (figura 1.16a). Al añadir $\mathrm{Cu}$ a un microcristal de Pd, éste tiende a situarse en los bordes y las esquinas, por lo que desactivan los centros de Pd más reductores, de esta manera la presencia de $\mathrm{Cu}$ favorece la selectividad a $\mathrm{N}_{2}$ del catalizador (figura 1.16b). Resultados similares los obtuvieron Miyazaki y col. [95] al estudiar el efecto de la morfología de las partículas de Pt en la reducción de nitratos. Sin embargo, si aumenta mucho el contenido en $\mathrm{Cu}$ del catalizador, la situación se invierte y aumenta la selectividad a amonio. Esto se debe a que el Cu se sitúa en toda la superficie del Pd y la mayor parte de los átomos de Pd se encuentran separados unos de otros por el $\mathrm{Cu}$, con lo que las moléculas de nitrito adsorbidas en los centros activos de Pd estarán separadas unas de otras, lo que lleva a la formación de amonio, debido a la dificultad en la recombinación de los átomos de $\mathrm{N}$ para formar $\mathrm{N}_{2}$. Este mecanismo explicaría los cambios de la selectividad a $\mathrm{N}_{2}$ observados con la adición de $\mathrm{Cu}$ (figura 1.16c). 


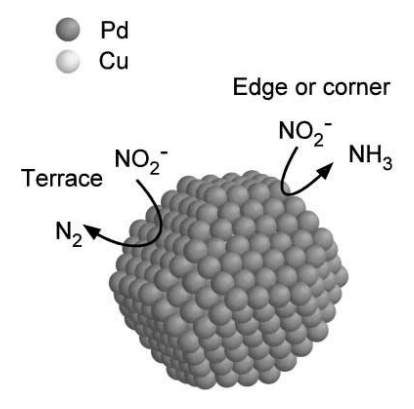

a

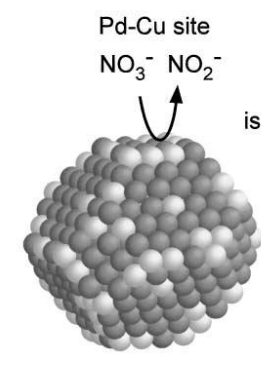

b

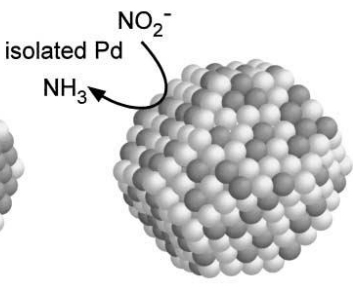

C

Figura 1. 16. Modelos propuestos para la eliminación de nitratos en las partículas de Pd y Pd-Cu: (a) $5 \% P d$, (b) $5 \% P d-0,6 \% C u$, (c) $5 \% P d-3 \% C u$.

Conclusiones similares han sido obtenidas por Zhang y col. [82] con un catalizador de $\mathrm{Pd}-\mathrm{Cu}$ soportado sobre $\mathrm{TiO}_{2}$. Según este trabajo la selectividad a nitrógeno viene determinada por el tamaño de las partículas $\mathrm{Pd}$-Cu así como por la relación entre la superficie recubierta de especies de $\mathrm{N}$ y las especies de reductor. Estos autores sugieren que la reducción de nitrato a nitrito se puede producir tanto en partículas metálicas grandes como en pequeñas. Por el contrario, la reducción del nitrito a nitrógeno o amonio depende del tamaño de la partícula de $\mathrm{Pd}^{0}$. Así, en los centros bimetálicos con tamaño inferior a 3,5 $\mathrm{nm}$, la superficie expuesta es demasiado pequeña para adsorber y activar dos especies- $\mathrm{N}$ simultáneamente para formar $\mathrm{N}_{2}$ (figura 1.17). Por el contrario, la formación de amonio resulta del contacto, por un efecto difusional en la superficie de los centros activos, de especies- $\mathrm{N}$ y especies-H que son mucho más pequeñas, por lo que el efecto del tamaño no es de gran importancia, y el amonio se observa como subproducto en todos los sistemas. Consecuentemente, la selectividad depende de la relación de la superficie cubierta por especies- $\mathrm{N}$ y especies hidrógeno $[42,96]$, a mayor relación $\mathrm{N}$ :hidrógeno, mayor es la selectividad a nitrógeno [82]. 


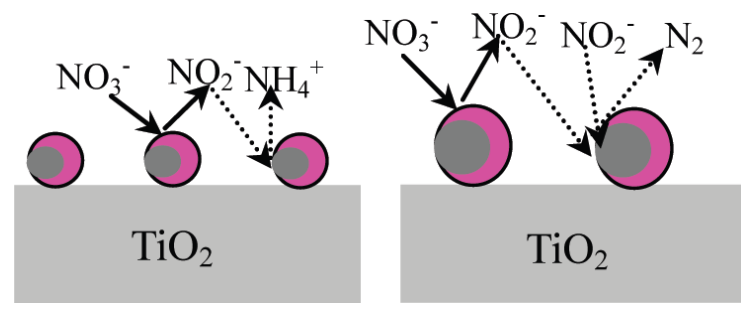

Figura 1. 17. Esquema de reacción propuesto para la eliminación de nitratos sobre catalizadores Pd$\mathrm{Cu} / \mathrm{TiO}_{2}$ con diferente tamaño de partícula.

Además, las características del soporte y del metal pueden también influir en la actividad del catalizador. Así, para los catalizadores basados en hidrotalcitas se ha propuesto el mecanismo esquematizado en la figura 1.18 [57, 94, 97]. Con este material el nitrato se adsorbe en el espacio interlaminar de la hidrotalcita donde es reducido a nitrito que se forma como intermedio de la reacción. Los nitritos permanecen entre las capas para compensar las cargas positivas de la estructura de la hidrotalcita y son reducidos a nitrógeno o amonio. Durante la reacción, la electroneutralidad del sistema se mantiene por los aniones $\mathrm{OH}^{-}$producidos durante la reducción de los nitritos. Dichos aniones mantienen el balance de cargas mientras que el nitrógeno (o el amonio) pasa a la solución fácilmente. Tras el ciclo, los aniones hidroxilo situados entre las capas se pueden intercambiar por más nitratos y así empezar un nuevo ciclo de reacción.

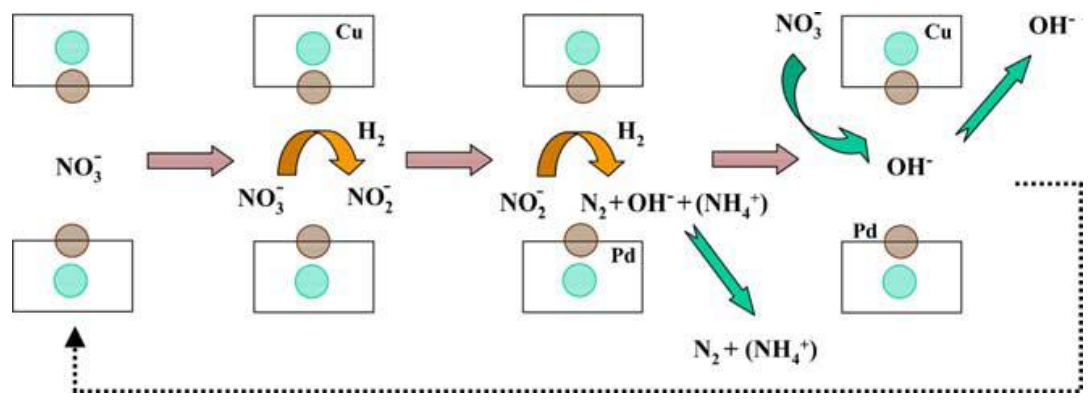

Figura 1. 18. Esquema de reacción propuesto al usar hidrotalcitas como soporte [97].

Por otro lado, Epron y col. [98] propusieron un mecanismo de reacción diferente, que se muestra en la figura 1.19. En este mecanismo se propone que el primer paso en la reducción de los nitratos es una reacción redox entre el $\mathrm{Cu}^{0}$ y el nitrato, oxidándose el $\mathrm{Cu}^{0}$ a $\mathrm{Cu}^{2+}$ y reduciendo los nitratos a nitritos, los cuales son productos intermedios que 
pueden seguir reduciéndose a $\mathrm{N}_{2} \circ \mathrm{NH}_{4}{ }^{+}$. En este caso, el papel del metal noble es activar el hidrógeno, permitiendo la nueva reducción del $\mathrm{Cu}^{2+}$ a $\mathrm{Cu}^{0}$ de acuerdo con el siguiente esquema de reacción:

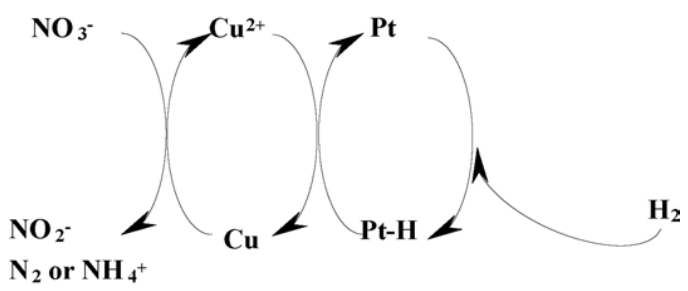

Figura 1. 19. Esquema de reacción propuesto para la reducción de nitratos usando catalizadores de Pt-Cu.

Sobre este esquema, Barrabés y col. [54] propusieron, basándose en los resultados que obtuvieron mediante espectroscopía fotoelectrónica de rayos $X$, que el metal noble no sólo está implicado en la reducción y regeneración del cobre mediante el hidrógeno quimisorbido, sino que sobre éste se reducen los nitritos para formar $\mathrm{N}_{2} \mathrm{O}$ amonio (figura 1.20).

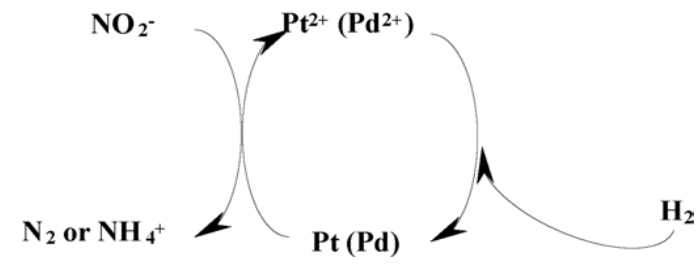

Figura 1. 20. Esquema propuesto para la reducción catalítica de los nitritos en agua.

Este mecanismo es también apoyado por Edelmann y col. [99] quienes en un trabajo en el que caracterizaron el catalizador mediante espectroscopía de absorción de rayos $\mathrm{X}$ in situ, concluyeron que al usar un catalizador de $\mathrm{Pd} / \mathrm{Cu} / \mathrm{Al}_{2} \mathrm{O}_{3}$, el $\mathrm{Pd}$ se encontraba en un estado reducido, mientras que el $\mathrm{Cu}$ se estabilizaba en un estado parcialmente oxidado. Además se formaba una fase PdCu que se situaba preferentemente sobre la superficie de las partículas ricas en Pd. El metal noble es la fase activa para la reducción de nitritos y estabiliza el metal no noble en un estado parcialmente reducido. La polaridad generada por las fases reducida y parcialmente oxidada en la superficie de las partículas 
de metal parece tener un efecto positivo en la actividad del catalizador para la reducción del nitrato.

Otros trabajos también estudian la importancia de la interacción metal noble-metal no noble. Así, según $[65,98]$ para que un centro bimetálico sea activo se requiere que los dos metales estén muy cercanos, pero que no estén formando una aleación. Estos autores indican que esta proximidad es suficiente para permitir que el hidrógeno activado sobre los centros de metal noble pase a los centros de cobre mediante una simple migración por la superficie por spill-over [50].

Recientemente, Soares y col. [76] han propuesto también que la reducción de nitratos puede ocurrir no únicamente con catalizadores bimetálicos sino con una mezcla física de catalizadores monometálicos, debido a la formación in situ del par Pd-Cu.

\subsubsection{Cinética de la reacción}

Al estudiar la influencia de diferentes variables de reacción como la temperatura de reacción, la presión parcial de hidrógeno, la cantidad de catalizador o la concentración inicial de nitratos, Pintar y col. [84] sugirieron que la cinética de la reacción de reducción de nitratos responde a una ecuación de adsorción del tipo Langmuir-Hinshelwood, obteniendo las siguientes ecuaciones para describir dicha cinética a partir de las reacciones 1.6 y 1.7 :

$$
\begin{aligned}
& \left(r_{N O_{3}^{-}}\right)=-\frac{d c_{N O_{3}^{-}}}{d t \cdot c_{c a t}}=\frac{k^{*} \cdot K_{H_{2}}^{n} \cdot K_{N O_{3}^{-}} \cdot c_{N O_{3}^{-}} \cdot p_{H_{2}}^{n}}{\left(1+K_{N O_{3}^{-}} \cdot c_{N O_{3}^{-}}\right) \cdot\left(1+K_{H_{2}}^{n} \cdot p_{H_{2}}^{n}\right)} \\
& \frac{\ln \frac{{ } \mathrm{NO}_{3}^{-}, 0}{{ } \mathrm{NO}_{3}^{-}}}{{ }_{\mathrm{NO}_{3}, 0^{-}{ }^{-} \mathrm{NO}_{3}^{-}}}+K_{\mathrm{NO}_{3}^{-}}=k^{*} \cdot \frac{K_{\mathrm{H}_{2}}^{n}}{1+K_{\mathrm{H}_{2}}^{n} \cdot p_{\mathrm{H}_{2}}^{n}} \cdot K_{\mathrm{NO}_{3}^{-}} \cdot c_{c a t} \cdot p_{\mathrm{H}_{2}}^{n} \cdot \frac{t}{c_{\mathrm{NO}_{3}^{-}, 0^{-} c_{N O_{3}^{-}}}} \\
& \frac{\ln \frac{{ }^{N_{O_{3}^{-}, 0}^{-}}}{c_{N O_{3}^{-}}}}{c_{\mathrm{NO}_{3}^{-}, 0}^{-} c_{N O_{3}^{-}}}+K_{\mathrm{NO}_{3}^{-}}=k_{s r, a p p} \cdot K_{\mathrm{NO}_{3}^{-}} \cdot c_{c a t} \cdot p_{\mathrm{H}_{2}}^{1 / 2} \cdot \frac{t}{c_{N O_{3}^{-}, 0^{-} c_{N O_{3}^{-}}}}
\end{aligned}
$$

Al calcular la energía de activación aparente del proceso se obtuvo que ésta era de $47 \mathrm{~kJ} / \mathrm{mol}$ y el calor de adsorción del nitrato $22 \mathrm{~kJ} / \mathrm{mol}$, para el catalizador de $\mathrm{Pd}$-Cu en la reacción de hidrogenación de nitratos en fase líquida [84]. También propusieron que la 
cinética de la eliminación de nitratos es consistente con reacciones catalizadas heterogéneamente pasando por intermedios iónicos, que requieren diferentes tipos de centros activos; descartando la posibilidad de mecanismos heterogéneos-homogéneos de radicales libres. Estos autores consideran que la reacción bimolecular entre las especies adsorbidas es una etapa limitante que transcurría por transferencia heterolítica de electrones. Por tanto, proponen que la eliminación de nitratos es directamente proporcional a la fracción cubierta en los diferentes centros por los reactantes, tal como se espera del modelo de adsorción de Langmuir. Mikami y col. [100] corroboraron también estos resultados, obteniendo órdenes de reacción muy bajos.

Por otra parte, Tacke y Vorlop [96] determinaron la velocidad de reacción total para la desaparición de nitrato utilizando un catalizador de $5 \% \mathrm{Pd}-1,25 \% \mathrm{Cu} / \mathrm{Al}_{2} \mathrm{O}_{3}$ a $10^{\circ} \mathrm{C}$, encontrando que el orden de la reacción era 0,7 respecto a la concentración de nitrato y que era independiente de la presión parcial de hidrógeno cuando ésta era superior a 1 bar. Por el contrario, Constantinou y col. [63] determinaron que el orden de la ecuación de velocidad era de 0,32 respecto al nitrato y 1,04 respecto al $\mathrm{H}_{2}$, indicando que éste último se modificaba por la presencia de aire en el medio de reacción. 


\section{Referencias}

[1] IMAES, Control y Gestión de una Planta de Potabilización de Aguas, Grupo de Ingeniería Química y Medioambiental. ETSII. UCLM (2009).

[2] J. A. Mendoza Roca, M. T. Montañés Sanjuan, A. E. Palomares Gimeno, Ciencia y Tecnología del Medio Ambiente, (1998).

[3] A. Gallardo Izquierdo, Máster en Medio Ambiente y Empresa. Módulo 6: Agua, Depuración, Departamento de Ingeniería Mecánica y Construcción. Universitat Jaume I (2008).

[4] Evaluación Ambiental Estratégica de la Estrategia Nacional para la Modernización Sostenible de los Regadíos. Horizonte 2015, Ministerio de Medio Ambiente y Medio Rural y Marino. Secretaría de Estado de Medio Rural y Agua. Dirección General del Agua (2010).

[5] Departamento Técnico de IDAGUA, S.A.; Tecnología del Agua, 4 (1982).

[6] J. G. Prato Moreno, PhD thesis, Universidad Politécnica de Valencia (Valencia), (2004).

[7] Ministerio de Medio Ambiente, Caracterización de las Fuentes Agrarias de Contaminación de las Aguas por Nitratos, (1996).

[8] L. Fernández Ruiz; Enseñanzas de la Tierra, 15 (2007) 257.

[9] NATO ASI Series, Nitrate contamination. Exposure,consequence and control, Vol. 30, Bogárdi, Istvan Kuzelka, Robert D. ed. (1990).

[10] Generalitat de Catalunya Departament de Salut, Los nitratos en el agua de consumo (2010).

[11] Organización Mundial de la Salud, Metahemoglobinemia (2010).

[12] G. Gulis, M. Czompolyova, J. R. Cerhan; Environmental Research, 88 (2002) 182.

[13] Real Decreto 140/2003, de 7 de febrero, por el que se establecen los criterios sanitarios de la calidad del agua de consumo humano, BOE 45 (2003).

[14] Ministerio de Medio Ambiente y Medio Rural y Marino, Perfil Ambiental de España (2009).

[15] Agencia Europea de Medio Ambiente, Nutrients in freshwater (2010).

[16] C. Stoate, N. D. Boatman, R. J. Borralho, C. R. Carvalho, G. R. d. Snoo, P. Eden; Journal of Environmental Management, 63 (2001) 337.

[17] C. Stoate, A. Báldi, P. Beja, N. D. Boatman, I. Herzon, A. van Doorn, G. R. de Snoo, L. Rakosy, C. Ramwell; Journal of Environmental Management, 91 (2009) 22.

[18] C. Ramos, A. Agut, A. L. Lidón; Environmental Pollution, 118 (2002) 215.

[19] L. Sánchez, J. A. Díez, A. Vallejo, M. C. Cartagena; Soil Biology and Biochemistry, 33 (2001) 1201.

[20] A. El Midaoui, F. Elhannouni, M. Taky, L. Chay, M. A. Menkouchi Sahli, L. Echihabi, M. Hafsi; Separation and Purification Technology, 29 (2002) 235.

[21] R. Molinari, P. Argurio, L. Romeo; Desalination, 138 (2001) 271.

[22] J. Bohdziewicz, M. Bodzek, E. Wasik; Desalination, 121 (1999) 139.

[23] E. J. McAdam, S. J. Judd; Desalination, 196 (2006) 135.

[24] C. T. Matos, S. Velizarov, J. G. Crespo, M. A. M. Reis; Water Research, 40 (2006) 231.

[25] E. J. McAdam, M. Pawlett, S. J. Judd; Water Research, 44 (2010) 69. 
[26] S. Aslan, A. Türkman; Process Biochemistry, 40 (2005) 935.

[27] S. Aslan, A. Turkman; Process Biochemistry, 41 (2006) 882.

[28] S. Aslan; Process Biochemistry, 40 (2005) 417.

[29] S. J. Ergas, D. E. Rheinheimer; Water Research, 38 (2004) 3225.

[30] W. Jianping, P. Lei Han Wei, D. Liping, M. Guozhu; Biochemical Engineering Journal, 15 (2003) 153.

[31] Z. Feleke, Y. Sakakibara; Water Research, 36 (2002) 3092.

[32] M. Prosnansky, Y. Sakakibara, M. Kuroda; Water Research, 36 (2002) 4801.

[33] J. W. Peel, K. J. Reddy, B. P. Sullivan, J. M. Bowen; Water Research, 37 (2003) 2512.

[34] Y. Wang, J. Qu, R. Wu, P. Lei; Water Research, 40 (2006) 1224.

[35] M. T. de Groot, M. T. M. Koper; Journal of Electroanalytical Chemistry, 562 (2004) 81.

[36] T. Mori, J. Suzuki, K. Fujimoto, M. Watanabe, Y. Hasegawa; Applied Catalysis B: Environmental, 23 (1999) 283.

[37] W. Gao, N. Guan, J. Chen, X. Guan, R. Jin, H. Zeng, Z. Liu, F. Zhang; Applied Catalysis B: Environmental, 46 (2003) 341.

[38] G. Centi, S. Perathoner; Applied Catalysis B: Environmental, 41 (2003) 15.

[39] K. D. Vorlop, T. Tacke; Chemie Ingenieur Technik, 61 (1989) 836.

[40] M. D'Arino, F. Pinna, G. Strukul; Applied Catalysis B: Environmental, 53 (2004) 161.

[41] F. Gauthard, F. Epron, J. Barbier; Journal of Catalysis, 220 (2003) 182.

[42] U. Prüsse, K.-D. Vorlop; Journal of Molecular Catalysis A: Chemical, 173 (2001) 313.

[43] A. Pintar; Catalysis Today, 77 (2003) 451.

[44] S. Hörold, K. D. Vorlop, T. Tacke, M. Sell; Catalysis Today, 17 (1993) 21.

[45] H. Berndt, I. Mönnich, B. Lücke, M. Menzel; Applied Catalysis B: Environmental, 30 (2001) 111.

[46] O. M. Ilinitch, L. V. Nosova, V. V. Gorodetskii, V. P. Ivanov, S. N. Trukhan, E. N. Gribov, S. V. Bogdanov, F. P. Cuperus; Journal of Molecular Catalysis A: Chemical, 158 (2000) 237.

[47] A. J. Lecloux; Catalysis Today, 53 (1999) 23.

[48] O. S. G. P. Soares, J. J. M. Órfão, M. F. R. Pereira; Applied Catalysis B: Environmental, 91 (2009) 441.

[49] U. Prüsse, M. Hähnlein, J. Daum, K.-D. Vorlop; Catalysis Today, 55 (2000) 79.

[50] J. Sá, J. Montero, E. Duncan, J. A. Anderson; Applied Catalysis B: Environmental, 73 (2007) 98.

[51] A. Garron, K. Lázár, F. Epron; Applied Catalysis B: Environmental, 65 (2006) 240.

[52] S. Hörold, T. Tacke, K.-D. Vorlop; Environmental Technology, 14 (1993) 931.

[53] U. Matatov-Meytal, M. Sheintuch; Catalysis Today, 102-103 (2005) 121.

[54] N. Barrabés, J. Just, A. Dafinov, F. Medina, J. L. G. Fierro, J. E. Sueiras, P. Salagre, Y. Cesteros; Applied Catalysis B: Environmental, 62 (2006) 77.

[55] O. S. G. P. Soares, J. J. M. Órfao, M. F. R. Pereira; Industrial \& Engineering Chemistry Research, 49 (2010) 7183. 
[56] A. E. Palomares, J. G. Prato, F. Márquez, A. Corma; Applied Catalysis B: Environmental, 41 (2003) 3.

[57] Y. Wang, J. Qu, H. Liu, C. Hu; Catalysis Today, 126 (2007) 476.

[58] A. Aristizábal, N. Barrabés, S. Contreras, M. Kolafa, J. Llorca, D. Tichit, F. Medina, J. E. Sueiras, in XXII CICAT - Congreso Iberoamericano de Catálisis, Chile (2010).

[59] A. Roveda, A. Benedetti, F. Pinna, G. Strukul; Inorganica Chimica Acta, 349 (2003) 203.

[60] I. Dodouche, F. Epron; Applied Catalysis B: Environmental, 76 (2007) 291.

[61] I. Dodouche, D. P. Barbosa, M. d. C. Rangel, F. Epron; Applied Catalysis B: Environmental, 93 (2009) 50.

[62] K. Nakamura, Y. Yoshida, I. Mikami, T. Okuhara; Applied Catalysis B: Environmental, 65 (2006) 31.

[63] C. L. Constantinou, C. N. Costa, A. M. Efstathiou; Catalysis Today, 151 (2010) 190.

[64] A. Garron, K. Lázár, F. Epron; Applied Catalysis B: Environmental, 59 (2005) 57.

[65] J. Sá, H. Vinek; Applied Catalysis B: Environmental, 57 (2005) 247.

[66] J. Sá, S. Gross, H. Vinek; Applied Catalysis A: General, 294 (2005) 226.

[67] J. Sá, D. Gasparovicova, K. Hayek, E. Halwax, J. A. Anderson, H. Vinek; Catalysis Letters, 105 (2005) 209.

[68] A. Pintar, J. Batista, I. Musevic; Applied Catalysis B: Environmental, 52 (2004) 49.

[69] G. Strukul, F. Pinna, M. Marella, L. Meregalli, M. Tomaselli; Catalysis Today, 27 (1996) 209.

[70] J. Sá, T. Berger, K. Föttinger, A. Riss, J. A. Anderson, H. Vinek; Journal of Catalysis, 234 (2005) 282.

[71] G. Fagherazzi, A. Benedetti, S. Polizzi, A. Mario, F. Pinna, M. Signoretto, N. Pernicone; Catalysis Letters, 32 (1995) 293.

[72] F. Epron, F. Gauthard, J. Barbier; Journal of Catalysis, 206 (2002) 363.

[73] M. J. Chollier-Brym, R. Gavagnin, G. Strukul, M. Marella, M. Tomaselli, P. Ruiz; Catalysis Today, 75 (2002) 49.

[74] R. Gavagnin, L. Biasetto, F. Pinna, G. Strukul; Applied Catalysis B: Environmental, 38 (2002) 91.

[75] O. S. G. P. Soares, J. J. M. Órfao, M. F. R. Pereira; Catalysis Letters, 126 (2008) 253.

[76] O. S. G. P. Soares, J. J. M. Órfão, M. F. R. Pereira; Applied Catalysis B: Environmental, 102 (2011) 424.

[77] D. Wan, H. Liu, X. Zhao, J. Qu, S. Xiao, Y. Hou; Journal of Colloid and Interface Science, 332 (2009) 151.

[78] D. Gasparovicová, M. Králik, M. Hronec, A. Biffis, M. Zecca, B. Corain; Journal of Molecular Catalysis A: Chemical, 244 (2006) 258.

[79] D. Gasparovicová, M. Králik, M. Hronec, Z. Vallusová, H. Vinek, B. Corain; Journal of Molecular Catalysis A: Chemical, 264 (2007) 93.

[80] Y. Matatov-Meytal, V. Barelko, I. Yuranov, M. Sheintuch; Applied Catalysis B: Environmental, 27 (2000) 127.

[81] F. Deganello, L. F. Liotta, A. Macaluso, A. M. Venezia, G. Deganello; Applied Catalysis B: Environmental, 24 (2000) 265.

[82] F. Zhang, S. Miao, Y. Yang, X. Zhang, J. Chen, N. Guan; The Journal of Physical Chemistry C, 112 (2008) 7665. 
[83] A. Pintar, M. Setinc, J. Levec; Journal of Catalysis, 174 (1998) 72.

[84] A. Pintar, J. Batista, J. Levec, T. Kajiuchi; Applied Catalysis B: Environmental, 11 (1996) 81.

[85] Y. Wang, J. Qu, H. Liu; Journal of Molecular Catalysis A: Chemical, 272 (2007) 31.

[86] Y. Sakamoto, Y. Kamiya, T. Okuhara; Journal of Molecular Catalysis A: Chemical, 250 (2006) 80.

[87] A. Pintar, J. Batista; Applied Catalysis B: Environmental, 63 (2006) 150.

[88] Y. Matatov-Meytal, Y. Shindler, M. Sheintuch; Applied Catalysis B: Environmental, 45 (2003) 127.

[89] C. L. Constantinou, C. N. Costa, A. M. Efstathiou; Environmental Science \& Technology, 41 (2007) 950.

[90] A. Pintar, J. Batista; Catalysis Today, 53 (1999) 35.

[91] A. Pintar, J. Batista, J. Levec; Catalysis Today, 66 (2001) 503.

[92] Y. Yoshinaga, T. Akita, I. Mikami, T. Okuhara; Journal of Catalysis, 207 (2002) 37.

[93] Y. Matatov-Meytal; Industrial \& Engineering Chemistry Research, 44 (2005) 9575.

[94] J. Wärna, I. Turunen, T. Salmi, T. Maunula; Chemical Engineering Science, 49 (1994) 5763.

[95] A. Miyazaki, T. Asakawa, Y. Nakano, I. Balint; Chemical Communications, 29 (2005) 3730.

[96] T. Tacke, K. D. Vorlop; Chemie Ingenieur Technik, 65 (1993) 1500.

[97] A. E. Palomares, J. G. Prato, F. Rey, A. Corma; Journal of Catalysis, 221 (2004) 62.

[98] F. Epron, F. Gauthard, C. Pinéda, J. Barbier; Journal of Catalysis, 198 (2001) 309.

[99] A. Edelmann, W. Shieber, H. Vinek, A. Jentys; Catalysis Letters, 69 (2000) 11.

[100] I. Mikami, Y. Sakamoto, Y. Yoshinaga, T. Okuhara; Applied Catalysis B: Environmental, 44 (2003) 79. 

2.

OBJETIVOS 

A lo largo de la introducción se ha visto que existen numerosas zonas del planeta cuyas aguas no son aptas para el consumo humano pues están contaminadas por nitratos. Es por ello que para su eliminación se necesita un método eficaz y que no genere nuevos contaminantes. La reducción catalítica de nitratos podría ser una técnica adecuada para conseguirlo.

Por tanto, el objetivo de esta tesis doctoral es el desarrollo de un sistema catalítico en continuo para la eliminación de nitratos en aguas naturales empleando hidrógeno como agente reductor. Para ello, se optimizarán las condiciones de reacción: el pH, la temperatura, la velocidad de agitación, el tiempo de contacto, el flujo de hidrógeno y la presión en el reactor.

Por otra parte, se optimizará el catalizador utilizado para la hidrogenación de nitratos de forma que sea activo y selectivo en la eliminación de nitratos. En este sentido, se realizará un estudio exhaustivo tanto de los posibles metales como de los posibles soportes que se pueden utilizar para diseñar los catalizadores. En este sentido, se estudiarán diversas combinaciones de metales basados en pares metal noble - metal no noble que se soportarán sobre diversos materiales como óxidos, zeolitas, carbones e hidrotalcitas y se determinará tanto la actividad como la selectividad de los catalizadores preparados en las condiciones óptimas de reacción.

El catalizador óptimo se estudiará con detalle, caracterizando el mismo, determinando su tiempo de vida y su capacidad de regeneración. En base a los resultados obtenidos con este catalizador, se tratará de determinar el mecanismo de la reacción y se propondrán nuevas rutas para preparar nuevos catalizadores activos. 

3.

PROCEDIMIENTO

EXPERIMENTAL 



\subsection{Materiales}

Los reactivos utilizados en el presente trabajo son los que se detallan a continuación:

\subsubsection{Gases}

Los gases usados en esta tesis fueron suministrados por Abelló Linde, S. A., siendo éstos los siguientes:

- $\quad$ Aire sintético 5.0, 99,995\%.

- Dióxido de carbono 5.0, 99,999\%.

- Hidrógeno 5.0, 99,999\%.

- $\quad$ Nitrógeno 5.0, 99,99\%.

\subsubsection{Líquidos}

- $\quad$ Agua Milli-Q, Millipore.

- $\quad$ Agua destilada.

- $\quad$ Agua natural de diferentes procedencias. En la siguiente tabla se muestran las propiedades más relevantes de los tipos de agua usada en el presente trabajo. En los experimentos habituales se utilizaba el agua natural de pozo.

Tabla 3. 1. Composición y procedencia de las aguas contaminadas por nitratos usadas en el trabajo de tesis.

\begin{tabular}{lccccc}
\hline Procedencia & $\begin{array}{c}\text { Conductividad } \\
(\mu \mathrm{S} / \mathrm{cm})\end{array}$ & $\begin{array}{c}\mathrm{Ca}^{2+} \\
(\mathrm{mg} / \mathrm{L})\end{array}$ & $\begin{array}{c}\mathrm{Cl}^{-} \\
(\mathrm{mg} / \mathrm{L})\end{array}$ & $\begin{array}{c}\mathrm{SO}_{4}{ }^{2-} \\
(\mathbf{m g} / \mathrm{L})\end{array}$ & $\begin{array}{c}\mathrm{NO}_{3}{ }^{-} \\
(\mathbf{m g} / \mathrm{L})\end{array}$ \\
\hline $\begin{array}{l}\text { Lagunas de Ruidera } \\
\text { Pozo en Picassent }\end{array}$ & 570 & 85 & 35 & 160 & 30 \\
$\begin{array}{l}\text { Pozo en Puzol } \\
\text { Agua procedente de }\end{array}$ & 1000 & 185 & 79 & 200 & 100 \\
industria química & 1580 & 280 & 232 & 173 & 150 \\
\hline
\end{tabular}




\subsubsection{Sólidos}

Los reactivos sólidos utilizados durante esta tesis y los sólidos usados como soportes son los siguientes:

- $\quad$ Acetato de estaño, $\mathrm{Sn}\left(\mathrm{CH}_{3} \mathrm{CO}_{2}\right)_{4}$, Aldrich.

- Ácido hexacloroplatínico, $\mathrm{H}_{2} \mathrm{PtCl}_{6} \cdot 4 \mathrm{H}_{2} \mathrm{O}, 40 \%$ Pt, Sigma-Aldrich.

- $\quad$ Alúmina, $\gamma-\mathrm{Al}_{2} \mathrm{O}_{3}, 99,5 \%$, Merck.

- Carbón Activo Norit GAC1240W.

- Carbón Activo Norit GAC830W.

- $\quad$ Carbón Activo Norit Rox 0.8

- Carbonato de sodio, $\mathrm{Na}_{2} \mathrm{CO}_{3}, 99 \%$, Fluka.

- $\quad$ Carburo de silicio, SiC, Carlo Erba Reagents.

- Clinoptilolita.

- Cloruro de amonio, $\mathrm{NH}_{4} \mathrm{Cl} \cdot 6 \mathrm{H}_{2} \mathrm{O},>99 \%$, Fluka.

- Cloruro de estaño (II), $\mathrm{SnCl}_{2} \cdot 2 \mathrm{H}_{2} \mathrm{O}, 98 \%$, Merck.

- Cloruro de estaño (IV), $\mathrm{SnCl}_{4} \cdot 5 \mathrm{H}_{2} \mathrm{O}, 98 \%$, Sigma-Aldrich.

- Cloruro de hierro (III), $\mathrm{FeCl}_{3}, 98 \%$, Riedel-de Haën.

- Cloruro de niobio (V), $\mathrm{NbCl}_{5}, 99 \%$, Aldrich.

- $\quad$ Cloruro de níquel (II), $\mathrm{NiCl}_{2}, 98 \%$, Merck.

- Cloruro de paladio, $\mathrm{PdCl}_{2}$, Aldrich.

- $\quad$ Cloruro de rodio, $\mathrm{RhCl}_{3} \cdot \mathrm{xH}_{2} \mathrm{O}, 40 \% \mathrm{Rh}$, Aldrich.

- Cloruro de rutenio, $\mathrm{RuCl}_{3} \cdot \mathrm{xH}_{2} \mathrm{O}$, Sigma-Aldrich.

- Cloruro de sodio, $\mathrm{NaCl}$, grado de síntesis, Scharlau.

- Faujasita.

- $\quad$ Grafito en barra de baja densidad, 99,999\%, Sigma-Aldrich.

- Hidróxido de sodio, $\mathrm{NaOH}$, grado de síntesis, Scharlau.

- Molibdato amónico, $\left(\mathrm{NH}_{4}\right)_{6} \mathrm{Mo}_{7} \mathrm{O}_{24} \cdot 4 \mathrm{H}_{2} \mathrm{O},>99 \%$, Fluka.

- Tungstanato amónico, $\left(\mathrm{NH}_{4}\right)_{6} \mathrm{~W}_{12} \mathrm{O}_{41} \cdot \mathrm{xH}_{2} \mathrm{O},>85 \% \mathrm{WO}_{3}$, Fluka.

- $\quad$ Mordenita, Si/Al=10, CBV20A.

- $\quad$ Nitrato de aluminio, $\mathrm{Al}\left(\mathrm{NO}_{3}\right)_{3} \cdot 9 \mathrm{H}_{2} \mathrm{O}, 98 \%$, Fluka.

- $\quad$ Nitrato de cerio, $\mathrm{Ce}\left(\mathrm{NO}_{3}\right)_{3},>98.5 \%$, Merck. 
- $\quad$ Nitrato de cobre (II), $\mathrm{Cu}\left(\mathrm{NO}_{3}\right)_{3} \cdot 3 \mathrm{H}_{2} \mathrm{O}, 98 \%$, Fluka.

- $\quad$ Nitrato de indio, $\ln \left(\mathrm{NO}_{3}\right)_{3} \cdot \mathrm{xH}_{2} \mathrm{O}$, Fluka.

- $\quad$ Nitrato de magnesio, $\mathrm{Mg}\left(\mathrm{NO}_{3}\right)_{2} \cdot 6 \mathrm{H}_{2} \mathrm{O}, 99 \%$, Fluka.

- $\quad$ Nitrato de manganeso, $\mathrm{Mn}\left(\mathrm{NO}_{3}\right)_{2} \cdot \mathrm{H}_{2} \mathrm{O},>97 \%$, Fluka.

- $\quad$ Nitrato de oro, $\mathrm{Au}\left(\mathrm{NO}_{3}\right)_{3}$, Aldrich.

- $\quad$ Nitrato de paladio (II), $\mathrm{Pd}\left(\mathrm{NO}_{3}\right)_{2} \cdot 2 \mathrm{H}_{2} \mathrm{O}, 40 \% \mathrm{Pd}$, Fluka.

- $\quad$ Nitrato de potasio, $\mathrm{KNO}_{3}, 99 \%$, Fluka.

- $\quad$ Nitrato de zinc, $\mathrm{Zn}\left(\mathrm{NO}_{3}\right)_{2} \cdot 6 \mathrm{H}_{2} \mathrm{O}, 99 \%$, Sigma-Aldrich.

- $\quad$ Nitrito de sodio, $\mathrm{NaNO}_{2}, 98 \%$, Fluka.

- $\quad$ Óxido de estaño, SnO, >95\%, Riedel deHaën.

- Óxido de titanio, $\mathrm{TiO}_{2},>99 \%$, Merck.

- Óxido de zirconio, $\mathrm{ZrO}_{2},>99,5 \%$, Riedel deHaën.

- Sepiolita.

- $\quad$ Sílice, $\mathrm{SiO}_{2}$, Basf.

- $\quad$ Sulfato de sodio, $\mathrm{NaSO}_{4},>99 \%$, Sigma-Aldrich.

- $\quad$ Test para el análisis de amonio Spectroquant ${ }^{\circledR}, 0,01-3,5 \mathrm{mg} / \mathrm{L} \mathrm{NH}_{4}{ }^{+}$, Merck.

- $\quad$ Test para el análisis de nitratos Spectroquant ${ }^{\circledR}, 1-90 \mathrm{mg} / \mathrm{L} \mathrm{NO}_{3}{ }^{-}$, Merck.

- $\quad$ Test para el análisis de nitritos Spectroquant ${ }^{\circledR}, 0,02-3,0 \mathrm{mg} / \mathrm{L} \mathrm{NH}_{4}{ }^{+}$, Merck.

- Zeolita Y, Si/Al=2,5, CBV500.

- Zeolita ZSM-5, Si/AI=140, CBV28014.

- Zeolita ZSM-5, Si/AI=25, CBV5020.

- Zeolita ZSM-5, Si/Al=40, CBV8020.

\subsection{Síntesis de los soportes catalíticos}

\subsubsection{Hidrotalcitas}

Se prepararon dos tipos de hidrotalcitas, unas conteniendo Mg-Al y otras con MgAl-Cu. Para la síntesis de estos materiales se prepararon dos disoluciones acuosas, una ácida y la otra básica. La disolución ácida contenía nitrato de magnesio, aluminio y cobre, en el caso que la hidrotalcita también contuviera este último elemento. La concentración 
total de iones en esta disolución era de 1,5 $\mathrm{M}$ y la relación $\mathrm{R}\left[\left(\mathrm{Al}^{3+} /\left(\mathrm{Mg}^{2+}+\mathrm{Al}^{3+}+\left(\mathrm{Cu}^{2+}\right)\right)\right]\right.$ de 0,2. La disolución básica se preparó mezclando las cantidades adecuadas de $\mathrm{NaOH}$ y $\mathrm{Na}_{2} \mathrm{CO}_{3}$ que permitían mantener una relación $\left[\mathrm{CO}_{3}{ }^{2-} /\left(\left(\mathrm{Cu}^{2+}\right), \mathrm{Mg}^{2+}+\mathrm{Al}^{3+}\right)\right]=0,66$ y el $\mathrm{pH}$ de síntesis en 13. Las disoluciones se añadieron simultáneamente a una velocidad de $20 \mathrm{~mL} / \mathrm{h}$ utilizando una bomba perfusora, a temperatura ambiente, presión atmosférica y con agitación mecánica vigorosa durante 4 horas. El gel obtenido se envejeció durante 12 horas, tras lo cual se filtró y se lavó con agua destilada hasta que el pH en las aguas de lavado fue aproximadamente de 7. Por último, la hidrotalcita se secó a $100^{\circ} \mathrm{C}$ durante 12 horas, y se calcinó en aire a $550^{\circ} \mathrm{C}$ durante 6 horas siguiendo el programa descrito en la figura 3.1, obteniendo así un óxido mixto de Cu-Mg-Al o Mg-Al.

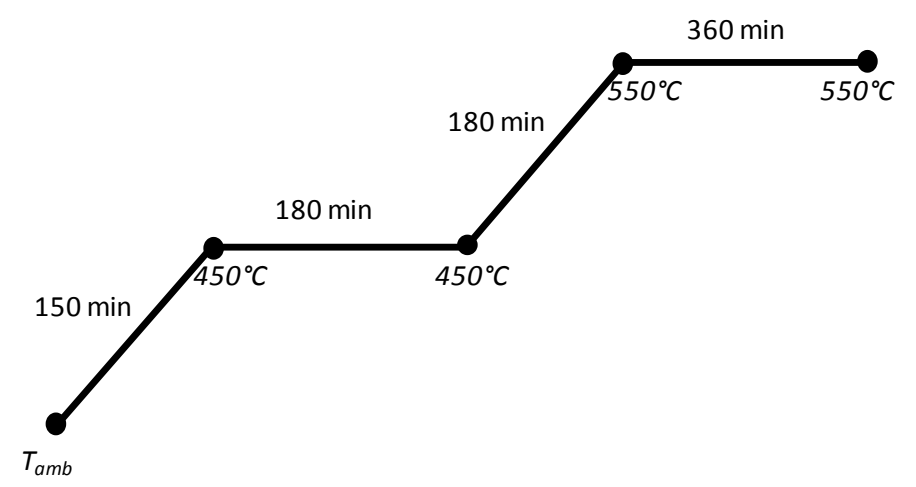

Figura 3. 1. Esquema del programa de calcinación de las hidrotalcitas.

\subsubsection{Zeolitas y materiales mesoporosos}

Las zeolitas MCM-22, ITQ-6 e ITQ-2, así como el material mesoporoso MCM-41 se prepararon en el Instituto de Tecnología Química, siguiendo los métodos descritos en bibliografía para la obtención de estos materiales [1-12]. Las zeolitas $\beta$, ZSM-5 y faujasita eran zeolitas comerciales.

\subsubsection{Alúmina de alta superficie}

La alúmina de alta superficie se preparó por coprecipitación [13] utilizando dos disoluciones acuosas, una ácida y la otra básica. La disolución ácida contenía nitrato de 
aluminio, mientras que la disolución básica se obtuvo mezclando $\mathrm{NaOH}$ y $\mathrm{Na}_{2} \mathrm{CO}_{3}$ para mantener un $\mathrm{pH}$ aproximadamente de 13. Las disoluciones se añadieron simultáneamente a una velocidad de $1 \mathrm{~mL} / \mathrm{min}$ utilizando una bomba perfusora, a temperatura ambiente, presión atmosférica y con agitación mecánica vigorosa. El gel obtenido se envejeció durante 12 horas, tras lo cual, el sólido se filtró y se lavó con agua destilada hasta que el $\mathrm{pH}$ en las aguas de lavado fue aproximadamente de 7. Por último, la alúmina de alta superficie se secó a $100^{\circ} \mathrm{C}$ durante 12 horas, y se calcinó en aire a $500^{\circ} \mathrm{C}$ durante 5 horas siguiendo el programa descrito en la figura 3.2.

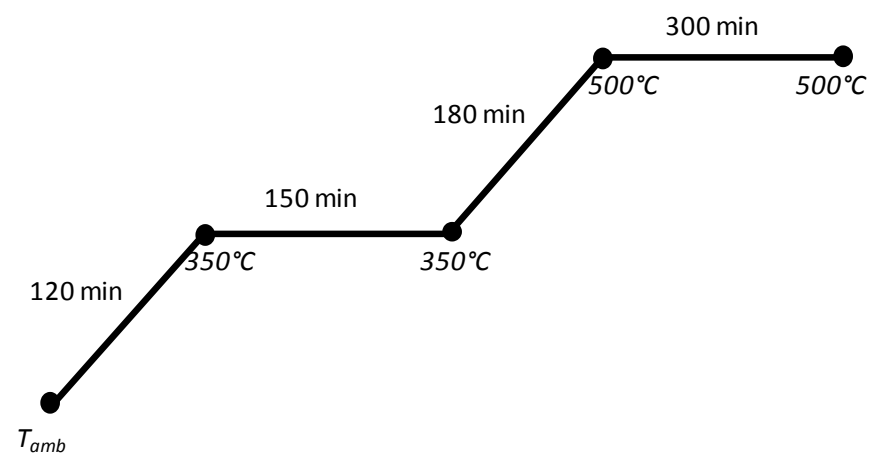

Figura 3. 2. Esquema del programa de calcinación de las alúminas de alta superficie.

\subsection{Preparación de los catalizadores}

\subsubsection{Catalizadores preparados por impregnación a volumen de poro}

Se prepararon distintos tipos de catalizadores por impregnación a volumen de poro. Estos catalizadores fueron:

- Catalizadores monometálicos: el soporte catalítico se impregnó con la disolución de la sal metálica de tal manera que el volumen de la disolución llenase todos los poros del sólido, evitándose la presencia de un exceso de disolución en el mismo. La disolución contenía la concentración necesaria de metal para conseguir la composición metálica deseada en el catalizador. Posteriormente, el catalizador se secó a $100^{\circ} \mathrm{C}$ y se calcinó en aire siguiendo la rampa de calcinación de la figura 3.3. 
- Catalizadores bimetálicos: la primera etapa se realizó igual que con los catalizadores monometálicos. Tras la calcinación se impregnó el sólido con la disolución del segundo metal a introducir y se procedió a su secado y calcinación como en el caso anterior. En algunos materiales se modificó la rampa de calcinación siguiendo la rampa indicada en la figura 3.4, con el fin de determinar la influencia del tipo de calcinación en la actividad de los catalizadores.

- Catalizadores bimetálicos preparados por coimpregnación: el soporte catalítico se impregnó con una disolución que contenía las sales de los dos metales a impregnar en concentración suficiente para conseguir la composición metálica final deseada. Tras esto, el catalizador se secó a $100^{\circ} \mathrm{C}$ y se calcinó siguiendo las rampas de calcinación descritas en las figuras 3.3 o 3.4 .

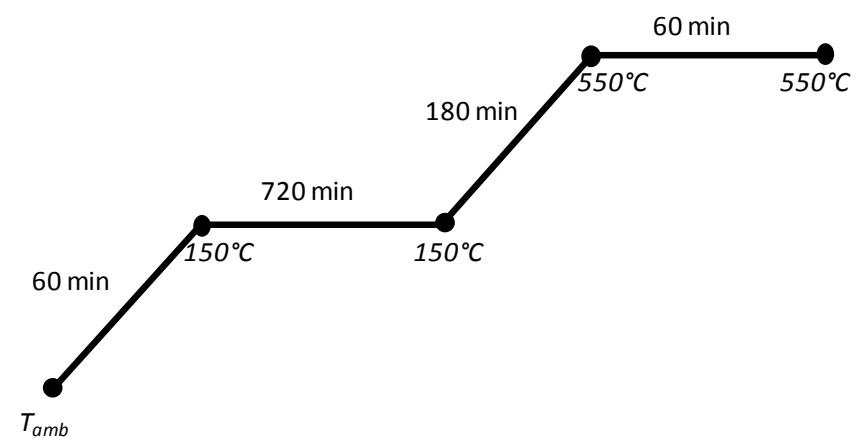

Figura 3. 3. Esquema del tratamiento térmico (I) de los catalizadores impregnados a volumen de poro. 


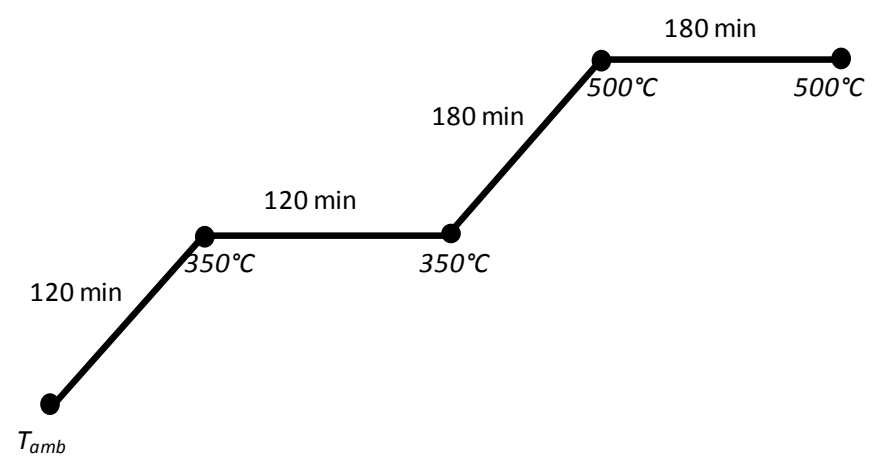

Figura 3. 4. Esquema del tratamiento térmico (II) de los catalizadores impregnados a volumen de poro.

\subsubsection{Catalizadores preparados por impregnación húmeda}

La impregnación húmeda consiste en preparar una disolución que contenga la cantidad necesaria de metal que se desea introducir en la muestra en un volumen de agua 5 veces mayor que la cantidad de muestra introducida. A esta disolución se le añade la muestra que se quiere impregnar y se introduce en un evaporador rotatorio para eliminar el exceso de disolvente. Este tipo de impregnación se utilizó para determinar la influencia del tipo de preparación del catalizador en su actividad catalítica. Posteriormente, se calcinó el material según el esquema de la figura 3.3.

\subsubsection{Activación de los catalizadores}

En la mayoría de los casos los catalizadores utilizados se activaron previamente a la reacción, con un flujo de hidrógeno de $200 \mathrm{~mL} / \mathrm{min}$ a $500^{\circ} \mathrm{C}$ durante 4 horas. En alguna de las reacciones realizadas se varió la temperatura de reducción para estudiar la influencia de esta variable en la actividad del catalizador.

Los catalizadores soportados sobre carbón se activaron calcinando los materiales en flujo de nitrógeno durante 1 hora a $200^{\circ} \mathrm{C}$ y seguidamente, se redujeron en flujo de hidrógeno durante 3 horas a la misma temperatura. 


\subsection{Técnicas de caracterización}

\subsubsection{Análisis químico por Plasma de Acoplamiento Inductivo acoplado a un Espectroscopio Óptico de Emisión (ICP-OES)}

El análisis químico de una muestra comprende la determinación cualitativa y cuantitativa de los elementos que la constituyen. La espectroscopía de emisión atómica estudia la emisión de radiación por átomos o iones libres en estado excitado. Esta técnica se basa en la generación y análisis de la radiación emitida por parte de los átomos presentes en un material que es sometido a una serie de procesos consecutivos de disolución, nebulización, ruptura de enlaces para obtener átomos en estado fundamental y excitación de los mismos [14].

En el presente trabajo, se determinó la composición química de los materiales empleando esta técnica y usando un equipo Varian 715-ES. Para el análisis de las muestras sólidas en polvo (20-30 mg, aproximadamente), éstas se disgregaron en una mezcla de $\mathrm{HNO}_{3} / \mathrm{HCl}$ de proporciones volumétricas $1 / 3$. Esta técnica también se utilizó para analizar distintas muestras de agua. En todos los casos, la recta de calibrado se adecuó a la concentración aproximada prevista de analito y se realizó utilizando disoluciones estándar (Aldrich).

\subsubsection{Análisis elemental}

El principal método para la determinación de carbono, hidrógeno, nitrógeno y azufre en una muestra es la técnica de microcombustión. En esta técnica la muestra, que previamente se ha pesado, se introduce en el analizador y se desgasifica, para eliminar los gases que puedan interferir en la medida. Posteriormente, se realiza la combustión en flujo de oxígeno puro a $1020^{\circ} \mathrm{C}$. La determinación de los gases de combustión se realiza mediante cromatografía de gases [14] y esto permite determinar el contenido de azufre, hidrógeno, nitrógeno y carbono de la muestra. 
El contenido en carbono, nitrógeno, azufre e hidrógeno de alguna de las muestras utilizadas se determinó con un analizador elemental Fisons EA1108 empleando sulfanilamida como referencia.

\subsubsection{Difracción de rayos $X$ en polvo}

La técnica de difracción de rayos $\mathrm{X}$ se basa en el análisis de la radiación difractada por un sólido sobre el cual incide un haz monocromático de rayos $\mathrm{X}$ con un ángulo variable. La longitud de onda de los rayos X $(\sim 1 \AA)$ es del orden de magnitud del espacio interplanar de la mayoría de las estructuras cristalinas, lo que provoca fenómenos de difracción. La difracción se produce como consecuencia de las interferencias constructivas debidas a la periodicidad cristalina de la muestra. Para cada línea de difracción, el ángulo de incidencia de la radiación se relaciona con el espaciado interplanar de acuerdo con la ecuación de Bragg [15]:

$$
n \lambda=2 d_{h k l} \cdot \operatorname{sen}(\theta) \quad \text { Ec. } 3.1
$$

donde $n$ es un número entero $(n=1,2,3, \ldots), d_{h k l}$ es el espaciado interplanar de los planos cristalinos con índices de Miller ( $\mathrm{h} \mathrm{k} \mathrm{I}), \lambda$ es la longitud de onda y $\theta$ el ángulo de incidencia del haz de rayos $X$.

En este trabajo se ha utilizado esta técnica para identificar las fases cristalinas que forman los materiales. Los difractogramas de rayos $\mathrm{X}$ de las muestras en polvo se adquirieron a temperatura ambiente, en un difractómetro Phillips X'Pert empleando radiación monocromática correspondiente a la línea $\mathrm{K} \alpha-\mathrm{Cu}$. El difractograma se obtuvo en el rango de ángulos $2 \theta=2-90^{\circ}$ empleando un incremento de $0,04^{\circ}$ por paso durante el barrido.

\subsubsection{Análisis textural. Adsorción de nitrógeno}

La técnica de adsorción de gases se fundamenta en el estudio de los fenómenos de adsorción y desorción gas-sólido para obtener información sobre las propiedades texturales del adsorbente. La interpretación de las isotermas de adsorción-desorción 
empleando las propiedades geométricas del adsorbato y la modelización matemática de los fenómenos superficiales que determinan la termodinámica de los procesos de adsorción y desorción permiten obtener información acerca de la superficie específica, el diámetro de los poros y el volumen de poro del sólido estudiado. El adsorbato más comúnmente empleado es el nitrógeno a la temperatura de $-196^{\circ} \mathrm{C}$.

Las isotermas de adsorción-desorción de nitrógeno se registraron a esta temperatura en un equipo Micromeritics ASAP 2000. Las muestras (aproximadamente 200 $\mathrm{mg}$ ) con un tamaño de partícula de $0,1-0,4 \mathrm{~mm}$, se trataron a $400^{\circ} \mathrm{C}$ y vacío durante 12 horas antes de las medidas de adsorción.

Las isotermas se ajustaron al modelo de Brunauer-Emmet-Teller (BET) $[14,16,17]$. Este modelo se basa en las hipótesis siguientes: a) la superficie del adsorbente es uniforme y no porosa, b) las moléculas del gas se adsorben en capas sucesivas, c) las interacciones laterales entre moléculas vecinas de adsorbato son despreciables. Estas suposiciones conducen a la siguiente ecuación matemática que describe el modelo BET:

$$
\begin{array}{ll}
\frac{P}{V \cdot\left(P-P_{0}\right)}=\frac{1}{V_{m} \cdot C}+\frac{(C-1) \cdot P}{V_{m} \cdot C \cdot P_{0}} \quad \text { Ec. } 3.2
\end{array}
$$

donde $\mathrm{V}$ es la cantidad de gas adsorbido a una presión $\mathrm{P}, \mathrm{P}_{0}$ es la presión de saturación, $V_{m}$ es el volumen de la monocapa del adsorbato y $C$ es una constante relacionada con el equilibrio de adsorción. La representación de la ecuación 3.2 es una recta de cuyos valores de ordenada en el origen y pendiente se pueden extraer los valores de $V_{m}$ y $C$. Conocido $V_{m}$ se puede calcular el área del material teniendo en cuenta el área ocupada por cada molécula de adsorbato y el número total de moléculas adsorbidas.

El área y el volumen de microporo se pueden calcular a partir de los datos de adsorción de nitrógeno utilizando el método de la curva t [18]. Éste consiste en representar el volumen de nitrógeno adsorbido frente al parámetro $t$, que representa el espesor estadístico de la capa adsorbida en una superficie no porosa a una determinada presión relativa.

El modelo utilizado habitualmente para obtener el valor de $\mathrm{t}$ (en $\AA$ ) es el desarrollado por Harkins y Jura [17, 19]. Este modelo se define mediante la ecuación 3.3, donde $\mathrm{P}$ es la presión de equilibrio y $\mathrm{P}_{0}$ es la presión de saturación: 


$$
t=\left(\frac{13.99}{0.34-\log \left(P / P_{0}\right)}\right)^{1 / 2} \quad \text { Ec. } 3.3
$$

Por último, la distribución de volumen de poro (equivalente a la distribución de diámetro de poro) se puede determinar a partir de la isoterma de adsorción de nitrógeno, ya que la isoterma de adsorción permite relacionar la cantidad de adsorbato adquirido en un paso, con el tamaño medio de los poros llenados en ese mismo paso. El cálculo de la distribución de volumen de poro se puede determinar mediante el método desarrollado por Barret, Joiner y Halenda, denominado más comúnmente como modelo B.J.H.

\subsubsection{Reducción a temperatura programada}

La técnica de reducción termoprogramada se utiliza para estudiar la reducibilidad de óxidos metálicos y de partículas de óxidos metálicos soportadas en otros materiales, así como el tipo y grado de interacción entre las partículas soportadas y el soporte [20]. Los experimentos de reducción termoprogramada consisten en una reacción de reducción en la cual se emplea una mezcla gaseosa diluida de $\mathrm{H}_{2}$ (en $\mathrm{He}$ o $\mathrm{Ar}$ ) como agente reductor, en la que la temperatura de reacción se va aumentando a una velocidad constante y controlada. Durante el proceso de reducción disminuye la concentración de $\mathrm{H}_{2}$ en la mezcla reductora debido al consumo de $\mathrm{H}_{2}$ por la propia reacción, lo que modifica la conductividad térmica del agente reductor (mezcla de $\mathrm{H}_{2}$ y He). La variación de la conductividad térmica durante el transcurso del experimento se registra en un detector de conductividad térmica. Su representación en función del tiempo y la temperatura, da lugar a un perfil característico que refleja la reducibilidad del metal presente en el catalizador en cuestión. La cantidad de $\mathrm{H}_{2}$ consumido en la reducción se determina a partir del área generada por el perfil de la curva de reducción y un calibrado previo del detector de conductividad térmica.

Los experimentos de reducción termoprogramada se llevaron a cabo en un equipo TPD-TPR Autochem 2910 empleando un detector de conductividad térmica (TCD). Para realizar los ensayos entre 30 y 100 mg de muestra, con una granulometría entre 0,8-1,0 $\mathrm{mm}$ se cargaron en forma de lecho fijo, entre lana de cuarzo, en un tubo en $\mathrm{U}$ de cuarzo. 
Las muestras se trataron en flujo de $\mathrm{Ar}$ a temperatura ambiente durante 30 minutos $\mathrm{y}$, posteriormente, el gas circulante se sustituye por $10 \% \mathrm{H}_{2}(\mathrm{vol}) / \mathrm{Ar}(50 \mathrm{~mL} / \mathrm{min})$ y la temperatura se incrementa desde temperatura ambiente hasta $900-1100^{\circ} \mathrm{C}$ a una velocidad de $10^{\circ} \mathrm{C} / \mathrm{min}$. Tras el reactor se coloca una trampa de 2-propanol/ $\mathrm{N}_{2}(\mathrm{I})$ para retener el agua formada en las reducciones, y se registra la variación de la conductividad térmica (TCD) de la mezcla gaseosa.

\subsubsection{Quimisorción de CO}

La técnica de quimisorción de gases emplea moléculas sencillas (normalmente $\mathrm{H}_{2}, \mathrm{CO}$ o $\mathrm{CO}_{2}$ ) para cuantificar la superficie de un sólido que participa de manera específica en el fenómeno de quimisorción. La quimisorción de $\mathrm{CO}$ es una de las técnicas empleadas para cuantificar superficies metálicas en catalizadores metálicos en su forma reducida, y está fundamentada en la capacidad que tienen las nanopartículas metálicas para quimisorber moléculas de CO, y en ciertas aproximaciones estequiométricas y geométricas [20].

La quimisorción de $\mathrm{CO}$ se ha empleado en este trabajo para conocer la dispersión metálica de los catalizadores estándar y el tamaño medio de las partículas de Pd metal.

Los experimentos de quimisorción de $\mathrm{CO}$ se llevaron a cabo en un equipo Micromeritics ASAP 2010C. En estos experimentos se cargan aproximadamente 0,5 g de catalizador, con un tamaño de partícula de 0,8-1,0 mm, en un tubo de cuarzo en forma de $\mathrm{U}$, y la muestra se seca en flujo de $\mathrm{He}$ a $120^{\circ} \mathrm{C}$ y se reduce durante 4 horas a $500^{\circ} \mathrm{C}$. Tras la reducción, la muestra se evacua a 1,3 Pa y se enfría en vacío hasta la temperatura a la que se registra la isoterma de quimisorción, $35^{\circ} \mathrm{C}$. Para determinar los cálculos de dispersión de metal y tamaño de partícula se supuso una estequiometría de quimisorción de $\mathrm{CO}: \mathrm{Pd}=1: 1$, una geometría de nanopartícula esférica y una densidad volumétrica de 12,02 $\mathrm{g} / \mathrm{cm}^{3}$ para el $\mathrm{Pd}^{0}$. 


\subsubsection{Técnicas de microscopía electrónica}

Las técnicas de microscopía electrónica proporcionan información acerca de la forma de las partículas y de la morfología y textura de la superficie del catalizador, así como de su composición química [14]. En el presente estudio se ha utilizado la microscopía electrónica de barrido y la microscopía de transmisión.

\subsubsection{Microscopía electrónica de barrido}

La técnica de microscopía electrónica de barrido o SEM (Scanning Electron Microscopy) emplea la transducción de los electrones secundarios (o retrodispersados) emitidos por una muestra, al ser sometida a un haz de electrones acelerados en un campo eléctrico, para construir una imagen de la morfología superficial de la muestra analizada.

Cuando el haz de electrones se enfoca sobre la muestra provoca una serie de tránsitos electrónicos entre diferentes niveles de energía. El ión excitado se relaja a su estado inicial por la transferencia de un electrón de un orbital exterior a una capa interior, lo que da lugar a la emisión de rayos $X$. Cada elemento tiene un espectro de emisión característico que consiste en una serie de máximos nítidos, cada uno de los cuales corresponde a una transición electrónica desde un orbital de alta energía a un orbital de baja energía. Este espectro es característico de cada elemento por lo que proporciona un método de análisis elemental. Para llevar a cabo el análisis del material es necesario separar adecuadamente los distintos máximos con el fin de poder cuantificarlos. Esto se realiza mediante análisis por dispersión de rayos $\mathrm{X}$ (XEDS) con un detector semiconductor que caracteriza los fotones de rayos $X$ según sus energías incidentes [14].

En el presente trabajo la técnica de SEM se ha utilizado para conocer la textura de algunos materiales así como para determinar, combinada con el análisis mediante XEDS y utilizando electrones retrodispersados, la localización y composición de las nanopartículas de metal presentes en dichas muestras.

Las micrografías electrónicas de barrido se registraron en un equipo Hitachi S-4100 de emisión de campo equipado con un detector BSE-AUTRATA. La muestra se preparó previamente dispersándola sobre una cinta adhesiva de doble cara adherida a un porta- 
muestras. Posteriormente, se metalizó la superficie con una fina capa de carbono para llevar a cabo el examen morfológico y el análisis mediante XEDS.

\subsubsection{Microscopía electrónica de transmisión}

La técnica de microscopía electrónica de transmisión o TEM (Transmission Electron Microscopy) genera una imagen de contraste, de resolución a escala nanométrica, a partir de los electrones transmitidos a través de una muestra ultrafina interpuesta en el camino de un haz de electrones acelerados.

A lo largo del presente trabajo, la microscopía TEM se ha empleado en el modo de campo brillante para conocer la morfología, el tamaño y la localización de nanopartículas metálicas soportadas sobre los distintos materiales.

Las micrografías electrónicas de transmisión se obtuvieron en un microscopio Philips CM10 operando a 100 kV. Las muestras se prepararon por suspensión del sólido en etanol y tratamiento en ultrasonidos durante un minuto. Posteriormente, la suspensión se dejó decantar durante otro minuto y se extrajo una gota de la parte superior de la misma que se depositó sobre una rejilla de cobre (300 mesh) recubierta por una capa agujereada de carbono.

Las distribuciones de tamaño de nanopartícula se obtuvieron a partir de la medida directa de 100-200 nanopartículas sobre diferentes micrografías tomadas en distintas posiciones de la gradilla porta-muestras. El tamaño medio de nanopartícula $\left(d_{T}\right)$ se calculó como media ponderada por superficie según la ecuación 3.4:

$$
\begin{array}{ll}
d_{T}=\frac{\sum_{i} n_{i} \cdot\left(d_{i}\right)^{3}}{\sum n_{i} \cdot\left(d_{i}\right)^{2}} \quad \text { Ec. } 3.4
\end{array}
$$

\subsubsection{Espectroscopía infrarroja}

La espectroscopía infrarroja es una técnica ampliamente utilizada para el estudio y caracterización de catalizadores sólidos. La técnica se fundamenta en el estudio de las vibraciones que modulan el momento dipolar en las moléculas. Un espectro de infrarrojo muestra unas bandas específicas, correspondientes a vibraciones características de 
tensión o flexión, para cada grupo de átomos, que se caracterizan por la intensidad y rango de frecuencia a las que se producen.

La espectroscopía infrarroja de absorción se basa en la medida de absorción de radiación infrarroja por la materia. La radiación absorbida origina cambios en los estados de vibración y de rotación de los grupos funcionales presentes en las moléculas de la muestra sólida [14].

Para analizar las muestras, éstas se pueden de mezclar con bromuro potásico y formar una pastilla. El espectro de radiación analizado en esta técnica fue de 500 a 4000 $\mathrm{cm}^{-1}$. Los estudios de infrarrojo se realizaron en un equipo Nicolet $710 \mathrm{FTIR}$.

\subsection{Ensayos catalíticos}

\subsubsection{Sistemas de reacción}

Los sistemas de reacción utilizados en el presente trabajo se basan en el empleo de un reactor de tanque agitado o en un reactor de flujo de pistón, y se describen a continuación.

\subsubsection{Reactor discontinuo de tanque agitado}

El reactor discontinuo de tanque agitado consiste en un reactor de vidrio de 1 litro equipado con un agitador de teflón, tal como se muestra en la figura 3.5. Los experimentos se realizaron a presión atmosférica y temperatura ambiente. Se utilizaron dos difusores de gases para introducir el hidrógeno que actúa como agente reductor y en su caso, el $\mathrm{CO}_{2}$ que se usa para controlar el pH del medio de reacción. 


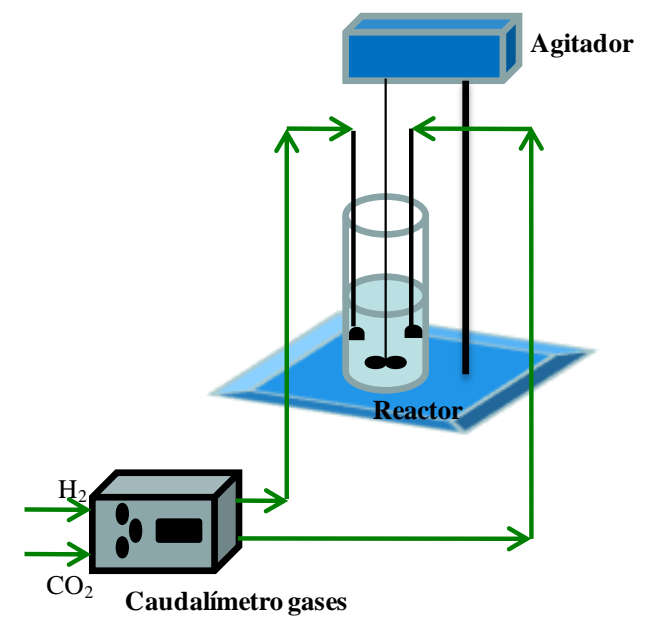

Figura 3. 5. Esquema del reactor discontinuo de tanque agitado.

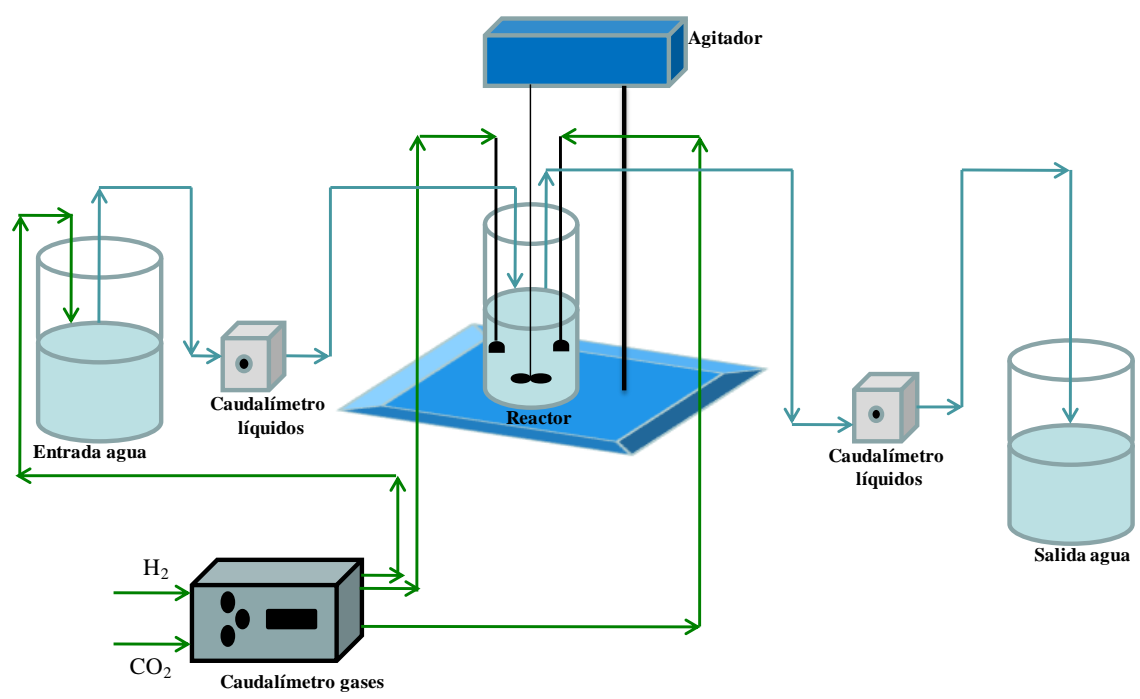

Figura 3. 6. Esquema del reactor continuo de tanque agitado.

\subsubsection{Reactor continuo de tanque agitado}

Los experimentos catalíticos realizados utilizando el reactor continuo de tanque agitado se llevaron a cabo en la mayoría de los casos a presión atmosférica y a temperatura ambiente, en un reactor de vidrio de 1 litro equipado con un agitador de 
teflón de velocidad regulable. En la figura 3.6 se muestra el esquema del reactor continuo de tanque agitado utilizado. El hidrógeno (utilizado como agente reductor) y el dióxido de carbono se introdujeron mediante sendos difusores de vidrio y se reguló su caudal mediante dos medidores de caudal electrónicos. Un tercer medidor de caudal se utilizó para regular el flujo de hidrógeno utilizado para hidrogenar el agua del depósito de entrada al reactor. El agua se introdujo y se extrajo del reactor controlando su caudal mediante dos bombas peristálticas.

\subsubsection{Reactor continuo de tanque agitado a presión}

Con el fin de determinar la influencia de la presión en la reducción catalítica de nitratos, se diseñó un reactor continuo de tanque agitado similar al descrito en el apartado anterior (figura 3.7), pero con un volumen mucho menor (20 mL) para que fuera fácilmente presurizable con los gases de reacción. Las presiones de trabajo utilizadas se fijaron entre 1 y 3 bares controlando la presión de trabajo con un manómetro. El caudal de salida se controlaba usando una válvula de aguja y la temperatura de reacción fue la temperatura ambiente.

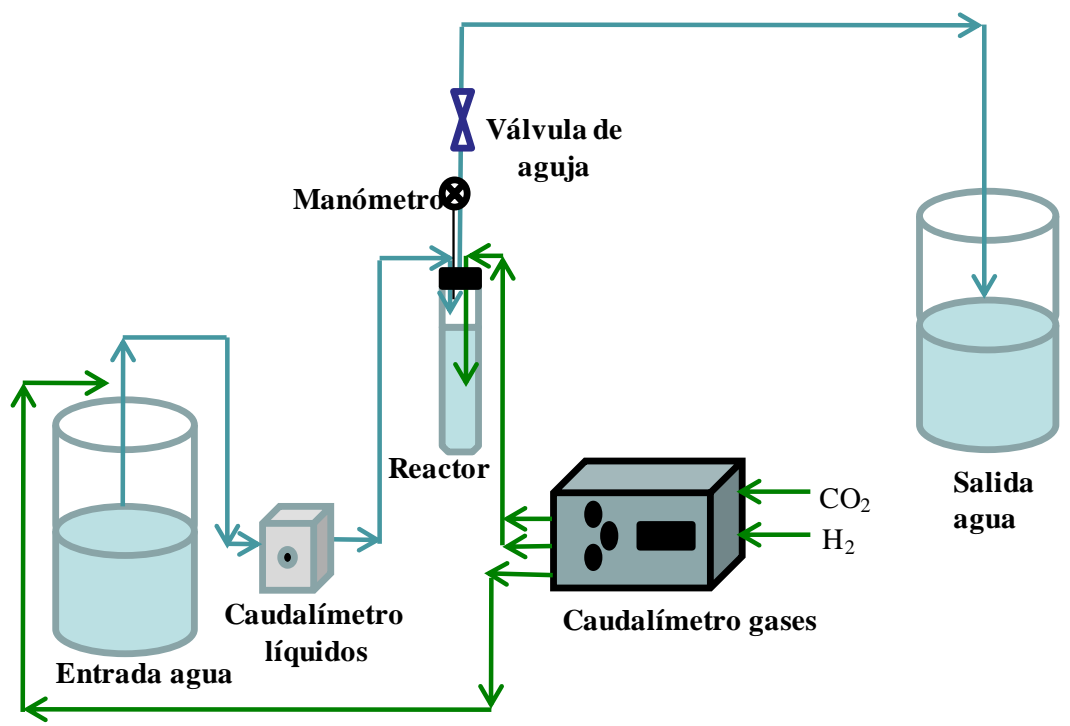

Figura 3. 7. Esquema del reactor continuo de tanque agitado a presión. 


\subsubsection{Reactor de flujo de pistón}

El reactor de flujo de pistón utilizado consiste en un tubo de vidrio de 1,5 cm de diámetro y $14,5 \mathrm{~cm}$ de longitud en el que se introduce la mezcla de hidrógeno y dióxido de carbono y el agua de reacción. En este sistema los gases se añadieron mediante un controlador de gases, mientras que el agua se añadió utilizando una bomba perfusora. Los gases y el agua se mezclaron en una pequeña zona previa al reactor y posteriormente se pusieron en contacto con el catalizador, el cual se encontraba mezclado con carburo de silicio. La salida de los gases y del agua después de reacción se realizó por la parte superior del reactor. Los experimentos se realizaron a presión y temperatura ambiente. En la figura 3.8 se muestra el esquema del reactor de flujo de pistón utilizado.

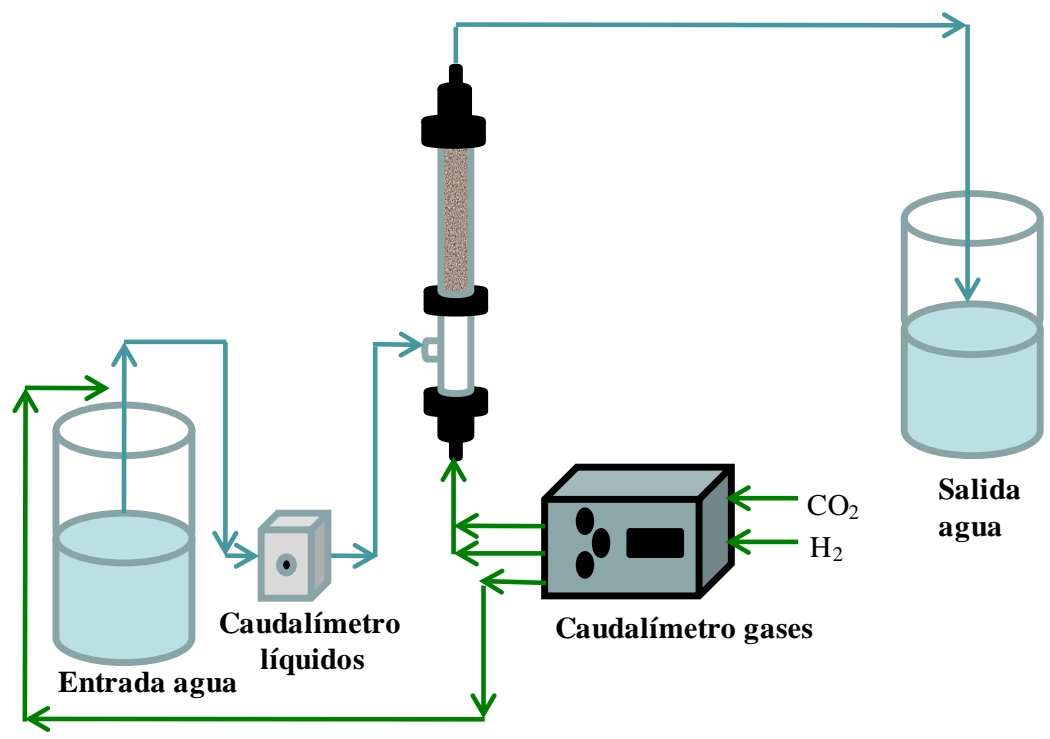

Figura 3. 8. Esquema del reactor de flujo de pistón.

\subsubsection{Descripción de los experimentos}

En este apartado se describe como se llevaron a cabo los experimentos con los distintos sistemas de reacción. 


\subsubsection{Reactor discontinuo de tanque agitado}

Los experimentos realizados con el reactor discontinuo de tanque agitado se inician hidrogenando previamente $600 \mathrm{~mL}$ del agua de reacción durante 1 hora. Después de esto se añade el catalizador (1 gramo) y se empieza la reacción añadiendo $250 \mathrm{~mL} / \mathrm{min}$ de hidrógeno y, en su caso, $250 \mathrm{~mL} / \mathrm{min}$ de dióxido de carbono. Se mantiene durante toda la reacción una agitación constante de $900 \mathrm{rpm}$. Con el fin de determinar las concentraciones de nitratos, nitritos y amonio, se toman, cada cierto tiempo, muestras del agua de reacción con una jeringa, filtrando el agua con el fin de que no existan restos de catalizador que la enturbien.

El catalizador se recupera al final de cada reacción filtrando el agua y dejándolo secar a $100^{\circ} \mathrm{C}$.

\subsubsection{Reactor continuo de tanque agitado}

Cuando se utiliza el reactor continuo de tanque agitado, éste se llena con el agua a tratar $(600 \mathrm{~mL})$, la cual se hidrogena previamente con $250 \mathrm{~mL} / \mathrm{min}$ de hidrógeno puro durante 1 hora. Al mismo tiempo el depósito de entrada del agua a tratar también se hidrogena con el mismo caudal de hidrógeno para desplazar el oxígeno del agua. Transcurrido este tiempo, se pasa un caudal de $250 \mathrm{~mL} / \mathrm{min}$ de $\mathrm{CO}_{2}$ durante unos 5 minutos por el reactor, sin añadir $\mathrm{H}_{2}$. Posteriormente, se añade la cantidad deseada de catalizador (normalmente 3 gramos) y se fijan los caudales de hidrógeno y de dióxido de carbono en $250 \mathrm{~mL} / \mathrm{min}$, cada uno. En ese momento se inicia la reacción y se comienza a añadir y extraer agua del reactor, con un caudal de $5 \mathrm{~mL} / \mathrm{min}$ trabajando en continuo. Las reacciones se llevan a cabo a temperatura ambiente y se mantiene la agitación en 900 rpm. Cada cierto tiempo se toman muestras del agua de salida de la reacción, para el análisis de nitratos, nitritos y amonio.

Al finalizar la reacción, el catalizador se recupera para su posterior caracterización, filtrándolo a vacío y secándolo en una estufa a $100^{\circ} \mathrm{C}$. 


\subsubsection{Reactor continuo de tanque agitado a presión}

En los experimentos a presión se utiliza un volumen de agua de reacción de 15 $\mathrm{mL}$. El reactor se llena con esta cantidad de agua y se añaden $50 \mathrm{mg}$ de catalizador, hidrogenando el sistema durante 15 minutos para que el agua esté saturada de hidrógeno. A continuación se empieza la reacción añadiendo un caudal de agua de 1,2 $\mathrm{mL} / \mathrm{min}$ y ajustando la salida con la válvula de aguja para que ésta sea la misma que la de la entrada y que la reacción sea en continuo. Se ajustan los flujos de hidrógeno y $\mathrm{CO}_{2}$ a 5 $\mathrm{mL} / \mathrm{min}$. La presión de trabajo está entre 1 y 3 bares, realizando los experimentos a temperatura ambiente. Al igual que en el caso anterior, las muestras del agua de salida se analizan con el fin de determinar la cantidad de nitrato, nitrito y amonio que hay en cada momento en el reactor.

\subsubsection{Reactor de flujo de pistón}

Como en los casos anteriores, en los experimentos con el reactor de flujo de pistón el agua a tratar del depósito de entrada se hidrogena previamente con el fin de desplazar el oxígeno existente. Posteriormente, se introduce en el reactor la cantidad de catalizador necesaria para cada reacción, que se ha mezclado previamente con el carburo de silicio. Cabe destacar que la cantidad de carburo de silicio utilizada es la suficiente para rellenar todo el volumen del reactor. A continuación se empiezan a añadir los gases $(500 \mathrm{~mL} / \mathrm{min}$ de $\mathrm{H}_{2}$ y $\mathrm{CO}_{2}$ en relación $\left.1: 1\right)$ y el agua de reacción $(5 \mathrm{~mL} / \mathrm{min})$ y se inicia la reacción. Del agua de salida de la reacción se van recogiendo muestras cada determinado tiempo para el posterior análisis de las concentraciones de nitratos, nitritos y amonio.

\subsubsection{Análisis de las muestras}

Las concentraciones de nitrato, nitrito y amonio presentes en las muestras se determinan mediante espectroscopía ultravioleta/visible de absorción, utilizando un equipo JASCO UV/VIS Spectrophotometer, modelo V-530. La espectroscopía UV/VIS de absorción es una técnica física que se basa en la absorción de radiación emitida a una 
determinada longitud de onda por parte de la muestra a analizar. La intensidad de la radiación que llega al detector se analiza y se compara con la intensidad de radiación inicial. La intensidad de radiación absorbida puede relacionarse con la concentración según la ley de Lambert y Beer, la cual se expresa como:

$$
A=a l c
$$

donde, $A$ es la absorbancia, $a$ la absortividad, I es el espesor de la capa o camino óptico y c la concentración [14].

De las muestras tomadas durante la reacción se toman tres alícuotas que se preparan para el análisis de nitrato, nitrito y amonio, agregándoles los reactivos para análisis fotométricos (Merck-Spectroquant ${ }^{\circledR}$ ), que permiten determinar la concentración de los tres iones en un rango variable de concentraciones. Una vez agregados los reactivos de los tests de análisis a las muestras, cada ión se analiza a una longitud de onda determinada y su concentración se determina a través de rectas de calibrado.

\subsubsection{Análisis de los resultados}

En cada experimento se determinan la conversión y las selectividades obtenidas a lo largo de la reacción.

La conversión a nitrato $(\mathrm{X})$ para cada tiempo $t$ se calcula mediante la siguiente expresión:

$$
X_{t}(\%)=\frac{n_{N O_{3,0}^{-}}-n_{N O_{3, t}^{-}}}{n_{N O_{3,0}^{-}}} \cdot 100 \quad \text { Ec. } 3.6
$$

donde, $n_{N_{3,0}^{-}}$es el número de moles de nitrato a tiempo cero $\left(\mathrm{mmol} \mathrm{NO}_{3}^{-}\right)$y $n_{N O_{3, t}^{-}}$ es el número de moles de nitrato a tiempo $t\left(\mathrm{mmol} \mathrm{NO}_{3}{ }^{-}\right)$.

Por otra parte, las selectividades a nitrito y a amonio $\left(S_{i, t}\right)$, se calculan mediante la ecuación 3.7:

$$
\begin{array}{ll}
S_{i, t}(\%)=\frac{n_{i, t}-n_{i, 0}}{n_{N O_{3,0}^{-}}-n_{N O_{3, t}^{-}}} \cdot 100 \quad \text { Ec. } 3.7
\end{array}
$$

siendo, $i$ el nitrito o el amonio, y $n_{i, t}$ el número de moles del ión $i$ estudiado a tiempo to a tiempo cero $\left(n_{i, 0}\right)$. 


\section{Referencias}

[1] A. Corma, V. Fornés, S. B. Pergher, T. L. M. Maesen, J. G. Buglass; Nature, 396 (1998) 353.

[2] S. Valencia Valencia, PhD thesis, Universidad Politécnica de Valencia (Valencia), (1997).

[3] M. T. Navarro Villalba, PhD thesis, Universidad Politécnica de Valencia (Valencia), (1997).

[4] U. M. Díaz Morales, PhD thesis, Universidad Politécnica de Valencia (Valencia), (2001).

[5] A. Corma, Q. Kan, M. T. Navarro, J. Perez-Pariente, F. Rey; Chemistry of Materials, 9 (1997) 2123.

[6] M. A. Camblor, A. Corma, S. Valencia; Journal of Materials Chemistry, 8 (1998) 2137.

[7] M. A. Camblor, A. Corma, S. Valencia; Microporous and Mesoporous Materials, 25 (1998) 59.

[8] A. Corma, U. M. Díaz Morales, V. Fornés, Valencia Patent, P200100268.

[9] S. B. Pergher, PhD thesis, Universidad Politécnica de Valencia (Valencia), (1997).

[10] M. E. Leonowich, J. A. Lawton, S. L. Lawton, M. K. Rubin; Science, 264 (1994) 1910.

[11] M. K. Rubin y col., US Patent, 4439409 (1984).

[12] A. Corma, U. M. Díaz Morales, M. Domine, V. Fornés; Angewandte Chemie, International Edition, 39 (2000) 1499.

[13] N. Morlanés Sánchez, PhD thesis, Universidad Politécnica de Valencia (Valencia), (2007).

[14] M. Faraldós, C. Goberna, Técnicas de análisis y caracterización de materiales, Consejo Superior de Investigaciones Científicas, Madrid, (2002).

[15] E. Lifshin, X-ray characterization of materials, Weinheim, New York, Chichester, Brisbane, Singapore, Toronto, (1999).

[16] S. Brunauer, P. H. Emmett, E. Teller; Journal of the American Chemical Society, 60 (1938) 309.

[17] S. Lowell, J. E. Shields, M. A. Thomas, M. Thommes, Characterization of porous solids and powders: surface area, pore size and density, Kluwer Academic Publishers, Dordrecht, Boston, London, (2003).

[18] B. C. Lippens, B. G. Linsen, J. H. Boer; Journal of Catalysis, 3 (1964) 32.

[19] W. D. Harkins, G. Jura; Journal of the American Chemical Society, 73 (1951) 373.

[20] J. R. Anderson, K. C. Pratt, Introduction to characterization and testing of catalysts, Australia, (1985). 
4.

ESTUDIO DE LAS

CONDICIONES DE REACCIÓN 

En este apartado se describen los experimentos realizados para determinar las condiciones de reacción más adecuadas para la eliminación de nitratos de aguas naturales en fase acuosa, en los cuales se comparó la actividad de los catalizadores preparados en esta tesis. Se han determinado las condiciones óptimas de $\mathrm{pH}$, temperatura de reacción, velocidad de agitación, tiempo de contacto, flujo de hidrógeno y presión en el reactor. Estos estudios se realizaron en agua natural procedente de pozos contaminados (tabla 3.1).

\section{1. $p H$}

El estudio para determinar el pH más adecuado para la reacción de reducción de nitratos en aguas naturales utilizando hidrógeno como agente reductor, se realizó en un reactor discontinuo de tanque agitado con un catalizador compuesto por $2,5 \%$ de Sn y $5 \%$ de Pd soportado sobre $\gamma$-alúmina comercial, el cual se ha descrito en bibliografía como activo para este tipo de reacciones [1-3].

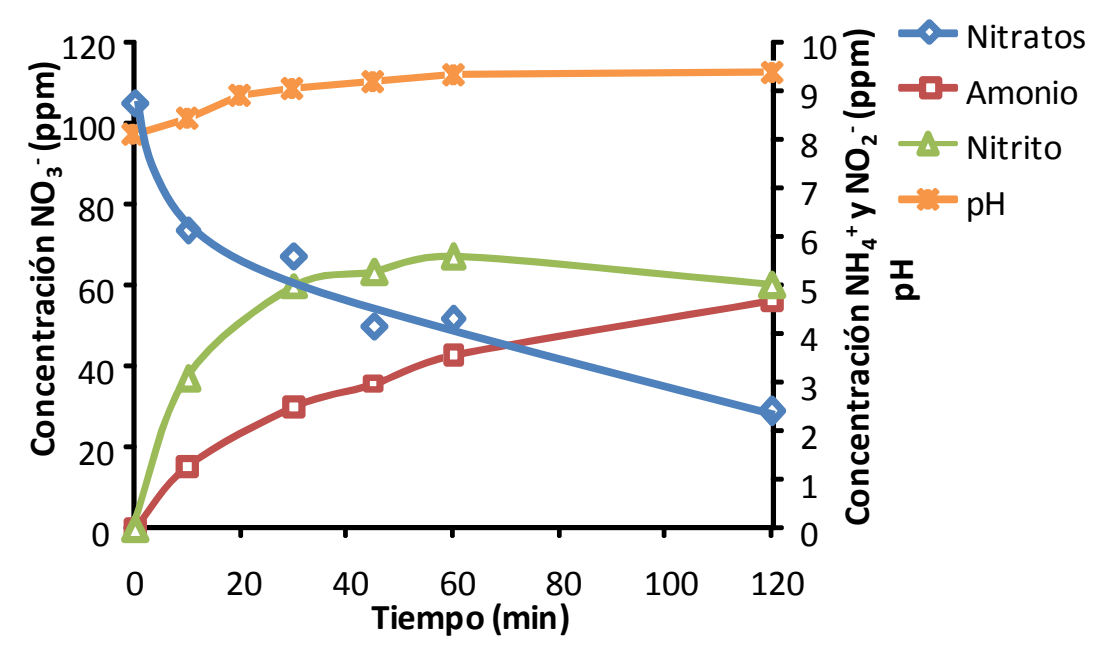

Figura 4. 1. Variación del pH y de las concentraciones de nitrato, amonio y nitrito al realizar una reacción en discontinuo con aguas naturales (1 gramo de catalizador 2,5\%Sn/5\% Pd/ $\gamma-\mathrm{Al}_{2} \mathrm{O}_{3}$, $250 \mathrm{~mL} / \mathrm{min} \mathrm{H}_{2}$ ). 
Los resultados obtenidos en una reacción estándar sin control del pH son los que aparecen descritos en la figura 4.1. Tal como se observa, el pH de partida de las aguas es básico $(\mathrm{pH}=8,1)$ y en el transcurso de la reacción va aumentando ligeramente hasta un valor de 9,6. En estas condiciones se consigue una reducción del $73 \%$ de los nitratos a los 120 minutos de reacción. Mientras que los nitratos van desapareciendo, se forma rápidamente nitritos hasta alcanzar un máximo a los 60 minutos de reacción a partir del cual disminuye ligeramente. También se forma más lentamente, pero de una forma constante, amonio hasta alcanzar una concentración de 5 ppm a las 3 horas de reacción.

El aumento del $\mathrm{pH}$ es debido a que al reducirse los nitratos a nitrógeno se forman iones hidroxilo, de acuerdo con la reacción general de reducción de los nitratos con hidrógeno (ver apartado 1.5):

$$
\begin{aligned}
& 2 \mathrm{NO}_{3}^{-}+5 \mathrm{H}_{2} \rightarrow \mathrm{N}_{2}+2 \mathrm{OH}^{-}+4 \mathrm{H}_{2} \mathrm{O} \\
& 2 \mathrm{NO}_{3}^{-}+8 \mathrm{H}_{2} \rightarrow 2 \mathrm{NH}_{4}^{+}+4 \mathrm{OH}^{-}+2 \mathrm{H}_{2} \mathrm{O}
\end{aligned}
$$

Tal como se ha comentado en el apartado $1.5 .2 \mathrm{el} \mathrm{pH}$ es un factor determinante para controlar la actividad y la selectividad del catalizador en este tipo de reacciones y se ha descrito que un aumento del pH favorece la generación de amonio [3-13], disminuyendo la selectividad de la reacción y favoreciendo la precipitación de algunas sales presentes en las aguas naturales como el carbonato cálcico. Una adecuada neutralización de los iones hidroxilo permitiría mejorar la actividad y la selectividad de la reacción [3, 5, 11-14]. Sin embargo, tal como describen D’Arino y col. [6] esto dependerá de la facilidad con que difundan los iones y el agente neutralizante.

Por este motivo se realizaron varios experimentos utilizando aguas naturales, pero controlando el $\mathrm{pH}$ de la reacción mediante la adición continua de $\mathrm{CO}_{2} \circ \mathrm{H}_{3} \mathrm{PO}_{4}$. En los experimentos con ácido fosfórico el control del pH se realiza por adición gota a gota del ácido en el medio de reacción, mientras que el $\mathrm{CO}_{2}$ se adiciona al reactor haciendo burbujear una corriente gaseosa de $250 \mathrm{~mL} / \mathrm{min}$ de $\mathrm{CO}_{2}$. Los $\mathrm{pH}$ de trabajo fueron:

- $\quad \mathrm{pH}=2,5$ : añadiendo $\mathrm{H}_{3} \mathrm{PO}_{4}$ 0,05M;

- $\quad \mathrm{pH}=4,5$ : añadiendo $\mathrm{H}_{3} \mathrm{PO}_{4} 0,05 \mathrm{M}$;

- $\quad \mathrm{pH}=6,5$ : añadiendo $\mathrm{CO}_{2}(250 \mathrm{~mL} / \mathrm{min})$; 
- $\quad \mathrm{pH}=9$ : $\sin$ añadir gas o ácido.

En la figura 4.2 se puede observar cómo varía la conversión de los nitratos tras 4 horas de reacción al modificar el pH del medio de reacción. La conversión más alta para esta reacción, en torno al $90 \%$, se consigue con un $\mathrm{pH}$ de $6-6,5$. A un pH más bajo o más alto la actividad del catalizador disminuye, siendo éste el pH óptimo de trabajo.

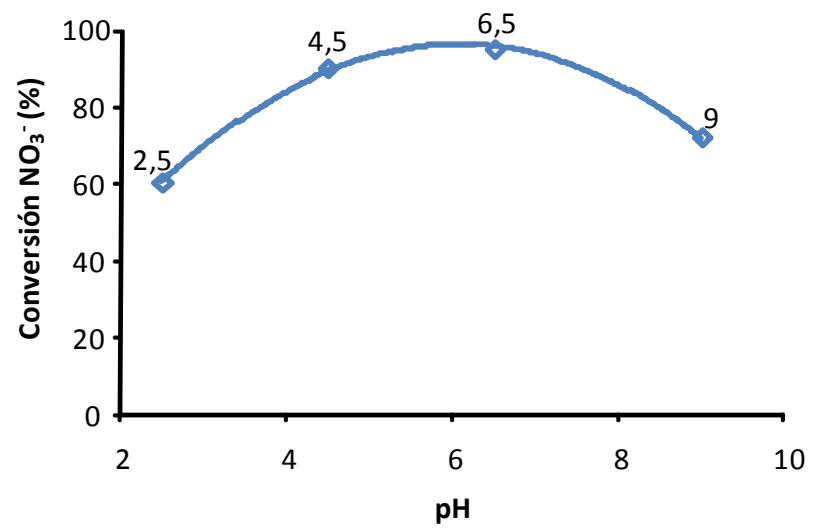

Figura 4. 2. Conversión de nitratos en los experimentos realizados con control del $\mathrm{pH}$ a las 4 horas de reacción (1 gramo de catalizador 2,5\% Sn/5\% Pd/ $\gamma-\mathrm{Al}_{2} \mathrm{O}_{3}, 250 \mathrm{~mL} / \mathrm{min} \mathrm{H}_{2}$ ).

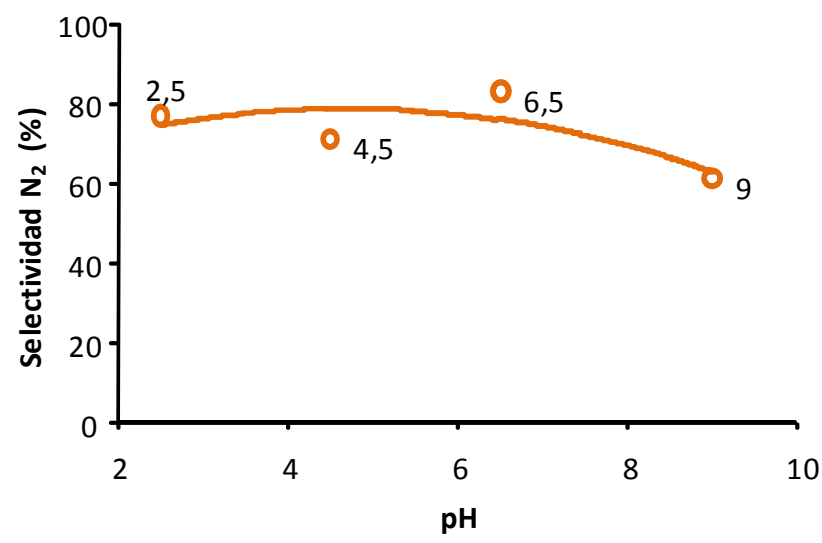

Figura 4. 3. Selectividad a nitrógeno en los experimentos realizados con control del $\mathrm{pH}$ a las 4 horas de reacción (1 gramo de catalizador 2,5\% Sn/5\% $\mathrm{Pd} / \gamma-\mathrm{Al}_{2} \mathrm{O}_{3}, 250 \mathrm{~mL} / \mathrm{min}_{2}$ ). 
En cuanto a la selectividad, se observa que al trabajar con aguas naturales la selectividad a nitrógeno no varía excesivamente al modificar el $\mathrm{pH}$, aunque hay una tendencia al aumento de la selectividad a nitrógeno al disminuir el pH en la reacción (figura 4.3). Se ha descrito que esta tendencia es mucho más acusada cuando se usa agua destilada con nitratos [6], observándose que en este caso la selectividad a nitrógeno puede variar del 5 al $25 \%$ al variar el pH de 4,5 a 12. La menor variación de selectividad al modificar el $\mathrm{pH}$, con aguas naturales, se debe a que los problemas difusionales de este sistema son mucho mayores que los que aparecen cuando se utiliza agua destilada conteniendo nitratos. La mayor movilidad de los iones al usar agua destilada facilita la neutralización de los iones hidroxilo que se van formando mejorando la selectividad del sistema, tal como se ha discutido en el apartado 1.5.2 [6]. Al trabajar con aguas naturales la movilidad iónica es menor con lo que, aunque se controle el pH del medio, resulta más difícil neutralizar localmente los iones hidroxilo en los mismos centros activos por lo que la variación de selectividad al modificar el $\mathrm{pH}$ es menos evidente. En cualquier caso, los resultados obtenidos muestran que la máxima actividad al utilizar aguas naturales se obtiene con un control del pH a 6,5 mediante el uso de $\mathrm{CO}_{2}$. El $\mathrm{CO}_{2}$ añadido neutraliza los iones hidroxilo formados durante la reacción, produciendo iones carbonato y bicarbonato de acuerdo con:

$$
\begin{array}{ll}
2 \mathrm{OH}^{-}+\mathrm{CO}_{2} \rightarrow \mathrm{CO}_{3}{ }^{2-}+\mathrm{H}_{2} \mathrm{O} & \text { Ec. } 4.3 \\
\mathrm{CO}_{3}{ }^{2-}+\mathrm{CO}_{2}+\mathrm{H}_{2} \mathrm{O} \rightarrow 2 \mathrm{HCO}_{3}^{-} & \text {Ec. } 4.4
\end{array}
$$

En la figura 4.4 se muestra la variación de las concentraciones de nitrato, amonio y nitrito al utilizar $\mathrm{CO}_{2}$ como agente controlante del $\mathrm{pH}$ del medio de reacción. Tal como se observa y a diferencia de lo que ocurría cuando no había control del pH (figura 4.1), la eliminación de nitratos del medio es completa a los 60 minutos de reacción, obteniéndose 7 ppm de amonio y desapareciendo los nitritos al terminar la reacción. Estos resultados ponen de manifiesto la necesidad de controlar el pH en esta reacción al utilizar aguas naturales. Por ello los experimentos se realizarán añadiendo simultáneamente $\mathrm{CO}_{2}$ e $\mathrm{H}_{2}$ con el fin de conseguir un pH estable de 6,5. 


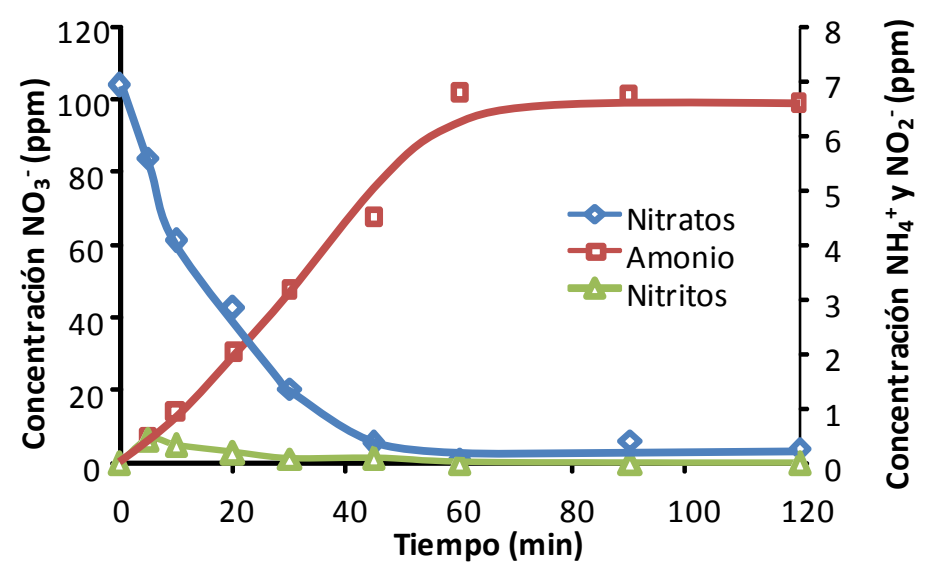

Figura 4. 4. Concentraciones de nitrato, amonio y nitrito en la reducción catalítica de nitratos en discontinuo con aguas naturales al añadir $\mathrm{CO}_{2}$ como agente controlante del pH (1 gramo de catalizador $2,5 \% \mathrm{Sn} / 5 \% \mathrm{Pd} / \gamma-\mathrm{Al}_{2} \mathrm{O}_{3}, 250 \mathrm{~mL} / \mathrm{min}_{2}$ ).

\subsection{Temperatura de reacción}

Los estudios sobre la influencia de la temperatura de reacción en la actividad del catalizador se efectuaron con el catalizador $2,5 \% \mathrm{Sn} / 5 \% \mathrm{Pd} / \gamma-\mathrm{Al}_{2} \mathrm{O}_{3}$ en continuo y con control del $\mathrm{pH}$ utilizando $\mathrm{CO}_{2}$ e hidrógeno como agente reductor. Se realizaron cuatro experimentos con temperaturas de reacción distintas, uno a temperatura ambiente $\left(25^{\circ} \mathrm{C}\right)$, dos utilizando un baño con hielo para conseguir temperaturas de reacción de 3 y $9^{\circ} \mathrm{C}$, y un cuarto experimento a $40^{\circ} \mathrm{C}$. En la figura 4.5 se observa cómo la actividad en los cuatro casos es prácticamente la misma, consiguiéndose conversiones próximas al 90\% para las cuatro temperaturas estudiadas, lo que indicaría que en estas condiciones y en este rango de temperaturas no hay un control cinético de la reacción. Por este motivo, los experimentos realizados para comparar la actividad de distintos catalizadores se realizaron a temperatura ambiente. 


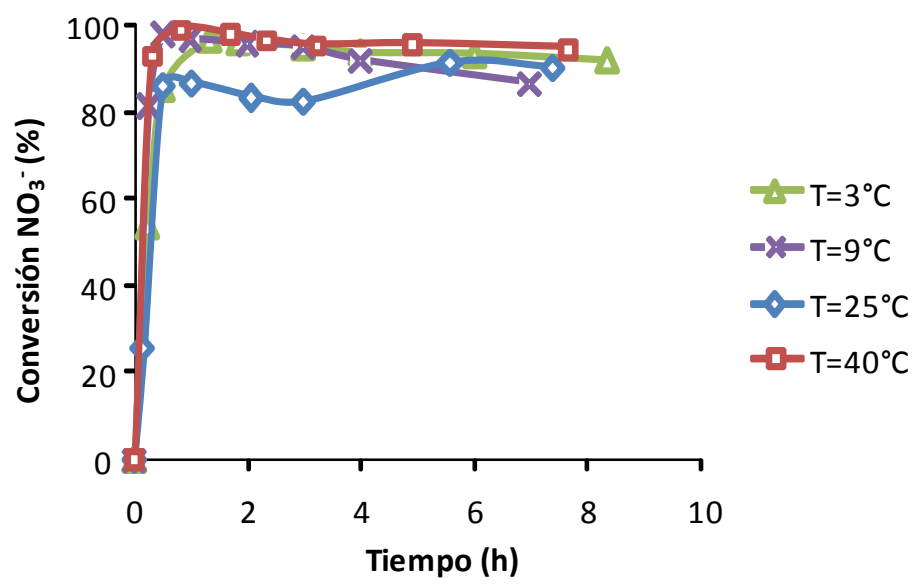

Figura 4. 5. Reducción catalítica de nitratos en continuo con aguas naturales al variar la temperatura de reacción (3 gramos de catalizador 2,5\% $\mathrm{Sn} / 5 \% \mathrm{Pd} / \gamma-\mathrm{Al}_{2} \mathrm{O}_{3}, 5 \mathrm{~mL} / \mathrm{min}$ agua, $250 \mathrm{~mL} / \mathrm{min}_{2}, 250$ $\left.\mathrm{mL} / \min \mathrm{CO}_{2}\right)$.

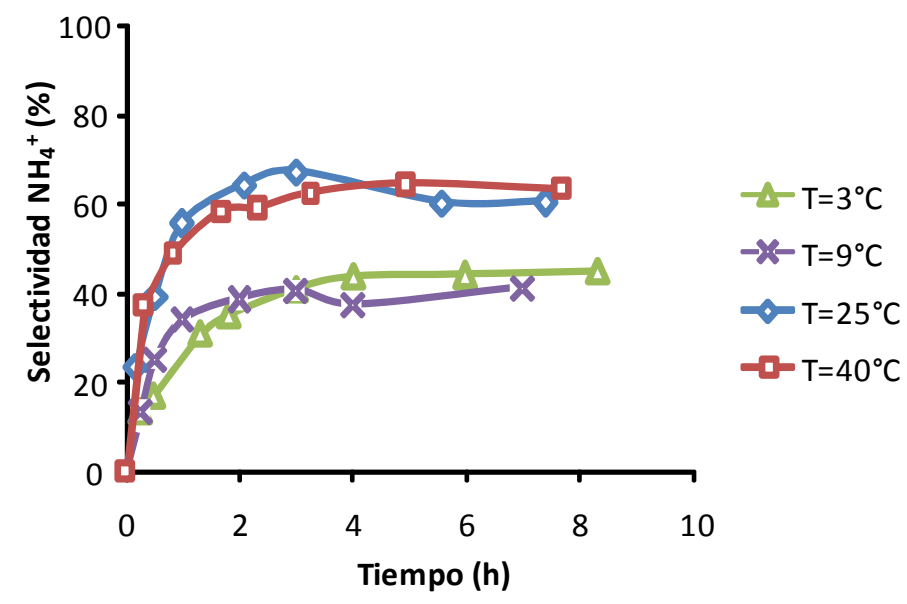

Figura 4. 6. Selectividad a amonio en la reducción catalítica de nitratos en continuo con aguas naturales al variar la temperatura de reacción (3 gramos de catalizador 2,5\% Sn/5\% Pd/ $\gamma-\mathrm{Al}_{2} \mathrm{O}_{3}, 5$ $\mathrm{mL} / \mathrm{min}$ agua, $250 \mathrm{~mL} / \mathrm{min} \mathrm{H}_{2}, 250 \mathrm{~mL} / \mathrm{min} \mathrm{CO}_{2}$ ).

Sin embargo, la selectividad a amonio sí que se ve afectada de forma considerable por la temperatura de reacción, de modo que al realizar la reacción a temperaturas por debajo de la temperatura ambiente, la selectividad a amonio disminuye del 60 al $40 \%$ 
(figura 4.6). Estos datos se corresponden con los obtenidos por Nakamura y col. [15], los cuales describieron que al utilizar un catalizador de $\mathrm{Pd}-\mathrm{Cu} /$ Mordenita para la reducción catalítica de nitratos la selectividad a amoniaco aumentaba al aumentar la temperatura de reacción. Estos resultados sugieren que aunque la reacción inicial de reducción de nitratos a nitritos (ecuación 1.2) no tiene un control cinético, las reacciones secundarias que generan el amonio (ecuaciones 1.4 y 1.5 ) se ven favorecidas al aumentar la temperatura de reacción.

\subsection{Velocidad de agitación}

Otra de las variables que se estudió fue la velocidad de agitación del agua de reacción en el reactor para asegurar que no existen problemas de difusión externa o de contacto entre las tres fases. Este estudio se realizó a temperatura ambiente, con control del $\mathrm{pH}$ y utilizando el catalizador $2,5 \% \mathrm{Sn} / 5 \% \mathrm{Pd} / \gamma-\mathrm{Al}_{2} \mathrm{O}_{3}$. El estudio de esta variable es muy importante debido a que se ha descrito que los problemas de transferencia de masa afectan sensiblemente a la reacción y a la selectividad del catalizador [16-18].

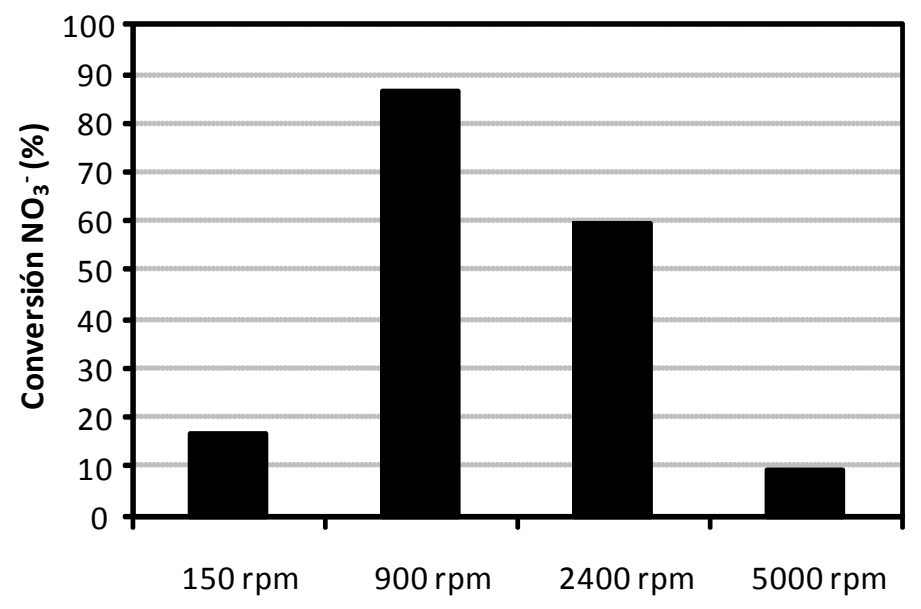

Figura 4. 7. Actividad del catalizador al modificar la velocidad de agitación (3 gramos de catalizador 2,5\% Sn/5\% Pd/ $\gamma-\mathrm{Al}_{2} \mathrm{O}_{3}, 5 \mathrm{~mL} / \mathrm{min}$ agua, $250 \mathrm{~mL} / \mathrm{min}_{2}, 250 \mathrm{~mL} / \mathrm{min} \mathrm{CO}_{2}$, resultados tras 4 horas de reacción). 
Como se puede observar en la figura 4.7 la máxima conversión se obtiene al utilizar una agitación de 900 rpm, mientras que al usar velocidades de agitación inferiores la actividad disminuía considerablemente debido a problemas de difusión externa. Al aumentar la velocidad de agitación también disminuye la actividad, esto se debe a la formación de vórtices en el reactor que impide un adecuado contacto entre las tres fases (sólida-líquida-gaseosa) del sistema. Por este motivo los experimentos se realizaron empleando una velocidad de agitación de 900 rpm.

\subsection{Tiempo de contacto}

El tiempo de contacto es un factor clave para determinar la masa de catalizador y el flujo de agua que deben utilizarse en la reacción en continuo con el fin de obtener los mejores resultados. En este apartado se ha estudiado cómo varía la actividad del catalizador al modificar la masa de catalizador y el flujo de agua utilizados.

\subsubsection{Masa de catalizador}

Estos experimentos se realizaron con un reactor en continuo trabajando con 5 $\mathrm{mL} / \mathrm{min}$ de agua natural conteniendo nitratos, $250 \mathrm{~mL} / \mathrm{min}$ de $\mathrm{H}_{2}$ y $250 \mathrm{~mL} / \mathrm{min}$ de $\mathrm{CO}_{2}$. Se realizaron ensayos con 0,$5 ; 1 ; 2$ y 3 gramos del catalizador $2,5 \% \mathrm{Sn} / 5 \% \mathrm{Pd} / \gamma-\mathrm{Al}_{2} \mathrm{O}_{3}$ obteniendo los resultados que se muestran en la figura 4.8. Como es de esperar al aumentar la masa de catalizador, es decir, al aumentar el tiempo de contacto, la actividad del catalizador también aumenta. De hecho, al utilizar 0,5 g de catalizador en la reacción se obtienen conversiones máximas del $60 \%$ frente a la conversión próxima al $100 \%$ obtenida al usar $3 \mathrm{~g}$ de catalizador. 


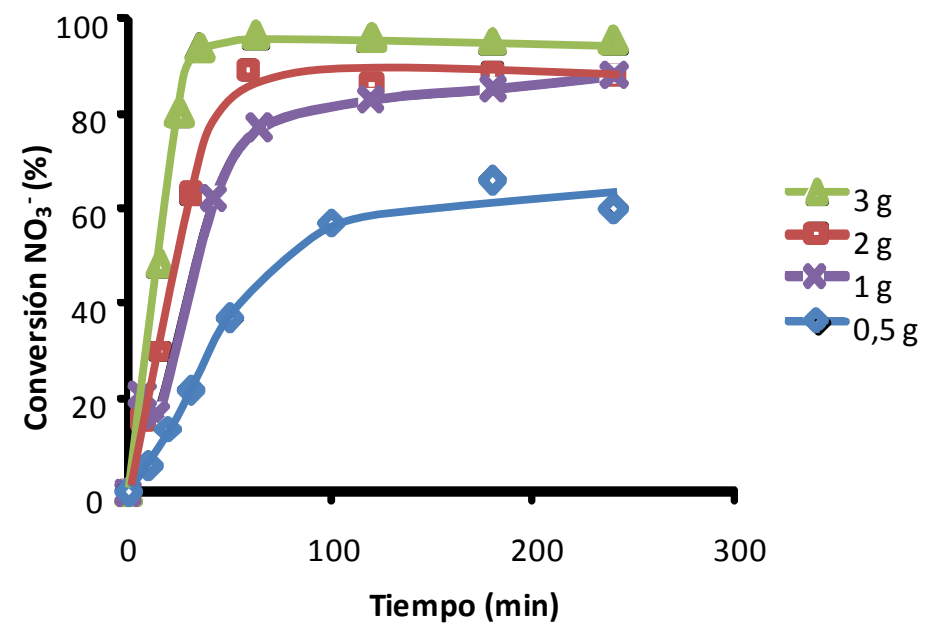

Figura 4. 8. Reducción catalítica de nitratos en continuo con aguas naturales con distinta masa de catalizador $\left(2,5 \% \mathrm{Sn} / 5 \% \mathrm{Pd} / \gamma-\mathrm{Al}_{2} \mathrm{O}_{3}, 5 \mathrm{~mL} / \mathrm{min}\right.$ agua, $\left.250 \mathrm{~mL} / \mathrm{min} \mathrm{H}_{2}, 250 \mathrm{~mL} / \mathrm{min} \mathrm{CO}_{2}\right)$.

\subsubsection{Caudal de agua}

Otro de los factores que determinan el tiempo de contacto es la variación del caudal de agua utilizada en la reacción. Para analizar esta variable se realizaron experimentos modificando el caudal de agua de 3,4 a $15 \mathrm{~mL} / \mathrm{min}$. Los resultados obtenidos se presentan en la figura 4.9 donde se observa que, aunque inicialmente se obtienen altas conversiones para todos los caudales estudiados, al cabo de 2 horas de reacción la actividad del catalizador $2,5 \% \mathrm{Sn} / 5 \% \mathrm{Pd} / \gamma-\mathrm{Al}_{2} \mathrm{O}_{3}$ disminuye de forma considerable para caudales de agua superiores a $5 \mathrm{~mL} / \mathrm{min}$. Así, para un caudal de agua de $15 \mathrm{~mL} / \mathrm{min}$ la actividad del catalizador cae rápidamente a partir de la primera hora de reacción, obteniendo una conversión de nitratos del $40 \%$ a las 8 horas de reacción. Al utilizar $10 \mathrm{~mL} / \mathrm{min}$ de agua la conversión no sufre una disminución tan brusca, alcanzando un valor del $70 \%$ a las 8 horas de reacción. Al utilizar 3,4 o $5 \mathrm{~mL} / \mathrm{min}$ de agua no se observa una desactivación del catalizador tras 8 horas de reacción, obteniéndose conversiones próximas al $90 \%$ en ambos casos. 
Estos resultados indican que si se quiere conseguir eliminar totalmente los nitratos en este tipo de aguas es necesario trabajar con una relación masa de catalizador/caudal de agua de $0,6 \mathrm{~g} \cdot \mathrm{min} / \mathrm{mL}$ o superior.

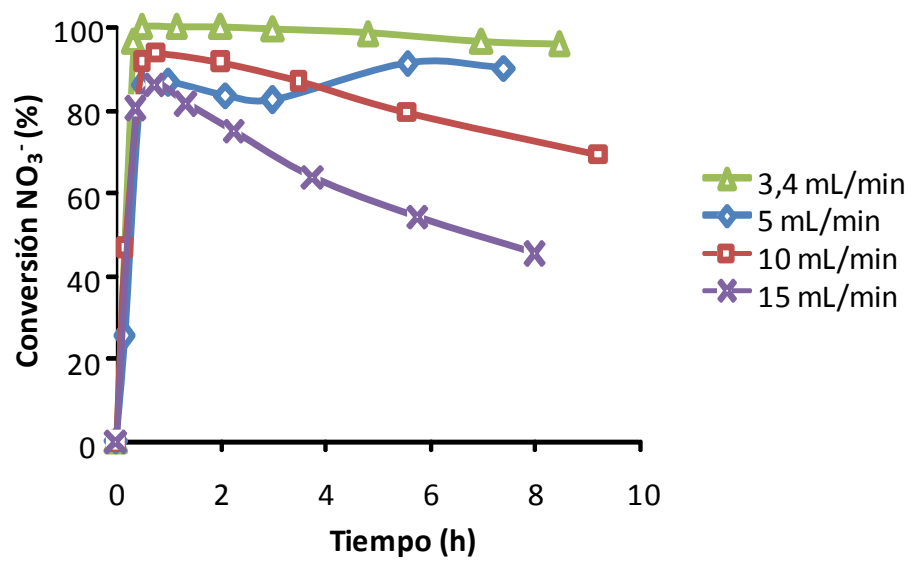

Figura 4. 9. Reducción catalítica de nitratos en continuo con aguas naturales con distintos caudales de agua (3 gramos de catalizador 2,5\% Sn/5\% $\mathrm{Pd} / \gamma-\mathrm{Al}_{2} \mathrm{O}_{3}, 250 \mathrm{~mL} / \mathrm{min} \mathrm{H}_{2}, 250 \mathrm{~mL} / \mathrm{min} \mathrm{CO}_{2}$ ).

\subsection{Hidrógeno en el medio}

Para estudiar la influencia del flujo de hidrógeno en la actividad del catalizador se realizaron dos tipos de ensayos. El primero consistió en modificar la presión parcial de hidrógeno en la mezcla de gases introducida en el reactor continuo de tanque agitado, mientras que el segundo consistía en modificar la presión de trabajo para aumentar la solubilidad de los gases en el sistema.

Si se comparan los resultados obtenidos al modificar la presión parcial de $\mathrm{H}_{2}$ introducida en el reactor manteniendo constante el flujo de $\mathrm{CO}_{2}$ (figura 4.10) se observa cómo al aumentar la presión parcial de hidrógeno la conversión prácticamente no varía. Sin embargo, la selectividad a amonio claramente aumenta al aumentar la presión parcial. Estos resultados están de acuerdo con los descritos en bibliografía con otros catalizadores y trabajando en un reactor en continuo con agua destilada conteniendo nitratos $[8,19$, 
20], ya que según las reacciones 4.1 y 4.2 una mayor presión parcial de hidrógeno favorecería la formación de amonio, al reducirse los nitratos del medio de reacción.

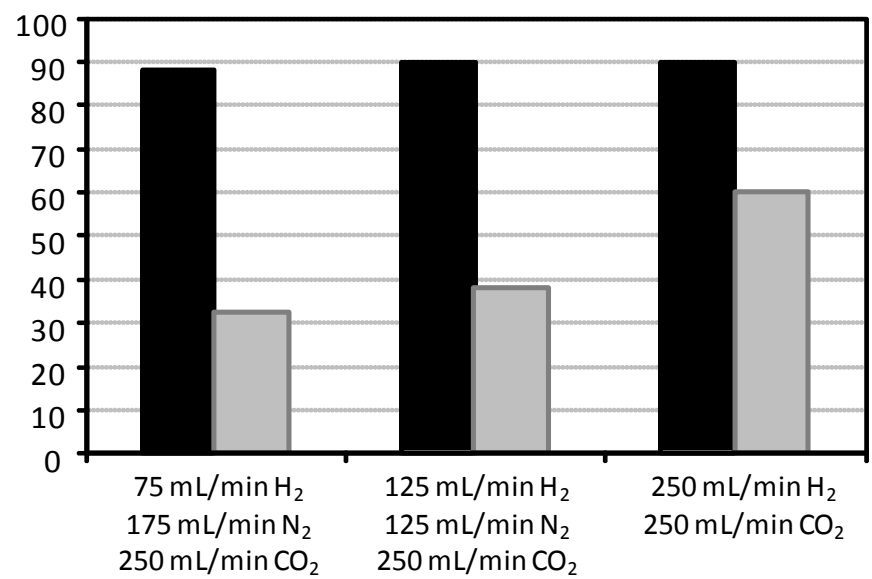

- Conversión $\mathrm{NO}_{3}{ }^{-}(\%) \quad \square$ Selectividad $\mathrm{NH}_{4}{ }^{+}$(\%)

Figura 4. 10. Variación de la actividad y selectividad a amonio al variar la presión parcial de $\mathrm{H}_{2}$ a las 4 horas de reacción (3 gramos de catalizador $2,5 \% \mathrm{Sn} / 5 \% \mathrm{Pd} / \gamma-\mathrm{Al}_{2} \mathrm{O}_{3}, 5 \mathrm{~mL} / \mathrm{min}$ agua).

Se estudió también cómo afectaba al sistema una presurización del mismo con los gases de reacción $\left(\mathrm{H}_{2}\right.$ y $\left.\mathrm{CO}_{2}\right)$. Para ello se realizaron pruebas a distinta presión utilizando el reactor a presión descrito en el apartado 3.5.1.3, trabajando a una presión parcial de hidrógeno de 0,5 y una presión total entre 1 y 3 bar. Los resultados obtenidos se muestran en las figuras 4.11 y 4.12. En estas figuras se observa cómo el aumento de la presión de trabajo no influye ni en la conversión ni en la selectividad del catalizador, obteniendo en todos los casos conversiones cercanas al $100 \%$ y selectividades a amonio próximas al $60 \%$.

Los resultados obtenidos en este apartado indican que una modificación de la cantidad de hidrógeno en el medio, bien por un aumento de la presión parcial o por una presurización del sistema, no influye en la conversión final obtenida. Sin embargo, el aumento de la presión parcial de hidrógeno en el medio sí que afecta a la selectividad de la reacción, de tal manera que la selectividad a amonio aumenta al aumentar la misma. No obstante, trabajando con una determinada presión parcial de hidrógeno, un aumento en la concentración del hidrógeno disuelto producida por un aumento en la presión de 
trabajo, no provoca variaciones sustanciales en la selectividad obtenida. Por ello, los experimentos se realizaron a presión atmosférica.

Estos resultados difieren de algunos descritos en bibliografía [4, 13, 21], en los cuales se muestra que la actividad del catalizador sí que aumenta al aumentar la presión parcial de hidrógeno así como la selectividad a amonio. Esta diferencia se puede atribuir al distinto tipo de agua utilizado.

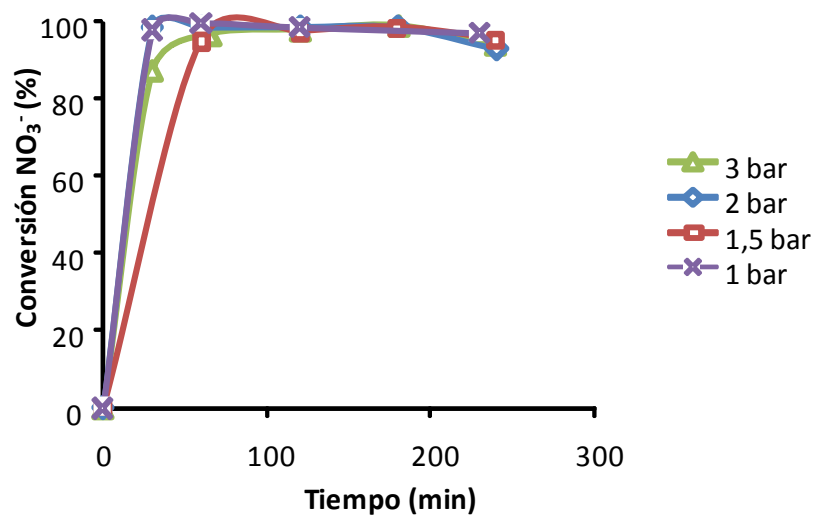

Figura 4. 111. Actividad del catalizador $2,5 \% \mathrm{Sn} / 5 \% \mathrm{Pd} / \gamma-\mathrm{Al}_{2} \mathrm{O}_{3}$ al variar la presión de trabajo $(50 \mathrm{mg}$, $1,2 \mathrm{~mL} / \mathrm{min}$ agua, $5 \mathrm{~mL} / \mathrm{min} \mathrm{H}_{2}, 5 \mathrm{~mL} / \mathrm{min} \mathrm{CO}_{2}$ ).

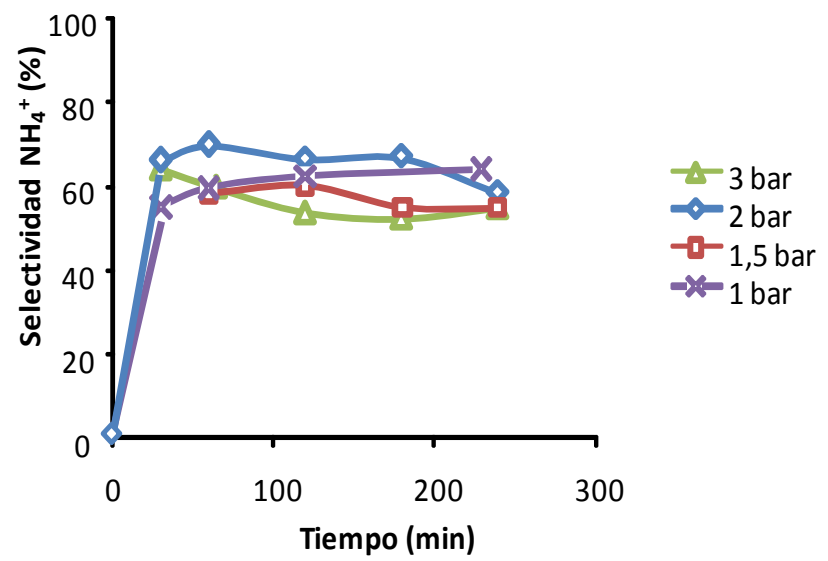

Figura 4. 12. Selectividad del catalizador $2,5 \% \mathrm{Sn} / 5 \% \mathrm{Pd} / \gamma-\mathrm{Al}_{2} \mathrm{O}_{3}$ al variar la presión de trabajo $(50 \mathrm{mg}$, $1,2 \mathrm{~mL} / \mathrm{min}$ agua, $5 \mathrm{~mL} / \mathrm{min} \mathrm{H}_{2}, 5 \mathrm{~mL} / \mathrm{min} \mathrm{CO}_{2}$ ). 


\subsection{Tipo de reactor}

Por último se estudió cómo se modificaba la actividad del catalizador $2,5 \% \mathrm{Sn} / 5 \% \mathrm{Pd} / \gamma-\mathrm{Al}_{2} \mathrm{O}_{3}$ al usar distintos tipos de reactores. Así se estudió la eliminación de nitratos en aguas naturales en un reactor continuo de tanque agitado y en un reactor de flujo de pistón.

Los resultados obtenidos con el reactor de flujo de pistón y el reactor continuo de tanque agitado se muestran en la figura 4.13. En esta figura se observa cómo la mayor conversión de nitratos se obtiene en el reactor continuo de tanque agitado. En las mismas condiciones de reacción, el reactor de flujo de pistón presenta una conversión de nitratos inferior, obteniendo un valor del $55 \%$ frente al $80 \%$ obtenido con el reactor continuo de tanque agitado. Estos resultados deben ser interpretados cuidadosamente, pues debido a las diferentes dimensiones del reactor, aunque el tiempo de contacto es el mismo, el tiempo de residencia del agua en el reactor varía, siendo en el caso del reactor continuo de tanque agitado de $7200 \mathrm{~s}$ y en el caso del reactor de flujo de pistón de $324 \mathrm{~s}$. La formación de amonio en ambos reactores también es diferente, siendo ésta mucho mayor en el reactor de tanque agitado, aunque también lo es la conversión obtenida.

Los resultados obtenidos indican que es posible trabajar con ambos reactores, aunque la conversión obtenida depende del tipo de reactor utilizado.

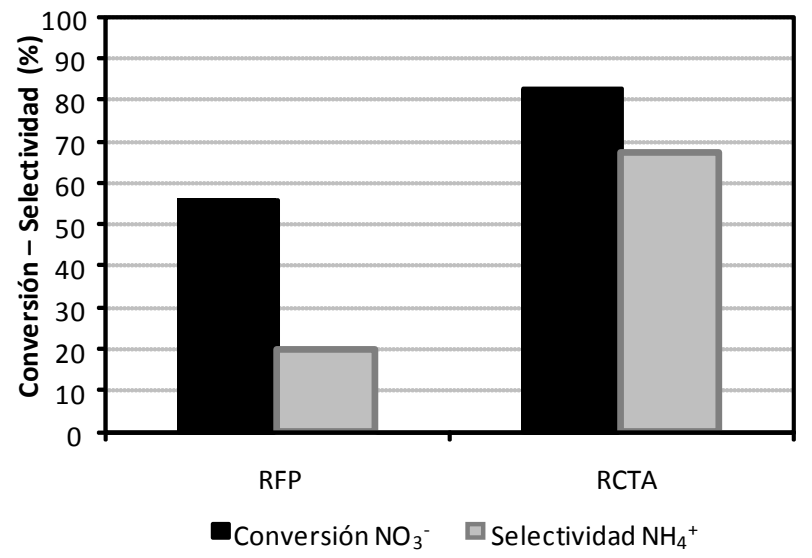

Figura 4. 13. Actividad del catalizador $2,5 \% \mathrm{Sn} / 5 \% \mathrm{Pd} / \gamma-\mathrm{Al}_{2} \mathrm{O}_{3}$ al usar un reactor de flujo de pistón (RFP) y un reactor en continuo de tanque agitado (RCTA) (3 gramos de catalizador). 


\subsection{Conclusiones parciales}

Los resultados obtenidos en este capítulo permiten establecer las condiciones de trabajo adecuadas para comparar la actividad en la eliminación de nitratos en aguas naturales, con un reactor en continuo, de los distintos catalizadores preparados en esta tesis. Estas condiciones son:

- Un pH próximo a 6,5 que se ajusta mediante el burbujeo de $\mathrm{CO}_{2}$ en el reactor, con el fin de neutralizar las especies hidroxilo formadas durante la reacción, las cuales favorecen la formación de amonio y la precipitación de carbonato cálcico en el catalizador.

- Temperatura ambiente, pues no se observa una variación sustancial de la actividad del catalizador al modificar la temperatura de reacción.

- Una velocidad de agitación de 900 rpm, ya que velocidades menores producen problemas de difusión externa y velocidades superiores provocan problemas de contacto del sistema gas-líquido-sólido.

- Para eliminar totalmente los nitratos de estas aguas se debe utilizar un caudal de agua de $5 \mathrm{~mL} / \mathrm{min}$ y una masa de catalizador de 3 gramos.

- Presión atmosférica, puesto que presurizar el sistema no modifica ni la actividad ni la selectividad del catalizador. 


\section{Referencias}

[1] A. Pintar, J. Batista, I. Musevic; Applied Catalysis B: Environmental, 52 (2004) 49.

[2] J. Sá, D. Gasparovicova, K. Hayek, E. Halwax, J. A. Anderson, H. Vinek; Catalysis Letters, 105 (2005) 209.

[3] U. Prüsse, M. Hähnlein, J. Daum, K.-D. Vorlop; Catalysis Today, 55 (2000) 79.

[4] A. Pintar, J. Batista; Applied Catalysis B: Environmental, 63 (2006) 150.

[5] U. Prüsse, K.-D. Vorlop; Journal of Molecular Catalysis A: Chemical, 173 (2001) 313.

[6] M. D'Arino, F. Pinna, G. Strukul; Applied Catalysis B: Environmental, 53 (2004) 161.

[7] D. Gasparovicová, M. Králik, M. Hronec, Z. Vallusová, H. Vinek, B. Corain; Journal of Molecular Catalysis A: Chemical, 264 (2007) 93.

[8] W. Gao, N. Guan, J. Chen, X. Guan, R. Jin, H. Zeng, Z. Liu, F. Zhang; Applied Catalysis B: Environmental, 46 (2003) 341.

[9] A. Roveda, A. Benedetti, F. Pinna, G. Strukul; Inorganica Chimica Acta, 349 (2003) 203.

[10] Y. Matatov-Meytal, V. Barelko, I. Yuranov, L. Kiwi-Minsker, A. Renken, M. Sheintuch; Applied Catalysis B: Environmental, 31 (2001) 233.

[11] R. Gavagnin, L. Biasetto, F. Pinna, G. Strukul; Applied Catalysis B: Environmental, 38 (2002) 91.

[12] G. Strukul, F. Pinna, M. Marella, L. Meregalli, M. Tomaselli; Catalysis Today, 27 (1996) 209.

[13] A. Pintar, M. Setinc, J. Levec; Journal of Catalysis, 174 (1998) 72.

[14] F. Gauthard, F. Epron, J. Barbier; Journal of Catalysis, 220 (2003) 182.

[15] K. Nakamura, Y. Yoshida, I. Mikami, T. Okuhara; Applied Catalysis B: Environmental, 65 (2006) 31.

[16] A. E. Palomares, J. G. Prato, F. Márquez, A. Corma; Applied Catalysis B: Environmental, 41 (2003) 3.

[17] K. Daub, G. Emig, M. J. Chollier, M. Callant, R. Dittmeyer; Chemical Engineering Science, 54 (1999) 1577.

[18] O. M. Ilinitch, F. P. Cuperus, L. V. Nosova, E. N. Gribov; Catalysis Today, 56 (2000) 137.

[19] S. Hörold, T. Tacke, K.-D. Vorlop; Environmental Technology, 14 (1993) 931.

[20] S. Hörold, K. D. Vorlop, T. Tacke, M. Sell; Catalysis Today, 17 (1993) 21.

[21] Y. Matatov-Meytal, Y. Shindler, M. Sheintuch; Applied Catalysis B: Environmental, 45 (2003) 127. 

5.

\section{OPTIMIZACIÓN DE LA} COMPOSICIÓN DEL CATALIZADOR Y DE SU PREPARACIÓN 

Una vez determinadas las condiciones de reacción, en este capítulo se va a optimizar la composición y el modo de preparación del catalizador para que sea activo en la reducción catalítica de los nitratos en aguas naturales con un reactor continuo. Para ello se estudiará la actividad de diversos catalizadores con distintos metales, con varios tipos de soportes y preparados de distinta forma.

\subsection{Composición del catalizador}

La mayor parte de los catalizadores descritos como activos para la reducción catalítica de nitratos en aguas empleando reactores en discontinuo y agua sintética son combinaciones de un metal noble y un metal no noble [1-6]. En base a estos estudios previos se prepararon las siguientes combinaciones de metales y se estudió su actividad en un reactor en continuo y empleando aguas naturales:

- $2,5 \% \mathrm{Sn} / 5 \% \mathrm{Pd} / \gamma-\mathrm{Al}_{2} \mathrm{O}_{3}$

- $2,5 \% \mathrm{Cu} / 5 \% \mathrm{Pd} / \gamma-\mathrm{Al}_{2} \mathrm{O}_{3}$

- $2,5 \% \mathrm{Sn} / 5 \% \mathrm{Rh} / \gamma-\mathrm{Al}_{2} \mathrm{O}_{3}$

- $2,5 \% \mathrm{Cu} / 5 \% \mathrm{Rh} / \gamma-\mathrm{Al}_{2} \mathrm{O}_{3}$

- $2,5 \% \mathrm{Sn} / 5 \% \mathrm{Ru} / \gamma-\mathrm{Al}_{2} \mathrm{O}_{3}$

- $2,5 \% \mathrm{Cu} / 5 \% \mathrm{Ru} / \gamma-\mathrm{Al}_{2} \mathrm{O}_{3}$

- $\quad 2,5 \% \mathrm{Sn} / 5 \% \mathrm{Pt} / \gamma-\mathrm{Al}_{2} \mathrm{O}_{3}$

- $2,5 \% \mathrm{Cu} / 5 \% \mathrm{Pt} / \gamma-\mathrm{Al}_{2} \mathrm{O}_{3}$

- $2,5 \% \mathrm{Ni} / 5 \% \mathrm{Mo} / \gamma-\mathrm{Al}_{2} \mathrm{O}_{3}$

- $2,5 \% \mathrm{Nb} / 5 \% \mathrm{Pd} / \gamma-\mathrm{Al}_{2} \mathrm{O}_{3}$

- $2,5 \% \mathrm{~W} / 5 \% \mathrm{Pd} / \gamma-\mathrm{Al}_{2} \mathrm{O}_{3}$

- $\quad 2,5 \% \mathrm{Ce} / 5 \% \mathrm{Pd} / \gamma-\mathrm{Al}_{2} \mathrm{O}_{3}$

- $\quad 2,5 \% \mathrm{Zn} / 5 \% \mathrm{Pd} / \gamma-\mathrm{Al}_{2} \mathrm{O}_{3}$

- $2,5 \% \mathrm{Mn} / 5 \% \mathrm{Pd} / \gamma-\mathrm{Al}_{2} \mathrm{O}_{3}$

- $2,5 \% \ln / 5 \% \mathrm{Pd} / \gamma-\mathrm{Al}_{2} \mathrm{O}_{3}$

- $2,5 \% \mathrm{Fe} / 5 \% \mathrm{Pd} / \gamma-\mathrm{Al}_{2} \mathrm{O}_{3}$

- $2,5 \% \mathrm{Fe} / 5 \% \mathrm{Cu} / \gamma-\mathrm{Al}_{2} \mathrm{O}_{3}$ 
$-2,5 \% \mathrm{Fe} / 5 \% \mathrm{Sn} / \gamma-\mathrm{Al}_{2} \mathrm{O}_{3}$

Los resultados obtenidos con estos catalizadores aparecen en las figuras 5.1 y 5.2 , donde se representa la conversión obtenida con los mismos tras 4 horas de reacción y la selectividad a amonio a este tiempo.

A la hora de analizar los resultados obtenidos, los catalizadores se han dividido en tres grupos: los que eran prácticamente inactivos (actividad inferior al 5\%), aquéllos que presentaban una baja-media actividad (inferior al 50\%) y los que mostraban alta actividad (superior al 50\%).

Los catalizadores que mostraban conversiones inferiores al $5 \%$ eran los que contenían Fe, es decir, las combinaciones Fe-Pd, Fe-Cu y Fe-Sn. Estos resultados difieren de los obtenidos Huang y col. [7], quienes añadiendo $\mathrm{Fe}^{0}$ al agua destilada conteniendo nitratos obtenían conversiones superiores al 95\%, probablemente por una reacción redox y no por una reacción catalítica. Sin embargo, otros autores $[6,8]$ obtuvieron resultados similares a los obtenidos en este trabajo, corroborando que los catalizadores con Fe eran inactivos para esta reacción.

En el segundo grupo se encuentran los catalizadores con conversiones inferiores al $50 \%$, que son los catalizadores de Cu-Ru, Ni-Mo, W-Pd, Mn-Pd, Sn-Ru, Ce-Pd, Nb-Pd y SnPt (figura 5.1). Las conversiones obtenidas con estos catalizadores varían desde un $7 \%$ obtenido con para el catalizador $\mathrm{Cu}-\mathrm{Ru}$ hasta un $29 \%$ obtenido con el catalizador de Sn-Pt. Estos catalizadores presentan en la mayoría de los casos selectividades a amonio que están por encima del $20 \%$ y en algunos casos selectividades a nitrito superiores al $10 \%$. Por tanto, las citadas combinaciones de metales no son apropiadas para la reducción catalítica de nitratos en aguas naturales, ya que presentan una baja actividad y su selectividad a nitrógeno no es muy elevada.

Analizando los resultados obtenidos con este grupo de catalizadores, se observa que la actividad obtenida con los catalizadores de $\mathrm{Cu}-\mathrm{Ru}$ y Sn-Pt concuerda con los obtenidos en bibliografía con agua sintética y reactores en discontinuo, donde se observa que estos catalizadores presentan bajas actividades en las condiciones de reacción estudiadas [8]. Por el contrario, los resultados obtenidos con el catalizador Pd-Ce 
soportado sobre alúmina difieren de los descritos para el catalizador $\mathrm{Pd}-\mathrm{CeO}_{2}$. Según Epron y col. [9] con este catalizador es posible obtener una eliminación completa de los nitratos a los 20 minutos de reacción y con una selectividad a amonio del 75\%, mientras que en las condiciones de reacción utilizadas en este trabajo (con agua natural y un reactor continuo) se ha obtenido una conversión del 12\%. Los mencionados autores atribuyen la actividad del catalizador $\mathrm{Pd}-\mathrm{CeO}_{2}$ a la formación de una especie de óxido de cerio parcialmente reducido que favorece la reacción. En nuestro caso esta especie probablemente no se forma porque alguno de los iones presentes en las aguas naturales, pueden oxidar la fase activa disminuyendo la actividad del catalizador, o bien por el diferente soporte utilizado.

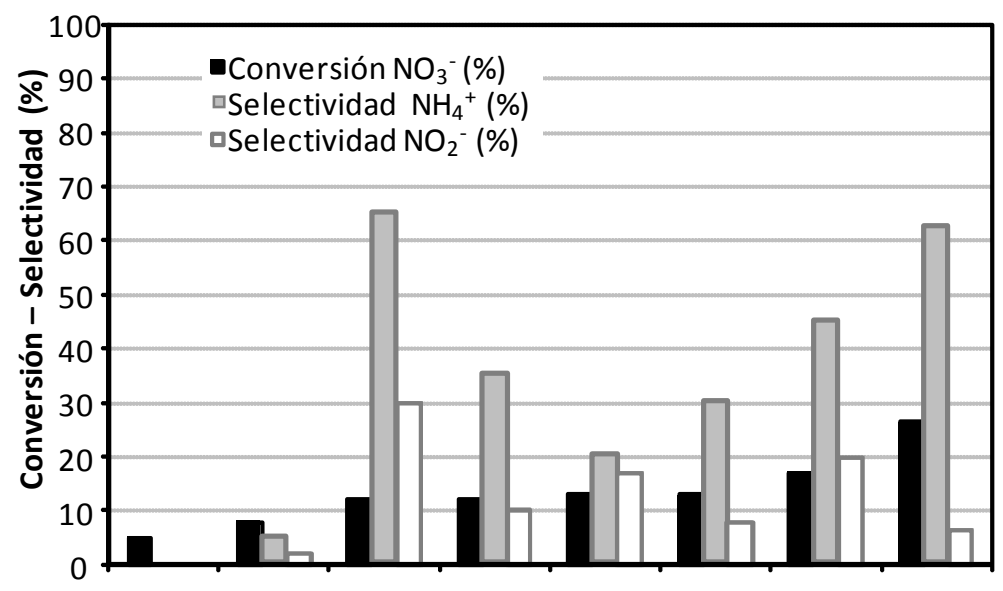

Cu-Ru Ni-Mo W-Pd Mn-Pd Sn-Ru Ce-Pd Nb-Pd Sn-Pt

Figura 5. 1. Actividad, selectividad a amonio y selectividad a nitrito tras 4 horas de reacción de los catalizadores preparados con distintos metales $\left(3 \mathrm{~g}\right.$ catalizador, $5 \mathrm{~mL} / \mathrm{min}$ agua, $250 \mathrm{~mL} / \mathrm{min} \mathrm{H}_{2}, 250$ $\left.\mathrm{mL} / \min \mathrm{CO}_{2}\right)$.

Por último, estaría el grupo de catalizadores que presentan una alta actividad. Estos son los catalizadores de Zn-Pd, Sn-Pd, Cu-Pt, Sn-Rh, Cu-Rh, In-Pd y Cu-Pd, los cuales muestran conversiones superiores al 70\% (figura 5.2). Pese a presentar todos ellos elevadas conversiones, la selectividad a amonio obtenida con cada uno de ellos es muy distinta. De hecho, se observa que los catalizadores con Rh no son apropiados en este tipo 
de reacciones, debido a que, aunque presentan conversiones cercanas al 95\%, la selectividad a amonio obtenida también es de este orden. Esto podría deberse a que el Rh facilita la hidrogenación del nitrito a amonio, tal como describen Soares y col. [10]. Los catalizadores de Cu-Pt también presentan una selectividad a amonio superior al $80 \%$. Estos resultados difieren de los descritos por Epron y col. [11] quienes en otras condiciones de reacción obtuvieron también una conversión de los nitratos muy elevada, pero una selectividad a amonio muy baja, y una selectividad a nitrito del $50 \%$. Probablemente esta diferencia se deba a que en los experimentos descritos en [11] se trabaja con un menor tiempo de contacto y aunque la reducción de nitrato a nitrito se ha producido completamente, la reducción del nitrito a amonio o a nitrógeno no se ha producido y por tanto, la selectividad a nitrito es muy elevada. Los resultados obtenidos con el catalizador de In-Pd son similares a los obtenidos en bibliografía $[2,12]$ con una selectividad a amonio del orden del 75\%. Los mejores resultados en cuanto a selectividad a nitrógeno se han obtenido con los catalizadores de $\mathrm{Zn}-\mathrm{Pd}$, Sn-Pd y Cu-Pd, aunque el par $\mathrm{Zn}$-Pd es menos activo que el resto. Los resultados obtenidos con el catalizador $\mathrm{Zn}$-Pd difieren de los descritos en [3] y [8] con catalizadores de Zn-Pd soportados sobre alúmina y carbón, en los que se muestra que las conversiones obtenidas son muy bajas. Estas diferencias están probablemente relacionadas con el tipo de preparación o con el distinto soporte utilizado.

De esta manera se puede afirmar que los mejores resultados tanto de actividad como de selectividad obtenidos al trabajar con aguas naturales y en continuo se consiguen con los catalizadores basados en $\mathrm{Cu}-\mathrm{Pd}$ y $\mathrm{Sn}-\mathrm{Pd}$, que también se han descrito en bibliografía como muy activos para la reducción catalítica de nitratos empleando agua destilada y trabajando en discontinuo [1, 3, 13, 14]. Por ello estos pares metálicos son los elegidos para optimizar la preparación del catalizador. 


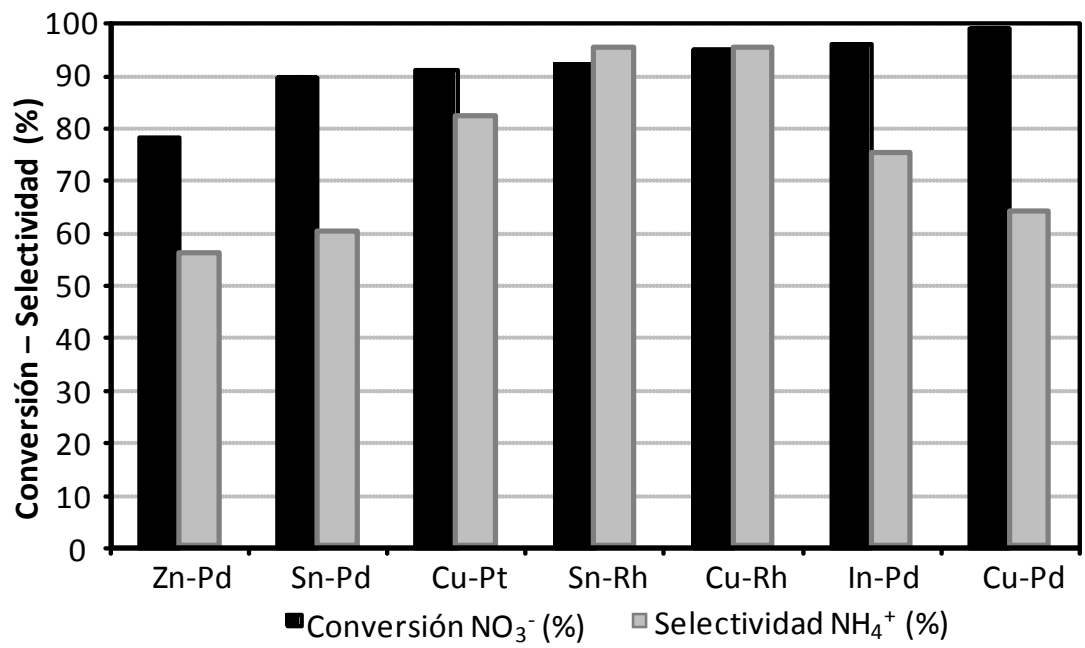

Figura 5. 2. Actividad y selectividad a amonio tras 4 horas de reacción de los catalizadores preparados con distintos metales ( $3 \mathrm{~g}$ catalizador, $5 \mathrm{~mL} / \mathrm{min}$ agua, $250 \mathrm{~mL} / \mathrm{min} \mathrm{H}_{2}, 250 \mathrm{~mL} / \mathrm{min} \mathrm{CO}_{2}$ ).

\subsection{Estudio del soporte}

Una vez determinado el par metálico más adecuado para la reducción catalítica de nitratos en agua con un reactor continuo, se estudió la influencia del tipo de soporte en la actividad del catalizador, pues al tener esta reacción problemas difusionales [15-17] va a ser muy importante intentar minimizar los problemas de difusión internos buscando un soporte adecuado. Por ello se estudió la actividad de varios catalizadores de $2,5 \% \mathrm{Sn} / 5 \% \mathrm{Pd}$ y $2,5 \% \mathrm{Cu} / 5 \% \mathrm{Pd}$ soportados sobre diversos materiales y se comparó su actividad y selectividad. Los soportes estudiados fueron distintos tipos de carbones, zeolitas, materiales mesoporosos y óxidos.

\subsubsection{Carbones}

Los carbones utilizados como soporte fueron: grafito (con un área superficial de 0,2 $\mathrm{m}^{2} / \mathrm{g}$ ), carbón activo Norit GAC $1240 \mathrm{~W}$ (con un área superficial de $1200 \mathrm{~m}^{2} / \mathrm{g}$ ) y carbón activo Norit ROX 0.8 (con un área superficial de $1100 \mathrm{~m}^{2} / \mathrm{g}$ ). 
Los resultados obtenidos con los catalizadores $2,5 \% \mathrm{Sn} / 5 \% \mathrm{Pd}$ o $2,5 \% \mathrm{Cu} / 5 \% \mathrm{Pd}$ soportados en grafito aparecen en la figura 5.3. Tal como se observa, la reacción es inicialmente muy lenta, siendo necesarias 2 o 3 horas para alcanzar la máxima conversión a las 3 horas de reacción, tras lo que ésta disminuye lentamente. Los resultados obtenidos con el catalizador de $\mathrm{Pd}$ y $\mathrm{Sn}$ son mejores que los obtenidos con el catalizador $\mathrm{Cu} / \mathrm{Pd}$, obteniendo conversiones cercanas al $80 \%$ a las 3 horas de reacción. Posteriormente, el catalizador se va desactivando hasta alcanzar un $65 \%$ de conversión a las 7 horas de reacción. Estos resultados indican que contrariamente a lo que ocurría con la alúmina (figura 5.2), al usar grafito como soporte la actividad del catalizador Cu-Pd es mucho menor que la del catalizador Sn-Pd.

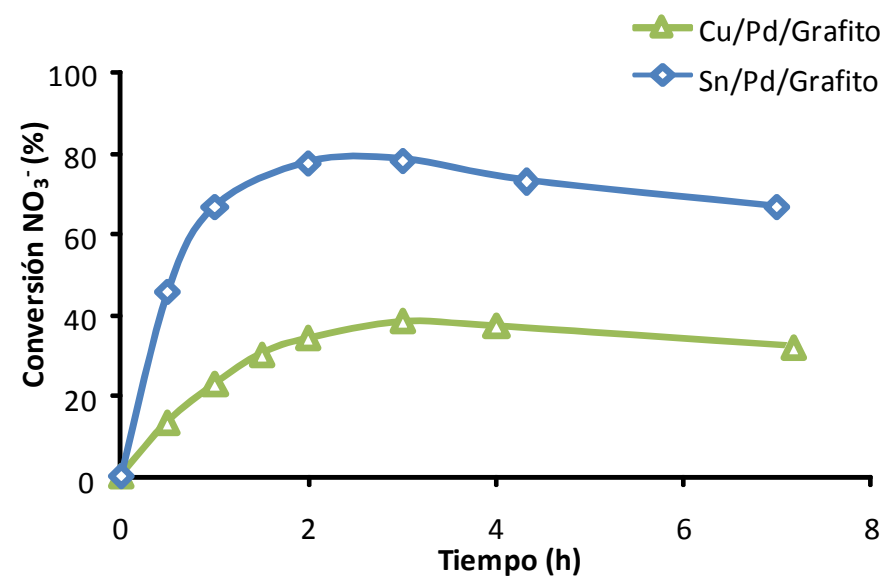

Figura 5. 3. Conversión de nitratos con catalizadores $2,5 \% \mathrm{Cu}-5 \% \mathrm{Pd}$ o 2,5\%Sn-5\%Pd soportados sobre grafito (3 g catalizador, $5 \mathrm{~mL} / \mathrm{min}$ agua, $250 \mathrm{~mL} / \mathrm{min}_{2}, 250 \mathrm{~mL} / \mathrm{min} \mathrm{CO}_{2}$ ).

Los resultados obtenidos con el catalizador de Sn-Pd soportado sobre grafito se compararon con los obtenidos con otros tipos de carbones: carbones activos Norit GAC 1240W y Norit ROX 0.8. En la figura 5.4 se observa que las conversiones obtenidas con el carbón activo Norit ROX 0.8 y el grafito son similares aunque el grafito es más selectivo a nitrógeno. La máxima conversión se consigue con el carbón activo Norit GAC 1240W, obteniéndose una conversión del $92 \%$ a las 4 horas de reacción. Esta conversión es similar a la obtenida con el catalizador soportado en alúmina (figura 5.2) pero la selectividad a 
amonio es mucho mayor (91\%). Esta elevada selectividad a amonio puede deberse a la mayor conductividad eléctrica de los carbones (alrededor de $15 \mathrm{~S} / \mathrm{cm}$ ) que facilita la adsorción de hidrógeno sobre la superficie de Pd produciendo una sobrerreducción de las moléculas de nitrito para formar amonio en lugar de nitrógeno [18].

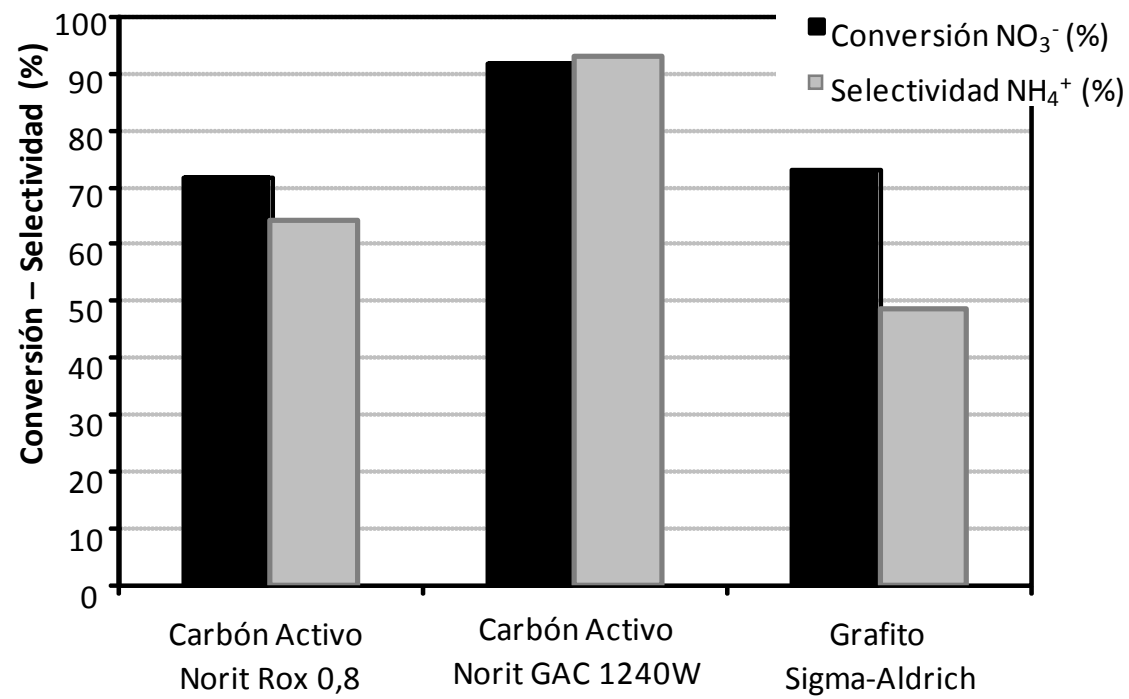

Figura 5. 4. Actividad y selectividad a amonio a las 4 horas de reacción del catalizador $2,5 \% \mathrm{Sn} / 5 \% \mathrm{Pd}$ soportado sobre los distintos carbones (3 g catalizador, $5 \mathrm{~mL} / \mathrm{min}$ agua, $250 \mathrm{~mL} / \mathrm{min}_{2}, 250 \mathrm{~mL} / \mathrm{min}$ $\left.\mathrm{CO}_{2}\right)$.

\subsubsection{Zeolitas y materiales mesoporosos}

En este apartado se ha estudiado el uso de materiales microposos y materiales mesoporosos como soportes para el catalizador de Sn-Pd. Para ello se prepararon diversos catalizadores para la reducción catalítica de nitratos en aguas naturales empleando distintas zeolitas, de diferente relación Si/Al y de diferente topología, y un material mesoporoso. Las zeolitas empleadas tenían canales de 8,10 y 12 miembros y relaciones Si/Al de 2,5; 10; 25; 40 y 140. También se utilizó como soporte un material mesoporoso como el MCM-41, preparando uno con una relación Si/Al de 30 y otro pura sílice. Estos soportes se impregnaron con $2,5 \%$ en peso de $\mathrm{Sn}$ y $5 \%$ en peso de $\mathrm{Pd}$ y se comparó su actividad y selectividad en reacción. 


\section{Materiales microporosos}

Los materiales microporosos estudiados como soportes para el catalizador 2,5\%Sn/5\%Pd fueron la zeolita ZSM-5, la zeolita Y, la zeolita Beta, la zeolita MCM-22 y la Mordenita.

La zeolita ZSM-5 es una zeolita sintética [19] sin equivalente natural, que se caracteriza por ser un material altamente poroso de simetría ortorrómbica que tiene dos tipos de canales (horizontales y verticales) diferentes, formados por anillos de 10 tetraedros de poro medio. Posee un canal recto y elíptico en la sección transversal y un canal sinusoidal formado por la intersección de los poros (modelo zigzag), en la sección transversal circular.

La zeolita $Y$ es un material sintético isoestructural de la zeolita natural faujasita [20]. Esta zeolita presenta simetría cúbica y un sistema tridireccional de canales cuya sección está formada por doce tetraedros con un diámetro de canal de 0,74 nm, por lo que es una zeolita de poro grande, los canales al cruzarse dan lugar a cavidades o supercajas de 1,2 $\mathrm{nm}$ de diámetro. A su vez se generan pequeñas cavidades con forma de cuboctaedro truncado, cuyo diámetro interno está delimitado por ocho octaedros, y que se denominan cajas de soldalita (diámetro interno 4,5 nm).

La zeolita Beta es un material sintético que presenta una estructura muy abierta, capaz de desarrollar en su interior centros ácidos muy fuertes [21], y está constituida por un sistema tridireccional de canales de tamaño de poro grande (canales aproximadamente de $0,7 \mathrm{~nm}$ ), isoestructural con la zeolita natural tchemichita [22].

La zeolita MCM-22 está formada por dos sistemas de poros independientes, siendo ambos accesibles por anillos de 10 miembros [23]. Uno de los sistemas de poros está definido por canales sinusoidales y bidireccionales de 0,52 $\mathrm{nm}$, mientras que el otro, consiste en grandes supercavidades con un diámetro interno libre de 0,71 nm delimitado por un anillo de 12 miembros y una altura interna de 1,82 $\mathrm{nm}$. Las supercavidades están interconectadas a través de ventanas de anillos de 10 miembros.

La mordenita se caracteriza por la presencia de dos canales, uno de 12 miembros con canales de $0,65 \times 0,7 \mathrm{~nm}$, es decir, poros de tamaño grande, y otro de 8 miembros con 
canales de $0,26 \times 0,47 \mathrm{~nm}$, o sea, poros de tamaño pequeño. La mordenita es un tipo de zeolita natural [24].

Estas zeolitas se prepararon en el laboratorio (MCM-22) o eran comerciales (zeolitas $\mathrm{Y}$, Beta, mordenita y ZSM-5). La zeolita ZSM-5 tenía una relación Si/Al=25, la zeolita $\mathrm{Y}$ tenía una relación $\mathrm{Si} / \mathrm{Al}=2,5$, la zeolita Beta tenía una relación $\mathrm{Si} / \mathrm{Al}=12,5$, la zeolita $\mathrm{MCM}-22$ tenía una relación $\mathrm{Si} / \mathrm{Al}=25$ y la zeolita Mordenita tenía una relación $\mathrm{Si} / \mathrm{Al}=10$. Estos soportes se impregnaron a volumen de poro para conseguir un catalizador con $2,5 \%$ de $\mathrm{Sn}$ y $5 \%$ de $\mathrm{Pd}$ y los resultados obtenidos se muestran en la figura 5.5. En esta figura se observa que la conversión obtenida al usar como soportes las zeolitas $Y$, Mordenita y Beta oscila entre un 20 y un $25 \%$, mientras que la obtenida con la ZSM- 5 y la MCM-22 es de un 45\%. Por tanto, se puede afirmar que al usar soportes microporosos la actividad obtenida es inferior al 50\%, mucho menor que la obtenida con la alúmina (figura 5.2) o los carbones (figura 5.4). La selectividad a amonio obtenida al usar como soportes materiales microporosos es inferior al 35\% en todos los casos excepto al usar zeolita $Y$ como soporte, que es del $50 \%$. La baja conversión obtenida al usar como soportes catalíticos materiales microporosos puede estar relacionada con problemas de difusión interna, que impiden que los nitratos puedan acceder a los centros activos de estos materiales debido al pequeño tamaño de los poros de las zeolitas. 


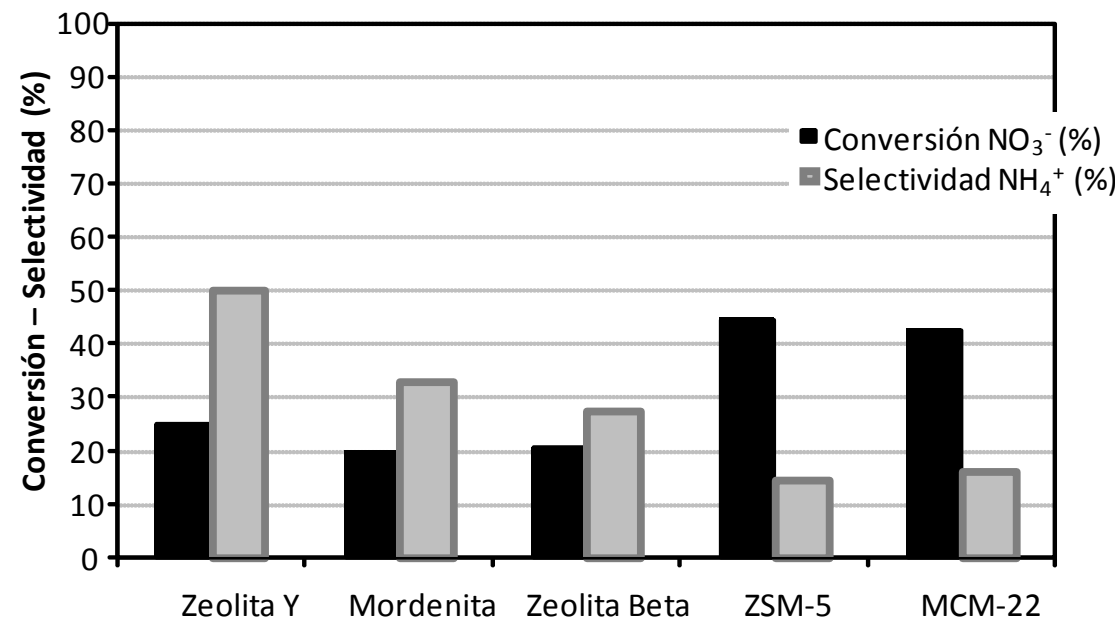

Figura 5. 5. Actividad y selectividad a amonio tras 4 horas del catalizador $2,5 \% \mathrm{Sn} / 5 \%$ Pd soportado sobre distintos materiales microporosos (3 g catalizador, $5 \mathrm{~mL} / \mathrm{min}$ agua, $250 \mathrm{~mL} / \mathrm{min}_{2}, 250$ $\left.\mathrm{mL} / \mathrm{min} \mathrm{CO}_{2}\right)$.

No obstante, el hecho de que las conversiones más altas se obtuviesen con las zeolitas que presentan una mayor relación Si/Al, llevó a estudiar la influencia de esta variable con un tipo de zeolita: la ZSM-5, que era uno de los soportes microporosos con los que mejores resultados se obtuvieron. La composición y las características superficiales de estas zeolitas aparecen en la tabla 5.1, donde se observa cómo tras impregnar el soporte con las sales de estaño y paladio hay una ligera disminución del área superficial total del catalizador mientras se mantiene constante el área externa, lo que se debe a que la deposición de las sales sobre el material microporoso bloquea parte de los canales de la zeolita, con lo que disminuye el área del soporte.

Tal como se observa en la figura 5.6, la máxima conversión se obtiene con la zeolita que presenta una mayor relación $\mathrm{Si} / \mathrm{Al}$, aunque ésta no supera el $65 \%$ ni parece que haya una clara correlación entre el aumento de la relación Si/Al y el aumento de la actividad del catalizador. Esto probablemente se debe a que las características estructurales del material microporoso no son las más adecuadas para esta reacción, y son estas propiedades y no la relación $\mathrm{Si} / \mathrm{Al}$ las que están determinando la actividad catalítica. 
Tabla 5. 1. Área BET de las zeolitas ZSM-5 de distinta relación Si/Al $\left(\mathrm{m}^{2} / \mathrm{g}\right)$.

\begin{tabular}{ccccc}
\hline Relación Si/AI & \multicolumn{2}{c}{ Área BET $\left(\mathrm{m}^{2} / \mathrm{g}\right)$} & \multicolumn{2}{c}{ Área externa $\left(\mathrm{m}^{2} / \mathrm{g}\right)$} \\
\hline $\begin{array}{c}\text { Muestra } \\
\text { original }\end{array}$ & $\begin{array}{c}\text { Muestra } \\
\text { impregnada }\end{array}$ & $\begin{array}{c}\text { Muestra } \\
\text { original }\end{array}$ & $\begin{array}{c}\text { Muestra } \\
\text { impregnada }\end{array}$ \\
\hline 25 & 413 & 383 & 68 & 65 \\
40 & 403 & 371 & 46 & 43 \\
140 & 382 & 364 & 43 & 40 \\
\hline
\end{tabular}

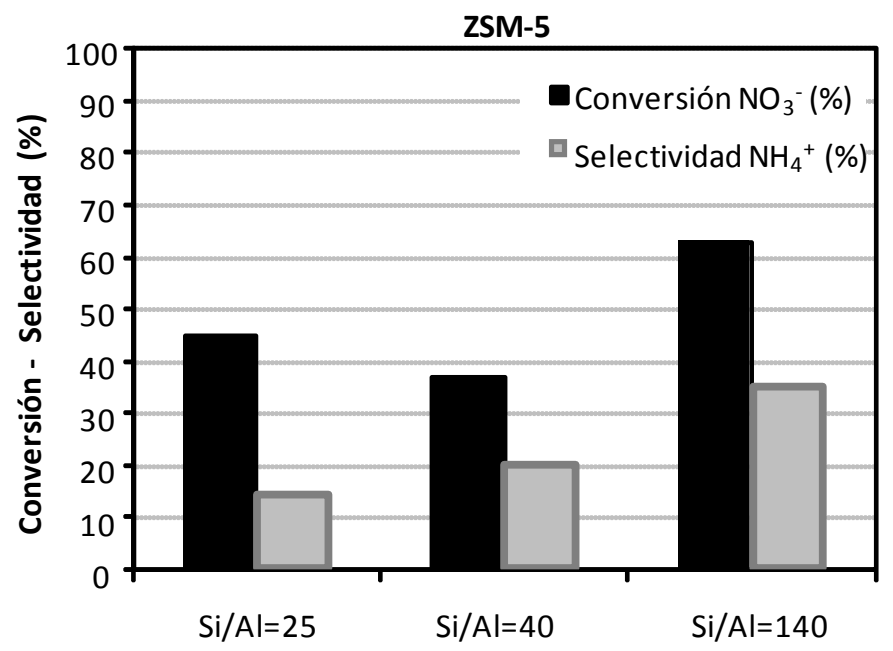

Figura 5. 6. Actividad y selectividad a amonio tras 4 horas del catalizador $2,5 \% \mathrm{Sn} / 5 \%$ Pd soportado en zeolitas ZSM-5 con distinta relación Si/Al (3 g catalizador, $5 \mathrm{~mL} / \mathrm{min}$ agua, $250 \mathrm{~mL} / \mathrm{min}_{2}, 250$ $\left.\mathrm{mL} / \min \mathrm{CO}_{2}\right)$.

\section{Materiales mesoporosos}

Otro material estudiado como soporte del catalizador para la reducción catalítica de nitratos ha sido el material mesoporoso MCM-41. El material MCM-41 se caracteriza por presentar un sistema de poros ordenados de tamaño uniforme entre 15 y $100 \AA$. La estructura de este material se debe a un empaquetamiento hexagonal de sus poros, pues la red inorgánica que constituye las paredes de los canales es amorfa. Esta estructura presenta un patrón de difracción de rayos $X$ muy simple, que se caracteriza por cuatro o 
cinco picos a ángulos muy bajos que pueden ser indexados en un sistema de simetría hexagonal (figura 5.7). Una indicación del carácter amorfo de sus paredes es que no aparecen reflexiones a mayores ángulos de difracción. El material MCM-41, se caracteriza por presentar áreas próximas a $1000 \mathrm{~m}^{2} / \mathrm{g}$, volúmenes de poro mayores de $0,8 \mathrm{~cm}^{3} / \mathrm{g}$ y una distribución de mesoporos muy estrecha.

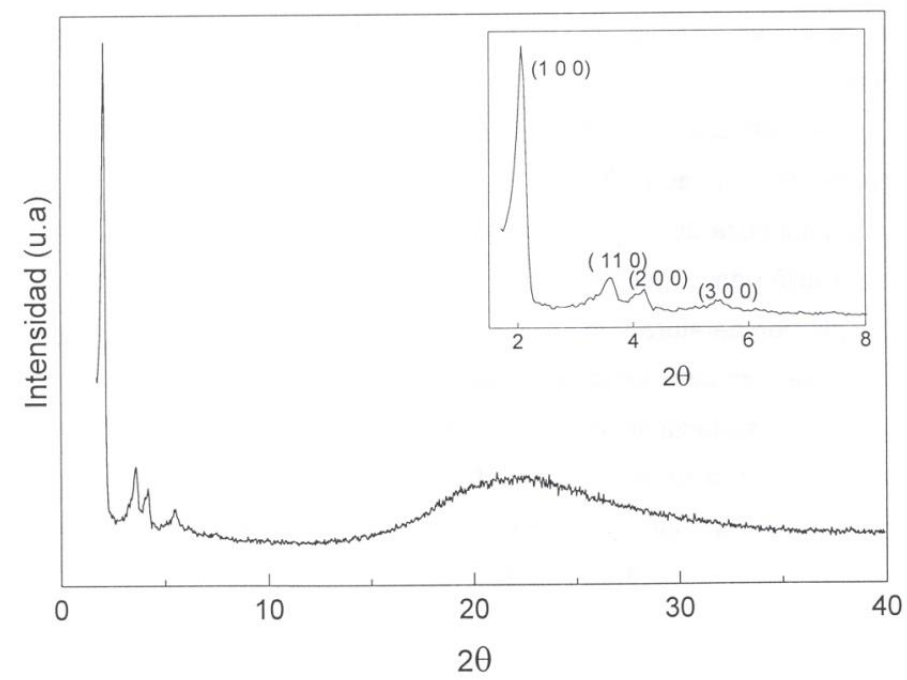

Figura 5. 7. Patrón de difracción del material MCM-41.

Se prepararon dos muestras de este material, una con relación $\mathrm{Si} / \mathrm{Al}=30$ y otra pura sílice. Éstas se impregnaron a volumen de poro con una disolución de Sn y otra de Pd para preparar un catalizador con $2,5 \%$ Sn y $5 \% \mathrm{Pd}$. La tabla 5.2 muestra el área del material MCM-41 original, de la muestra después de impregnar y de la muestra después de reacción. La muestra original presenta una elevada área superficial (superior a $900 \mathrm{~m}^{2} / \mathrm{g}$ ), aunque ésta disminuye después de impregnar con las sales de estaño y paladio, lo que puede deberse a que el material MCM-41 está formado por canales tubulares que durante la impregnación se pueden bloquear, disminuyendo el área superficial de las muestras. Después de reacción, la muestra de relación $\mathrm{Si} / \mathrm{Al}=30$ presenta la misma área superficial lo que indica que durante la reacción no se ha modificado la superficie del catalizador, en cambio, en la muestra pura sílice, disminuye considerablemente el área después de reacción. 
Tabla 5. 2. Área BET del material MCM-41 con distinta relación Si/Al ( $\left.\mathrm{m}^{2} / \mathrm{g}\right)$.

\begin{tabular}{cccc}
\hline $\begin{array}{c}\text { Relación } \\
\text { Si/Al }\end{array}$ & $\begin{array}{c}\text { Muestra } \\
\text { original }\end{array}$ & $\begin{array}{c}\text { Muestra } \\
\text { impregnada }\end{array}$ & $\begin{array}{c}\text { Muestra después } \\
\text { de reacción }\end{array}$ \\
\hline 30 & 964 & 779 & 782 \\
inf & 924 & 746 & 590 \\
\hline
\end{tabular}

En la figura siguiente (figura 5.8) se muestra la conversión obtenida y la selectividad a amonio de los catalizadores Sn/Pd soportados sobre el material MCM-41 con relación $\mathrm{Si} / \mathrm{Al}$ de 30 y pura sílice. Los resultados obtenidos muestran que las conversiones alcanzadas con el catalizador soportado sobre un material mesoporoso son mucho mayores que las alcanzadas con los catalizadores soportados sobre materiales microporosos (figura 5.5). Esto se debe a que al utilizar un material mesoporoso, más accesible, disminuyen los problemas difusionales que presentan los materiales microporosos. Comparando la actividad del material MCM-41 con una relación Si/Al=30 y el material pura sílice se observa cómo la zeolita con menor relación Si/Al presenta mayor actividad que la de mayor relación Si/Al y una selectividad similar en ambas. Esto puede deberse a la mayor estabilidad de la muestra que contiene Al, pues al observar la tabla 5.2 se aprecia claramente que el material MCM-41 pura sílice ha sufrido en el transcurso de la reacción una pérdida del $20 \%$ de su área superficial.

Estos resultados indican que es más adecuado el uso de materiales mesoporosos, con menos problemas difusionales, que el uso de materiales microporosos como soportes para el catalizador de reducción de nitratos. 


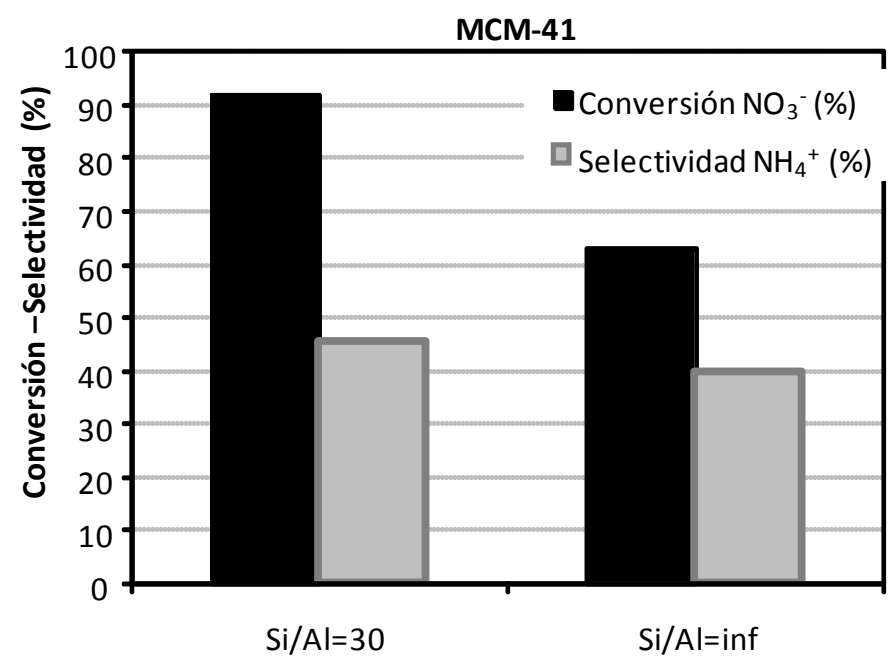

Figura 5. 8. Actividad y selectividad a amonio de los catalizadores $2,5 \% \mathrm{Sn} / 5 \% \mathrm{Pd}$ soportados en el material MCM-41 de relación Si/Al 30 y pura sílice $\left(3 \mathrm{~g}\right.$ catalizador, $5 \mathrm{~mL} / \mathrm{min}$ agua, $250 \mathrm{~mL} / \mathrm{min} \mathrm{H}_{2}$ $250 \mathrm{~mL} / \mathrm{min}\left(\mathrm{CO}_{2}\right)$.

\subsection{3. Óxidos}

El último grupo de soportes estudiados fue el de los óxidos. Los óxidos estudiados así como sus correspondientes áreas BET se muestran en la tabla 5.3.

Tabla 5. 3. Área BET de los óxidos utilizados como soportes en la reducción catalítica de nitratos en aguas naturales.

\begin{tabular}{cc}
\hline Óxido & Área BET $\left(\mathrm{m}^{2} / \mathrm{g}\right)$ \\
\hline $\mathrm{ZrO}_{2}$ & 6 \\
$\mathrm{SnO}$ & 9 \\
$\mathrm{TiO}_{2}$ & 42 \\
$\mathrm{Al}_{2} \mathrm{O}_{3}$ & 125 \\
$\mathrm{SiO}_{2}$ & 456 \\
\hline
\end{tabular}


Estos óxidos se utilizaron como soporte para el catalizador $2,5 \% \mathrm{Sn} / 5 \% \mathrm{Pd}$ y los resultados obtenidos tras 4 horas de reacción con agua natural y usando un reactor en continuo se muestran en la figura 5.9. En esta figura se observa cómo la conversión de nitratos más baja se obtiene con el catalizador soportado sobre $\mathrm{SnO}$, siendo ésta de alrededor del $10 \%$. Los catalizadores soportados sobre los óxidos de zirconio y silicio presentan conversiones algo mayores, entre el 40 y el 55\%, respectivamente. Los mejores resultados se obtienen con los catalizadores soportados sobre $\mathrm{TiO}_{2}$ y $\mathrm{Al}_{2} \mathrm{O}_{3}$, obteniendo una conversión del 90 y 100\%, respectivamente.

Los resultados obtenidos con el catalizador soportado sobre $\mathrm{SiO}_{2}$ coinciden con los obtenidos en [25] utilizando un catalizador de Sn-Pd, pero difieren de los obtenidos por Yoshinaga y col. [26], quienes obtuvieron conversiones muy elevadas con este soporte pero con un catalizador de $\mathrm{Pd}-\mathrm{Cu}$. En dicho estudio se comparó la actividad de un catalizador $\mathrm{Pd}-\mathrm{Cu}$ soportado sobre $\mathrm{SiO}_{2}, \mathrm{TiO}_{2}$ y $\mathrm{Al}_{2} \mathrm{O}_{3}$ observando que la máxima conversión se obtenía con el catalizador soportado sobre $\mathrm{SiO}_{2}$ y la menor se obtenía con el catalizador soportado sobre $\mathrm{Al}_{2} \mathrm{O}_{3}$. Estos resultados difieren a los obtenidos en esta tesis, lo que podría deberse a la distinta interacción entre el $\mathrm{Cu}$ y el $\mathrm{Sn}$ con los soportes estudiados o al uso de aguas naturales. Gavagnin y col. [27] también estudiaron la influencia del soporte en un catalizador Cu-Pd comparando la actividad de un catalizador soportado en $\mathrm{ZrO}_{2}$ con la de uno soportado en $\mathrm{SnO}_{2}$. Los resultados obtenidos con el $\mathrm{ZrO}_{2}$ mostraron que, igual como hemos observado en este trabajo, con este soporte se obtiene una mayor actividad que la obtenida al usar $\mathrm{SnO}_{2}$ como soporte, pero también es más selectivo a la formación de amonio. En cuanto al uso de catalizadores soportados sobre $\mathrm{TiO}_{2}$, los resultados obtenidos al usar agua destilada con nitratos y reactores discontinuos coinciden con los obtenidos en esta tesis. Así, Gao y col. [1] obtuvieron altas actividades y bajas selectividades a nitrógeno (inferior al 40\%) para el catalizador $\mathrm{Pd}-\mathrm{Cu} / \mathrm{TiO}_{2}$, lo mismo que Sá y col. $[28,29]$ quienes indicaban que al usar un catalizador de $\mathrm{Pd} / \mathrm{TiO}_{2}$ el soporte promueve la eliminación de nitratos por la reducción parcial de las especies de titanio, pero obteniendo selectividades a amonio mucho mayores que las obtenidas al usar alúmina como soporte. 
Los resultados obtenidos indicarían que el $\mathrm{TiO}_{2}$ o el $\mathrm{Al}_{2} \mathrm{O}_{3}$ son los mejores soportes catalíticos (figura 5.9), pero al comparar la selectividad a amonio obtenida con ambos catalizadores, se observa que al utilizar $\mathrm{TiO}_{2}$ como soporte, la selectividad a amonio es muy elevada, llegando a alcanzar el 90\%. Esto podría deberse a que la interacción entre el metal y el soporte favorece la reacción de formación de amonio o a que el soporte actúa como fase activa en la reacción favoreciendo la reducción del nitrito a amonio [28, 29]. Por ello, se podría considerar que el mejor óxido que se puede utilizar como soporte en este tipo de reacciones es la alúmina, que, aunque presenta menor actividad que el óxido de titanio, su selectividad a amonio es inferior a la de éste.

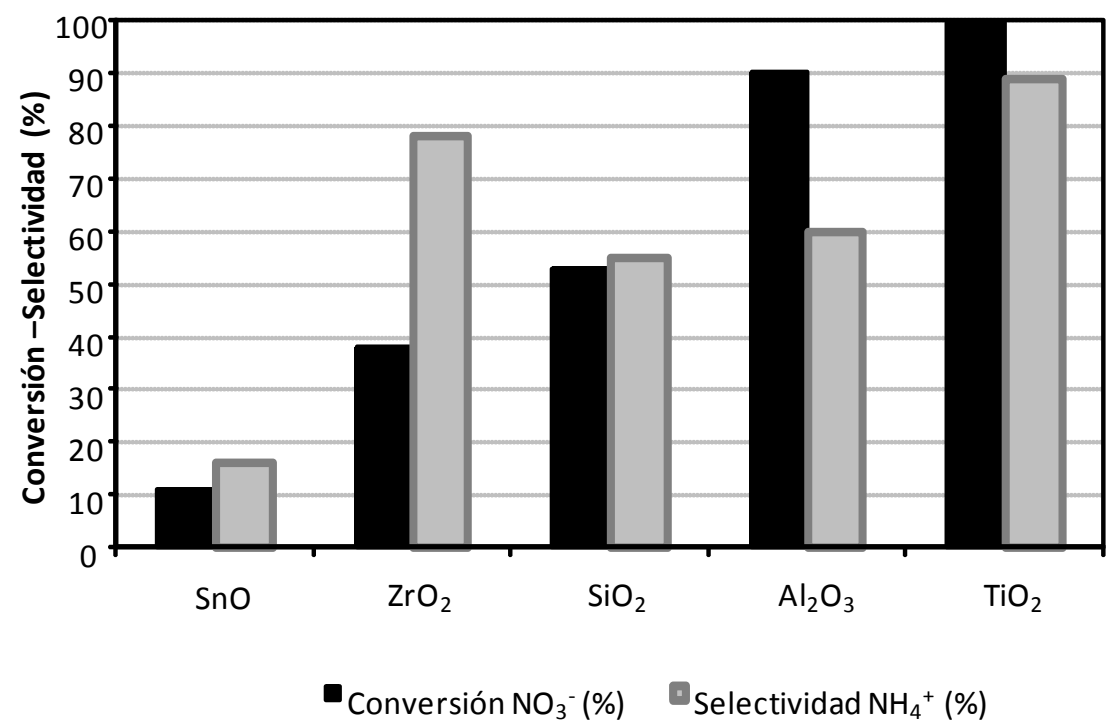

Figura 5. 9. Actividad y la selectividad a amonio del catalizador $2,5 \% \mathrm{Sn} / 5 \% \mathrm{Pd}$ soportado sobre diferentes óxidos (3 g catalizador, $5 \mathrm{~mL} / \mathrm{min}$ agua, $250 \mathrm{~mL} / \mathrm{min}_{2}$, $250 \mathrm{~mL} / \mathrm{min}\left(\mathrm{O}_{2}\right)$.

Cabe resaltar que los resultados obtenidos en nuestro estudio, muestran que la actividad del catalizador utilizado en la reducción catalítica de nitratos en aguas naturales depende en gran medida del óxido utilizado como soporte, pero no depende directamente del área específica del soporte utilizado. Así, comparando los resultados de la tabla 5.3 y los resultados de la figura 5.9 se observa que aunque los soportes con áreas 
superficiales muy bajas presentan menor actividad, el catalizador con la mayor área suerficial no es el más activo, obteniéndose las máximas conversiones con los catalizadores soportados sobre $\mathrm{TiO}_{2}$ y $\mathrm{Al}_{2} \mathrm{O}_{3}$ que poseen un área superficial intermedia.

Con el fin de determinar claramente la posible influencia del área específica del catalizador en su actividad, se preparó en el laboratorio una alúmina de alta superficie, según el procedimiento descrito en el apartado 3.2.3, la cual presentaba un área de 355 $\mathrm{m}^{2} / \mathrm{g}$ frente a los $139 \mathrm{~m}^{2} / \mathrm{g}$ que mostraba la alúmina comercial. Los resultados obtenidos se muestran en la figura 5.10 donde se puede apreciar que sólo hay una pequeña diferencia en la conversión de nitratos obtenida para los dos catalizadores. En las primeras horas de reacción, se obtienen los mejores resultados para el catalizador soportado sobre alúmina de elevada superficie, sin embargo, después de 8 horas de reacción, la conversión obtenida para ambos catalizadores es prácticamente la misma. En cuanto a la selectividad a amonio, tampoco existen diferencias importantes entre ambos soportes, siendo ésta de alrededor del $60 \%$. Estos resultados indican que cuando se trabaja con óxidos como soportes catalíticos, aunque un mínimo de área superficial es necesaria (los óxidos con baja área presentaban una muy baja actividad), una vez superado éste, el área del catalizador no es un factor determinante en la actividad del catalizador.

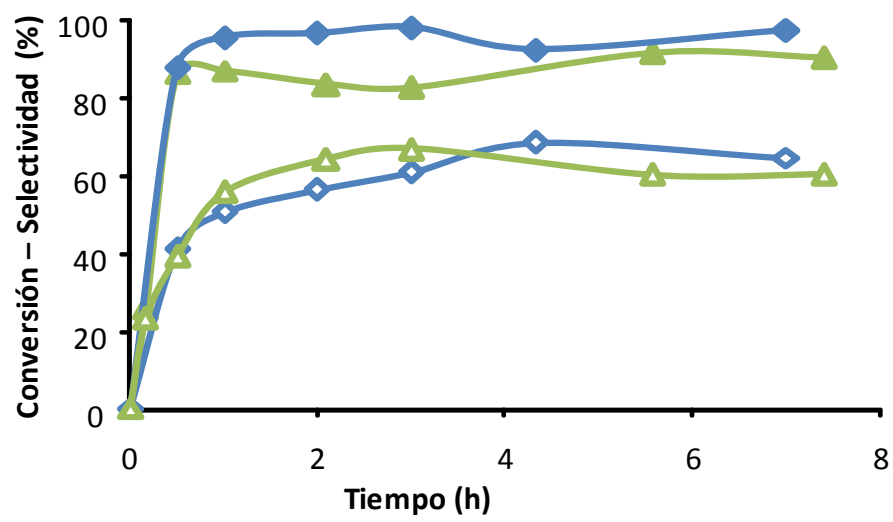

Figura 5. 10. Actividad para los catalizadores de 2,5\%Sn y 5\%Pd soportados en alúmina con diferente área superficial: ( $(\nabla)$ conversión y $(\diamond)$ selectividad a amonio del catalizador con $355 \mathrm{~m}^{2} / \mathrm{g} ;(\Delta)$ conversión y $(\triangle)$ selectividad a amonio del catalizador con $139 \mathrm{~m}^{2} / \mathrm{g}(3 \mathrm{~g}$ catalizador, $5 \mathrm{~mL} / \mathrm{min}$ agua, $250 \mathrm{~mL} / \mathrm{min} \mathrm{H}_{2}, 250 \mathrm{~mL} / \mathrm{min} \mathrm{CO}_{2}$ ). 


\subsubsection{Comparación de los distintos soportes}

De la comparación de los mejores resultados obtenidos en los apartados anteriores se obtiene la figura 5.11, donde se presenta la máxima conversión y la selectividad a amonio obtenidas al utilizar como soportes un carbón activo (el carbón Norit GAC 1240W), un material microporoso (la zeolita ZSM-5), un material mesoporoso (MCM-41) y un óxido (la alúmina), todos impregnados con $2,5 \% \mathrm{Sn}$ y $5 \% \mathrm{Pd}$.

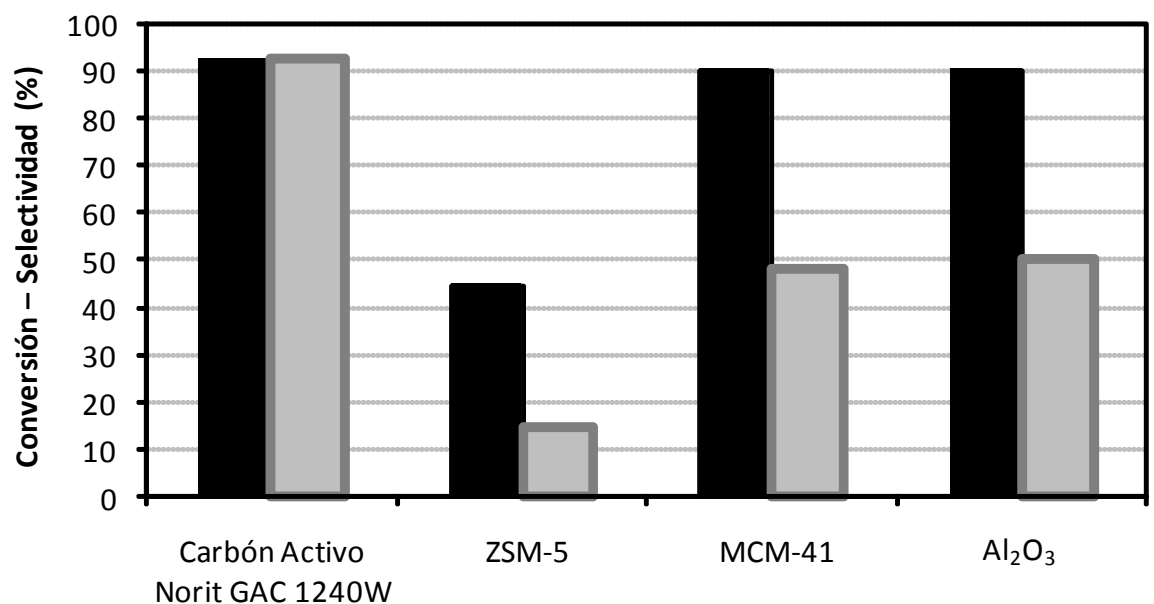

Conversión $\mathrm{NO}_{3}{ }^{-}(\%) \quad$ Selectividad $\mathrm{NH}_{4}{ }^{+}(\%)$

Figura 5. 11. Conversión y selectividad a amonio a las 4 horas de reacción de los catalizadores Sn-Pd soportados con distintos tipos de materiales $\left(3 \mathrm{~g}\right.$ catalizador, $5 \mathrm{~mL} / \mathrm{min}$ agua, $250 \mathrm{~mL} / \mathrm{min} \mathrm{H}_{2}$, $\left.250 \mathrm{~mL} / \mathrm{min} \mathrm{CO}_{2}\right)$.

Tal como se observa en la figura anterior, los peores resultados se obtienen al utilizar el material microporoso como soporte, lo que se debe a que en este material los centros activos son menos accesibles, aumentando los problemas difusionales, por lo que disminuye la actividad. Por otra parte, al usar como soportes materiales más accesibles como un carbón activo, un material mesoporoso o un óxido, las conversiones alcanzadas son mucho mayores. Lo que difiere bastante entre ellos es la selectividad a amonio obtenida en cada caso. Así, con el catalizador soportado sobre carbón, la selectividad es bastante superior a la obtenida con los otros dos soportes, esto puede deberse, tal como se ha descrito en el apartado 5.2.1, a la elevada conductividad eléctrica del mismo, que 
facilita la adsorción del hidrógeno y la sobrerreducción de los nitratos. Los mejores resultados, tanto de selectividad como de conversión, se han obtenido con el material mesoporoso MCM-41 y la alúmina ya que ambos poseen una baja conductividad eléctrica, no presentan microporos y tiene una adecuada área específica. Sin embargo, en este estudio se ha preferido el uso de la alúmina como soporte por su menor valor económico y por su mayor disponibilidad.

\subsection{Estudio de la relación (Cu o Sn)/Pd}

Una vez determinados el par metálico y el soporte más adecuados para la reducción catalítica de nitratos en aguas naturales trabajando en continuo, se ha realizado un estudio de cómo afecta la modificación de la relación metal noble/metal no noble en la actividad del catalizador. Para ello se prepararon distintos catalizadores soportados sobre $\gamma-\mathrm{Al}_{2} \mathrm{O}_{3}$ con distintas relaciones ( $\mathrm{Cu}$ o $\mathrm{Sn}$ )/Pd y se estudió su actividad en esta reacción.

Los resultados obtenidos al modificar las cantidades relativas de $\mathrm{Cu}$ y $\mathrm{Pd}$ se muestran en las figuras 5.12 y 5.13 .

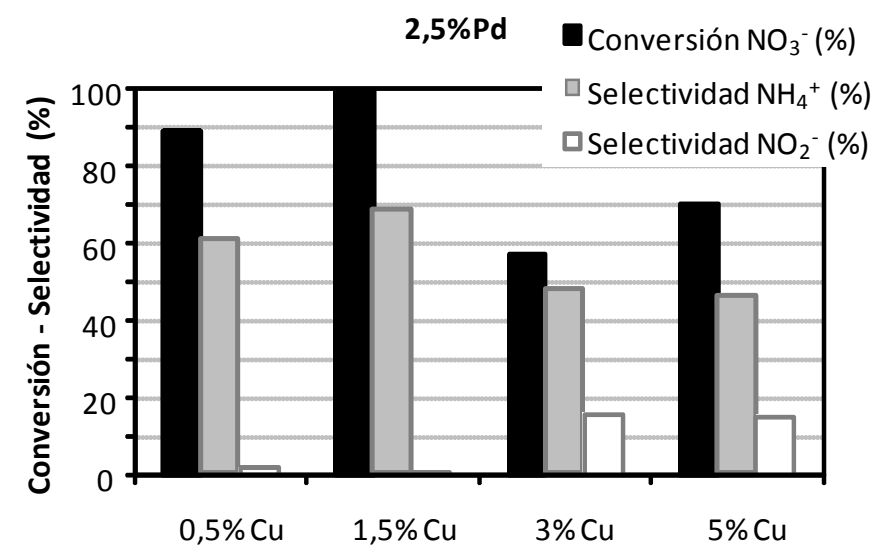

Figura 5. 12. Actividad y selectividad tras 4 horas de reacción de catalizadores $C u-P d$ con $2,5 \%$ Pd y cantidades variables de Cu (porcentaje de metal en masa, $3 \mathrm{~g}$ de catalizador, $5 \mathrm{~mL} / \mathrm{min}$ agua, 250 $\mathrm{mL} / \mathrm{min} \mathrm{H}_{2}, 250 \mathrm{~mL} / \mathrm{min} \mathrm{CO}_{2}$ ). 
En la figura 5.12 se observa la conversión de nitratos, la selectividad a amonio y la selectividad a nitrito de los catalizadores al mantener constante la cantidad de Pd y variar el porcentaje de $\mathrm{Cu}$ entre 0,5 y $5 \%$. De esta figura se desprende que la actividad de los catalizadores $\mathrm{Cu}-\mathrm{Pd}$ es mayor cuando la cantidad de Pd es superior a la de $\mathrm{Cu}$. Por el contrario, cuando la cantidad de $\mathrm{Cu}$ es mayor que la cantidad de Pd, la actividad del catalizador disminuye considerablemente. La selectividad a amonio es, en todos los casos, superior al 40\%, siendo mayor cuanta más conversión presenta el catalizador. Por el contrario, la selectividad a nitrito es mayor cuanto menor es la conversión obtenida con el catalizador.

En la figura 5.13 se muestra la variación de la actividad y la selectividad de los catalizadores Cu-Pd al mantener constante la cantidad de Cu y modificar la cantidad de Pd. Tal como se observa en dicha gráfica, y como ocurría en el caso anterior, la máxima actividad se obtiene cuando el contenido en Pd supera el de $\mathrm{Cu}$, obteniendo el valor máximo para el catalizador con una relación $\mathrm{Pd} / \mathrm{Cu}=1,7$. No obstante, cuando la relación $\mathrm{Pd} / \mathrm{Cu}$ es muy elevada, la actividad del catalizador disminuye, hecho que también se observaba en la figura 5.12.

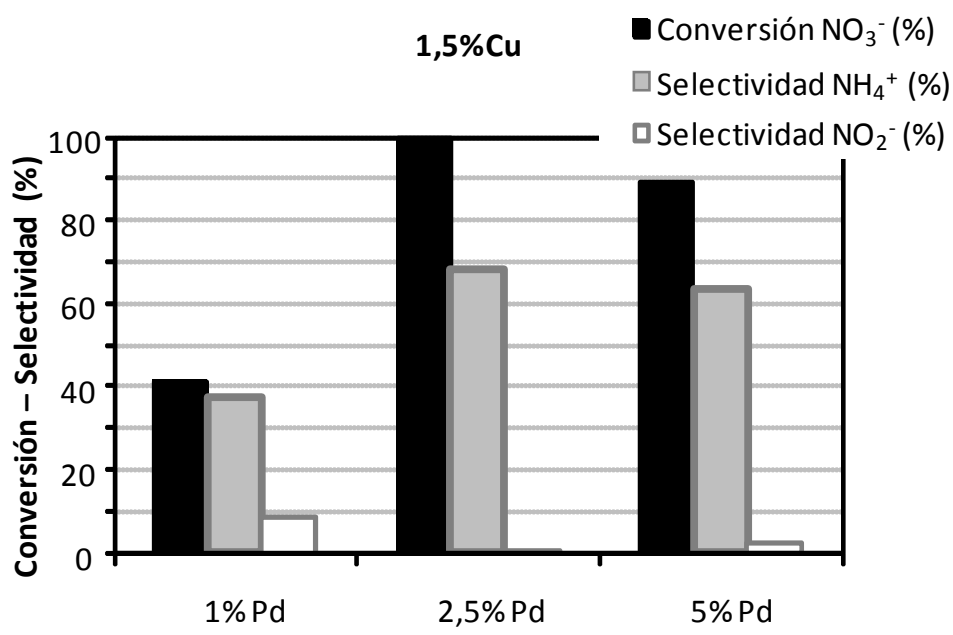

Figura 5. 13. Actividad y selectividad tras 4 horas de reacción de catalizadores Cu-Pd con 1,5\%Cu y cantidades variables de Pd (porcentaje de metal en masa, $3 \mathrm{~g}$ de catalizador, $5 \mathrm{~mL} / \mathrm{min}$ agua, 250 $\mathrm{mL} / \mathrm{min} \mathrm{H}_{2}, 250 \mathrm{~mL} / \mathrm{min} \mathrm{CO}_{2}$ ). 
Un estudio similar al realizado con los catalizadores $\mathrm{Cu}-\mathrm{Pd}$ se hizo con los catalizadores Sn-Pd y, tal como se observa en las figuras 5.14 y 5.15, los resultados obtenidos se correlacionan con los obtenidos con los catalizadores Pd-Cu. En la figura 5.14 se muestra la conversión de nitrato y las selectividades a amonio y nitrito de los catalizadores preparados con un $5 \%$ en peso de Pd y cantidades variables de Sn (entre 0 y $10 \%$ en peso). En dicha figura se aprecia que la actividad del catalizador es máxima para relaciones $\mathrm{Pd} / \mathrm{Sn}$ comprendidas entre 2 y 3,3. Para contenidos en $\mathrm{Sn}$ superiores o inferiores, la actividad del catalizador disminuye de forma considerable. La selectividad a amonio se sitúa alrededor del 40\% para los catalizadores que tienen la máxima conversión y disminuye al disminuir la conversión obtenida. En cuanto a la selectividad a nitrito, tal como ocurría con los catalizadores Cu-Pd, se observa como ésta es mayor cuanto menor es la conversión de nitrato, llegando a alcanzar el $20 \%$ para las muestras sin Sn o con un $1 \%$ en peso, y un $45 \%$ para contenidos en Sn del $10 \%$.

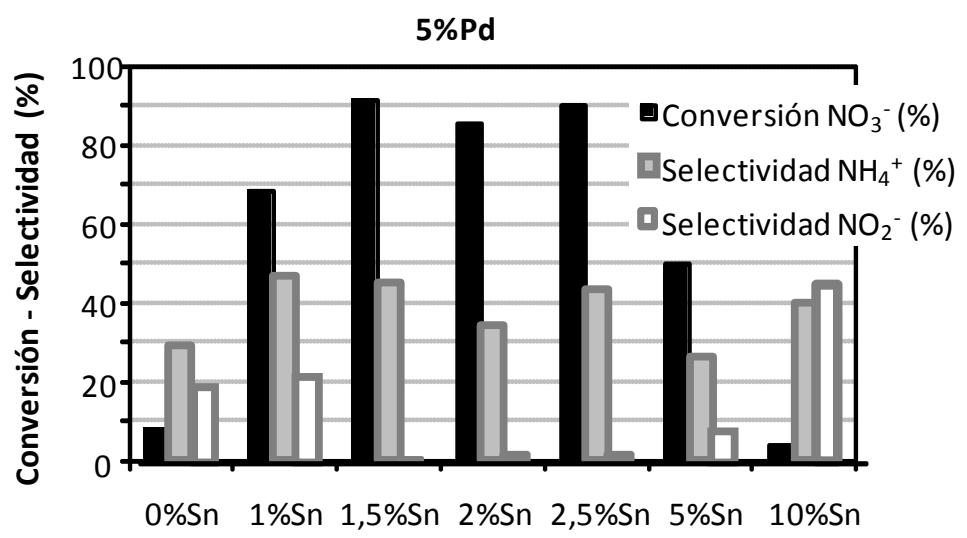

Figura 5. 14. Actividad y selectividad a las 4 horas de reacción de catalizadores Sn-Pd con 5\%Pd y cantidades variables de Sn (porcentaje de metal en masa, $3 \mathrm{~g}$ de catalizador, $5 \mathrm{~mL} / \mathrm{min}$ agua, 250 $\left.\mathrm{mL} / \mathrm{min} \mathrm{H}_{2}, 250 \mathrm{~mL} / \mathrm{min} \mathrm{CO}_{2}\right)$.

Los resultados obtenidos al realizar los experimentos con catalizadores que poseen la misma cantidad de Sn (1\% en peso) pero cantidad variable de Pd (figura 5.15) muestran resultados similares. Así, se observa que la conversión de nitratos aumenta al aumentar la 
relación $\mathrm{Pd} / \mathrm{Sn}$, hasta llegar a un máximo a partir del cual la actividad disminuye. La máxima actividad corresponde al catalizador formado por un $1 \%$ de $\mathrm{Sn}$ y un $2,5 \%$ de Pd, es decir, para una relación $\mathrm{Pd} / \mathrm{Sn}=2,5$, como también ocurría con los catalizadores $\mathrm{Cu}$-Pd. Por último cabe destacar que, tal como se observa en las figura 5.13 y 5.14, en ausencia de $\mathrm{Sn}$ o de $\mathrm{Pd}$, el catalizador es prácticamente inactivo para la reducción de nitratos.

Por tanto, de este estudio se concluye que el catalizador más adecuado es aquél que presenta una relación metal noble/metal no noble entre 2 y 4 . Si la relación es inferior a 1 o superior a 5 la actividad del catalizador disminuye drásticamente. Consideraciones económicas, aconsejarían trabajar en la menor relación metal noble/metal no noble posible, por eso se escoge la relación metal noble/metal no noble de 2 como la más adecuada.

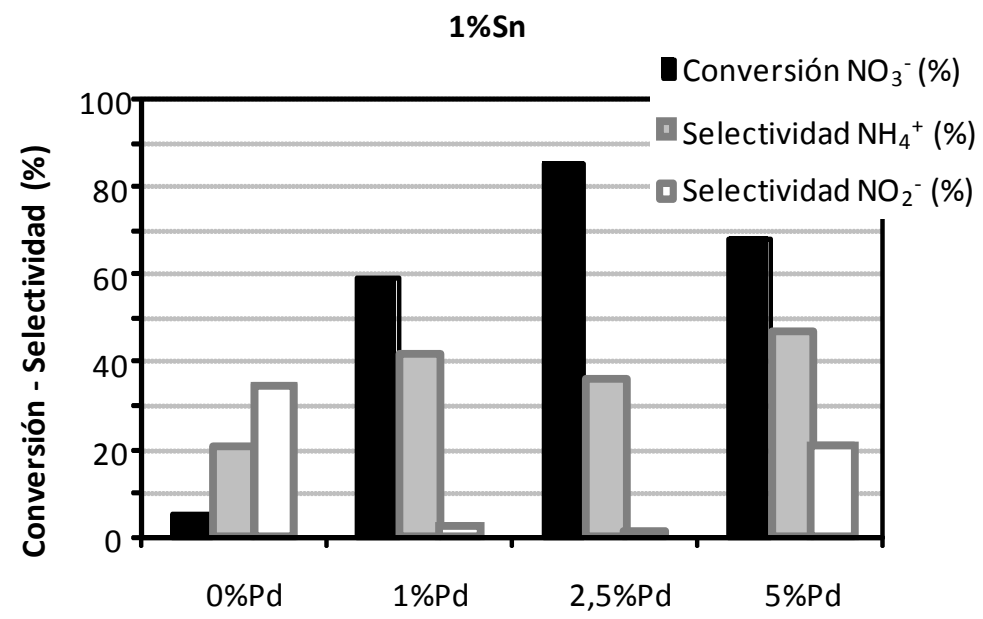

Figura 5. 15. Actividad y selectividad a las 4 horas de reacción de los catalizadores Sn-Pd con $1 \%$ Sn y cantidades variables de Pd (porcentaje de metal en masa, $3 \mathrm{~g}$ de catalizador, $5 \mathrm{~mL} / \mathrm{min}$ agua, 250 $\mathrm{mL} / \mathrm{min} \mathrm{H}_{2}, 250 \mathrm{~mL} / \mathrm{min} \mathrm{CO}_{2}$ ).

\subsection{Comparación entre el catalizador Sn/Pd y el catalizador Cu/Pd}

En el apartado anterior se ha determinado que los mejores resultados se obtienen con un catalizador $(\mathrm{Cu}$ o $\mathrm{Sn}) / \mathrm{Pd}$ soportado sobre alúmina con una relación metal 
noble/metal no noble de 2 . En este apartado se va a comparar más detalladamente la actividad de ambos catalizadores en la reacción de reducción de nitratos en aguas naturales empleando un reactor continuo. Para ello se han preparado dos catalizadores con $2,5 \% \mathrm{Cu} / 5 \% \mathrm{Pd}$ y $2,5 \% \mathrm{Sn} / 5 \% \mathrm{Pd}$ soportados sobre $\gamma-\mathrm{Al}_{2} \mathrm{O}_{3}$. Los resultados obtenidos (figura 5.16) muestran que la actividad de ambos es similar, obteniéndose en ambos casos una conversión constante a partir de la primera hora de reacción cercana al $90 \%$. En cambio, al observar la variación de la selectividad a amonio para ambos catalizadores (figura 5.17) se puede ver que la selectividad a amonio del catalizador de Pd-Sn es inferior a la obtenida con el catalizador de Pd-Cu, es decir, el catalizador de Pd-Sn muestra una mayor selectividad a nitrógeno. Resultados similares se habían obtenido ya en el apartado anterior al estudiar la relación metal noble/metal no noble (figuras 5.12 a 5.14). En dichas figuras se aprecia claramente que en la mayoría de los casos, los catalizadores de Sn/Pd presentan una menor selectividad a amonio que los catalizadores Cu-Pd.

Estos resultados clarifican lo descrito en bibliografía para reacciones en discontinuo y con agua destilada conteniendo nitratos, donde unos autores afirman que el catalizador óptimo es el de Cu-Pd [1], mientras que otros proponen que el mejor, tanto en actividad como en selectividad, es el de $\mathrm{Sn}-\mathrm{Pd}[3,13,14]$. Así, se puede afirmar que trabajando en continuo y con aguas naturales, aunque la conversión obtenida es muy similar en ambos catalizadores, los mejores resultados obtenidos de selectividad a nitrógeno conseguidos con el catalizador Sn-Pd justifican su elección como el catalizador más adecuado para esta reacción en nuestras condiciones de trabajo. 


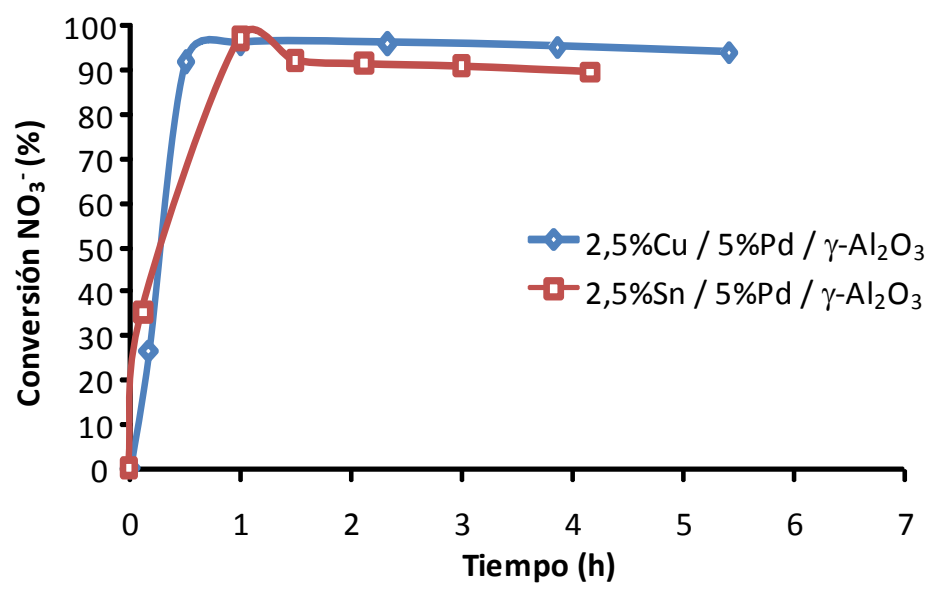

Figura 5. 16. Comparación de la actividad de los catalizadores $2,5 \% \mathrm{Cu} / 5 \% \mathrm{Pd} / \mathrm{Al}_{2} \mathrm{O}_{3}$ y 2,5\% Sn/5\% Pd/Al $\mathrm{O}_{3}$ (3 g catalizador, $5 \mathrm{~mL} / \mathrm{min}$ agua, $250 \mathrm{~mL} / \mathrm{min} \mathrm{H}_{2}, 250 \mathrm{~mL} / \mathrm{min} \mathrm{CO}_{2}$ ).

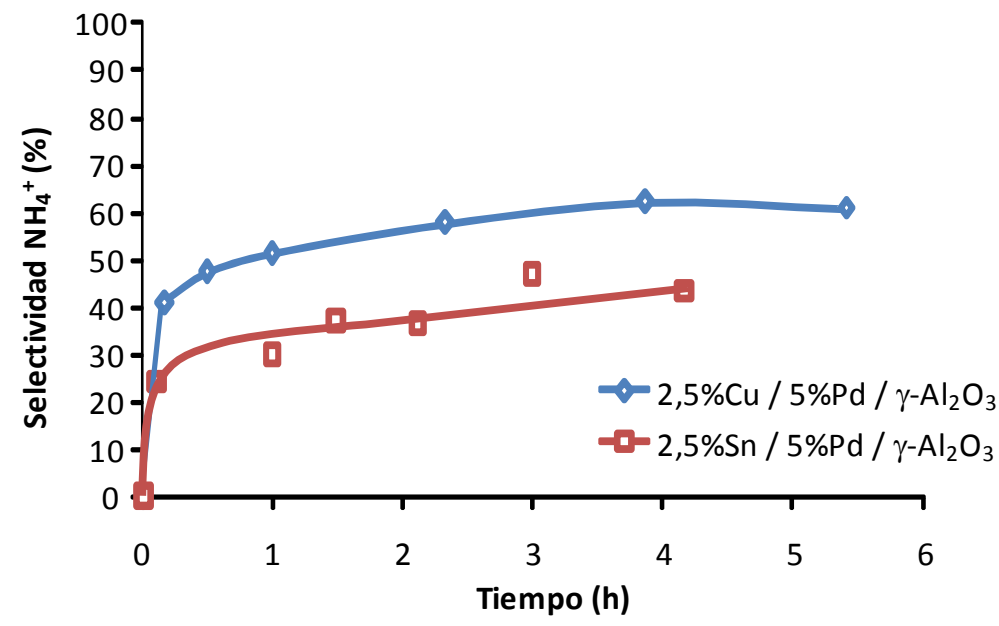

Figura 5. 17. Comparación de la selectividad a amonio de los catalizadores $2,5 \% \mathrm{Cu} / 5 \% \mathrm{Pd} / \mathrm{Al}_{2} \mathrm{O}_{3}$ y 2,5\% $\mathrm{Sn} / 5 \% \mathrm{Pd} / \mathrm{Al}_{2} \mathrm{O}_{3}$ (3 g catalizador, $5 \mathrm{~mL} / \mathrm{min}$ agua, $250 \mathrm{~mL} / \mathrm{min} \mathrm{H}_{2}, 250 \mathrm{~mL} / \mathrm{min} \mathrm{CO}_{2}$ ). 


\subsection{Preparación del catalizador}

Una vez establecido que el catalizador óptimo es el catalizador Sn-Pd soportado sobre $\mathrm{Al}_{2} \mathrm{O}_{3}$ con una relación $\mathrm{Pd} / \mathrm{Sn}=2$ se procedió a optimizar el método de preparación del mismo. Para ello se estudiaron distintas técnicas para soportar el metal en la superficie del catalizador, se estudió el uso de diferentes precursores de paladio y estaño y se estudió la influencia del tratamiento térmico del catalizador en su actividad final. Estas variables se estudiaron con el catalizador de $2,5 \%$ Sn y $5 \% \mathrm{Pd}$ soportado en alúmina.

\subsubsection{Incorporación del metal}

Con el fin de determinar la influencia de la forma de incorporar el metal al catalizador en su actividad, se prepararon varios catalizadores con la misma composición preparados por dos procedimientos distintos y modificando el orden de incorporar el metal al soporte catalítico. Así, se preparó un catalizador $\mathrm{Sn} / \mathrm{Pd}$ mediante impregnación a volumen de poro y otro por impregnación húmeda. En ambos casos se impregnó primero la sal de Pd y después la sal de Sn. Tal como se observa en la figura 5.18 los resultados obtenidos con ambas preparaciones son prácticamente los mismos indicando que en ambos casos la distribución de metales sobre la superficie del catalizador es similar.

Por otro lado, se estudió también la influencia del orden en que se impregnan las sales en la actividad final del catalizador. Por ello, se prepararon por impregnación a volumen de poro tres catalizadores con la misma composición, pero en uno se impregnó primero la sal de Sn, se calcinó y luego se impregnó la sal de Pd; en otro se impregnó primero la sal de Pd, se calcinó y luego se impregnó la sal de Sn; y en un tercero se impregnaron ambas sales a la vez (coimpregnación).

Los resultados que se muestran en la figura 5.18 indican que la actividad del catalizador varía mucho en función del orden en que se incorporen las sales precursoras. Así, si se incorpora primero la sal de Sn, se calcina y luego se añade la sal de Pd o se añaden ambas al mismo tiempo, se obtienen mucho mejores resultados que si se incorpora primero la sal de Pd, se calcina y luego se añade la sal de Sn. En los dos primeros 
casos se obtiene un $90 \%$ de conversión durante al menos 8 horas de reacción, mientras que en el otro caso se obtiene una conversión menor.

Por tanto, se puede concluir que aunque la forma de incorporar el metal al soporte no es tan importante, sí lo es el orden de impregnación de las sales metálicas, siendo más adecuado impregnar primero el $\mathrm{Sn}$ y luego el $\mathrm{Pd}$ o coimpregnarlos al mismo tiempo.

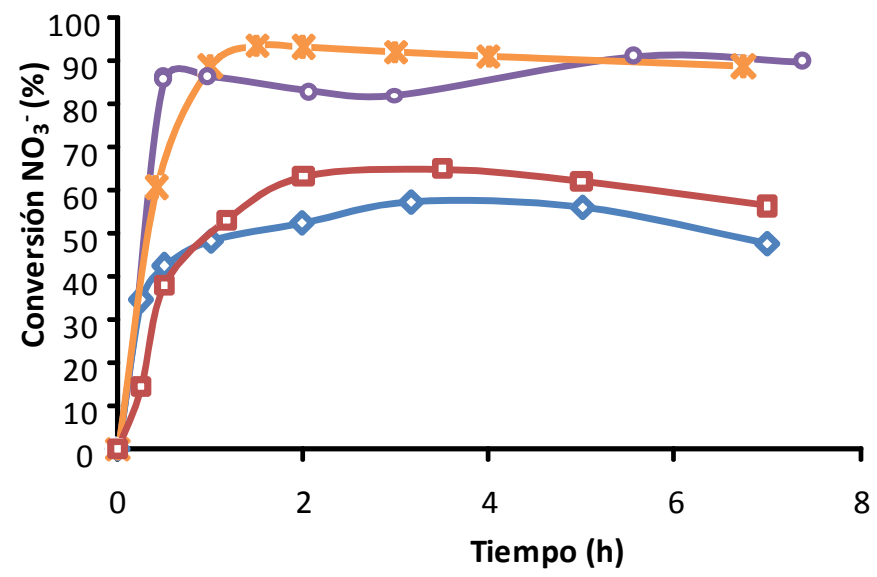

\footnotetext{
- Volumen de poro. Primero Pd y luego Sn

- Impregnación húmeda. Primero Pd y luego Sn

- Volumen de poro. Primero Sn y luego Pd

-Volumen de poro. Coimpregnación
}

Figura 5. 18. Actividad del catalizador $2,5 \% \mathrm{Sn} / 5 \% \mathrm{Pd} / \mathrm{Al}_{2} \mathrm{O}_{3}$ al depositar los metales de distinta forma sobre el soporte ( 3 g catalizador, $5 \mathrm{~mL} / \mathrm{min}$ agua, $250 \mathrm{~mL} / \mathrm{min}_{2}, 250 \mathrm{~mL} / \mathrm{min} \mathrm{CO}_{2}$ ).

\subsubsection{Tipo de sal precursora}

Se estudió también la influencia del tipo de sal precursora en la actividad del catalizador, para ello se prepararon dos catalizadores con la misma composición pero utilizando distintos precursores de paladio y estaño. Los precursores de paladio utilizados fueron $\mathrm{Pd}\left(\mathrm{NO}_{3}\right)_{2} \cdot 2 \mathrm{H}_{2} \mathrm{O}$ y $\mathrm{PdCl}_{2}$, mientras que para impregnar el estaño, se utilizaron las sales de $\mathrm{SnCl}_{4} \cdot 5 \mathrm{H}_{2} \mathrm{O}$ y $\mathrm{SnCl}_{2}$, obteniéndose los resultados que se muestran en la figura 5.19. En esta figura se observa que no hay importantes diferencias en los resultados catalíticos según se use una sal precursora u otra, obteniendo quizás unos resultados un 
poco mejores en cuanto a conversión al usar sales cloradas, aunque estas diferencias no son significativas.

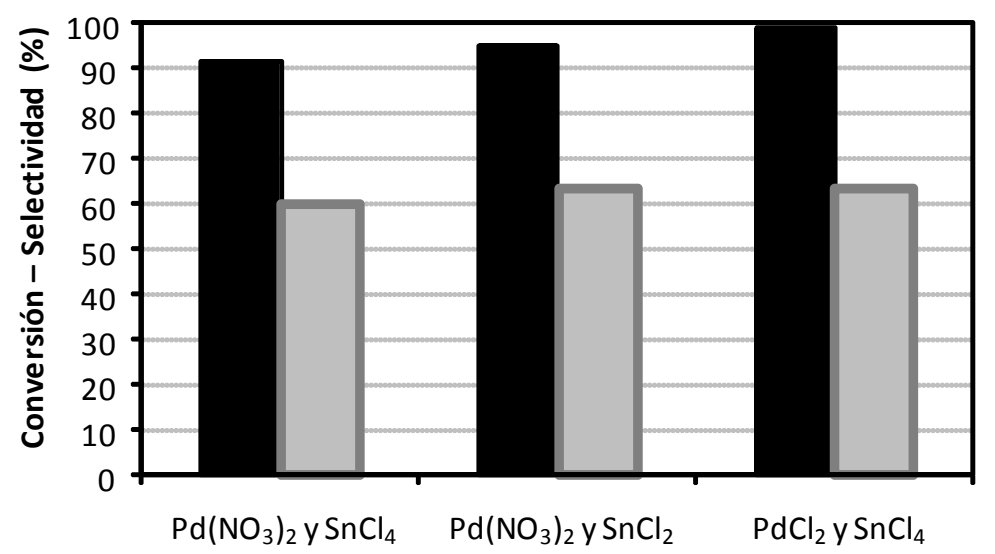

- Conversión $\mathrm{NO}_{3}{ }^{-}(\%)$ Selectividad $\mathrm{NH}_{4}{ }^{+}$(\%)

Figura 5. 19. Actividad y selectividad a amonio del catalizador $2,5 \% \mathrm{Sn} / 5 \% \mathrm{Pd} / \mathrm{Al}_{2} \mathrm{O}_{3}$ al utilizar precursores distintos de paladio y estaño $\left(3 \mathrm{~g}\right.$ catalizador, $5 \mathrm{~mL} / \mathrm{min}$ agua, $250 \mathrm{~mL} / \mathrm{min}_{2}, 250$ $\left.\mathrm{mL} / \mathrm{min} \mathrm{CO}_{2}\right)$.

\subsubsection{Tratamiento térmico}

Por último se estudió la influencia del tratamiento térmico en la actividad final del catalizador. Para ello se prepararon diversos catalizadores con la misma composición pero se variaron los tratamientos térmicos para su preparación y su activación. Los dos tratamientos térmicos estudiados para descomponer las sales metálicas impregnadas sobre el soporte aparecen esquematizados en las figuras 5.20 y 5.21 . La principal diferencia entre ambas es el tiempo total de calcinación y la temperatura final alcanzada. 


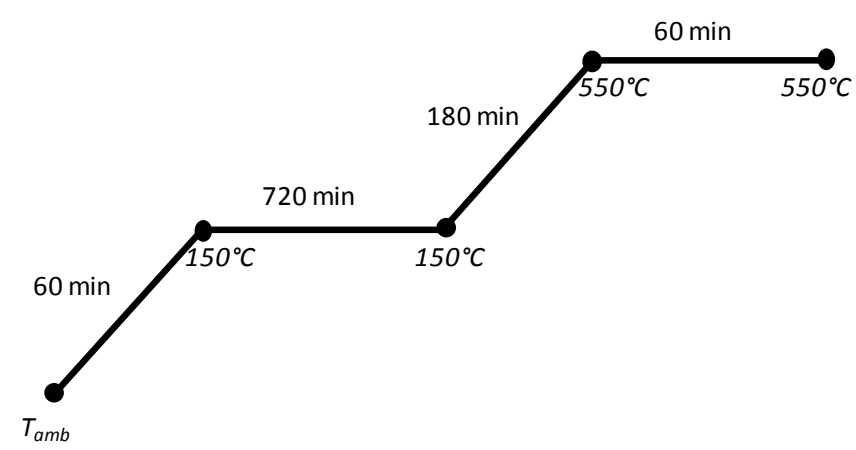

Figura 5. 20. Esquema del tratamiento térmico (I) de los catalizadores impregnados a volumen de poro.

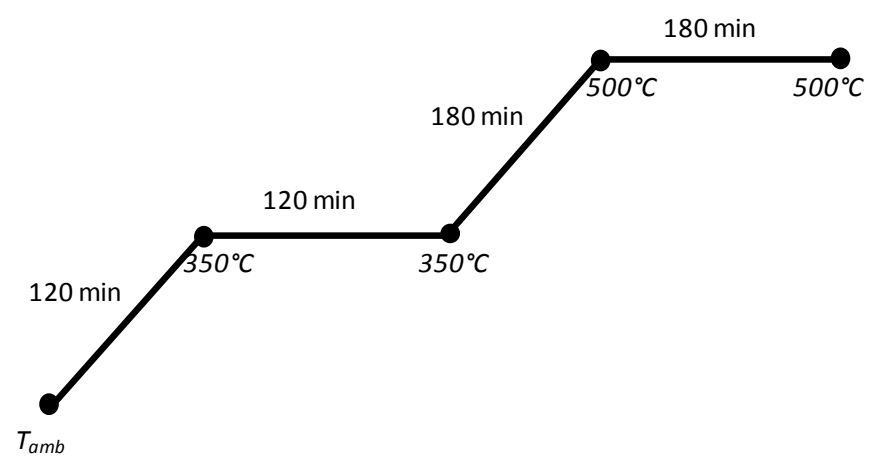

Figura 5. 21. Esquema del tratamiento térmico (II) de los catalizadores impregnados a volumen de poro.

En la figura 5.22 se muestra la conversión de nitratos y la selectividad a amonio obtenidas al calcinar el catalizador $2,5 \% \mathrm{Sn} / 5 \% \mathrm{Pd} / \gamma-\mathrm{Al}_{2} \mathrm{O}_{3}$ utilizando ambos tratamientos térmicos. En estas gráficas se observa cómo la actividad y la selectividad del catalizador no varían prácticamente al calcinar el catalizador de una u otra forma, por lo que, mientras se alcancen los $500^{\circ} \mathrm{C}$ para que se descompongan totalmente las sales impregnadas, los resultados obtenidos serán similares. 


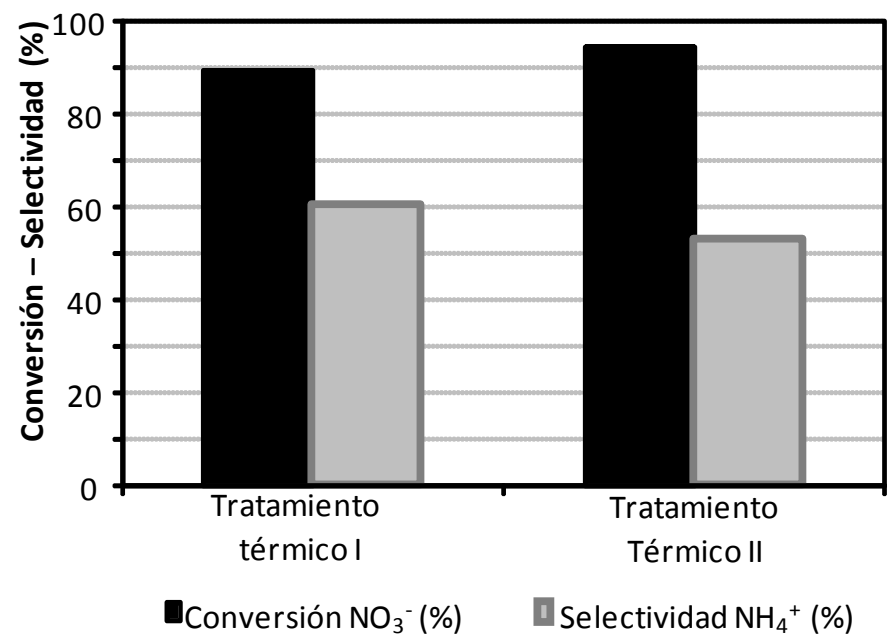

Figura 5. 22. Actividad del catalizador $2,5 \% \mathrm{Sn} / 5 \% \mathrm{Pd} / \gamma-\mathrm{Al}_{2} \mathrm{O}_{3}$ calcinado según el tratamiento térmico I o según el tratamiento térmico II (3 g catalizador, $5 \mathrm{~mL} / \mathrm{min}$ agua, $250 \mathrm{~mL} / \mathrm{min} \mathrm{H}_{2}, 250 \mathrm{~mL} / \mathrm{min} \mathrm{CO}_{2}$ ).

Por último, se estudió la influencia del tipo de activación del catalizador en su actividad, para ello se preparó el mismo catalizador y se activó con hidrógeno a distintas temperaturas. En la figura 5.23 aparecen los resultados obtenidos al variar la temperatura de activación del catalizador y se observa que a temperaturas mayores de $500^{\circ} \mathrm{C}$ la actividad del catalizador disminuye a tiempos de reacción largos, siendo esta disminución muy drástica para el catalizador activado a $700^{\circ} \mathrm{C}$. Los mejores resultados se obtienen cuando se activa el catalizador a bajas temperaturas (entre 50 y $200^{\circ} \mathrm{C}$ ), en este caso la conversión es cercana al $100 \%$ durante 80 horas de reacción. La selectividad a amonio no se ve influenciada por la activación y en todos los casos, oscila entre el 40 y el 50\%. 


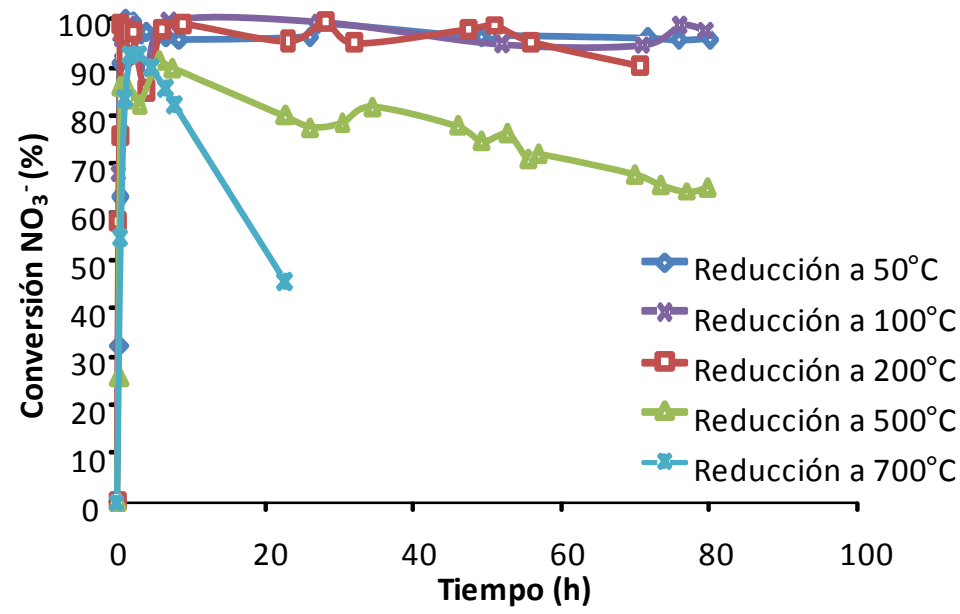

Figura 5. 23. Conversión frente al tiempo para distintas temperaturas de reducción $13 \mathrm{~g}$ $2,5 \% \mathrm{Sn} / 5 \% \mathrm{Pd} / \gamma-\mathrm{Al}_{2} \mathrm{O}_{3}, 5 \mathrm{~mL} / \mathrm{min}$ agua, $\left.250 \mathrm{~mL} / \mathrm{min} \mathrm{H}_{2}, 250 \mathrm{~mL} / \mathrm{min} \mathrm{CO}_{2}\right)$.

\subsection{Conclusiones parciales}

En este capítulo se ha optimizado la composición del catalizador para la eliminación de nitratos en continuo en aguas naturales y las condiciones de preparación del mismo. Así, se ha determinado que la combinación de metales que da mejores resultados es la de $\mathrm{Pd}$ y Sn, obteniendo con esta combinación una elevada actividad y la mejor selectividad a nitrógeno. La relación $\mathrm{Pd} / \mathrm{Sn}$ en este catalizador debe estar entre 2 y 4 , pues si esta relación es menor que 1 o mayor que 5, la actividad cae drásticamente. En cuanto al soporte utilizado, los mejores resultados se obtienen con los catalizadores soportados sobre alúmina. Debido a los problemas difusionales de esta reacción, la elección de un soporte adecuado es fundamental, siendo necesario un soporte con una baja conductividad eléctrica para obtener una buena selectividad, con ausencia de microporos $y$, aunque no parece ser un factor determinante, con una adecuada área específica. Se ha visto también que algunas variables en la preparación el catalizador influyen en gran medida en su actividad. La variable más importante es el orden de impregnación de las sales metálicas, obteniendo los mejores resultados impregnando primero la sal de Sn y 
luego la de Pd o coimpregnando ambos. Por el contrario, el tipo de precursor utilizado para cada metal no influye en su actividad catalítica. En cuanto a la activación del catalizador, los mejores resultados se obtienen activando el catalizador con hidrógeno a temperaturas inferiores a $200^{\circ} \mathrm{C}$, evitando en cualquier caso que éste supere los $500^{\circ} \mathrm{C}$. 


\section{Referencias}

[1] W. Gao, N. Guan, J. Chen, X. Guan, R. Jin, H. Zeng, Z. Liu, F. Zhang; Applied Catalysis B: Environmental, 46 (2003) 341.

[2] U. Prüsse, K.-D. Vorlop; Journal of Molecular Catalysis A: Chemical, 173 (2001) 313.

[3] U. Prüsse, M. Hähnlein, J. Daum, K.-D. Vorlop; Catalysis Today, 55 (2000) 79.

[4] I. Mikami, Y. Yoshinaga, T. Okuhara; Applied Catalysis B: Environmental, 49 (2004) 173.

[5] S. Hörold, K. D. Vorlop, T. Tacke, M. Sell; Catalysis Today, 17 (1993) 21.

[6] S. Hörold, T. Tacke, K.-D. Vorlop; Environmental Technology, 14 (1993) 931.

[7] C.-P. Huang, H.-W. Wang, P.-C. Chiu; Water Research, 32 (1998) 2257.

[8] O. S. G. P. Soares, J. J. M. Órfao, M. F. R. Pereira; Catalysis Letters, 126 (2008) 253.

[9] F. Epron, F. Gauthard, J. Barbier; Journal of Catalysis, 206 (2002) 363.

[10] O. S. G. P. Soares, J. J. M. Órfão, M. F. R. Pereira; Applied Catalysis B: Environmental, 102 (2011) 424.

[11] F. Epron, F. Gauthard, C. Pinéda, J. Barbier; Journal of Catalysis, 198 (2001) 309.

[12] F. A. Marchesini, S. Irusta, C. Querini, E. Miró; Applied Catalysis A: General, 348 (2008) 60.

[13] A. Pintar, J. Batista, I. Musevic; Applied Catalysis B: Environmental, 52 (2004) 49.

[14] J. Sá, D. Gasparovicova, K. Hayek, E. Halwax, J. A. Anderson, H. Vinek; Catalysis Letters, 105 (2005) 209.

[15] A. E. Palomares, J. G. Prato, F. Márquez, A. Corma; Applied Catalysis B: Environmental, 41 (2003) 3.

[16] K. Daub, G. Emig, M. J. Chollier, M. Callant, R. Dittmeyer; Chemical Engineering Science, 54 (1999) 1577.

[17] O. M. Ilinitch, F. P. Cuperus, L. V. Nosova, E. N. Gribov; Catalysis Today, 56 (2000) 137.

[18] J. K. Chinthaginjala, L. Lefferts; Applied Catalysis B: Environmental, 101 (2010) 144.

[19] P. A. Jacobs, R. Von Ballmoos; The Journal of Physical Chemistry, 86 (1982) 3050.

[20] D. W. Breck, U.S. Patent, 3130007.

[21] W. M. Meir, D. H. Olson, C. Baerlocher, Atlas of Zeolite Structure Types, Amsterdam, (1996).

[22] M. A. Camblor, J. Pérez-Pariente; Zeolites, 11 (1991) 202.

[23] M. E. Leonowich, J. A. Lawton, S. L. Lawton, M. K. Rubin; Science, 264 (1994) 1910.

[24] M. A. Hernández, F. Rojas, V. H. Lara, R. Portillo, R. Castelán, G. Pérez, R. Salas; Superficies y Vacío, 23 (2010) 51.

[25] A. Garron, K. Lázár, F. Epron; Applied Catalysis B: Environmental, 59 (2005) 57.

[26] Y. Yoshinaga, T. Akita, I. Mikami, T. Okuhara; Journal of Catalysis, 207 (2002) 37.

[27] R. Gavagnin, L. Biasetto, F. Pinna, G. Strukul; Applied Catalysis B: Environmental, 38 (2002) 91.

[28] J. Sá, G. D. Arteaga, R. A. Daley, J. Bernardi, J. A. Anderson; The Journal of Physical Chemistry B, 110 (2006) 17090. 
[29] J. Sá, T. Berger, K. Föttinger, A. Riss, J. A. Anderson, H. Vinek; Journal of Catalysis, 234 (2005) 282. 

6.

ESTUDIO DEL

CATALIZADOR Sn/Pd/AI ${ }_{2} \mathrm{O}_{3}$ 

En el capítulo anterior se ha concluido que el catalizador más adecuado para la reducción catalítica de nitratos en continuo con agua natural es el de $\mathrm{Sn} / \mathrm{Pd} / \gamma-\mathrm{Al}_{2} \mathrm{O}_{3}$ con una relación $\mathrm{Pd} / \mathrm{Sn}=2$. En este capítulo se va a hacer un estudio en profundidad de este catalizador, el cual se va a caracterizar por diversas técnicas y se van a hacer estudios adicionales para determinar su tiempo de vida, su comportamiento con distintos tipos de agua, la variación de su actividad al disminuir el contenido en metales y los posibles tratamientos de regeneración. En este capítulo se van a estudiar también las distintas opciones para eliminar el amonio generado en la reacción. Finalmente, en base a todos los resultados obtenidos, se propondrá un posible mecanismo de reacción.

\subsection{Estudios de desactivación y regeneración del catalizador}

\subsubsection{Estudio de la desactivación del catalizador}

Uno de los aspectos fundamentales que se deben determinar para estudiar la eficacia de un catalizador en un proceso, es su tiempo de vida, es decir, el tiempo que dicho catalizador es activo antes de su desactivación. Este estudio se realizó con el catalizador $2,5 \% \mathrm{Sn} / 5 \% \mathrm{Pd} / \gamma-\mathrm{Al}_{2} \mathrm{O}_{3}$, utilizando agua natural cuya composición aparece en la tabla 6.1. Los ensayos se realizaron en un reactor continuo de tanque agitado durante 11 días. Las condiciones de reacción son las que se muestran en la tabla 6.2 y los resultados obtenidos aparecen en la figura 6.1.

Tabla 6. 1. Principales características del agua natural usada en las reacciones.

\begin{tabular}{cc}
\hline Conductividad & $1000 \mu \mathrm{S} / \mathrm{cm}$ \\
{$\left[\mathrm{Ca}^{2+}\right]$} & $185 \mathrm{ppm}$ \\
{$[\mathrm{Cl}]$} & $79 \mathrm{ppm}$ \\
{$\left[\mathrm{SO}_{4}{ }^{2-}\right]$} & $200 \mathrm{ppm}$ \\
{$\left[\mathrm{NO}_{3}{ }^{-}\right]$} & $100 \mathrm{ppm}$ \\
\hline
\end{tabular}


Tabla 6. 2. Condiciones de reacción para el estudio del tiempo de vida del catalizador $2,5 \% \mathrm{Sn} / 5 \% \mathrm{Pd} / \gamma-\mathrm{Al}_{2} \mathrm{O}_{3}$.

\begin{tabular}{cc}
\hline Masa de catalizador & $3 \mathrm{~g}$ \\
Flujo de agua & $5 \mathrm{~mL} / \mathrm{min}$ \\
Flujo de $\mathrm{H}_{2}$ & $250 \mathrm{~mL} / \mathrm{min}$ \\
Flujo de $\mathrm{CO}_{2}$ & $250 \mathrm{~mL} / \mathrm{min}$ \\
Agitación & $900 \mathrm{rpm}$ \\
\hline
\end{tabular}

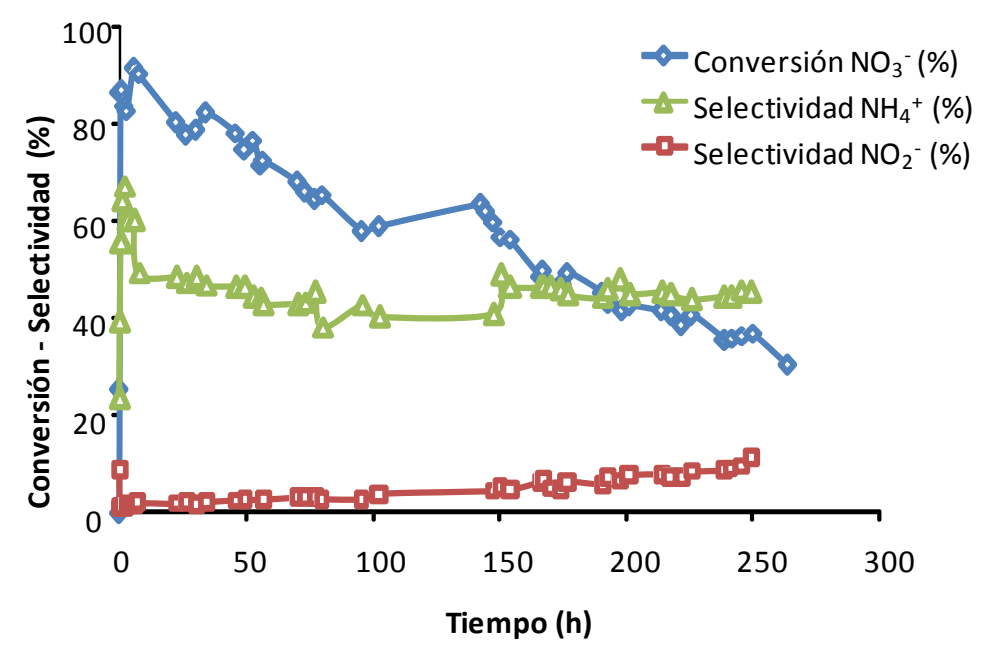

Figura 6. 1. Estudio del tiempo de vida del catalizador $2,5 \% \mathrm{Sn} / 5 \% \mathrm{Pd} / \gamma-\mathrm{Al}_{2} \mathrm{O}_{3}$ utilizando agua natural.

En dicha figura se aprecia cómo el catalizador estudiado presenta una conversión del $90 \%$ durante las primeras 6 horas de reacción, para posteriormente desactivarse lentamente hasta llegar al 30\% de conversión a las 263 horas de reacción, es decir, aproximadamente a los 11 días de reacción. Por otra parte, en lo que a selectividad a amonio respecta, ésta se mantiene alrededor del $45 \%$ durante toda la reacción, mientras que la selectividad a nitrito es mayor cuanto menor es la conversión a nitratos, siendo el valor máximo obtenido del $10 \%$ al final de la reacción. 
En base a estos resultados y ajustando los mismos a una recta de desactivación (figura 6.2) se puede estimar que el catalizador tardaría 415 horas (17 días) en desactivarse totalmente.

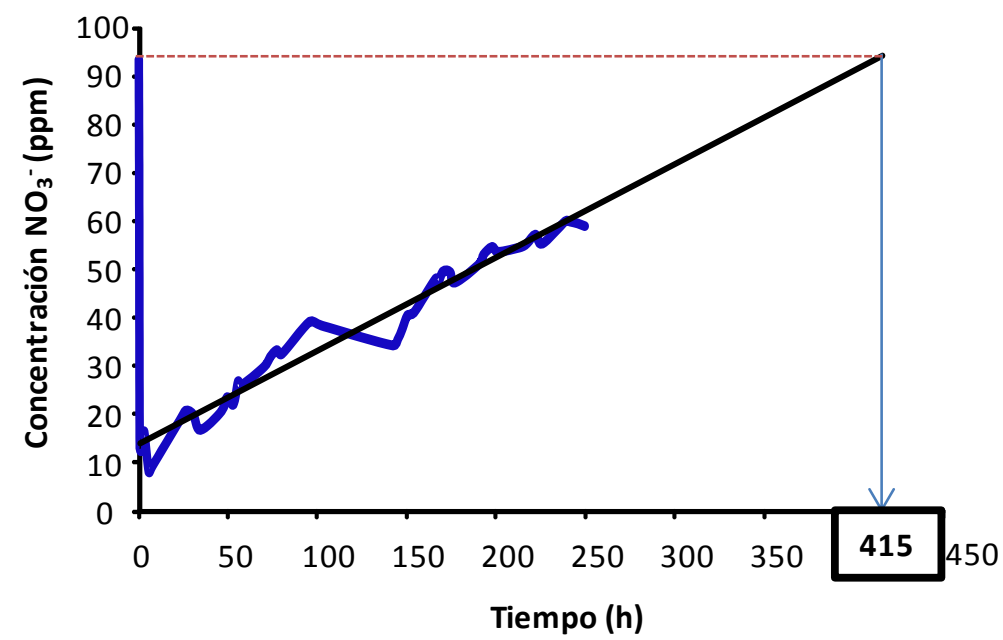

Figura 6. 2. Recta de desactivación del catalizador $2,5 \% \mathrm{Sn} / 5 \% \mathrm{Pd} / \gamma-\mathrm{Al}_{2} \mathrm{O}_{3}$ en la reducción catalítica utilizando agua natural (concentración inicial de nitratos=95 mg/L).

Los resultados obtenidos con este catalizador son mejores que los descritos en bibliografía para largos tiempos de reacción y con aguas que sólo contienen nitratos [1-3]. Así, Matatov-Meytal [1] muestra que el catalizador basado en Cu-Pd sobre carbón activo, es activo durante casi 30 horas de reacción, con una conversión del $75 \%$ a las 28 horas de reacción, mientras que en nuestro caso, a ese tiempo se obtienen conversiones superiores al $80 \%$. Estos resultados también son mejores que los descritos por Prüsse y col. [2] con un catalizador basado en $\mathrm{Pd}$-In sobre alúmina el cual presenta una actividad estable durante al menos 90 horas de reacción con una conversión del 45\%. La estabilidad de nuestro catalizador es también superior a la indicada por Pintar y col. [3] con los catalizadores basados en $\mathrm{Pd}-\mathrm{Cu} /$ Alúmina, los cuales muestran una conversión estable durante 30 horas de reacción, inferior a la conseguida en nuestro caso con el catalizador $\mathrm{Sn} / \mathrm{Pd} / \mathrm{Al}_{2} \mathrm{O}_{3}$. Por tanto, en las condiciones de reacción estudiadas, el catalizador $\mathrm{Sn} / \mathrm{Pd} / \gamma-\mathrm{Al}_{2} \mathrm{O}_{3}$ estudiado parece ser el más activo en la reducción de nitratos en aguas naturales utilizando un reactor continuo. 
No obstante, el catalizador acaba desactivándose tras 17 días de reacción por ello es muy importante determinar las posibles causas de la desactivación del mismo, las cuales podrían estar relacionadas con la deposición de algunas especies en los centros activos o con cambios en el estado de oxidación de los centros activos del catalizador.

La primera hipótesis es bastante plausible, pues las aguas naturales utilizadas tenían una gran dureza y un gran número de especies iónicas. Para comprobar si la deposición de estos iones estaba desactivando el catalizador, se realizó un experimento con el mismo catalizador, utilizando las mismas condiciones de reacción, pero con agua destilada a la que se le añadió la cantidad necesaria de $\mathrm{NaNO}_{3}$ con el fin de conseguir 100 ppm de nitratos.

En la figura 6.3 se observa la variación de la conversión a nitratos y la selectividad a amonio y nitrito del catalizador $2,5 \% \mathrm{Sn} / 5 \% \mathrm{Pd} / \gamma-\mathrm{Al}_{2} \mathrm{O}_{3}$ utilizando agua conteniendo nitratos. En ella se ve que el catalizador presenta una conversión inicial a nitratos del 95\% durante 95 horas de reacción. Posteriormente, y muy lentamente, la actividad de este catalizador disminuye hasta alcanzar el $80 \%$ de conversión a nitratos a las 197 horas de reacción, es decir, a los 8 días de reacción. La selectividad a amonio es similar a la obtenida en el caso anterior pero en este caso no se observa la formación de nitritos durante 200 horas de reacción.

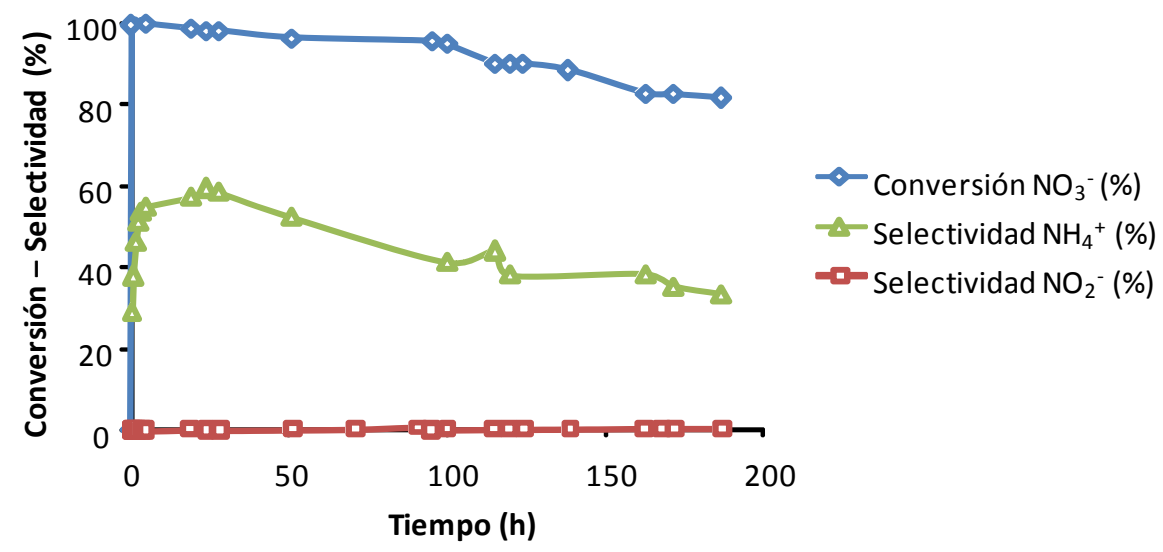

Figura 6. 3. Estudio del tiempo de vida del catalizador $2,5 \% \mathrm{Sn} / 5 \% \mathrm{Pd} / \gamma-\mathrm{Al}_{2} \mathrm{O}_{3}$ utilizando agua destilada conteniendo nitratos. 


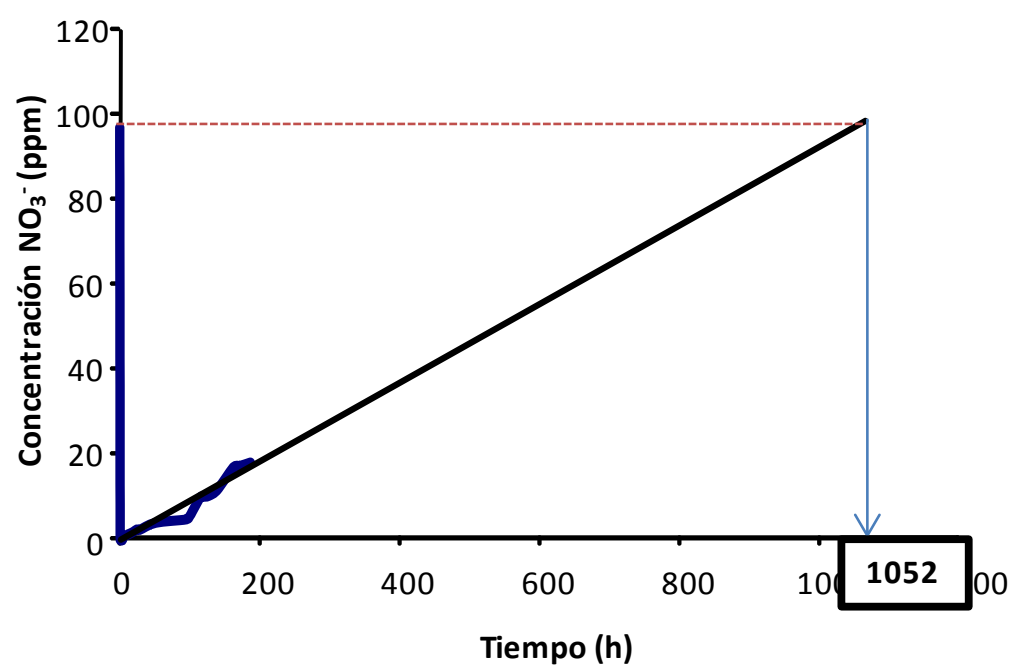

Figura 6. 4. Recta de desactivación del catalizador $2,5 \% \mathrm{Sn} / 5 \% \mathrm{Pd} / \gamma-\mathrm{Al}_{2} \mathrm{O}_{3}$ en la reducción catalítica utilizando agua destilada conteniendo nitratos (concentración inicial de nitratos=98 $\mathrm{mg} / \mathrm{L}$ ).

Si se comparan estos resultados con los obtenidos al utilizar aguas naturales (figura 6.1), se observa que la desactivación del catalizador es mucho menor al usar agua destilada conteniendo nitratos que al utilizar aguas naturales. Al extrapolar el tiempo que tardaría el catalizador en desactivarse totalmente (figura 6.4), se puede estimar que en este caso el catalizador $2,5 \% \mathrm{Sn} / 5 \% \mathrm{Pd} / \gamma-\mathrm{Al}_{2} \mathrm{O}_{3}$ sería activo durante 1052 horas (44 días). Estos resultados indican claramente que una parte importante de la desactivación del catalizador está relacionada con la presencia de otros iones en el medio de reacción.

Para determinar la naturaleza de estas especies se realizó un análisis elemental de $\mathrm{C}, \mathrm{N}$ y $\mathrm{S}$ del catalizador después de la reacción con agua natural. En la tabla 6.3 se observan los resultados obtenidos, que indican que tras reacción se han depositado en el catalizador distintas especies carbonatadas, sulfatadas y nitrogenadas, probablemente carbonatos, sulfatos y nitratos. La deposición de estas sales sobre la superficie del catalizador, impide a los reactivos el acceso a los centros activos del catalizador, desactivando paulatinamente el mismo. 
Tabla 6. 3. Análisis elemental del catalizador $2,5 \% \mathrm{Pd} / 5 \% \mathrm{Pd} / \gamma-\mathrm{Al}_{2} \mathrm{O}_{3}$ después de ser utilizado en una reacción con agua natural.

\begin{tabular}{llll}
\cline { 3 - 4 } & \% C & $\% \mathbf{N}$ & $\% \mathbf{S}$ \\
\hline Catalizador $2,5 \% \mathrm{Pd} / 5 \% \mathrm{Pd} / \gamma-\mathrm{Al}_{2} \mathrm{O}_{3}$ & 0,201 & 0,164 & 0,134 \\
\hline
\end{tabular}

Estos resultados nos permiten afirmar que hay un doble mecanismo de desactivación, el más importante es la deposición de determinadas especies iónicas sobre la superficie del catalizador, pero tal como se observa al usar el catalizador con agua destilada conteniendo nitratos no puede ser éste el único motivo, pues en este tipo de agua el catalizador también termina desactivándose. El otro mecanismo de desactivación puede estar relacionado con la oxidación de los centros metálicos, a partir de la disolución del oxígeno del aire en el agua de reacción durante los experimentos de larga duración.

\subsubsection{Estudio de la regeneración del catalizador}

Una vez que se han determinado las posibles causas de desactivación del catalizador, es muy importante determinar si es posible su regeneración, pues ello va a tener una importancia fundamental en la aplicación comercial del proceso. En este apartado se estudió la regeneración del catalizador $2,5 \% \mathrm{Sn} / 5 \% \mathrm{Pd} / \gamma-\mathrm{Al}_{2} \mathrm{O}_{3}$. Para ello, se realizaron varias pruebas con catalizadores usados en reacciones anteriores, que habían sufrido un proceso de desactivación y que se intentaron regenerar por varios métodos. Los tratamientos de regeneración estudiados fueron los siguientes:

- Tratamientos térmicos:

- Calcinación a $500^{\circ} \mathrm{C}$ durante 1 hora en atmósfera de aire y posterior reducción a $500^{\circ} \mathrm{C}$ durante 4 horas en flujo de hidrógeno.

- $\quad$ Reducción a $600^{\circ} \mathrm{C}$ durante 4 horas en flujo de hidrógeno.

- $\quad$ Reducción a $500^{\circ} \mathrm{C}$ durante 16 horas en flujo de hidrógeno.

- Lavado con $\mathrm{H}_{2} \mathrm{O}_{2}$ y reducción a $500^{\circ} \mathrm{C}$ durante 4 horas en flujo de hidrógeno.

- Lavado con agua destilada y reducción a $500^{\circ} \mathrm{C}$ durante 4 horas en flujo de hidrógeno. 
- Tratamientos físico-químicos a temperatura ambiente:

- $\quad$ Lavado con agua destilada.

- $\quad$ Lavado con ácido $\left(\mathrm{H}_{2} \mathrm{SO}_{4}\right)$.

- Lavado con $\mathrm{H}_{2} \mathrm{O}_{2}$.

Los resultados obtenidos se muestran en la figura 6.5 donde se puede apreciar que la máxima regeneración del catalizador se obtiene tras los tratamientos físico-químicos a temperatura ambiente, mientras que las regeneraciones térmicas no consiguen recuperar la actividad original del catalizador. Esto último podría relacionarse con la sinterización del metal en la superficie del catalizador formando aglomerados de partículas metálicas que reducirían la actividad de estos catalizadores. Por ello, los mejores tratamientos para regenerar el catalizador son el lavado con agua, con ácido o con agua oxigenada a temperatura ambiente. De todos ellos el propuesto es el lavado con agua destilada, puesto que es el menos agresivo y el más económico.

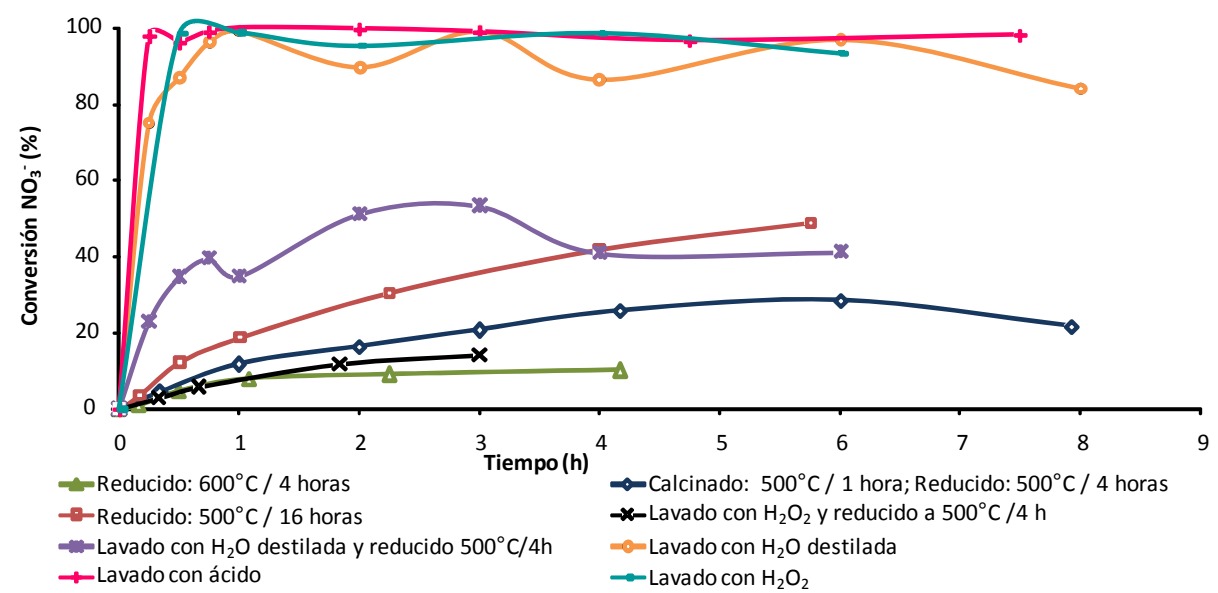

Figura 6. 5. Conversión obtenida al regenerar el catalizador $2,5 \% \mathrm{Sn} / 5 \% \mathrm{Pd} / \mathrm{Al}_{2} \mathrm{O}_{3}$ utilizando distintos tratamientos.

Para comprobar la eficacia del tratamiento de regeneración, se regeneró un catalizador después de usarlo en una reacción de larga duración (50 horas) tras la que el catalizador había perdido un $60 \%$ de actividad. En la figura 6.6 se observa que el 
catalizador regenerado con agua destilada recupera prácticamente la actividad inicial, perdiendo sólo un $15 \%$ de la actividad respecto al catalizador original. La selectividad a amonio de ambos catalizadores aparece en la figura 6.7, observándose que aunque ésta es menor con el catalizador lavado con agua, durante las primeras horas de la reacción, tras 20 horas los resultados obtenidos son muy similares a los obtenidos con el catalizador original.

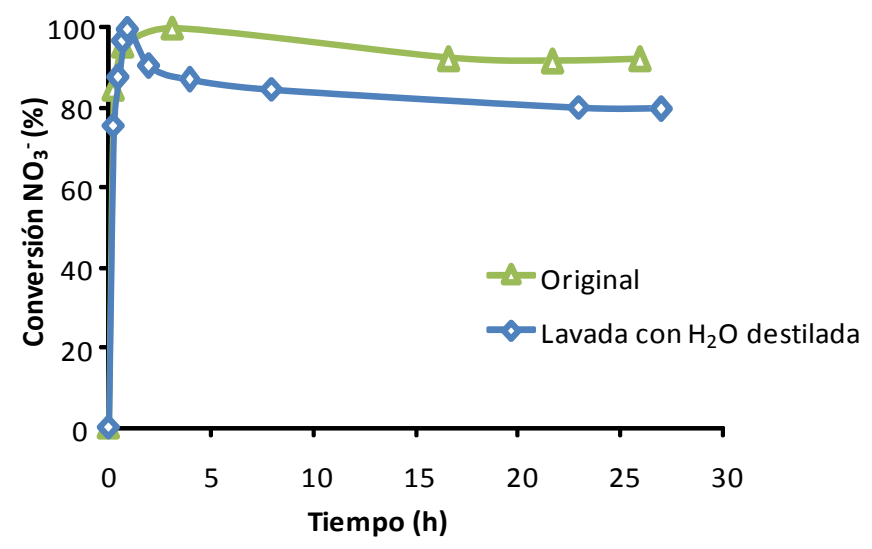

Figura 6. 6. Comparación entre la conversión de nitratos obtenida al regenerar el catalizador $2,5 \% \mathrm{Sn} / 5 \% \mathrm{Pd} / \gamma-\mathrm{Al}_{2} \mathrm{O}_{3}$ y la obtenida con el catalizador original.

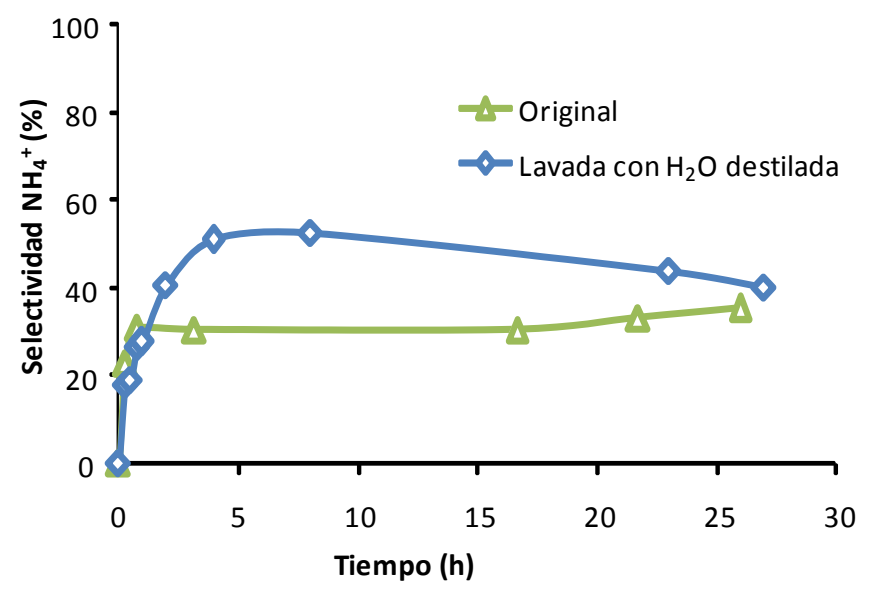

Figura 6. 7. Comparación entre la selectividad a amonio obtenida al regenerar el catalizador $2,5 \% \mathrm{Sn} / 5 \% \mathrm{Pd} / \gamma-\mathrm{Al}_{2} \mathrm{O}_{3}$ y la obtenida con el catalizador original. 
Es muy importante determinar cuántos ciclos de reacción-regeneración puede soportar el catalizador sin desactivarse, para ello se hicieron experimentos sucesivos de reacción-regeneración con una cantidad menor de catalizador (1 gramo) con el fin que se desactivara antes y poder realizar las regeneraciones varias veces. Así, tal como se observa en la figura 6.8 , se realizaron hasta 3 regeneraciones del catalizador original, observándose que tras tres ciclos de reacción-regeneración la pérdida de actividad del catalizador es tan sólo de un $15-20 \%$, y esta menor actividad podría deberse no tanto a la desactivación irreversible del catalizador como a la pérdida de masa del catalizador en los sucesivos lavados. De hecho, tras finalizar los tres ciclos reacción-regeneración se había perdido hasta un $46 \%$ de masa del catalizador, mientras que la pérdida de actividad del catalizador era de un $20 \%$. En cuanto a la selectividad a amonio (figura 6.9), el comportamiento del catalizador tras las sucesivas regeneraciones es muy similar al del catalizador original.

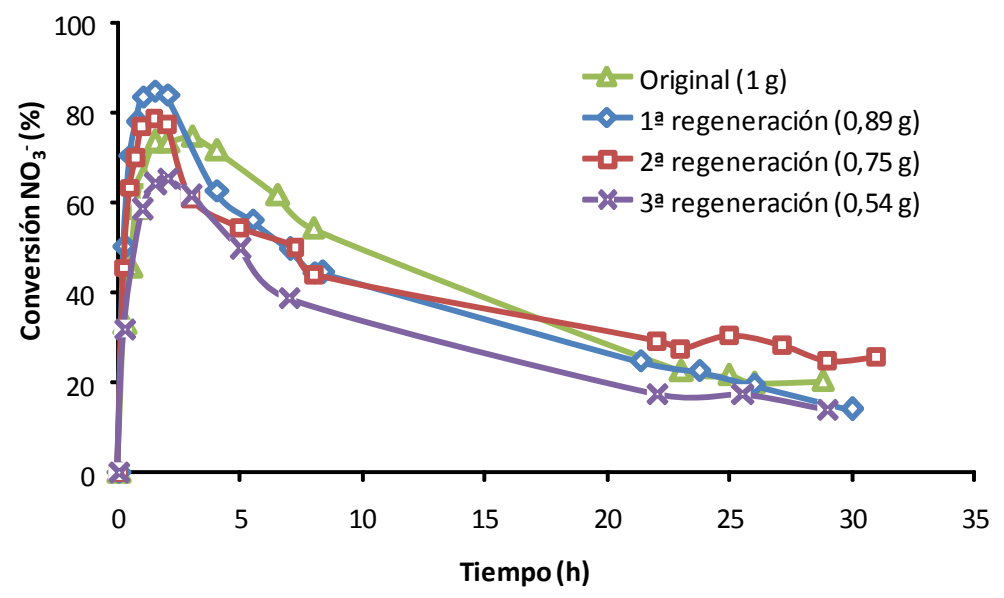

Figura 6. 8. Conversión de nitratos obtenida al regenerar 3 veces 1 gramo de catalizador $2,5 \% \mathrm{Sn} / 5 \% \mathrm{Pd} / \gamma-\mathrm{Al}_{2} \mathrm{O}_{3}$ lavándolo con agua (los valores entre paréntesis indican la cantidad de catalizador en cada experimento). 


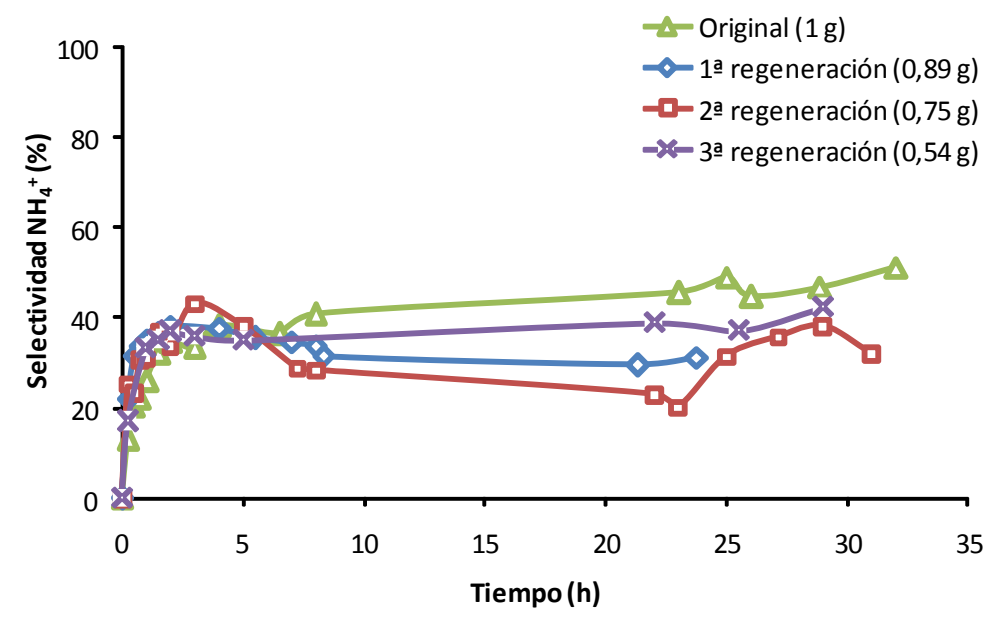

Figura 6. 9. Selectividad a amonio obtenida al regenerar 3 veces 1 gramo de catalizador $2,5 \% \mathrm{Sn} / 5 \% \mathrm{Pd} / \gamma-\mathrm{Al}_{2} \mathrm{O}_{3}$ lavándolo con agua (los valores entre paréntesis corresponden a la cantidad de catalizador en cada experimento).

Experimentos similares se realizaron con un catalizador $1,5 \% \mathrm{Sn} / 3 \% \mathrm{Pd} / \gamma-\mathrm{Al}_{2} \mathrm{O}_{3}$ que contenía una menor cantidad de Pd y Sn pero con la relación óptima Pd/Sn de 2 (figuras 6.10 y 6.11). En este caso para minimizar la pérdida de masa en el proceso de lavado, la regeneración del catalizador se realizó en el mismo reactor sin extraer el catalizador. Tal como se observa en estas figuras, y como ocurría con el catalizador con mayor contenido en paladio, el catalizador es activo durante 3 ciclos reacción - regeneración sin modificarse prácticamente la conversión a nitratos ni la selectividad a amonio obtenida en el primer ciclo, y disminuyendo ligeramente la conversión (un 10\%) tras 3 ciclos sucesivos de reacción - regeneración. Como en el caso anterior tampoco se observaron variaciones en la selectividad a amonio de los catalizadores regenerados.

Estos resultados indican que es posible regenerar el catalizador simplemente con un lavado con agua destilada y que el catalizador puede soportar sucesivos ciclos de reacción - regeneración con una pérdida mínima de su actividad. 


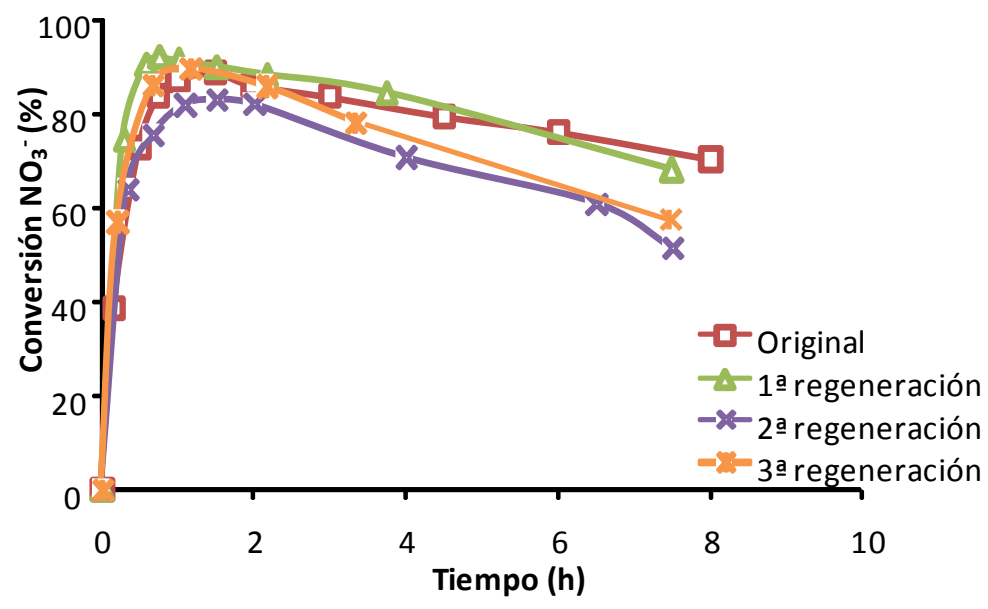

Figura 6. 10. Conversión de nitratos obtenida al regenerar 3 veces 3 gramos de catalizador $1,5 \% \mathrm{Sn} / 3 \% \mathrm{Pd} / \gamma-\mathrm{Al}_{2} \mathrm{O}_{3}$ lavándolo con agua.

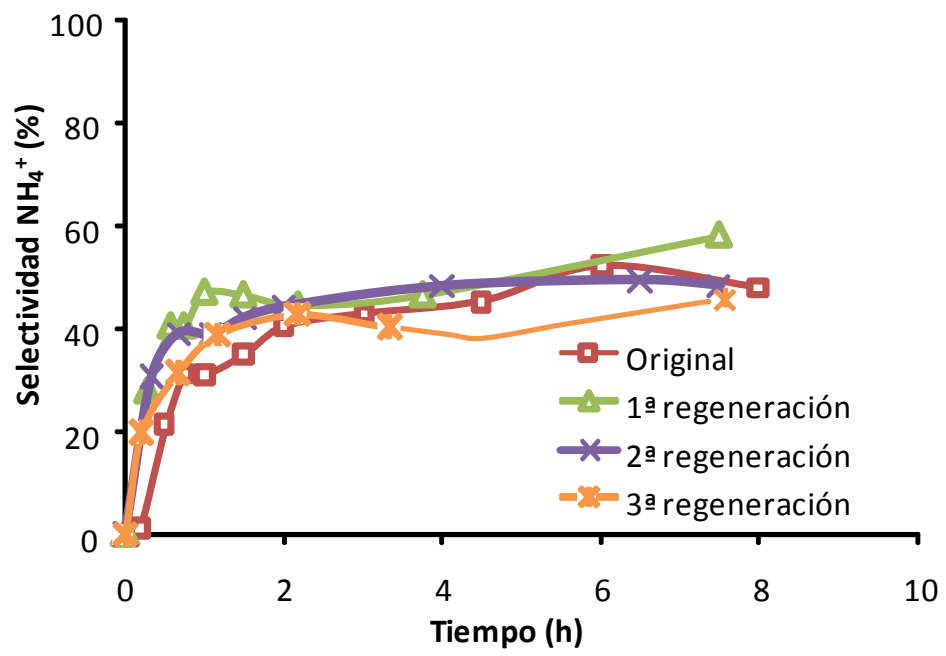

Figura 6. 11. Selectividad a amonio obtenida al regenerar 3 veces 3 gramos de catalizador $1,5 \% \mathrm{Sn} / 3 \% \mathrm{Pd} / \gamma-\mathrm{Al}_{2} \mathrm{O}_{3}$ lavándolo con agua. 


\subsection{Actividad del catalizador con distintos tipos de aguas contaminadas}

En este apartado se ha estudiado la actividad del catalizador $2,5 \% \mathrm{Sn} / 5 \% \mathrm{Pd} / \gamma-\mathrm{Al}_{2} \mathrm{O}_{3}$ usando diferentes tipos de agua naturales de distinta procedencia y un agua residual cuyas composiciones aparecen en la tabla 6.4. Tal como se observa en la figura 6.12 el catalizador es activo en tales tipos de aguas estudiadas, pero la conversión obtenida depende de la conductividad del agua utilizada, es decir, de la concentración de iones en la misma. Así, aunque las diferencias en la conversión del catalizador obtenidas al utilizar aguas naturales (aguas A, B y C) no son muy importantes, sí que se observa que la actividad del catalizador disminuye al aumentar la conductividad de las aguas tratadas. Esta tendencia es claramente significativa si se comparan los resultados obtenidos con las aguas naturales y los obtenidos con un agua residual industrial (agua D), la cual tiene una conductividad 20 veces mayor que la del agua natural. En este caso la máxima conversión obtenida es del $50 \%$ frente al $90-100 \%$ obtenido en las aguas naturales. Tal como se ha discutido en la introducción y como describieron Pintar y otros autores [4-6], la menor actividad del catalizador en aguas con un mayor contenido de especies iónicas puede deberse a la adsorción competitiva de los distintos iones presentes en el agua sobre los centros activos del catalizador o, tal como se ha descrito en el apartado 6.1.1, a una desactivación parcial del mismo debido a la precipitación de algunas especies iónicas que contiene el agua sobre los centros activos del catalizador.

Tabla 6. 4. Composición química y procedencia de las aguas estudiadas.

\begin{tabular}{llccccc}
\hline Agua & Procedencia & $\begin{array}{c}\text { Conductividad } \\
(\mu \mathrm{S} / \mathrm{cm})\end{array}$ & $\begin{array}{c}\mathrm{Ca}^{2+} \\
(\mathrm{mg} / \mathrm{L})\end{array}$ & $\begin{array}{c}\mathrm{Cl}^{-} \\
(\mathrm{mg} / \mathrm{L})\end{array}$ & $\begin{array}{c}\mathrm{SO}_{4}{ }^{2-} \\
(\mathrm{mg} / \mathrm{L})\end{array}$ & $\begin{array}{c}\mathrm{NO}_{3}{ }^{-} \\
(\mathrm{mg} / \mathrm{L})\end{array}$ \\
\hline$A$ & Lagunas de Ruidera & 570 & 85 & 35 & 160 & 30 \\
$B$ & Pozo Picassent & 1000 & 185 & 79 & 200 & 90 \\
$C$ & Pozo Puzol & 1580 & 280 & 232 & 173 & 150 \\
& Agua residual de & & & & & 1300 \\
\hline & industria química & 24000 & 1,2 & 5 & 4,2 & \\
\hline
\end{tabular}




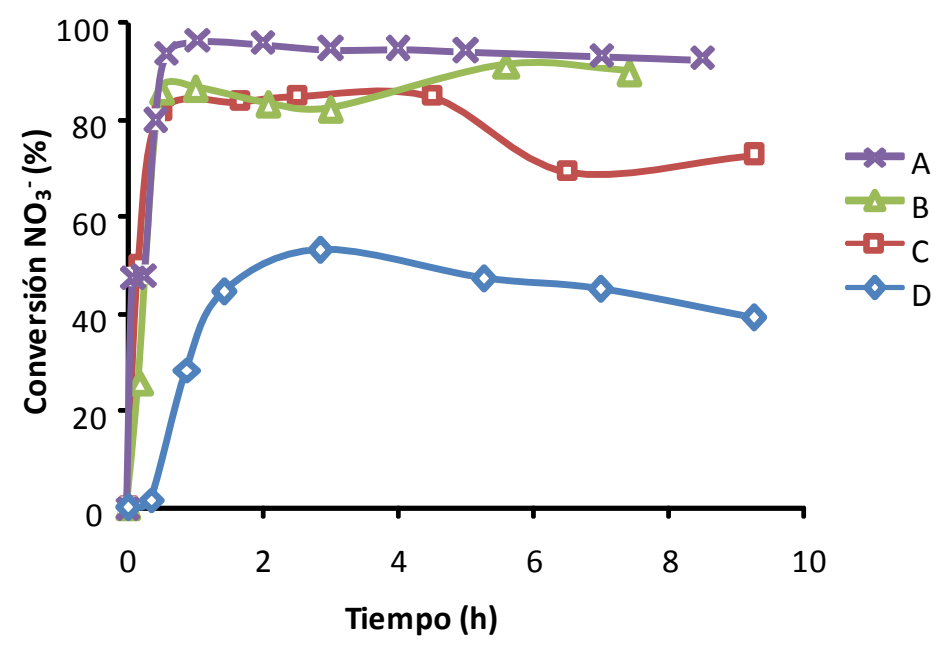

Figura 6. 12. Actividad del catalizador $2,5 \% \mathrm{Sn} / 5 \% \mathrm{Pd} / \gamma-\mathrm{Al}_{2} \mathrm{O}_{3}$ usando aguas de distintas procedencias.

\subsection{Actividad del catalizador al variar el contenido en metales}

Tal como se ha mostrado en los apartados anteriores, el catalizador $2,5 \% \mathrm{Sn} / 5 \% \mathrm{Pd} / \gamma-\mathrm{Al}_{2} \mathrm{O}_{3}$ es activo en la eliminación de nitratos incluso utilizando agua de distinta naturaleza. Sin embargo, desde un punto de vista económico sería interesante utilizar un catalizador con una menor cantidad de metal noble. Por ello se estudió la actividad de un catalizador con una menor cantidad de metales, pero se mantuvo la relación $\mathrm{Pd} / \mathrm{Sn}$ de 2, y se comparó su actividad con la del catalizador de referencia. Los resultados obtenidos aparecen en la figura 6.13 donde se observa cómo una disminución del $40 \%$ en el contenido en paladio solamente produce una disminución en el $20 \%$ de la conversión tras 7 horas de reacción, siendo la selectividad a amonio inferior con el catalizador que contiene menor cantidad de paladio (figura 6.14). 


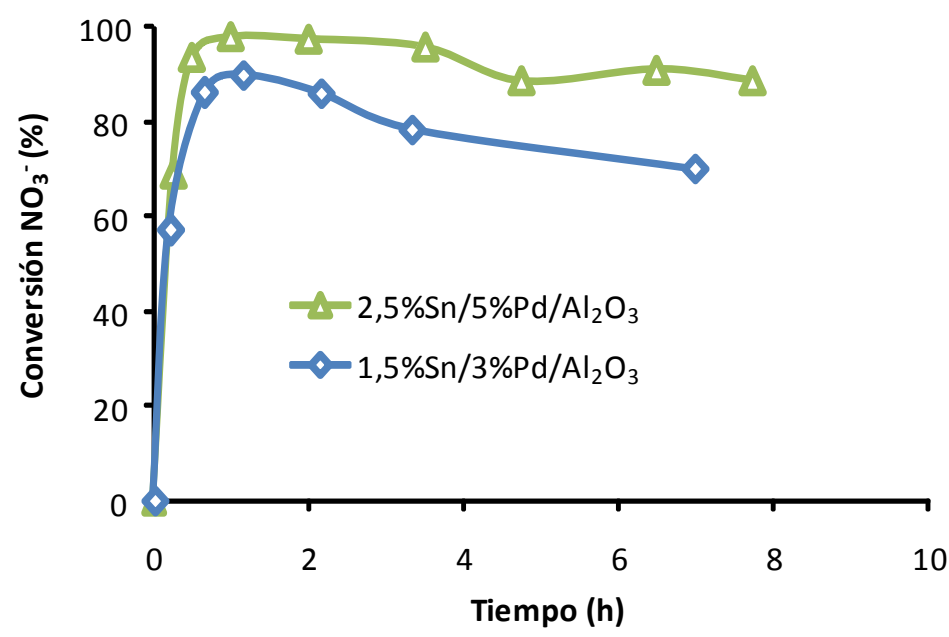

Figura 6. 13. Conversión obtenida con los catalizadores $2,5 \% \mathrm{Sn} / 5 \% \mathrm{Pd} / \gamma-\mathrm{Al}_{2} \mathrm{O}_{3}$ y $1,5 \% \mathrm{Sn} / 3 \% \mathrm{Pd} /$ $\gamma-\mathrm{Al}_{2} \mathrm{O}_{3}$ (3 g de catalizador, $5 \mathrm{~mL} / \mathrm{min}$ agua, $250 \mathrm{~mL} / \mathrm{min} \mathrm{H}_{2}, 250 \mathrm{~mL} / \mathrm{min}^{\mathrm{CO}} \mathrm{CO}_{2}$ ).

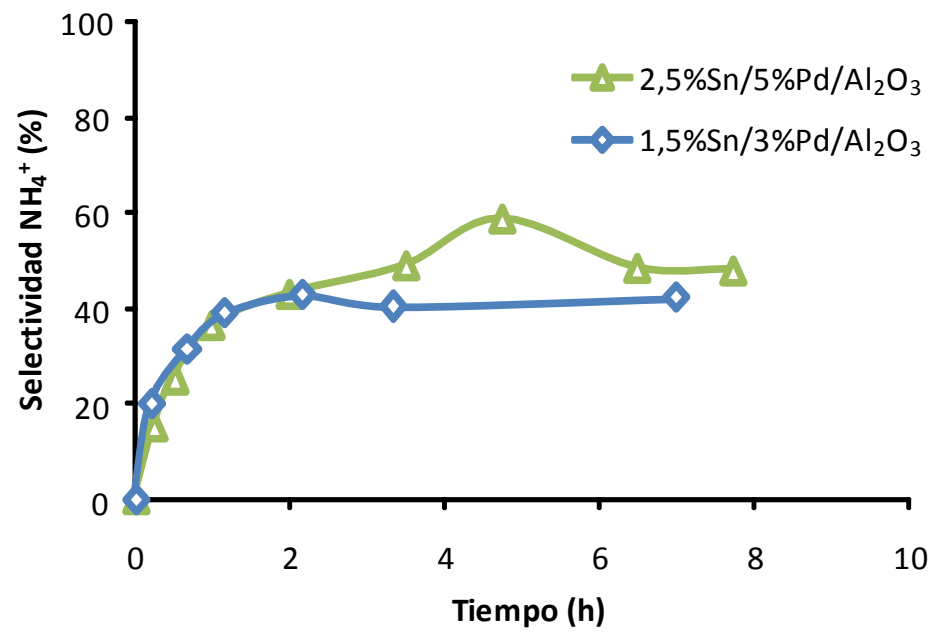

Figura 6. 14. Selectividad a amonio obtenida con los catalizadores $2,5 \% \mathrm{Sn} / 5 \% \mathrm{Pd} / \gamma-\mathrm{Al}_{2} \mathrm{O}_{3} \mathrm{y}$ 1,5\%Sn/3\% $\mathrm{Pd} / \gamma-\mathrm{Al}_{2} \mathrm{O}_{3}$ (3 g de catalizador, $5 \mathrm{~mL} / \mathrm{min}$ agua, $250 \mathrm{~mL} / \mathrm{min} \mathrm{H}_{2}, 250 \mathrm{~mL} / \mathrm{min} \mathrm{CO}_{2}$ ).

A la vista de los resultados obtenidos se preparó un catalizador con una cantidad 5 veces menor de paladio pero que mantuviera la relación $\mathrm{Pd} / \mathrm{Sn}$ de 2 , utilizando como 
soporte una alúmina de alta superficie $(0,5 \% \mathrm{Sn} / 1 \% \mathrm{Pd} / \mathrm{AAS})$. En la figura 6.15 se presentan los resultados obtenidos con este catalizador y se compara su actividad con la del catalizador $2,5 \% \mathrm{Sn} / 5 \% \mathrm{Pd} / \gamma-\mathrm{Al}_{2} \mathrm{O}_{3}$. Tal como se observa en dicha figura, al alcanzar el estado estacionario la conversión obtenida con el catalizador que contiene 5 veces menos paladio es sólo 1,2 veces inferior a la obtenida con el catalizador que contiene $5 \% \mathrm{Pd}$. Además, en la figura 6.16 se observa que la selectividad a amonio obtenida con el catalizador que contiene $1 \% \mathrm{Pd}$ es muy inferior a la obtenida con el catalizador que contiene $5 \% \mathrm{Pd}$. Estos resultados muestran que es posible preparar catalizadores activos con una menor cantidad de $\mathrm{Pd}$, siendo el catalizador $0,5 \% \mathrm{Sn} / 1 \% \mathrm{Pd}$ soportado en alúmina de alta superficie especialmente interesante no sólo por su bajo coste, sino también por su alta actividad y su selectividad a nitrógeno.

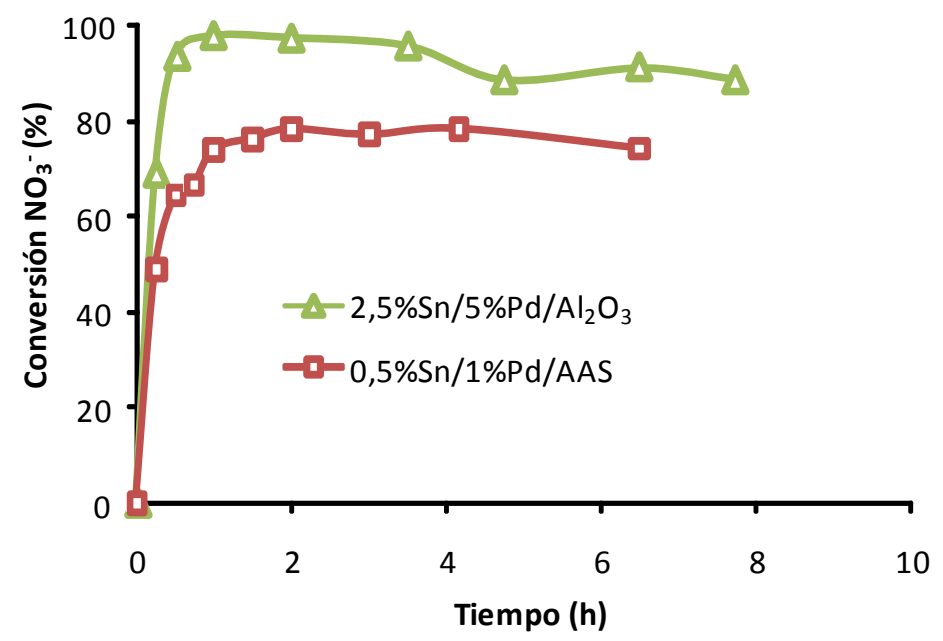

Figura 6. 15. Conversión obtenida con los catalizadores $2,5 \% \mathrm{Sn} / 5 \% \mathrm{Pd} / \gamma-\mathrm{Al}_{2} \mathrm{O}_{3}$ y $0,5 \% \mathrm{Sn} / 1 \% \mathrm{Pd} / \mathrm{AAS}$ (3 g de catalizador, $5 \mathrm{~mL} / \mathrm{min}$ agua, $250 \mathrm{~mL} / \mathrm{min}_{2}, 250 \mathrm{~mL} / \mathrm{min} \mathrm{CO}_{2}$ ). 


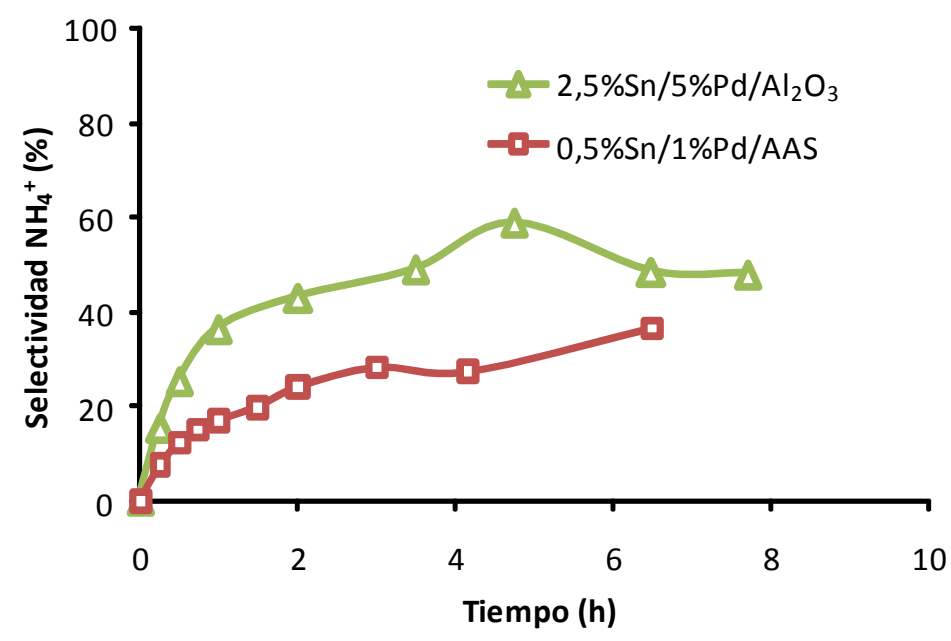

Figura 6. 16. Selectividad a amonio obtenida con los catalizadores $2,5 \% \mathrm{Sn} / 5 \% \mathrm{Pd} / \gamma-\mathrm{Al}_{2} \mathrm{O}_{3}$ y 0,5\%Sn/1\%Pd/AAS (3 g de catalizador, $5 \mathrm{~mL} / \mathrm{min}$ agua, $250 \mathrm{~mL} / \mathrm{min}_{2}, 250 \mathrm{~mL} / \mathrm{min} \mathrm{CO}_{2}$ ).

\subsection{Eliminación de amonio}

Los resultados obtenidos hasta ahora han mostrado que los catalizadores Sn/Pd soportados sobre alúmina con una relación $\mathrm{Pd} / \mathrm{Sn}=2$ y con bajo contenido en $\mathrm{Pd}$ son catalizadores activos para la eliminación de nitratos en aguas naturales trabajando en continuo. Estos catalizadores son activos durante un periodo prolongado de tiempo y es posible su regeneración simplemente con un lavado con agua destilada. Sin embargo, al no ser la selectividad a nitrógeno suficientemente elevada es necesario aplicar un posttratamiento para alcanzar el límite legal de concentración de amonio en aguas para consumo humano, que es de $0,5 \mathrm{mg} / \mathrm{L}$ [7]. Por ello se ha realizado un estudio sobre las distintas opciones para la eliminación de este subproducto. Las técnicas estudiadas fueron la oxidación forzada o natural, la oxidación catalítica, la oxidación química y el intercambio iónico.

La primera alternativa analizada fue la oxidación forzada, la cual consistía en añadir oxígeno a presión atmosférica y temperatura ambiente al agua recogida tras una reacción con un catalizador $2,5 \% \mathrm{Sn} / 5 \% \mathrm{Pd} / \gamma-\mathrm{Al}_{2} \mathrm{O}_{3}$ y que contenía $7 \mathrm{mg} / \mathrm{L}$ de amonio. El oxígeno se 
aplicaba difundiendo una corriente de aire a través del líquido con un borboteador (flujo de $200 \mathrm{~mL} / \mathrm{min}$ ) o por contacto forzado con el oxígeno atmosférico mediante agitación mecánica. Los resultados obtenidos muestran cómo al añadir aire al agua después de reacción se producía una eliminación paulatina de amonio, consiguiendo eliminar entre el 45 y el $50 \%$ del amonio original (figura 6.17). En esta figura se observa también que, para la eliminación de amonio, es más efectiva y rápida la agitación mecánica que la adición de aire por difusión.

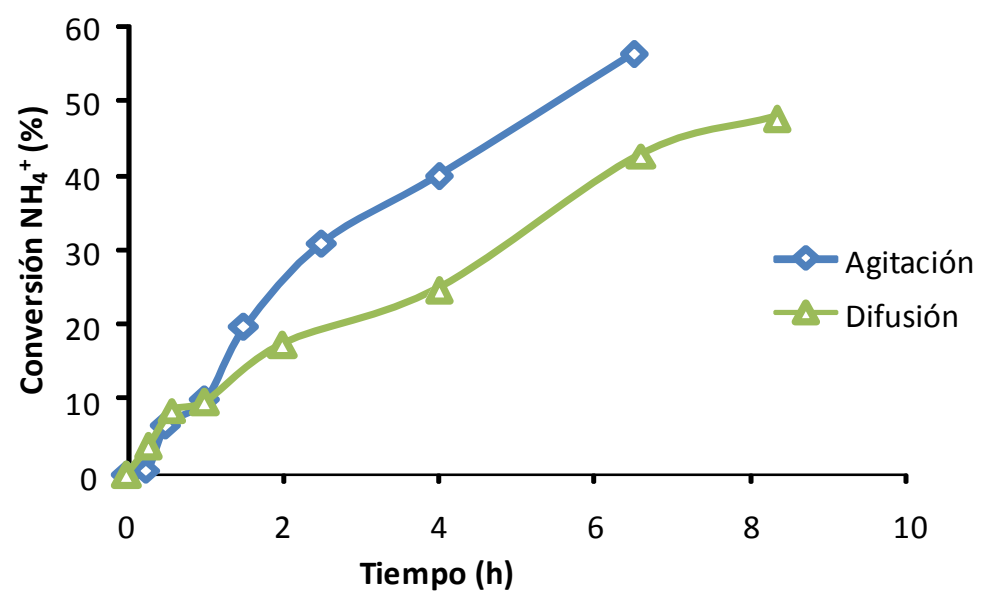

Figura 6. 17. Eliminación de amonio por oxidación forzada o por difusión de aire.

Otra de las opciones estudiadas para la eliminación de amonio fue su eliminación catalítica a temperatura ambiente usando aire como oxidante. Para ello se estudió la actividad de varios catalizadores con las aguas recogidas de un experimento de eliminación de nitratos y que contenían 7 ppm de amonio. Los catalizadores estudiados fueron catalizadores de oxidación descritos en la bibliografía como activos para la oxidación de amonio a nitrógeno [8-14] a temperaturas superiores a $150^{\circ} \mathrm{C}$. Los catalizadores preparados fueron los siguientes: $3 \% \mathrm{Pt} / \gamma-\mathrm{Al}_{2} \mathrm{O}_{3}$ calcinado, $3 \% \mathrm{Pt} / \gamma-\mathrm{Al}_{2} \mathrm{O}_{3}$ reducido, $3 \% \mathrm{Pd} / \gamma-\mathrm{Al}_{2} \mathrm{O}_{3}$ calcinado, $3 \% \mathrm{Pd} / \gamma-\mathrm{Al}_{2} \mathrm{O}_{3}$ reducido, $3 \% \mathrm{Ru} / \gamma-\mathrm{Al}_{2} \mathrm{O}_{3}$ reducido y $3 \% \mathrm{Ru} / \mathrm{TiO}_{2}$ reducido. En la figura 6.18 se muestran los resultados obtenidos tras 6 horas de reacción para cada uno de los catalizadores anteriores. En esta figura se puede observar que en general (salvo el catalizador $3 \% \mathrm{Ru} / \mathrm{TiO}_{2}$ ) los catalizadores que están 
reducidos son más activos que los que están sólo calcinados, obteniendo la máxima conversión con el catalizador $3 \% \mathrm{Pt} / \gamma-\mathrm{Al}_{2} \mathrm{O}_{3}$ reducido. Sin embargo, esta conversión (55\%) es sólo un poco mayor que la obtenida tras 6 horas añadiendo oxígeno por agitación mecánica sin catalizador (figura 6.17), lo que indicaría que la oxidación catalítica del amonio a temperatura ambiente no sería adecuada para eliminar el amonio formado y sería necesario aumentar la temperatura de trabajo, lo que desde el punto de vista económico no es viable.

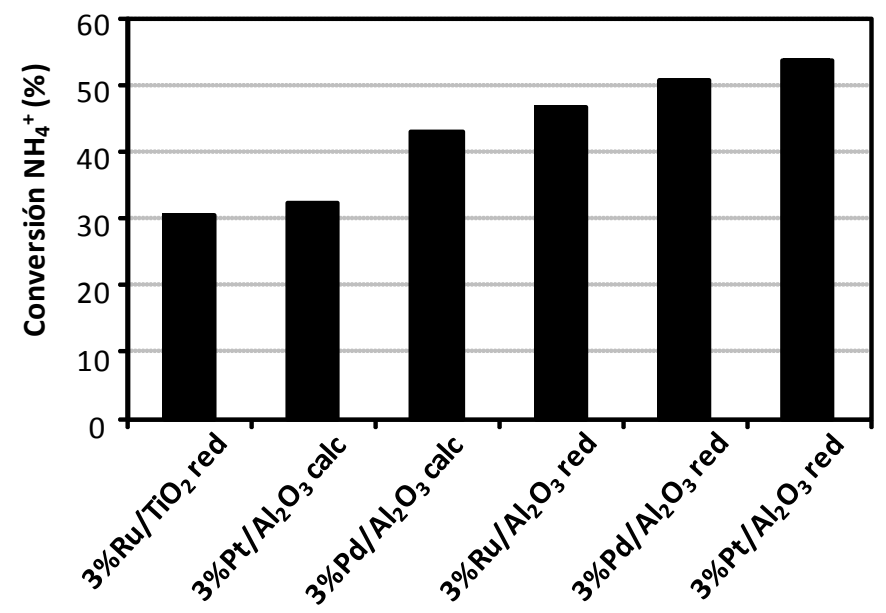

Figura 6. 18. Conversión de amonio tras 6 horas de reacción empleando distintos catalizadores (1 gramo de catalizador, $200 \mathrm{~mL} / \mathrm{min}$ de aire).

La tercera opción analizada para la eliminación de amonio fue la oxidación química con $\mathrm{H}_{2} \mathrm{O}_{2}$. Para ello, al agua recogida después de una reacción de reducción de nitratos se le fueron añadiendo cantidades sucesivas de $\mathrm{H}_{2} \mathrm{O}_{2}$. Los resultados obtenidos aparecen en la figura 6.19, donde se observa que al añadir $\mathrm{H}_{2} \mathrm{O}_{2}$ al agua de reacción el amonio va desapareciendo, pero contrariamente a lo que ocurría en los casos anteriores, la oxidación del amonio con $\mathrm{H}_{2} \mathrm{O}_{2}$ es demasiado intensa y no produce nitrógeno sino que se forman de nuevo nitratos, siendo la cantidad de nitratos formada equivalente a la de amonio oxidado, lo que indica que este método tampoco es adecuado para eliminar el amonio formado. 


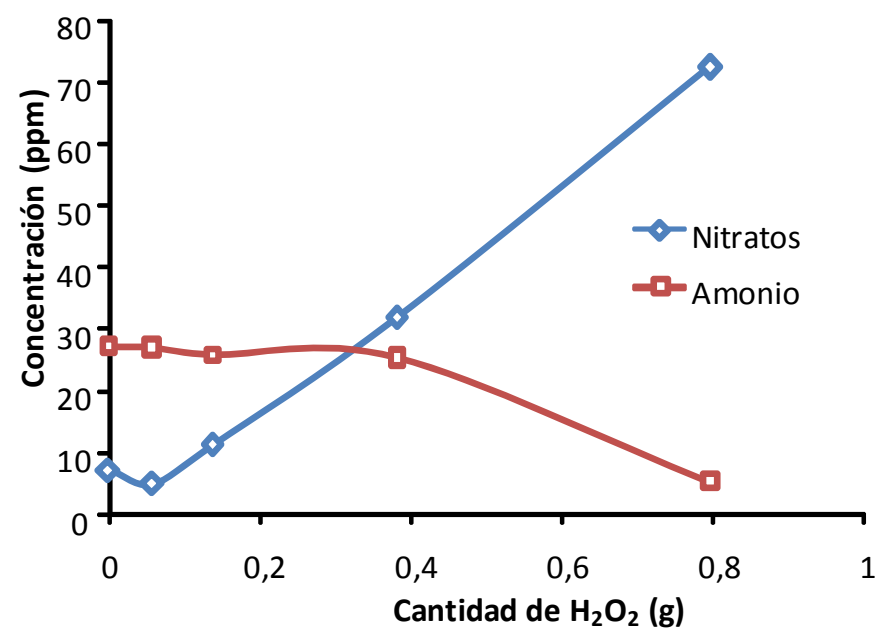

Figura 6. 19. Variación de las concentraciones de amonio y nitratos con la adición de $\mathrm{H}_{2} \mathrm{O}_{2}$.

La última opción es la eliminación de amonio utilizando materiales que actúan como intercambiadores iónicos. Estos experimentos se realizaron haciendo pasar un flujo de $5 \mathrm{~mL} / \mathrm{min}$ del agua recogida después de reacción con una concentración promedio de $10 \mathrm{mg} / \mathrm{L}$ de amonio a través de un lecho fijo de un material que actúa como intercambiador iónico. Los materiales que se estudiaron fueron materiales abundantes y baratos como la sepiolita, la faujasita y la clinoptilolita.

Por ello se determinó la capacidad de intercambio de nitratos de estos materiales obteniendo los siguientes resultados:

- Sepiolita: 0,056 mg amonio eliminado/g sepiolita.

- Faujasita: 0,210 mg amonio eliminado/g faujasita.

- Clinoptilolita: 1,9 mg amonio eliminado/g clinoptilolita.

Como se observa, los mejores resultados se obtienen con la clinoptilolita que es una zeolita natural con un bajo coste, la cual se podría usar como intercambiador iónico para retener todo el amonio formado durante la reacción de reducción catalítica de nitratos en aguas. 
Esto se comprobó en un experimento en el que el agua que salía del reactor donde se había producido la reducción catalítica de los nitratos, con un catalizador de $2,5 \% \mathrm{Sn} / 5 \% \mathrm{Pd} / \gamma-\mathrm{Al}_{2} \mathrm{O}_{3}$, pasaba por una columna de intercambio que contenía clinoptilolita. Tal como se observa en la figura 6.20, con esta configuración es posible eliminar en continuo al menos durante 30 horas el amonio formado como subproducto en la reacción de eliminación de nitratos hasta que se satura la columna. Una vez saturada la columna ésta se puede regenerar con una disolución saturada de $\mathrm{NaCl}$.

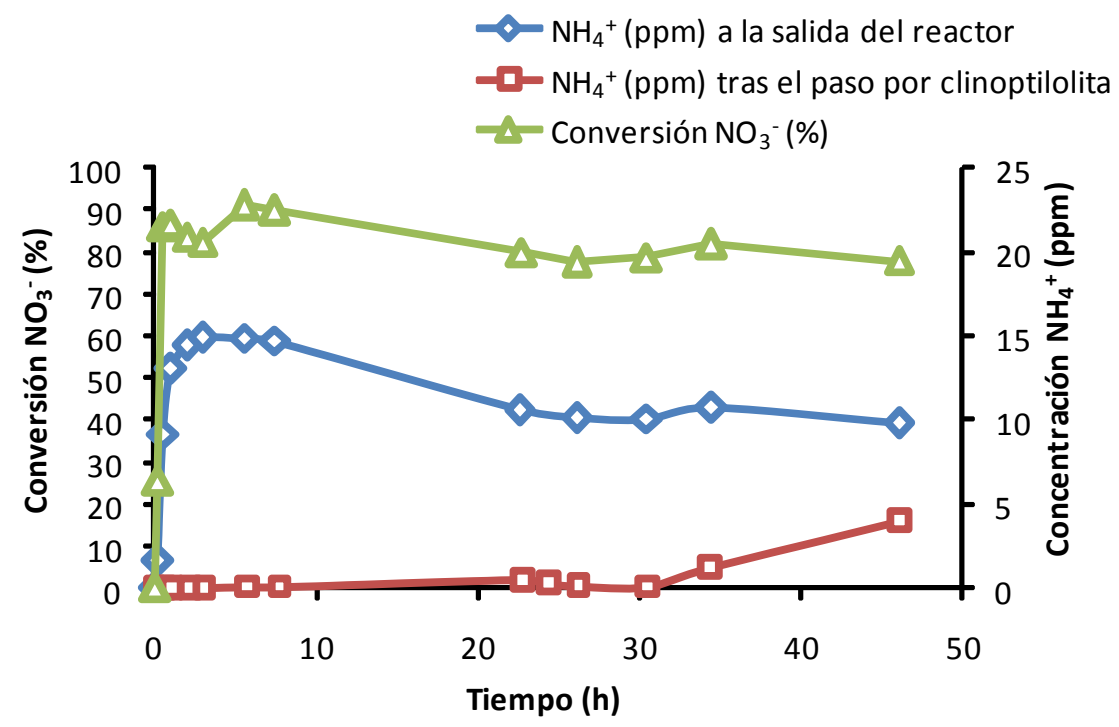

Figura 6. 20. Conversión de nitratos con un catalizador de 2,5\% Sn/5\% $\mathrm{Pd} / \mathrm{Al}_{2} \mathrm{O}_{3}$ y variación de la concentración de amonio a la salida del reactor y tras el paso por una columna de intercambio conteniendo clinoptilolita $(20 \mathrm{~g})$.

Por tanto, de estos estudios se puede concluir que el mejor método para eliminar el amonio formado como subproducto en la reacción de reducción de nitratos es el intercambio iónico usando como material de intercambio la clinoptilolita.

\subsection{Caracterización del catalizador}

El catalizador óptimo para la reducción de nitratos en continuo en aguas naturales, el catalizador de $\mathrm{Sn} / \mathrm{Pd} / \gamma-\mathrm{Al}_{2} \mathrm{O}_{3}$, se caracterizó por diversas técnicas como la difracción de 
rayos $\mathrm{X}$, la reducción a temperatura programada, el análisis textural, la quimisorción de CO y la microscopía electrónica de barrido y de transmisión. El catalizador se caracterizó antes y después de reacción con el fin de determinar sus fases, sus propiedades texturales, la dispersión de los metales en la superficie del catalizador y su estado de oxidación.

\subsubsection{Difracción de rayos $X$}

La técnica de difracción de rayos $\mathrm{X}$ permite determinar las fases que aparecen en el catalizador durante su preparación. Así, en la figura 6.21 se observan los difractogramas del soporte (a), del catalizador $2,5 \% \mathrm{Sn} / 5 \% \mathrm{Pd}(\mathrm{b})$, del catalizador tras su activación (c) y del catalizador tras reacción (d).

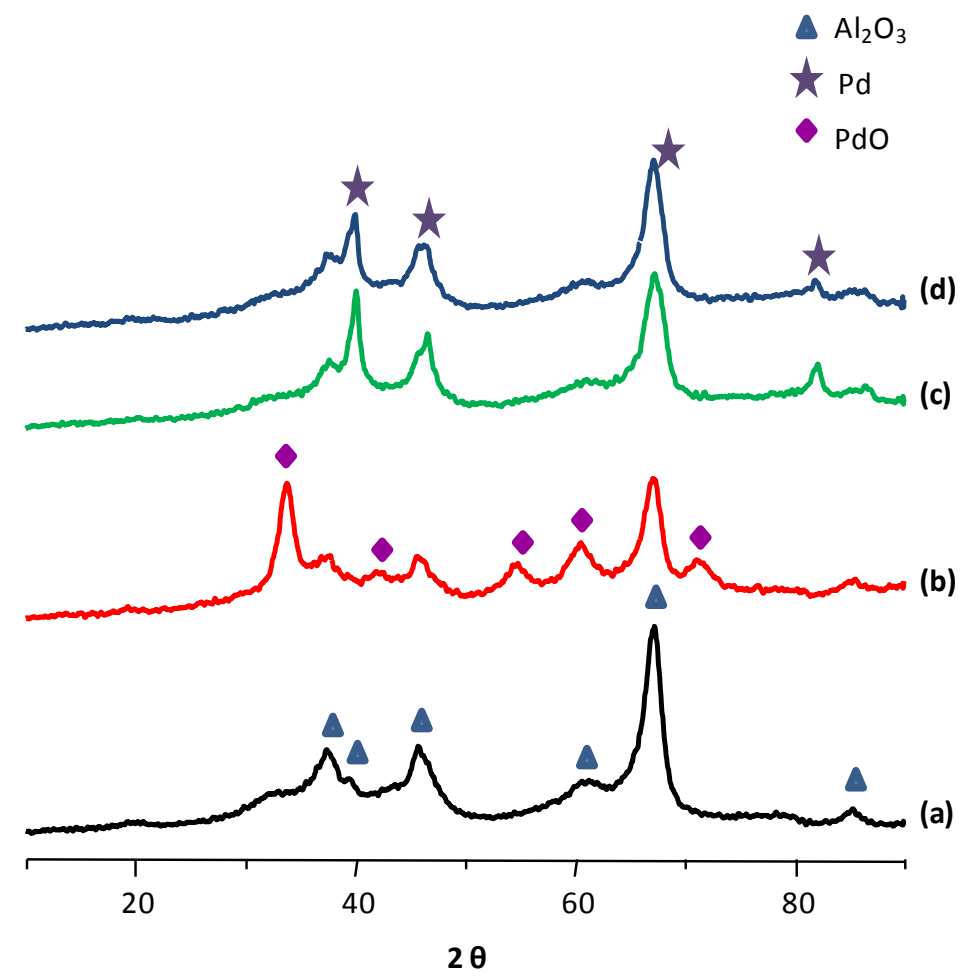

Figura 6. 21. Difractogramas de rayos $X$ de las muestras: (a) $\mathrm{Al}_{2} \mathrm{O}_{3}$, (b) $2,5 \% \mathrm{Sn} / 5 \% \mathrm{Pd} / \gamma-\mathrm{Al}_{2} \mathrm{O}_{3}$ calcinada, (c) 2,5\% $\mathrm{Sn} / 5 \% \mathrm{Pd} / \gamma-\mathrm{Al}_{2} \mathrm{O}_{3}$ después de activación con hidrógeno a $500^{\circ} \mathrm{C}$, (d) $2,5 \% \mathrm{Sn} / 5 \% \mathrm{Pd} / \gamma-\mathrm{Al}_{2} \mathrm{O}_{3}$ después de reacción. 
En esta figura se observa que en todos ellos aparecen a $2 \theta=37,5 ; 39,5 ; 45,9 ; 61$ y $66,9^{\circ}$ los picos asociados a la $\gamma$-alúmina. Si se compara el difractograma de rayos $\mathrm{X}$ del soporte con el del catalizador $\mathrm{Sn} / \mathrm{Pd} / \mathrm{Al}_{2} \mathrm{O}_{3}$, se observa que en este último los picos asignados a la alúmina disminuyen en intensidad, debido probablemente a una pérdida de cristalinidad en los sucesivos ciclos de calcinación que sufre el material en la impregnación de las sales precursoras. Además de los picos asociados a la alúmina, el difractograma de rayos $\mathrm{X}$ del catalizador $\mathrm{Sn} / \mathrm{Pd} / \mathrm{Al}_{2} \mathrm{O}_{3}$ (b) muestra nuevos picos a $2 \theta=33,9 ; 42,2 ; 54,7 ; 60,5$ y $71,5^{\circ}$ asociados al PdO. Sin embargo, no se observan picos asociados a especies de Sn, debido a la baja cantidad de Sn en el catalizador y a su elevada dispersión. Tras activar el catalizador con hidrógeno (c) desaparecen los picos de PdO y aparecen nuevos picos a $2 \theta=39 ; 45,4$ y $66,2^{\circ}$ asociados al Pd metálico [15]. Estos picos permanecen después de reacción $(d)$, siendo el difractograma de rayos $X$ de la muestra tras reacción muy similar al de la muestra después de activar, lo que indica que durante la reacción el catalizador no ha sufrido cambios significativos en su estructura.

Se caracterizaron también por esta técnica las muestras estudiadas en el apartado 5.3 con un contenido en $\mathrm{Pd}$ del $5 \%$ y cantidades variables de Sn. Los difractogramas de rayos $X$ de estos catalizadores se muestran en la figura 6.22. Tal como se observa, en todas las muestras se aprecian los picos característicos de la $\gamma-\mathrm{Al}_{2} \mathrm{O}_{3}$ y los picos característicos del Pd. Sin embargo, cabe destacar que ni siquiera en la muestra con un $5 \%$ Sn se aprecian picos correspondientes a especies de Sn. Sólo es posible observar picos asociados al Sn en la muestra que contiene un $10 \%$ Sn, los cuales aparecen a $2 \theta=39,6 ; 40,9$; 58,$5 ; 65,5 ; 74,2$ y $80,8^{\circ}$ y se han asignado a la fase $\mathrm{Pd}_{3} \mathrm{Sn}_{2}$. Estos resultados muestran que el estaño añadido a la muestra está muy disperso y que sólo para elevados contenidos en $\mathrm{Sn}$, éste forma una fase estable asociada al $\mathrm{Pd}$, aunque no hay que descartar que para cantidades menores de estaño esta fase también puede formarse, aunque en este caso estaría altamente dispersa.

La elevada dispersión del estaño podría explicar la mayor selectividad a nitrógeno obtenida con el catalizador Pd-Sn frente a la obtenida con el otro catalizador más activo, el de Pd-Cu (apartado 5.3). De hecho si se observan los difractogramas de los catalizadores $\mathrm{Pd}$-Cu con cantidades variables de Cu (figura 6.23), se aprecia que ya en el catalizador con 
un $1,5 \% \mathrm{Cu}$ empiezan a aparecer los picos asociados con el cobre, los cuales son claramente observados en el catalizador con un 3\%Cu. Para mayores contenidos en $\mathrm{Cu}$, los picos más intensos son los relacionados con la fase $\mathrm{Cu}^{0}$. Estos datos indican claramente que hay una menor dispersión del metal no noble en los catalizadores Pd-Cu que en los catalizadores $\mathrm{Pd}-\mathrm{Sn}$, lo que parece resultar en un aumento en la selectividad a nitrógeno de este catalizador frente a la obtenida con el catalizador Pd-Cu (figura 5.17).

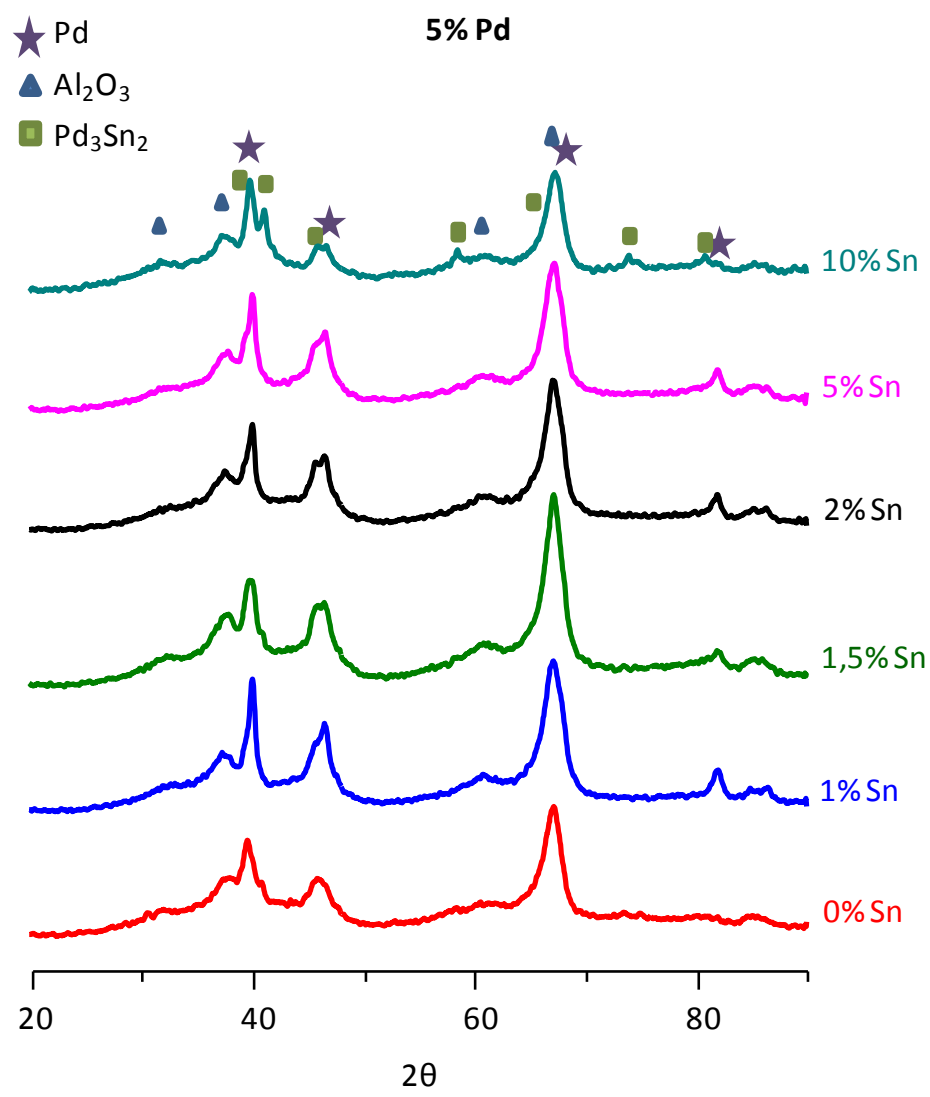

Figura 6. 22. Difractogramas de rayos $X$ de las muestras después de reacción con $5 \%$ de Pd y cantidad variable de Sn. 


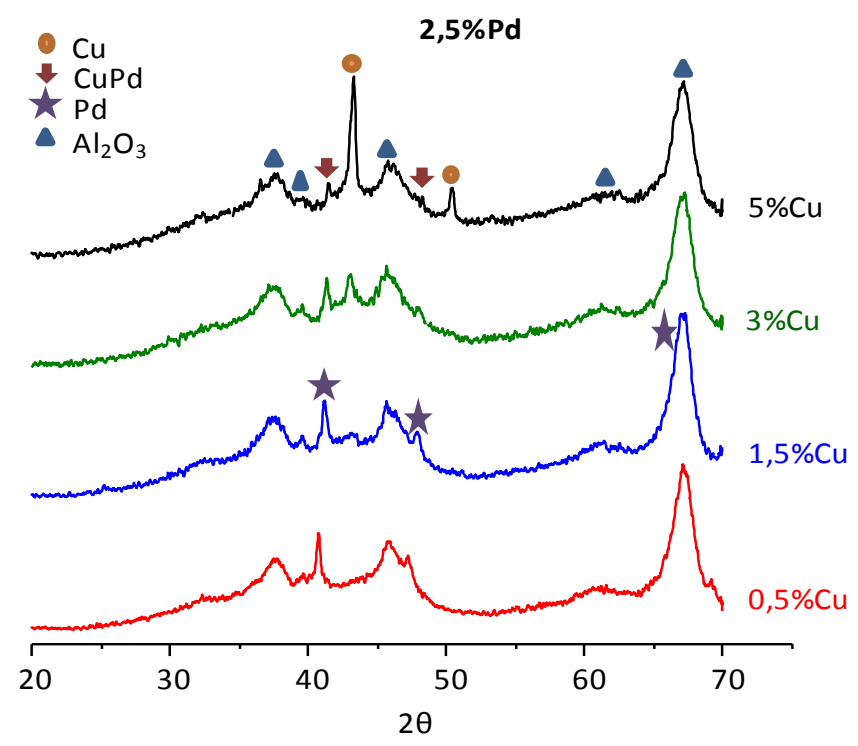

Figura 6. 23. Difractogramas de rayos $X$ de las muestras después de reacción con $2,5 \%$ de $P d y$ cantidad variable de Cu.

\subsubsection{Reducción a temperatura programada}

Con el fin de determinar las especies con propiedades redox presentes en el catalizador se ha estudiado la reducción a temperatura programada con hidrógeno $\left(\mathrm{H}_{2}-\right.$ TPR) del catalizador $2,5 \% \mathrm{Sn} / 5 \% \mathrm{Pd} / \gamma-\mathrm{Al}_{2} \mathrm{O}_{3}$ antes de su activación.

En la figura 6.24 se observa el perfil de $\mathrm{H}_{2}$-TPR del catalizador, en ella se observa que existen varios picos de consumo de hidrógeno a distintas temperaturas lo que indica la presencia de distintas especies que se pueden reducir más o menos fácilmente. El hecho más característico es la presencia de un pico negativo de desorción de hidrógeno a $74^{\circ} \mathrm{C}$ que corresponde a la descomposición del $\beta-\mathrm{PdH}$, el cual se forma a temperaturas inferiores [16-18]. A temperaturas mayores hay una banda ancha de consumo de hidrógeno entre 250 y $450^{\circ} \mathrm{C}$, la cual, según aparece en bibliografía [17, 19, 20], podría atribuirse a la reducción de las especies oxidadas de estaño a $\mathrm{Sn}^{0}$ o a la aparición de las 
especies $\mathrm{Pd}_{x} \mathrm{Sn}_{y}$ observadas por difracción de rayos $\mathrm{X}$ en los catalizadores con alto contenido en Sn.

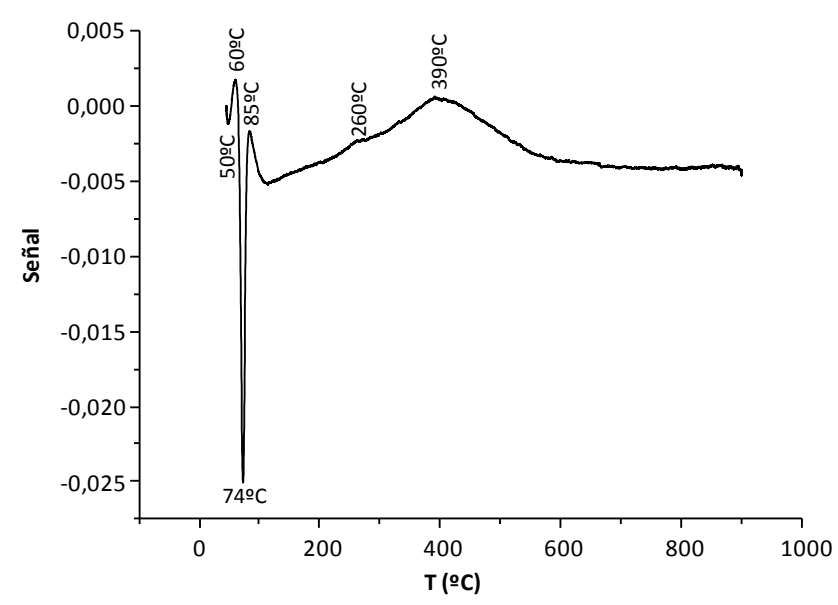

Figura 6. 24. Perfil de $\mathrm{H}_{2}$-TPR del catalizador $2,5 \% \mathrm{Sn} / 5 \% \mathrm{Pd} / \gamma-\mathrm{Al}_{2} \mathrm{O}_{3}$.

Estos datos se pueden relacionar con los resultados obtenidos en el apartado 5.5.3 en el que se estudiaba la activación del catalizador que proporcionaba los mejores resultados catalíticos. En ese apartado se observaba que la mejor activación se conseguía al reducir el catalizador a temperaturas inferiores a $200^{\circ} \mathrm{C}$, mientras que el catalizador activado a temperaturas superiores a $500^{\circ} \mathrm{C}$ presentaba una menor actividad. Esto indicaría que la aparición de las especies $\mathrm{Pd}_{x} \mathrm{Sn}_{\mathrm{y}}$ o la formación de $\mathrm{Sn}^{0}$ observada a temperaturas superiores a $200^{\circ} \mathrm{C}$, resulta en una disminución de la actividad del catalizador, probablemente por la formación de fases inactivas. De esta manera, los centros activos en la eliminación catalítica de nitratos serían el paladio metal y el estaño en forma de $\mathrm{Sn}^{2+}$ pero no en forma $\mathrm{Sn}^{0}$ o como $\mathrm{Pd}_{\mathrm{x}} \mathrm{Sn}_{\mathrm{y}}$.

\subsubsection{Quimisorción de CO}

Esta técnica permite determinar el tamaño de partícula del paladio depositado sobre la alúmina y su dispersión. Se basa en la adsorción de moléculas de CO en la 
superficie del metal, el cual se ha reducido previamente a $500^{\circ} \mathrm{C}$. Los resultados obtenidos se han presentado en la tabla 6.5, en la cual se observa que el tamaño de las partículas de $\mathrm{Pd}$ obtenidas para el catalizador $2,5 \% \mathrm{Sn} / 5 \% \mathrm{Pd} / \gamma-\mathrm{Al}_{2} \mathrm{O}_{3}$ es bastante grande $(57,5 \mathrm{~nm})$, dando, por tanto, una dispersión muy pequeña. Esto puede ser debido al procedimiento de preparación del catalizador o al alto contenido en paladio que haría que las partículas de metal se aglomeraran dando un tamaño de partícula bastante elevado. Para determinar esto, se caracterizó mediante la misma técnica un catalizador con una menor cantidad de metal $\left(1 \% \mathrm{Sn} / 2,5 \% \mathrm{Pd} / \gamma-\mathrm{Al}_{2} \mathrm{O}_{3}\right)$ observándose que el tamaño medio de cristal es 3,5 veces inferior al del catalizador que contiene el doble de Pd, haciendo que la dispersión del metal sobre el soporte sea mayor. La misma tendencia se observa al estudiar la quimisorción de CO de la muestra compuesta por $0,5 \%$ Sn y $1 \% \mathrm{Pd}$ soportada sobre una alúmina de alta superficie, cuya actividad catalítica se ha descrito en el apartado 6.3. En esta muestra se observa una disminución drástica del tamaño medio de cristal $(2,88 \mathrm{~nm})$ y un notable aumento de la dispersión del Pd sobre la superficie del catalizador. El aumento de la dispersión del Pd y la disminución de su tamaño de partícula al disminuir el contenido de metal fue observado también por Höller y col. [21], quienes obtuvieron diámetros de partícula metálica de alrededor de $50 \mathrm{~nm}$ para muestras del 1\%Pd en peso soportado sobre fibras de carbón activo, disminuyendo el tamaño al disminuir la cantidad de Pd en el catalizador.

Tabla 6. 5. Dispersión y tamaño de cristal determinados por quimisorción de CO de distintos catalizadores $\mathrm{Sn}-\mathrm{Pd} / \gamma-\mathrm{Al}_{2} \mathrm{O}_{3}$.

\begin{tabular}{lccc}
\hline Muestra & $\begin{array}{c}\text { Área del metal } \\
\text { activo }\left(\mathbf{m}^{2} / \mathrm{g}\right)\end{array}$ & $\begin{array}{c}\text { Dispersión del } \\
\text { metal (\%) }\end{array}$ & $\begin{array}{c}\text { Tamaño medio } \\
\text { de cristal (nm) }\end{array}$ \\
\hline $2,5 \% \mathrm{Sn} / 5 \% \mathrm{Pd} / \gamma-\mathrm{Al}_{2} \mathrm{O}_{3}$ & 0,4336 & 1,9 & 57,56 \\
$1 \% \mathrm{Sn} / 2,5 \% \mathrm{Pd} / \gamma-\mathrm{Al}_{2} \mathrm{O}_{3}$ & 0,7626 & 6,8 & 16,37 \\
$0,5 \% \mathrm{Sn} / 1 \% \mathrm{Pd} / \gamma-\mathrm{Al}_{2} \mathrm{O}_{3}$ alta & 1,736 & 38,9 & 2,88 \\
superficie & & & \\
\hline
\end{tabular}


La dispersión del paladio también puede depender del proceso de activación del catalizador, por ello se estudió la dispersión del Pd en un catalizador $2,5 \% \mathrm{Sn} / 5 \% \mathrm{Pd} / \gamma-\mathrm{Al}_{2} \mathrm{O}_{3}$ reducido a $500^{\circ} \mathrm{C}$ y en otro reducido a $50^{\circ} \mathrm{C}$. Tal como se observa en la tabla 6.6 , el tamaño medio de cristal y la dispersión del paladio son mayores cuanto menor es la temperatura de activación. Esto puede deberse a que al reducir el material a temperaturas superiores a $200^{\circ} \mathrm{C}$ podrían formarse aglomerados de partículas de $\mathrm{Pd}$ metal y especies $\mathrm{Pd}_{\mathrm{x}} \mathrm{Sn}_{\mathrm{y}}$. La formación de estas especies y la aglomeración del paladio hacen disminuir la actividad del catalizador, tal como se ha descrito en el apartado 5.5.3 al estudiar la actividad del catalizador bajo distintos procesos de activación.

Tabla 6. 6. Resultados de quimisorción de CO del catalizador $2,5 \% \mathrm{Sn} / 5 \% \mathrm{Pd} / \gamma-\mathrm{Al}_{2} \mathrm{O}_{3}$ reducido a $500^{\circ} \mathrm{C}$ y $50^{\circ} \mathrm{C}$.

\begin{tabular}{lccc}
\hline Muestra & $\begin{array}{c}\text { Área del metal } \\
\text { activo }\left(\mathrm{m}^{2} / \mathrm{g}\right)\end{array}$ & $\begin{array}{c}\text { Dispersión del } \\
\text { metal (\%) }\end{array}$ & $\begin{array}{c}\text { Tamaño medio } \\
\text { de cristal (nm) }\end{array}$ \\
\hline $\begin{array}{l}2,5 \% \mathrm{Sn} / 5 \% \mathrm{Pd} / \mathrm{Al}_{2} \mathrm{O}_{3} \text { reducido a } \\
500^{\circ} \mathrm{C}\end{array}$ & 0,434 & 1,9 & 57,56 \\
$2,5 \% \mathrm{Sn} / 5 \% \mathrm{Pd} / \mathrm{Al}_{2} \mathrm{O}_{3}$ reducido a & 2,608 & 11,7 & 9,57 \\
$50^{\circ} \mathrm{C}$ & & & \\
\hline
\end{tabular}

\subsubsection{Microscopía electrónica de barrido y de transmisión}

El catalizador $2,5 \% \mathrm{Sn} / 5 \% \mathrm{Pd} / \gamma-\mathrm{Al}_{2} \mathrm{O}_{3}$ también se caracterizó por microscopía electrónica, la cual se utilizó con el fin de determinar la morfología del material y las especies presentes en la superficie del mismo. La caracterización por microscopía electrónica de barrido de la muestra $2,5 \% \mathrm{Sn} / 5 \% \mathrm{Pd} / \gamma-\mathrm{Al}_{2} \mathrm{O}_{3}$ antes de reacción, aparece en la figura 6.25. En la micrografía se observan zonas más claras correspondientes a la presencia de elementos más pesados, es decir, al Pd y al Sn (zonas 1 y 2), mientras que las zonas más oscuras se atribuyen a la alúmina (zona 3 ).

Esto se comprobó mediante dispersión de rayos X (SEDX) obteniendo los resultados de la tabla 6.7. En esta tabla se observa que en las zonas 1 y 2 la cantidad de Pd presente 
es muy elevada, cercana al $60 \%$ lo que indica que existe una aglomeración de metal en ellas haciendo que, tal como han indicado los datos de quimisorción de $\mathrm{CO}$, la dispersión del paladio sobre el catalizador sea bastante baja. En las otras zonas, como en la zona 3, la presencia de $\mathrm{Pd}$ es muy baja. Por el contrario, el Sn está distribuido más homogéneamente en la superficie del catalizador, obteniéndose entre un 1 y un 2,6\% de este metal en las tres zonas estudiadas. Estos resultados equivalen a los vistos al estudiar el material por difracción de rayos $X$ (apartado 6.5.1), que indicaban también una elevada dispersión de la fase $\mathrm{Sn}$ en los catalizadores $\mathrm{Sn} / \mathrm{Pd} / \mathrm{Al}_{2} \mathrm{O}_{3}$.

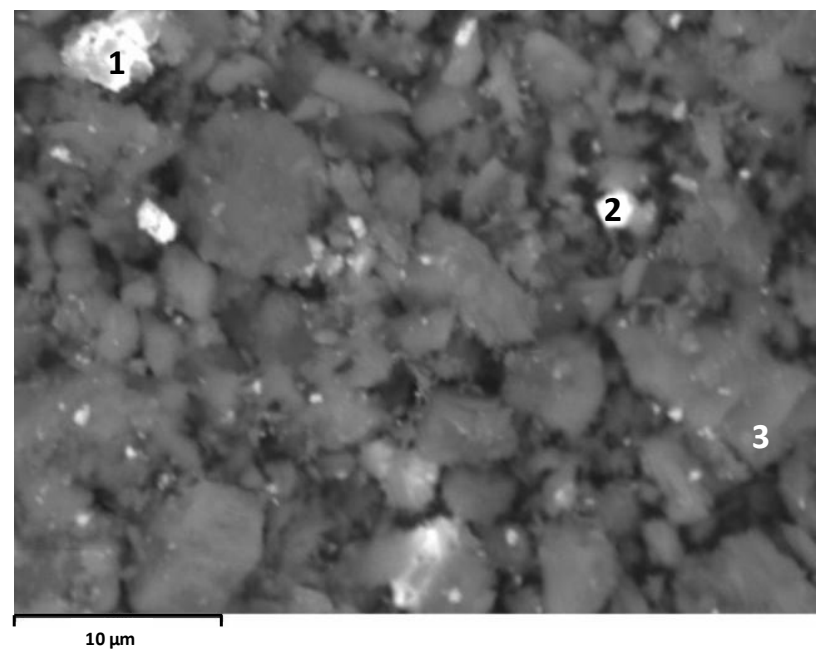

Figura 6. 25. Micrografía del catalizador $2,5 \% \mathrm{Sn} / 5 \% \mathrm{Pd} / \gamma-\mathrm{Al}_{2} \mathrm{O}_{3}$ obtenida mediante microscopía electrónica de barrido.

Tabla 6. 7. Análisis por dispersión de rayos $X$ del catalizador $2,5 \% \mathrm{Sn} / 5 \% \mathrm{Pd} / \gamma-\mathrm{Al}_{2} \mathrm{O}_{3}$.

\begin{tabular}{llll}
\hline \multirow{2}{*}{ Elemento } & \multicolumn{3}{c}{ \% en peso } \\
\cline { 2 - 4 } & Zona 1 & Zona 2 & Zona 3 \\
\cline { 2 - 4 } Pd & 59,33 & 60,8 & 5,6 \\
Sn & 2,64 & 1,03 & 2,63 \\
\hline
\end{tabular}

La caracterización del catalizador mediante microscopía electrónica de transmisión da como resultado las micrografías que se muestran en la figura 6.26. En estas micrografías las zonas más oscuras corresponden a los metales pesados presentes en el 
material. Esto permite determinar el tamaño medio de partícula metálica mediante la expresión siguiente:

$$
d\left(P d^{0}\right)_{T}=\frac{\sum_{i} n_{i} \cdot\left(d_{i}\right)^{3}}{\sum n_{i} \cdot\left(d_{i}\right)^{2}} \quad \text { Ec. } 6.1
$$

El tamaño medio obtenido para las partículas metálicas medidas es de 23,2 nm, siendo la distribución de tamaños de partícula (a partir de la medida de 90 partículas de distintas zonas de la muestra) la que se muestra en la figura 6.27, la cual tiene forma de campana de Gauss centrada en un tamaño de partícula entre 4 y $7 \mathrm{~nm}$.

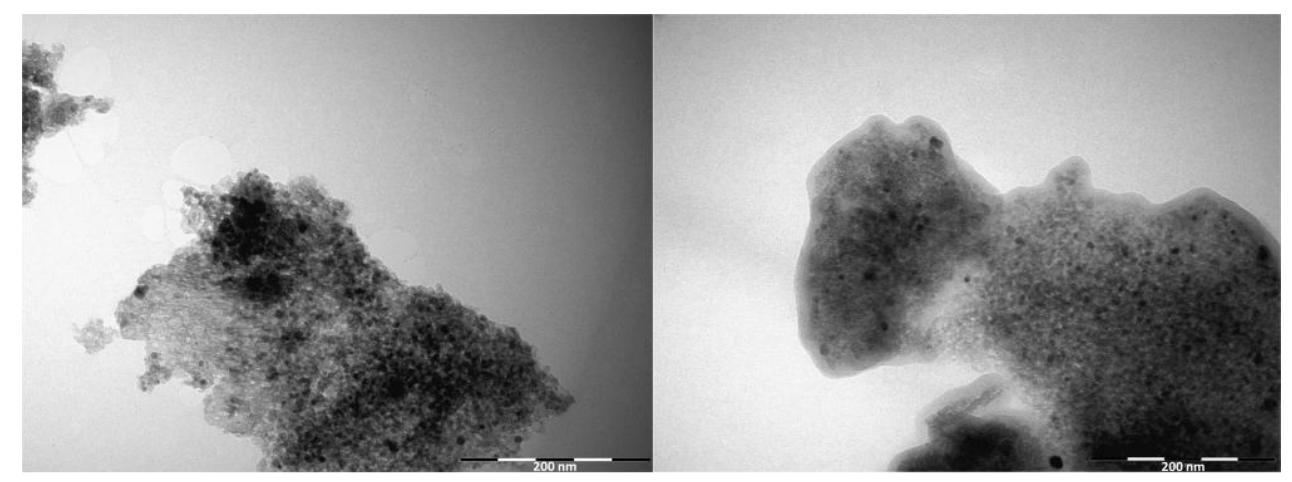

Figura 6. 26. Micrografías de microscopía electrónica de transmisión de la muestra $2,5 \% \mathrm{Sn} / 5 \% \mathrm{Pd} / \gamma$ $\mathrm{Al}_{2} \mathrm{O}_{3}$.

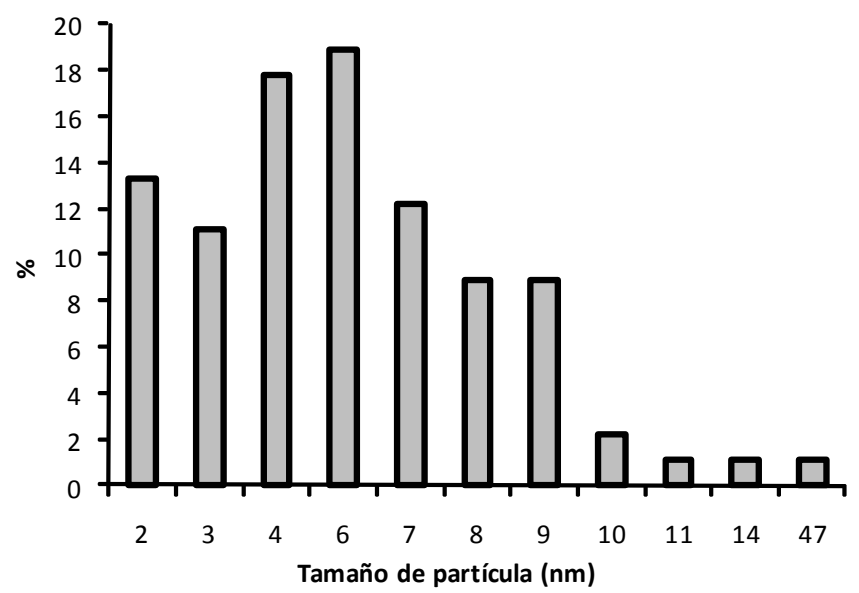

Figura 6. 27. Distribución de tamaño de partícula del metal obtenida mediante microscopía electrónica de transmisión. 


\subsubsection{Análisis textural}

En la tabla 6.8 se muestran las propiedades texturales del catalizador $2,5 \% \mathrm{Sn} / 5 \% \mathrm{Pd} / \gamma-\mathrm{Al}_{2} \mathrm{O}_{3}$ antes y después de reacción así como de la alúmina original. Tal como se observa, el área superficial de las tres muestras es similar, aunque hay una pequeña disminución en el área de las muestras tras añadir los metales, posiblemente debido a un taponamiento de los poros por los metales depositados en la superficie del material, siendo el área del catalizador de $125 \mathrm{~m}^{2} / \mathrm{g}$. En cuanto al volumen y tamaño de poro, los resultados obtenidos en las tres muestras también son similares, observando una disminución del volumen de poro tras añadir los metales al soporte. Es importante destacar que tras reacción no hay variación en las propiedades texturales del catalizador, ni tampoco en sus propiedades estructurales como se había observado en el estudio de difracción de rayos $X$ (apartado 6.5.1). Esto ratificaría la hipótesis propuesta en el apartado 6.1.1 de que la desactivación del catalizador estaría relacionada con el envenenamiento de los centros metálicos por adsorción de especies iónicas o por una modificación del estado de oxidación del metal y no por cambios estructurales irreversibles del catalizador.

Tabla 6. 8. Propiedades texturales de la alúmina y el catalizador $2,5 \% \mathrm{Sn} / 5 \% \mathrm{Pd} / \gamma-\mathrm{Al}_{2} \mathrm{O}_{3}$ antes y después de reacción.

\begin{tabular}{lccc}
\hline Muestra & $\begin{array}{c}\text { Área BET } \\
\left(\mathbf{m}^{2} / \mathbf{g}\right)\end{array}$ & $\begin{array}{c}\text { Volumen de poro } \\
\mathbf{B J H}\left(\mathbf{c m}^{\mathbf{3}} / \mathbf{g}\right)\end{array}$ & $\begin{array}{c}\text { Tamaño de poro } \\
\mathbf{B J H}(\AA)\end{array}$ \\
\hline $\mathrm{Al}_{2} \mathrm{O}_{3}$ & 139 & 0,232 & 53,91 \\
$2,5 \% \mathrm{Sn} / 5 \% \mathrm{Pd} / \gamma-\mathrm{Al}_{2} \mathrm{O}_{3}$ antes de reacción & 125 & 0,195 & 52,76 \\
$2,5 \% \mathrm{Sn} / 5 \% \mathrm{Pd} / \gamma-\mathrm{Al}_{2} \mathrm{O}_{3}$ después de reacción & 127 & 0,208 & 58,11 \\
\hline
\end{tabular}

\subsection{Mecanismo de la reacción}

Los resultados catalíticos y de caracterización discutidos en el apartado anterior nos han llevado a proponer un mecanismo de reacción para este catalizador, similar al propuesto por Vorlop y col. [22] el cual aparece representado en la figura 6.28. Según este 
mecanismo los nitratos son inicialmente reducidos a nitritos en los centros de Pd-Me por el $\mathrm{H}_{2}$ añadido al medio de reacción y que se había adsorbido y activado en los centros de $\mathrm{Pd}$. El nitrito es reducido posteriormente en los centros de Pd metálico para dar NO, el cual formará $\mathrm{N}_{2} \circ \mathrm{NH}_{4}^{+}$dependiendo de numerosos factores relacionados con la proximidad de las especies nitrogenadas y con fenómenos de transferencia de materia. Cuando la reacción se realiza con control de $\mathrm{pH}$ añadiendo $\mathrm{CO}_{2}$ al medio, la reacción de reducción de nitritos es más rápida que la reacción de reducción de nitratos, de tal manera que en la mayoría de las reacciones en continuo no se observa la presencia de esta especie en medio de reacción.

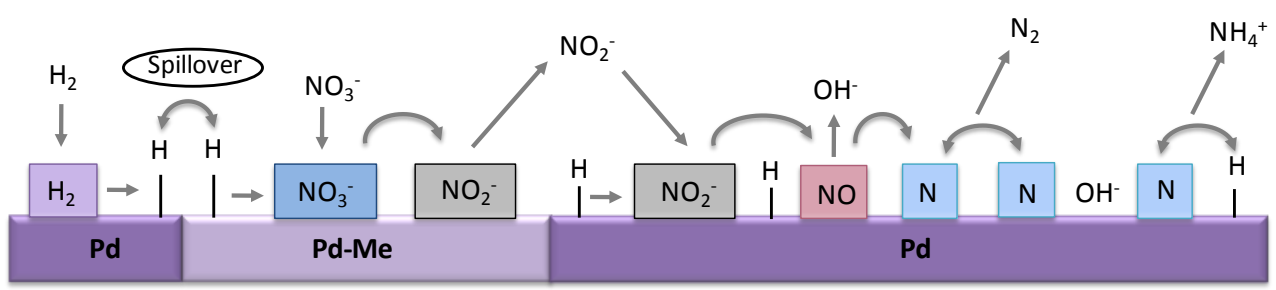

Figura 6. 28. Esquema de reacción propuesto por Vorlop y col. [22].

Esta propuesta se fundamenta en los resultados experimentales presentados y discutidos en los capítulos anteriores de esta tesis. Así, cuando en el apartado 5.3 se estudió la influencia de la relación metal noble/metal no noble en la actividad del catalizador, se veía que la máxima actividad catalítica se obtenía cuando la relación $\mathrm{Pd} / \mathrm{Sn}$ era de alrededor de 2, disminuyendo drásticamente para relaciones inferiores a 1 o superiores a 5 . Esto indicaría que la presencia de Pd aislado y de centros Pd-Sn es fundamental para obtener un catalizador activo, lo que está de acuerdo con el esquema propuesto en la figura 6.28. Los centros de Pd aislados serían necesarios para adsorber y activar el hidrógeno y también lo serían para reducir el nitrito a nitrógeno. Los centros PdSn serían necesarios para adsorber el nitrato y reducirlo a nitrito. Esto se comprobó estudiando la actividad de catalizadores monometálicos conteniendo sólo Pd o Sn. En la figura 6.29 se compara la actividad en la reacción de reducción de nitratos del catalizador $\mathrm{Sn} / \mathrm{Pd} / \gamma-\mathrm{Al}_{2} \mathrm{O}_{3}$ con la de los catalizadores monometálicos. Tal como se observa, ninguno de los dos catalizadores monometálicos es capaz de reducir a los nitratos en presencia de 
hidrógeno, siendo necesaria la presencia del par Sn-Pd para que se inicie la reacción y el nitrato se pueda reducir a nitrito.

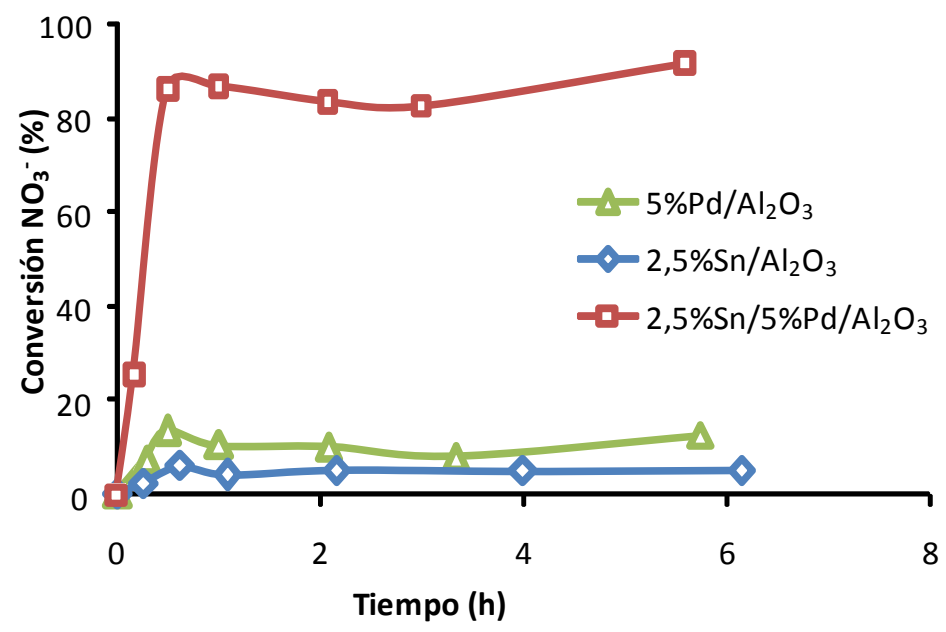

Figura 6. 29. Actividad de los catalizadores $5 \% \mathrm{Pd} / \gamma-\mathrm{Al}_{2} \mathrm{O}_{3}, 2,5 \% \mathrm{Sn} / \gamma-\mathrm{Al}_{2} \mathrm{O}_{3}$ y $2,5 \% \mathrm{Sn} / 5 \% \mathrm{Pd} / \gamma-\mathrm{Al}_{2} \mathrm{O}_{3}$ en la eliminación de nitratos en aguas naturales.

De acuerdo con el modelo propuesto, el nitrito formado debe ser posteriormente reducido a nitrógeno o amonio en los centros de $\mathrm{Pd}$ aislados. Esto último se comprobó estudiando el comportamiento de un catalizador monometálico de paladio en la eliminación de nitritos. Tal como se observa en la figura 6.30 este catalizador es muy activo en la reducción de los nitritos obteniéndose una eliminación total de éstos a los 10 minutos de reacción. Por tanto, todos los resultados ratifican la necesidad de la existencia de los centros Pd-Sn y Pd para tener un catalizador activo. El primero es necesario para reducir los nitratos, mientras que el segundo reduciría los nitritos formados. Así pues, aquellos catalizadores con una relación $\mathrm{Pd} / \mathrm{Sn}$ inferior a 1 presentan una actividad muy baja, pues en ellos no hay apenas centros de paladio aislados que activen el hidrógeno y reduzca el nitrito, mientras que en los catalizadores con una relación $\mathrm{Pd} / \mathrm{Sn}$ superior a 5 apenas aparecen pares $\mathrm{Pd}$-Sn necesarios para iniciar la reacción con lo que la actividad de este catalizador disminuye. 


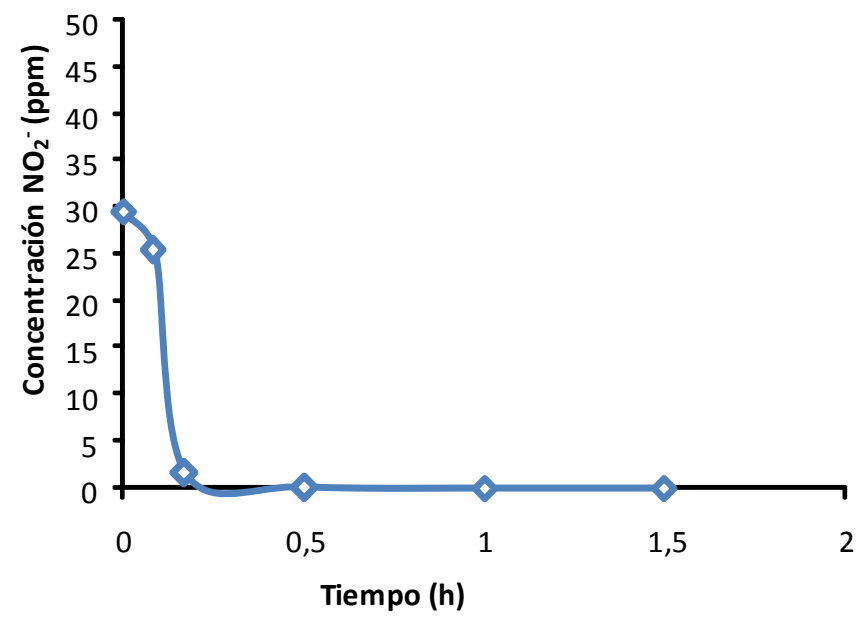

Figura 6. 30. Eliminación de nitritos usando el catalizador $5 \% \mathrm{Pd} / \gamma-\mathrm{Al}_{2} \mathrm{O}_{3}$.

Este esquema también justificaría los resultados obtenidos en el apartado 5.5.3 al estudiar la actividad del catalizador tras distintos tipos de activación. En base al modelo propuesto, los centros de Pd deben estar previamente reducidos para activar el hidrógeno y reducir el nitrito, de hecho se comprobó que, tal como se observa en la figura 6.31, si no se reduce el catalizador éste no es activo. Sin embargo, la reducción tampoco debe llevarse a cabo a temperaturas muy elevadas para evitar la sinterización del Pd (tabla 6.6) y la formación de especies de $\mathrm{Sn}^{0}$ o de fases $\mathrm{Pd}_{x} \mathrm{Sn}_{\mathrm{y}}$ que no son activas en esta reacción y que se forman a temperaturas de reducción elevadas (apartado 6.5.2).

Por tanto, se puede concluir que para tener un catalizador activo es necesaria la presencia de centros Pd y pares Sn-Pd, por ello la cantidad de Pd debe ser superior a la de $\mathrm{Sn}$ con una relación óptima $\mathrm{Pd} / \mathrm{Sn}=2-4$. Así pues, el paladio debe estar como Pd metálico y lo más disperso posible para adsorber el hidrógeno y reducir los nitritos, mientras que el Sn no debe estar como $\mathrm{Sn}^{0}$ ni formando fases $\mathrm{Pd}_{\mathrm{x}} \mathrm{Sn}_{\mathrm{y}}$. 


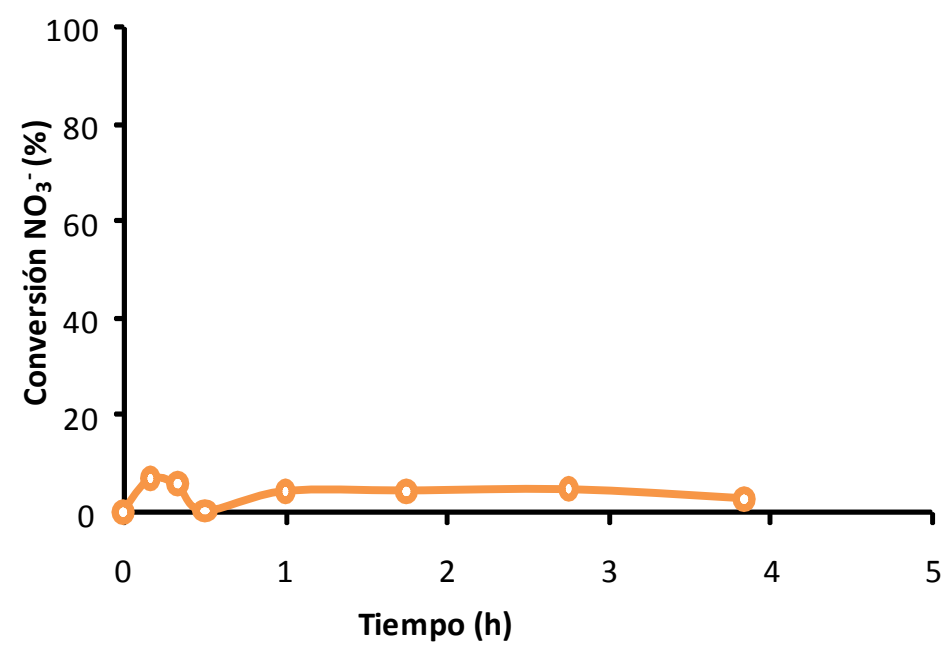

Figura 6. 31. Actividad del catalizador $2,5 \% \mathrm{Sn} / 5 \% \mathrm{Pd} / \gamma-\mathrm{Al}_{2} \mathrm{O}_{3}$ sin reducir en la eliminación de nitratos en aguas naturales.

Sin embargo, el mecanismo propuesto no explica la diferente selectividad obtenida al utilizar los distintos catalizadores o modificar las condiciones de reacción. La mayor parte de los trabajos que han estudiado la selectividad a amonio de esta reacción la relacionan con posibles problemas de transferencia de materia que impiden una rápida difusión de los intermedios nitrogenados formados produciendo una sobrerreducción de los mismos que lleva a la formación de amonio [23-25]. Otros autores indican que la selectividad de la reacción está relacionada con la superficie cubierta por especies- $\mathrm{N}$ y por especies $H$, ya que la formación de amonio requiere sólo una especie-N $[22,26,27]$, mientras que la formación de nitrógeno requiere la presencia de dos especies- $\mathrm{N}$ próximas. Los resultados obtenidos en el apartado 4.5 donde se observa que la presión parcial de hidrógeno y por tanto la presencia de $\mathrm{H}$ sobre el catalizador, aumenta la selectividad a amonio, apoyarían esta teoría. Esta teoría también se vería apoyada por los resultados obtenidos en el apartado 5.2.2 al estudiar la selectividad del catalizador Sn/Pd soportado sobre carbones, donde se observa que la elevada conductividad eléctrica de los mismos favorece la adsorción del $\mathrm{H}$ sobre el catalizador, aumentando la selectividad a amonio. Sin embargo, esta hipótesis no es contradictoria con la anterior ya que una disminución de los 
problemas difusionales, aparte de evitar la sobrerreducción de especies- $\mathrm{N}$, facilitaría el encuentro entre especies- $N$, favoreciendo la formación de $N_{2}$ frente a la formación de $\mathrm{NH}_{4}{ }^{+}$. De hecho, los resultados obtenidos muestran efectivamente que una disminución de los problemas difusionales, como la ausencia de microporos en el soporte (apartado 5.2), la neutralización de los iones hidroxilo formados que ajusta el pH de la reacción (apartado 4.1), una velocidad de agitación adecuada (apartado 4.3) y la disminución de la conductividad del medio (apartado 6.2), mejoran la selectividad de la reacción y aumentan la actividad del catalizador. Por tanto, ambos factores sobrerreducción de las especies- $\mathrm{N}$ por problemas difusionales y la interacción entre átomos $\mathrm{N}-\mathrm{N}$ frente a la interacción entre especies $\mathrm{N}-\mathrm{H}$ son los que controlan la selectividad de esta reacción.

No obstante, ninguna de las dos hipótesis explica necesariamente la diferente selectividad obtenida con los catalizadores de $\mathrm{Sn} / \mathrm{Pd}$ y $\mathrm{Cu} / \mathrm{Pd}$ soportados sobre alúmina. Tal como se vio en el apartado 5.4, la selectividad obtenida con el catalizador Sn/Pd era mejor que la obtenida con el catalizador $\mathrm{Cu} / \mathrm{Pd}$ trabajando en aguas naturales $\mathrm{y}$ en reacciones en continuo. Los mismos resultados se obtienen con un reactor discontinuo de tanque agitado donde es más fácil seguir el transcurso de la reacción. En las figuras 6.32 y 6.33 se representan los resultados obtenidos con ambos catalizadores al utilizar este reactor. En la figura 6.32 se observa que al usar el catalizador de $\mathrm{Cu} / \mathrm{Pd}$ los nitratos prácticamente desaparecen a los 120 minutos de reacción. Inicialmente, a medida que se eliminan los nitratos, se van formando nitritos, alcanzando un valor máximo de $15 \mathrm{ppm}$ a los 30 minutos de la reacción, tras lo que van desapareciendo progresivamente. De acuerdo con el mecanismo propuesto por Vorlop y col. [22] la reducción de nitratos a nitritos sería el primer paso de la reacción catalítica, siendo el nitrito un intermedio de reacción que seguiría reduciéndose a amonio o nitrógeno, tal como se observa que ocurre en la figura 6.32. Para el catalizador de $\mathrm{Sn} / \mathrm{Pd}$ el mecanismo sería el mismo, aunque en este caso y tal como se aprecia en la figura 6.33, las diferencias de velocidades de formación y desaparición de nitrito son mayores que en el caso del catalizador $\mathrm{Cu} / \mathrm{Pd}$, de manera que al ser la velocidad de reducción de nitratos a nitrito más lenta que la velocidad de reducción de nitrito a amonio o a nitrógeno, apenas se observa la formación de nitrito en el medio de reacción, lo que sí ocurría con el catalizador $\mathrm{Cu} / \mathrm{Pd}$. 
Las diferentes velocidades de reacción y las diferentes selectividades obtenidas con ambos catalizadores, indican que existe una interacción diferente de los metales entre sí y con el soporte, que llevan a la obtención de distintos resultados.

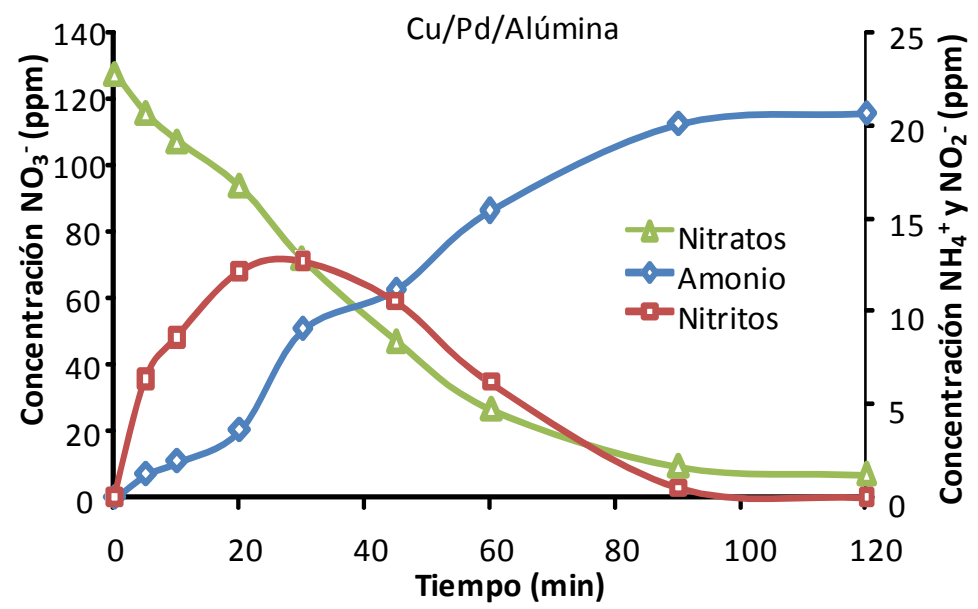

Figura 6. 32. Concentraciones de nitratos, nitritos y amonio al usar el catalizador $2,5 \% \mathrm{Cu} / 5 \% \mathrm{Pd} / \gamma$ $\mathrm{Al}_{2} \mathrm{O}_{3}$ en la eliminación de nitratos en aguas naturales.

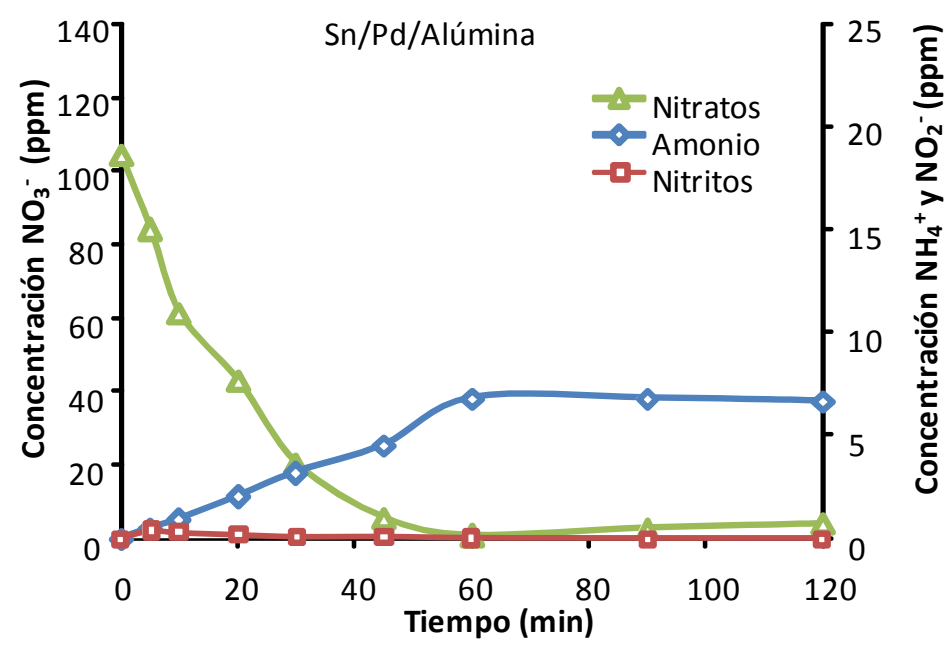

Figura 6. 33. Concentraciones de nitratos, nitritos y amonio al usar el catalizador $2,5 \% \mathrm{Sn} / 5 \% \mathrm{Pd} / \gamma$ $\mathrm{Al}_{2} \mathrm{O}_{3}$ en la eliminación de nitratos en aguas naturales. 
Esta interacción se puede modificar variando la cantidad de metales soportados, lo que además, tal como se vio en el apartado 6.5.3, lleva a una diferente dispersión de los metales sobre la superficie del soporte. De hecho, en la tabla 6.9 se muestra la dispersión de $\mathrm{Pd}$ y las selectividades obtenidas con varios catalizadores con la misma relación $\mathrm{Pd} / \mathrm{Sn}$ pero cuya cantidad de metal era variable. En esta tabla se puede apreciar que, para una conversión a nitratos de un $80 \%$, la selectividad a amonio y a nitrito aumenta a medida que aumenta la cantidad de metal y que disminuye la dispersión del mismo, medida por quimisorción de CO.

Tabla 6. 9. Dispersión de Pd, conversión a nitrato y selectividades a amonio, nitrógeno y nitrito, de los catalizadores $0,5 \% \mathrm{Sn} / 1 \% \mathrm{Pd} / \gamma-\mathrm{Al}_{2} \mathrm{O}_{3}, 1,5 \% \mathrm{Sn} / 3 \% \mathrm{Pd} / \gamma-\mathrm{Al}_{2} \mathrm{O}_{3}$ y $2,5 \% \mathrm{Sn} / 5 \% \mathrm{Pd} / \gamma-\mathrm{Al}_{2} \mathrm{O}_{3}$.

\begin{tabular}{lccccc}
\hline Catalizador & $\begin{array}{c}\text { Conversión } \\
\mathbf{N O}_{3}^{-}{ }^{-}(\%)\end{array}$ & $\begin{array}{c}\text { Selectividad } \\
\mathbf{N H}_{4}^{+} \text {(\%) }\end{array}$ & $\begin{array}{c}\text { Selectividad } \\
\mathbf{N}_{\mathbf{2}} \text { (\%) }\end{array}$ & $\begin{array}{c}\text { Selectividad } \\
\mathbf{N O}_{\mathbf{2}}^{-} \text {(\%) }\end{array}$ & $\begin{array}{c}\text { Dispersión } \\
\mathbf{P d}(\%)\end{array}$ \\
\hline $0,5 \% \mathrm{Sn} / 1 \% \mathrm{Pd} / \gamma-\mathrm{Al}_{2} \mathrm{O}_{3}$ & 79,3 & 37,4 & 62,3 & 0,3 & 38,9 \\
$1,5 \% \mathrm{Sn} / 3 \% \mathrm{Pd} / \gamma-\mathrm{Al}_{2} \mathrm{O}_{3}$ & 79,8 & 45,3 & 53,7 & 1,1 & 6,4 \\
$2,5 \% \mathrm{Sn} / 5 \% \mathrm{Pd} / \gamma-\mathrm{Al}_{2} \mathrm{O}_{3}$ & 80 & 49,1 & 48,8 & 2 & 1,9 \\
\hline
\end{tabular}

De manera equivalente los catalizadores $\mathrm{Pd} / \mathrm{Cu}$ son menos selectivos a nitrógeno que los catalizadores $\mathrm{Pd} / \mathrm{Sn}$, pues tal como se había obtenido en el estudio de difracción de rayos $X$ de estos catalizadores (apartado 6.5.1), había una mayor dispersión metálica en el catalizador $\mathrm{Pd} / \mathrm{Sn}$ que en el catalizador $\mathrm{Pd} / \mathrm{Cu}$. Estos resultados indicarían que aquella interacción metal-soporte que favorece la dispersión de los metales sobre la superficie del catalizador, también favorece la selectividad del catalizador a $\mathrm{N}_{2}$, probablemente debido a que esto aumenta la superficie activa del catalizador aumentando la probabilidad de interacción entre dos especies- $\mathrm{N}$ que lleven a la formación de $\mathrm{N}_{2}$ y no de $\mathrm{NH}_{4}{ }^{+}$.

\subsection{Conclusiones parciales}

El catalizador $\mathrm{Sn} / \mathrm{Pd}$ soportado sobre alúmina con una relación $\mathrm{Pd} / \mathrm{Sn}=2$ es activo para la eliminación en continuo a temperatura ambiente de los nitratos presentes en distintos tipos de aguas naturales e industriales. El catalizador es estable y durante la 
reacción no sufre modificaciones en su estructura ni en sus propiedades texturales. No obstante, el catalizador sufre un proceso de desactivación que es más rápido en aguas naturales que en agua destilada conteniendo nitratos, y que en gran medida está relacionado con la deposición de las especies iónicas en la superficie del catalizador que obstruyen los centros activos. Esta desactivación es reversible, recuperándose el 80-90\% de la actividad original con un lavado con agua destilada y durante sucesivos ciclos reacción - regeneración. Los mejores resultados se han obtenido con un catalizador de $0,5 \% \mathrm{Sn} / 1 \% \mathrm{Pd}$ soportado sobre alúmina de alta superficie con el que se obtiene una conversión del $80 \%$ y una selectividad a amonio del $30 \%$. El amonio formado se puede eliminar con el uso de una zeolita natural, la clinoptilolita, que actúa como intercambiador iónico. El mecanismo de reacción propuesto se basa en la necesidad de centros Pd-Sn para reducir los nitratos a nitritos y centros $\mathrm{Pd}$ aislados para activar el hidrógeno y reducir el nitrato a amonio o nitrógeno. El paladio debe estar reducido y altamente disperso, mientras que el estaño no ha de estar como $\mathrm{Sn}^{0} \mathrm{ni}$ formando especies $\mathrm{Pd}_{\mathrm{x}} \mathrm{Sn}_{\mathrm{y}}$. La selectividad de la reacción viene determinada por la dispersión de los centros activos del catalizador que debe ser la máxima posible para minimizar los problemas de transferencia de materia y evitar la producción de especies- $\mathrm{N}$ aisladas que formarán $\mathrm{NH}_{4}^{+}$en vez de $\mathrm{N}_{2}$. 


\section{Referencias}

[1] Y. Matatov-Meytal; Industrial \& Engineering Chemistry Research, 44 (2005) 9575.

[2] U. Prüsse, M. Hähnlein, J. Daum, K.-D. Vorlop; Catalysis Today, 55 (2000) 79.

[3] A. Pintar, J. Batista; Catalysis Today, 53 (1999) 35.

[4] A. Pintar, M. Setinc, J. Levec; Journal of Catalysis, 174 (1998) 72.

[5] B. P. Chaplin, E. Roundy, K. A. Guy, J. R. Shapley, C. J. Werth; Environmental Science \& Technology, 40 (2006) 3075.

[6] Y. Wang, J. Qu, H. Liu; Journal of Molecular Catalysis A: Chemical, 272 (2007) 31.

[7] Real Decreto 140/2003, de 7 de febrero, por el que se establecen los criterios sanitarios de la calidad del agua de consumo humano, BOE 45 (2003).

[8] J. Qin, K.-i. Aika; Applied Catalysis B: Environmental, 16 (1998) 261.

[9] R. Ukropec, B. F. M. Kuster, J. C. Schouten, R. A. van Santen; Applied Catalysis B: Environmental, 23 (1999) 45.

[10] J. Taguchi, T. Okuhara; Applied Catalysis A: General, 194-195 (2000) 89.

[11] T.-L. Huang, J. M. Maclnnes, K. R. Cliffe; Water Research, 35 (2001) 2113.

[12] J. Barbier Jr, L. Oliviero, B. Renard, D. Duprez; Catalysis Today, 75 (2002) 29.

[13] D. K. Lee, J. S. Cho, W. L. Yoon; Chemosphere, 61 (2005) 573.

[14] D. K. Lee; Environmental Science \& Technology, 37 (2003) 5745.

[15] A. K. Datye, J. Bravo, T. R. Nelson, P. Atanasova, M. Lyubovsky, L. Pfefferle; Applied Catalysis A: General, 198 (2000) 179.

[16] A. Pintar, J. Batista; Applied Catalysis B: Environmental, 63 (2006) 150.

[17] R. Gavagnin, L. Biasetto, F. Pinna, G. Strukul; Applied Catalysis B: Environmental, 38 (2002) 91.

[18] G. Fagherazzi, A. Benedetti, S. Polizzi, A. Mario, F. Pinna, M. Signoretto, N. Pernicone; Catalysis Letters, 32 (1995) 293.

[19] E. A. Sales, J. Jove, M. de Jesus Mendes, F. Bozon-Verduraz; Journal of Catalysis, 195 (2000) 88.

[20] R. Sasikala, S. K. Kulshreshtha; Journal of Thermal Analysis and Calorimetry, 78 (2004) 723.

[21] V. Höller, K. Rådevik, I. Yuranov, L. Kiwi-Minsker, A. Renken; Applied Catalysis B: Environmental, 32 (2001) 143.

[22] U. Prüsse, K.-D. Vorlop; Journal of Molecular Catalysis A: Chemical, 173 (2001) 313.

[23] W. Gao, N. Guan, J. Chen, X. Guan, R. Jin, H. Zeng, Z. Liu, F. Zhang; Applied Catalysis B: Environmental, 46 (2003) 341.

[24] S. Hörold, K. D. Vorlop, T. Tacke, M. Sell; Catalysis Today, 17 (1993) 21.

[25] S. Hörold, T. Tacke, K.-D. Vorlop; Environmental Technology, 14 (1993) 931.

[26] F. Zhang, S. Miao, Y. Yang, X. Zhang, J. Chen, N. Guan; The Journal of Physical Chemistry C, 112 (2008) 7665.

[27] T. Tacke, K. D. Vorlop; Chemie Ingenieur Technik, 65 (1993) 1500. 

7.

OTROS SOPORTES CATALIITICOS 

En este último capítulo se ha estudiado la actividad de los catalizadores $\mathrm{Cu} / \mathrm{Pd}$ y $\mathrm{Sn} / \mathrm{Pd}$ sobre distintos soportes catalíticos que presentan unas características especiales. Estos soportes son las hidrotalcitas y las zeolitas ITQ-6 e ITQ-2. El estudio del catalizador basado en hidrotalcitas se realizó ya que experimentos previos realizados en discontinuo habían mostrado que las especiales características de este material podían hacerlo adecuado como soporte catalítico para esta reacción. El estudio del catalizador con los materiales zeolíticos se hizo ya que estos materiales se han descubierto recientemente [1, 2] y su estructura deslaminada también podía hacerlos adecuados como soporte catalítico en esta reacción.

\subsection{Hidrotalcitas}

En este apartado se va a estudiar la actividad de catalizadores basados en hidrotalcitas con cobre para la eliminación de nitratos. En trabajos anteriores [3-5] se ha descrito este material como un catalizador efectivo para la eliminación de nitratos en un reactor discontinuo, empleando agua destilada conteniendo una cantidad determinada de nitratos. En este apartado se estudiará la eliminación de nitratos de aguas por estos materiales, pero trabajando en continuo con un reactor de flujo de pistón y con aguas naturales.

Las hidrotalcitas son hidróxidos dobles laminares (LDHs) que presentan una estructura compuesta por láminas individuales de polihidroxicationes bidimensionales con exceso de carga positiva, que se compensa por aniones hidratados que se sitúan en el espacio interlaminar [6]. Las hidrotalcitas se pueden representar mediante la siguiente fórmula química [6-8]:

$$
\left[\left(\mathrm{M}^{2+}\right)_{1-\mathrm{x}}\left(\mathrm{M}^{3+}\right)_{x}(\mathrm{OH})_{2}\right]\left[\mathrm{A}^{\mathrm{n}-}\right]_{\mathrm{x} / \mathrm{n}} \cdot \mathrm{mH}_{2} \mathrm{O}
$$

donde $A$ es un anión de carga negativa $n, \mathrm{M}^{2+}$ es el metal de carga bivalente y $\mathrm{M}^{3+}$ es el metal trivalente.

Las láminas de estos metales están compuestas por unidades estructurales constituidas por cationes divalentes, que están coordinados octaédricamente por grupos $\mathrm{OH}^{-}$(figura 7.1). Cada unidad octaédrica comparte sus vértices con tres octaedros 
contiguos que forman a lo largo una lámina bidimensional infinita. La sustitución de un catión bivalente $\left(\mathrm{Mg}^{2+}, \mathrm{Cu}^{2+}, \mathrm{Mn}^{2+}, \mathrm{Zn}^{2+}, \mathrm{Ca}^{2+}\right.$, etc.) por un catión trivalente $\left(\mathrm{Fe}^{3+}, \mathrm{Al}^{3+}\right.$, etc.) en la lámina crea un exceso de carga que ha de ser compensado por un anión intercambiable $\left(\mathrm{CO}_{3}{ }^{2-}, \mathrm{Cl}^{-}, \mathrm{OH}^{-}, \mathrm{NO}_{3}{ }^{-}\right.$, etc. $)$, situado en espacio interlaminar, que contiene además, moléculas de agua. El anión con mayor afinidad hacia las láminas debido a su densidad de carga y su tamaño es el ión carbonato, $\mathrm{CO}_{3}{ }^{2-}[6,8]$. Sin embargo, es posible la introducción en el espacio interlaminar de diferentes aniones orgánicos o inorgánicos [9].

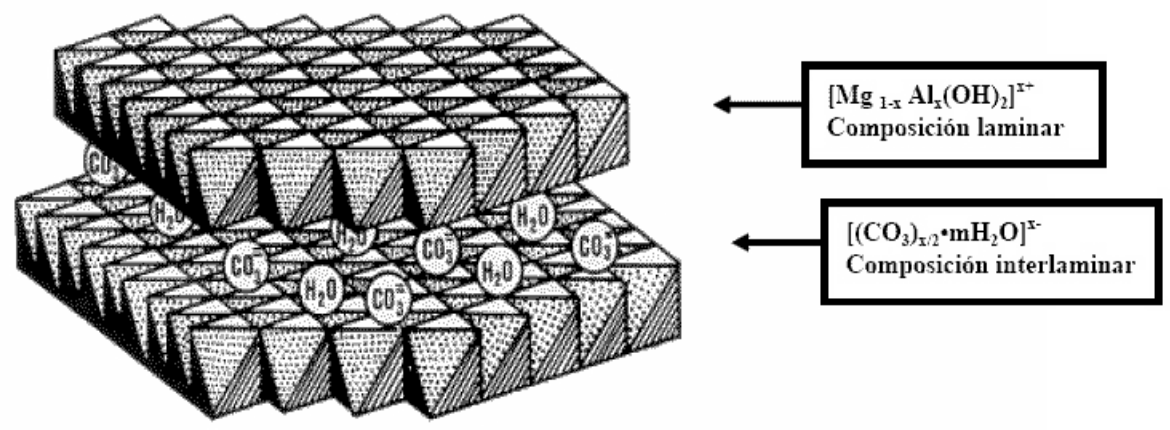

Figura 7. 1. Estructura de una hidrotalcita.

Durante el proceso de calcinación de una hidrotalcita se produce un fenómeno de deshidroxilación provocando el colapsamiento de la estructura y dando lugar a la formación de un óxido mixto amorfo con propiedades básicas. La calcinación de hidrotalcitas de $\mathrm{Al} / \mathrm{Mg}$, en un rango de temperaturas de 350 a $800^{\circ} \mathrm{C}$, conduce a la formación de óxidos mixtos o soluciones sólidas de $\mathrm{Al} / \mathrm{Mg}$ capaces de recuperar, por tratamiento con agua o en solución acuosa, la estructura laminar original de la hidrotalcita al situarse los aniones del medio en el espacio interlaminar [6, 10]. Este fenómeno constituye un método muy importante para obtener hidrotalcitas intercaladas o intercambiadas con diferentes aniones orgánicos o inorgánicos. En la literatura la conversión del óxido mixto en hidrotalcitas ha sido denominada como "regeneración", "reconstrucción", "restauración" o "rehidratación" y el proceso completo ha sido designado como proceso de "calcinación-rehidratación" o "efecto memoria" [10]. 
Un parámetro importante para caracterizar una hidrotalcita es la relación molar entre el catión trivalente y el bivalente $(R)$, definida como:

$$
R=\frac{M^{3+}}{M^{2+}+M^{3+}} \quad \text { Ec. } 7.1
$$

La obtención de una fase de hidrotalcita pura corresponde a un rango de $\mathrm{R}$ desde 0,2 a $0,33[7,10]$. Sin embargo, la posibilidad de obtener sólidos de estructura tipo hidrotalcita se define para un rango de $R$ entre 0,1 y 0,5 .

\subsubsection{Hidrotalcitas $\mathrm{Mg}-\mathrm{Al}-\mathrm{Cu}$}

En primer lugar se ha estudiado la actividad en la reacción de reducción de nitratos de un óxido mixto $\mathrm{Mg} / \mathrm{Al} / \mathrm{Cu}$ derivado de la hidrotalcita sin añadir Pd al mismo. La relación molar de este material era de 0,2. Para comparar con estudios previos realizados en discontinuo [3-5] se ha trabajado con agua destilada que contenía nitratos.

En la figura 7.2a se observa que, contrariamente a lo observado en el apartado 6.6 con los catalizadores monometálicos, este catalizador es capaz de eliminar los nitratos en la reacción en estudio, consiguiendo disminuir la concentración de nitrato de los $80 \mathrm{mg} / \mathrm{L}$ iniciales a concentraciones inferiores a 50 ppm durante 3,5 horas de reacción, sin formación de amonio ni nitrito. Esto podría hacer de este material un catalizador muy interesante por su selectividad a nitrógeno del $100 \%$.

No obstante, hay que tener en cuenta que el óxido mixto derivado de la hidrotalcita tiene la capacidad de regenerar la estructura laminar de la hidrotalcita original al entrar en contacto con una disolución que contiene aniones. Por ello, con este material es fundamental distinguir los nitratos eliminados del medio al reconstruir la estructura de la hidrotalcita, de los reducidos por la actividad catalítica del material. Para conseguir esto, se realizó una reacción con el mismo catalizador pero sin añadir hidrógeno al medio, observando que aunque desaparece una menor cantidad de nitratos que en el caso anterior, también se eliminan los nitratos del medio en ausencia de un reductor (figura 7.2b). En ausencia de hidrógeno esto no se puede deber a una reducción catalítica sino que la eliminación de nitratos del medio de reacción se debe atribuir únicamente a la incorporación de los mismos sobre el óxido mixto para reconstruir la estructura de la 
hidrotalcita. Por tanto, se puede afirmar que con las hidrotalcitas ( $\mathrm{HT}(\mathrm{Mg}-\mathrm{Al}-7 \% \mathrm{Cu})$ ) una parte importante de la eliminación de los nitratos del medio se consigue no por la actividad catalítica del material sino por su incorporación al material en el proceso de regeneración de la estructura.

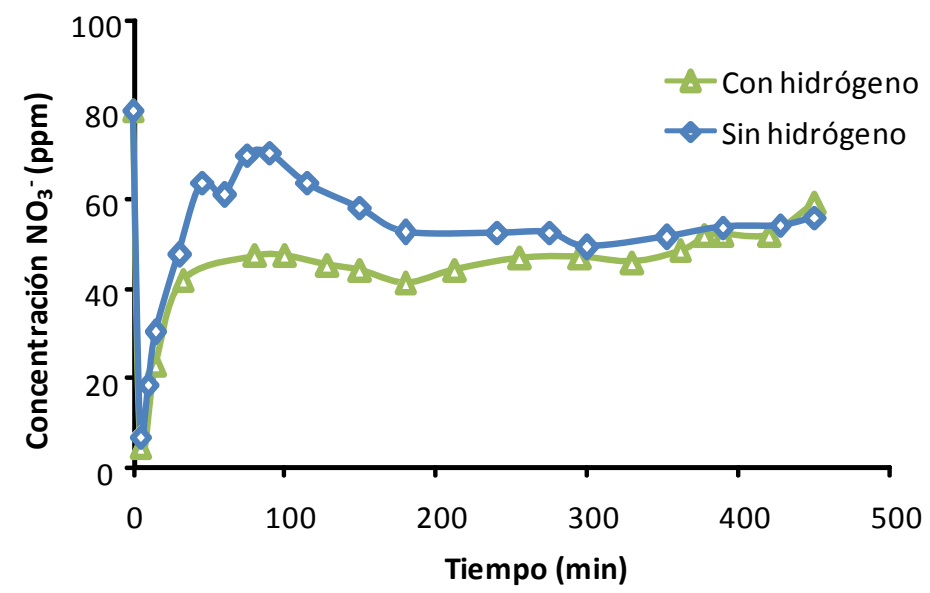

Figura 7. 2. Concentración de nitratos para experimentos realizados (a) con hidrógeno, o (b) sin hidrógeno (3,5 g de HT(Mg-Al-7\%Cu), $35 \mathrm{~mL} / \mathrm{min}$ de agua destilada conteniendo $80 \mathrm{mg} / \mathrm{L}$ de nitratos).

Es posible cuantificar la incorporación de los nitratos al material, determinando el porcentaje de $\mathrm{N}$ en la muestra tras reacción, mediante análisis elemental. Comparando estos resultados con la cantidad total de $\mathrm{N}$ eliminada se puede saber por diferencia la cantidad de nitratos reducidos. Los resultados obtenidos aparecen en la tabla 7.1 donde se puede observar que, en ambos experimentos, tras reacción existe $\mathrm{N}$ en el catalizador, lo que indica que parte de los nitratos se han incorporado a la estructura del catalizador. Al comparar la cantidad de $\mathrm{N}$ en la muestra en la que se hizo la reacción sin hidrógeno frente a la cantidad total de $\mathrm{N}$ eliminado, se puede comprobar que prácticamente todo el $\mathrm{N}$ eliminado en la reacción está en la estructura del catalizador. Por el contrario, en presencia de hidrógeno la cantidad de $\mathrm{N}$ eliminada por su incorporación al material es del $73 \%$, mientras que el $27 \%$ se ha eliminado por reducción catalítica. Estos datos indican que aunque con las hidrotalcitas $\mathrm{Mg}-\mathrm{Al}-\mathrm{Cu}$ la eliminación de nitratos se produce 
mayoritariamente por su incorporación al material para regenerar la hidrotalcita, hay un bajo porcentaje de nitratos que se elimina por reducción catalítica.

Tabla 7. 1. Contenido en nitrógeno del catalizador $H T(M g-A l-7 \% C u)$ tras una reacción con o sin hidrógeno.

\begin{tabular}{ccc}
\hline Reacción & Contenido en N (\%) & N eliminado (\%) \\
\hline Con $\mathrm{H}_{2}$ & 1,9 & 2,6 \\
$\operatorname{Sin~} \mathrm{H}_{2}$ & 2,0 & 2,2 \\
\hline
\end{tabular}

Estos resultados son interesantes pues la mayoría de estudios relacionados con la eliminación de nitratos en aguas muestran que, tal como se vio con el catalizador Pd-Sn en el apartado 6.6 y como se ha descrito por otros autores [11-14], es necesaria la presencia de un metal noble y un metal no noble para que se produzca la reducción. En cambio, los resultados obtenidos con las hidrotalcitas $\mathrm{Mg}-\mathrm{Al}-\mathrm{Cu}$ indicarían que es posible la reducción parcial de los nitratos sin la presencia de un metal noble. Estos resultados se podrían explicar basándose en el esquema de reacción propuesto por Epron y col. [15]. Estos autores proponen que la reducción de los nitratos se produce por una reacción redox entre éstos y el $\mathrm{Cu}^{0}$, el cual pasaría a $\mathrm{Cu}^{2+}$ y reduciría los nitratos a nitrógeno o amonio. $\mathrm{EI}$ papel del metal noble sería la activación del hidrógeno para permitir la reducción del cobre de acuerdo con la figura 7.3. En el caso del catalizador basado en HT(Mg-Al-Cu) la reducción de los nitratos se produciría también a partir de la oxidación del $\mathrm{Cu}^{0} \mathrm{a} \mathrm{Cu}^{2+} \mathrm{y}$ sería posible con este material la regeneración de los centros $\mathrm{Cu}^{0}$ por el hidrógeno del medio de reacción, sin necesidad de la presencia de un metal noble que activase al mismo.

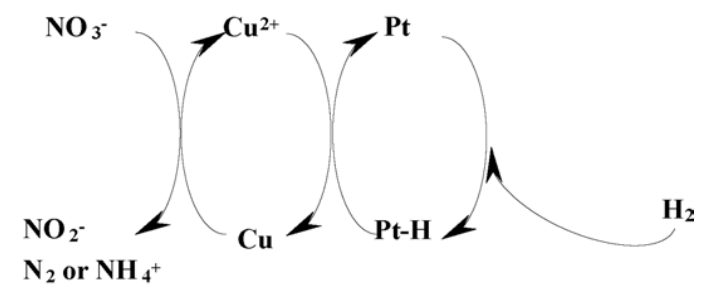

Figura 7. 3. Esquema de reacción propuesto para la reducción de nitratos usando catalizadores de $\mathrm{Pt}-\mathrm{Cu}$. 
Para comprobar esta hipótesis se realizaron dos tipos de experimentos. Por una parte, se estudió la eliminación de nitratos con hidrógeno utilizando un catalizador HT(Mg-Al-7\%Cu) sin reducir previamente, y por otra parte, se utilizó un catalizador basado en una hidrotalcita isomórfica que sólo contenía Mg y Al. Los resultados de eliminación de $\mathrm{N}$ y el porcentaje de $\mathrm{N}$ presente en la muestra aparecen en la tabla 7.2. En esta tabla se observa cómo en ambos casos, la eliminación de $\mathrm{N}$ coincide prácticamente con la cantidad de $\mathrm{N}$ que posee la muestra, lo que indica que con estos materiales la eliminación de nitrato se produce únicamente por la incorporación de los nitratos al material al regenerar la estructura de la hidrotalcita y no por reducción catalítica lo que sólo ocurrirá si existe $\mathrm{Cu}^{0}$. Los datos indican también que la presencia de $\mathrm{Cu}$ en la estructura del material modifica su capacidad para incorporar nitratos en la hidrotalcita regenerada, favoreciendo la incorporación de los mismos en el material.

Tabla 7. 2. Contenido en nitrógeno del catalizador $H T(\mathrm{Mg}-\mathrm{Al}-7 \% \mathrm{Cu})$ sin reducir y del catalizador HT(Mg-Al).

\begin{tabular}{lcc}
\hline Catalizador & Contenido en N (\%) & N eliminado (\%) \\
\hline HT(Mg-Al-7\%Cu) sin reducir & 1,79 & 1,82 \\
HT(Mg-Al) & 0,7 & 0,71 \\
\hline
\end{tabular}

La incorporación de los nitratos a la hidrotalcita $\mathrm{Mg}-\mathrm{Al}-\mathrm{Cu}$ y la regeneración de la fase hidrotalcita se corroboró también claramente al caracterizar mediante espectroscopía infrarroja y difracción de rayos X el catalizador de $\mathrm{HT}(\mathrm{Mg}-\mathrm{Al}-7 \% \mathrm{Cu}$ ). Así, los espectros de infrarrojo del catalizador $\mathrm{HT}(\mathrm{Mg}-\mathrm{Al}-7 \% \mathrm{Cu})$ utilizado en la eliminación de nitratos en presencia de hidrógeno y en ausencia del mismo se muestran en la figura 7.4. En esta figura se observa cómo en ambos casos aparecen los picos correspondientes a la vibración de estiramiento asimétrico del nitrato a $1384 \mathrm{~cm}^{-1}$, indicando que el $\mathrm{NO}_{3}{ }^{-}$ presente en el agua de reacción ha sido incorporado a la hidrotalcita [16]. 


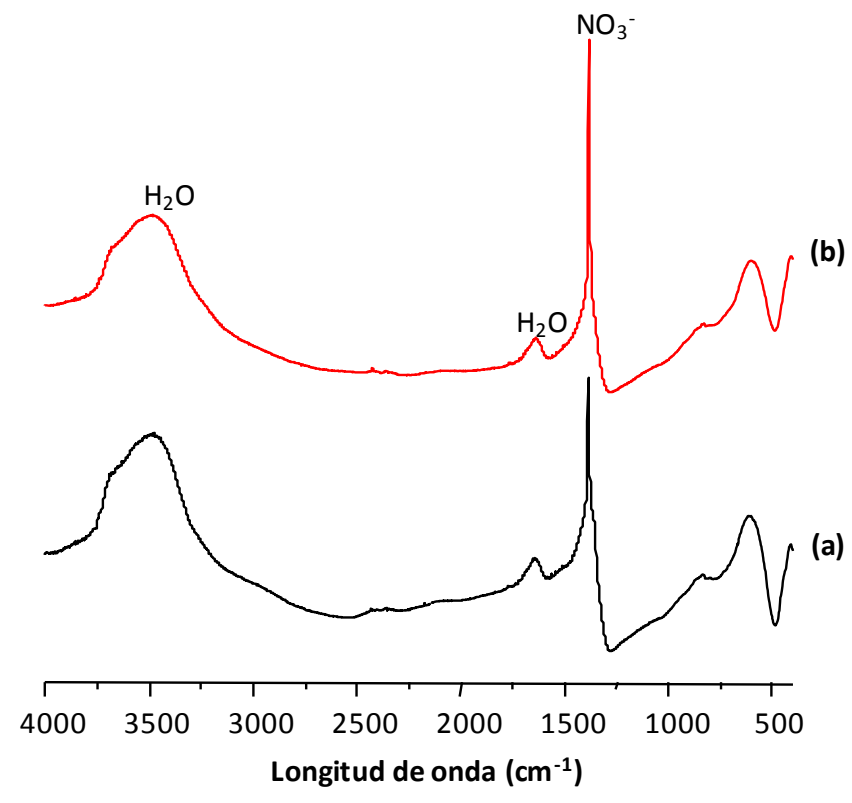

Figura 7. 4. Espectros de infrarrojo de las muestras utilizadas en un experimento (a) con o (b) $\sin$ hidrógeno (catalizador $\mathrm{HT}(\mathrm{Mg}-\mathrm{Al}-7 \% \mathrm{Cu})$ ).

Los difractogramas de rayos $\mathrm{X}$ de los catalizadores $\mathrm{HT}(\mathrm{Mg}-\mathrm{Al}-7 \% \mathrm{Cu})$ antes de calcinar, después de calcinar, después de la activación y después de reducir, se muestran en la figura 7.5. Tal como se observa en esta figura, el catalizador antes de calcinar, muestra los picos característicos de una hidrotalcita $(2 \theta=11,2 ; 22,7 ; 34,4 ; 38,4 ; 45,5 ; 46,7$; 60,$1 ; 61,8$ y $\left.65,3^{\circ}\right)$, picos que desaparecen tras la calcinación del catalizador apareciendo los picos del MgO, a $2 \theta=37 ; 43,1$ y $62,6^{\circ}$; lo que indica que la hidrotalcita tras la calcinación se ha transformado en un óxido mixto $\mathrm{Mg}-\mathrm{Al}-\mathrm{Cu}$. Los mismos picos de difracción se observan en el catalizador después de reducir. Por el contrario, después de reacción reaparecen los picos de difracción de la hidrotalcita, lo que indica que el material ha regenerado su estructura en contacto con el agua conteniendo nitratos pasando el óxido mixto a hidrotalcita. 


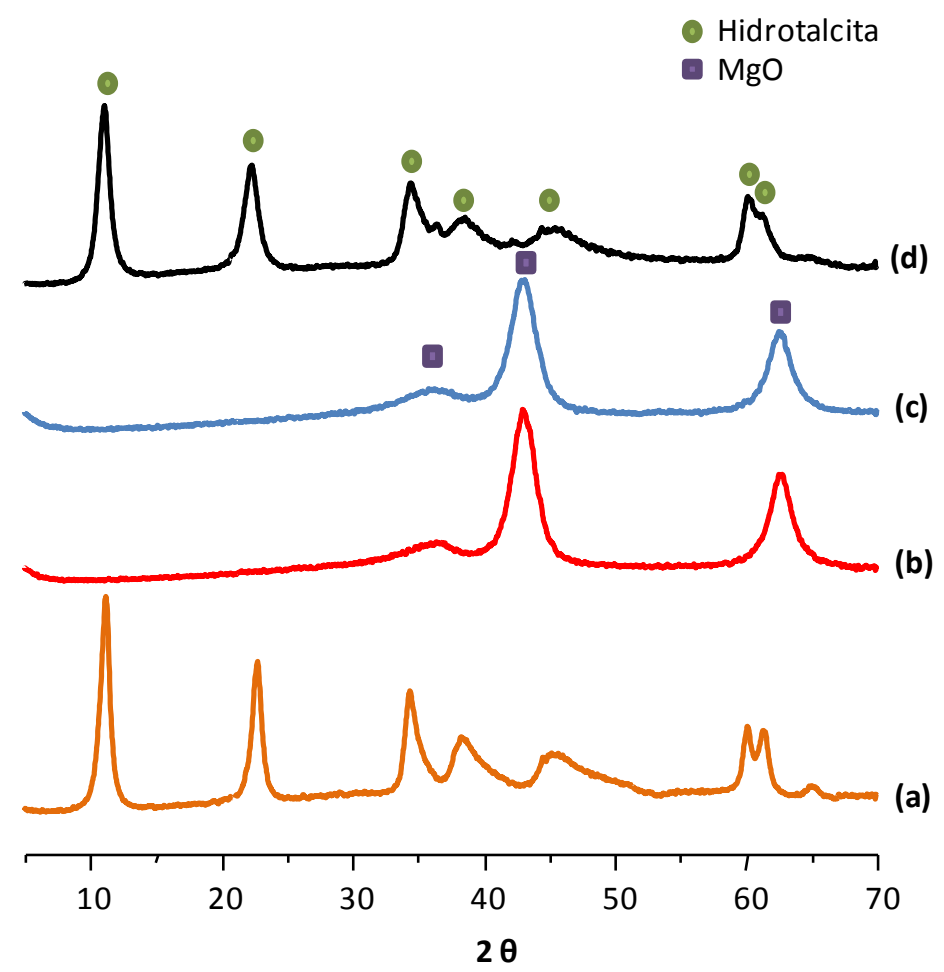

Figura 7. 5. Difractogramas de rayos X del catalizador HT(Mg-Al-7\%Cu): (a) antes de calcinar; (b) después de calcinar, (c) después de reducir, (d) después de reacción.

\subsubsection{Hidrotalcitas $\mathrm{Mg}-\mathrm{Al}-\mathrm{Cu}$ impregnadas con $\mathrm{Pd}$}

Con el fin de aumentar la actividad catalítica de las hidrotalcitas Mg-Al-Cu se realizaron experimentos añadiendo a este material cantidades variables de paladio. Las hidrotalcitas poseían una relación molar de 0,2 y un contenido en cobre en peso del 1,5\%.

Como en el caso anterior se hicieron experimentos con hidrógeno (500 mL/min) y sin hidrógeno para distinguir los nitratos eliminados por reducción catalítica de los eliminados al regenerar la hidrotalcita. Los resultados obtenidos con el catalizador $5 \% \mathrm{Pd} / \mathrm{HT}(\mathrm{Mg}-\mathrm{Al}-1,5 \% \mathrm{Cu})$ se muestran en la figura 7.6 , donde se observa que este material presenta una mayor actividad que los catalizadores sin paladio (figura 7.2). En este caso el catalizador es capaz de eliminar el 50\% de los nitratos alimentados al sistema durante 4 horas de reacción. Como en el caso anterior la eliminación de los nitratos es más efectiva 
en la reacción con hidrógeno que en la reacción sin hidrógeno debido a que en el primer caso junto a la eliminación de nitratos por regeneración de la hidrotalcita hay también una reducción catalítica de los mismos. Estos datos se cuantifican en la tabla 7.3, donde se aprecia cómo en la reacción llevada a cabo en presencia de hidrógeno la cantidad de $\mathrm{N}$ eliminada es del $53 \%$ mientras que la incorporación al catalizador es del $47 \%$. Por el contrario, en la reacción sin hidrógeno prácticamente todo el $\mathrm{N}$ eliminado del medio está en el catalizador.

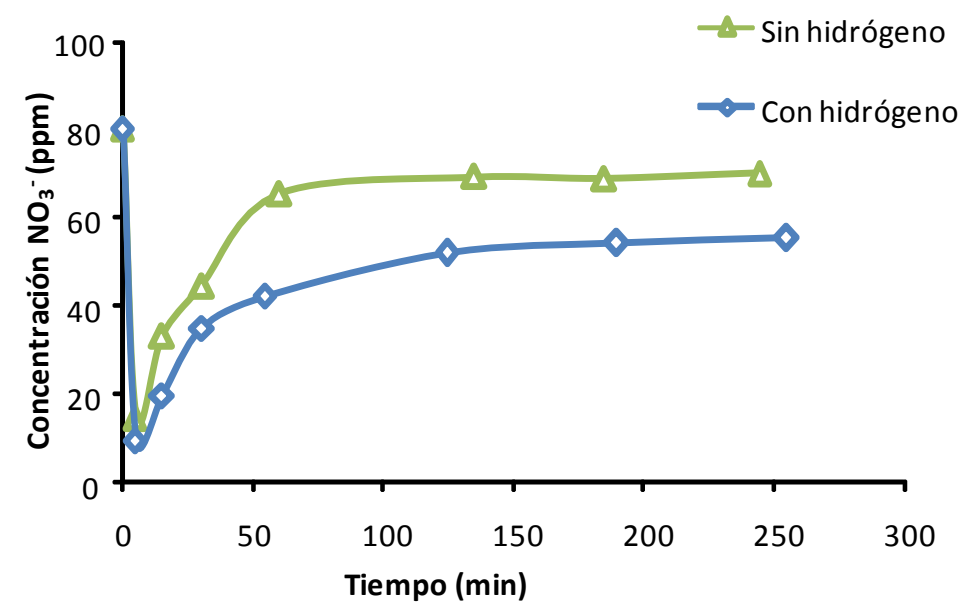

Figura 7. 6. Concentración de nitratos para experimentos realizados con y sin hidrógeno $(2 \mathrm{~g}$ de catalizador 5\%Pd/HT(Mg-Al-1,5\%Cu), $20 \mathrm{~mL} / \mathrm{min}$ de agua destilada con $80 \mathrm{mg} / \mathrm{L}$ de nitratos).

Tabla 7. 3. Contenido en $N$ del catalizador y $N$ eliminado en la reacción al realizar experimentos con o sin hidrogenación (catalizador 5\%Pd/HT(Mg-Al-1,5\%Cu)).

\begin{tabular}{lcc}
\hline Reacción & Contenido en $\mathbf{N}(\%)$ & N eliminado (\%) \\
\hline Con $\mathrm{H}_{2}$ & 1,67 & 3,52 \\
Sin $\mathrm{H}_{2}$ & 0,65 & 0,67 \\
\hline
\end{tabular}

El mecanismo por el que transcurre la reacción al utilizar este catalizador ha sido propuesto en [4] y aparece representado en la figura 7.7. Se basa en que el óxido mixto derivado de la hidrotalcita conteniendo paladio y cobre al introducirse en el medio de reacción, recupera la fase hidrotalcita, al situarse los nitratos en el espacio interlaminar. 
Estos aniones son concentrados en este espacio interlaminar por fuerzas iónicas para compensar el exceso de carga positiva de las capas, lo que permite que el nitrato se sitúe en la estructura de la hidrotalcita, cerca de los centros activos de $\mathrm{Pd}-\mathrm{Cu}$, donde reacciona rápidamente con el hidrógeno del medio formando nitrito. Posteriormente, este nitrito es reducido a nitrógeno o amonio y $\mathrm{OH}^{-}$. Para mantener la electronegatividad del sistema, los iones $\mathrm{OH}^{-}$producidos durante la reducción, se ubican en el espacio interlaminar de la hidrotalcita, mientras que las especies neutras o positivas, como el $\mathrm{N}_{2} \mathrm{O}$ el $\mathrm{NH}_{4}^{+}$son expulsadas a la solución.

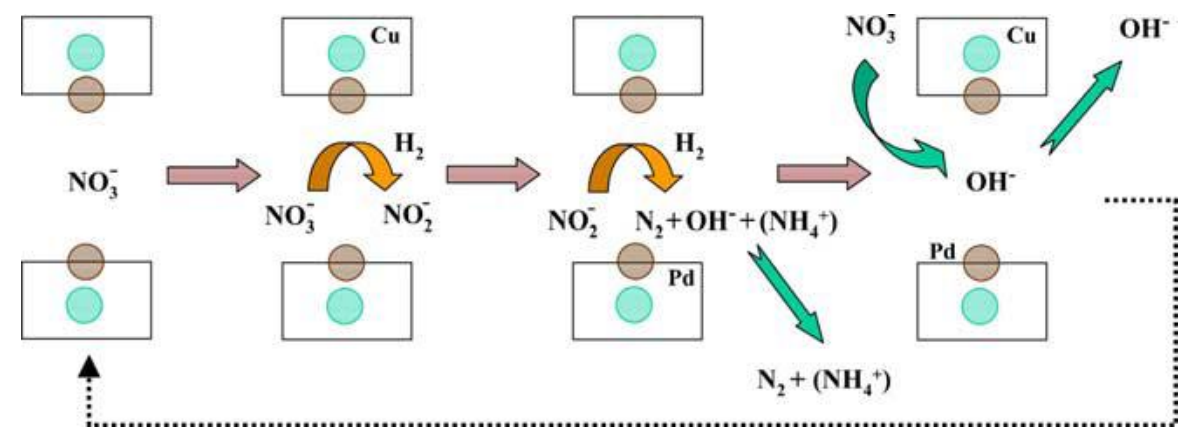

Figura 7. 7. Esquema propuesto para la reacción de eliminación de nitratos utilizando hidrotalcitas como catalizadores [4].

Con estos catalizadores se estudió también la influencia en la actividad del catalizador de las cantidades de $\mathrm{Pd}$ y $\mathrm{Cu}$ presentes en el mismo. En la figura 7.8 se observan los resultados obtenidos al usar una hidrotalcita con un 1,5\% de Cu en su estructura y otra con un $7 \%$ de $\mathrm{Cu}$, ambas impregnadas con un $5 \%$ en Pd. Los resultados muestran que al aumentar la cantidad de $\mathrm{Cu}$ en la estructura de la hidrotalcita el catalizador es más activo. Esto puede deberse a que al aumentar el contenido en Cu las láminas de la hidrotalcita formada son más anchas, con lo que el nitrato tiene más facilidad para colocarse en su interior disminuyendo los problemas de difusión y aumentando la actividad del catalizador.

Por otra parte, se estudió la actividad de un catalizador $\mathrm{HT}(\mathrm{Mg}-\mathrm{Al}-7 \% \mathrm{Cu}$ ) con distintos contenidos en Pd. Los resultados aparecen en la figura 7.9. En ella se aprecia cómo la actividad del catalizador no varía prácticamente al utilizar contenidos en Pd entre 
el $1 \%$ y el $3 \%$, en cambio, al utilizar un $5 \%$ en peso de $\mathrm{Pd}$ en el catalizador la actividad de éste aumenta de forma considerable, obteniendo un $45 \%$ de conversión a nitratos a las 8 horas de reacción.

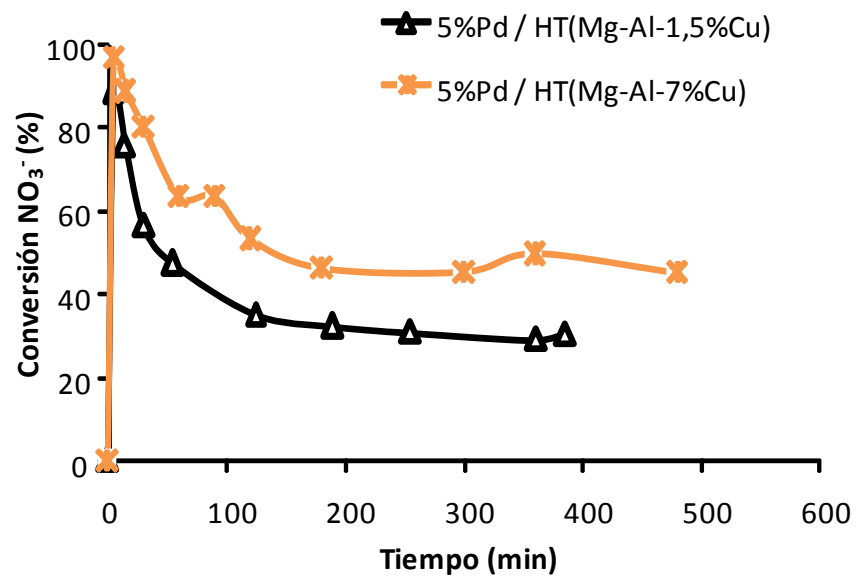

Figura 7. 8. Actividad del catalizador $5 \% \mathrm{Pd} / \mathrm{HT}(\mathrm{Mg}-\mathrm{Al}-\mathrm{Cu})$ al modificar la cantidad de Cu en la estructura de la hidrotalcita (2 gramos de catalizador, $15 \mathrm{~mL} / \mathrm{min}$ de agua destilada con $80 \mathrm{mg} / \mathrm{L}$ de nitratos).

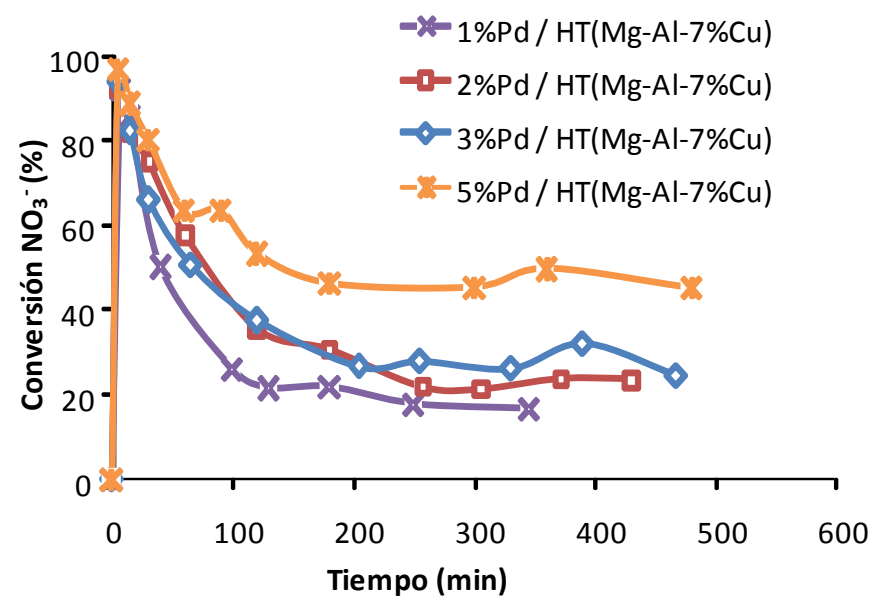

Figura 7. 9. Actividad del catalizador $P d / H T(M g-A l / 7 \% C u)$ al modificar la cantidad de Pd impregnada en el catalizador (2 gramos de catalizador, $15 \mathrm{~mL} / \mathrm{min}$ de agua con $80 \mathrm{mg} / \mathrm{L}$ de nitratos). 
Los resultados obtenidos podrían sugerir que los catalizadores basados en hidrotalcitas Mg-Al-Cu son interesantes para esta reacción, pero también indicarían que la incorporación de distintas especies aniónicas en el espacio interlaminar será un factor clave que determinará su actividad final. Por ello se realizaron experimentos en continuo con el agua natural procedente de un pozo contaminado por nitratos de la Comunidad Valenciana, la cual contenía otras especies aniónicas además de los nitratos. Las principales características del agua utilizada son:

- $162 \mathrm{ppm} \mathrm{NO}_{3}^{-}$

- $232 \mathrm{ppm} \mathrm{Cl}^{-}$

- $\quad 18 \mathrm{ppm} \mathrm{SO}_{4}{ }^{2-}$

- 96 ppm Na${ }^{+}$

- $281 \mathrm{ppm} \mathrm{Ca}^{2+}$

- $1580 \mu \mathrm{S} / \mathrm{cm}$

- $\quad \mathrm{pH}=8$

En la figura 7.10 se muestran las diferencias en la conversión de nitratos obtenidas en dos reacciones, una con agua destilada conteniendo nitratos y otra con agua natural. Tal como se aprecia, existe gran diferencia en los resultados obtenidos, siendo la actividad del catalizador utilizado en la reacción con agua destilada conteniendo nitratos muy superior a la del catalizador usado en la reacción con agua natural, incluso trabajando en condiciones más desfavorables (relación masa/caudal=0,4 g.min $/ \mathrm{mL}$ frente a 0,1 $\mathrm{g} \cdot \mathrm{min} / \mathrm{mL}$ ). Esto se explica basándonos en el esquema de reacción propuesto en la figura 7.7, ya que al utilizar agua de pozo habrá una adsorción competitiva entre los nitratos y los demás aniones presentes en el agua, los cuales también tenderán a situarse en el espacio interlaminar de la hidrotalcita impidiendo el acceso de los nitratos a los centros activos, y por tanto, disminuyendo la actividad del catalizador. 


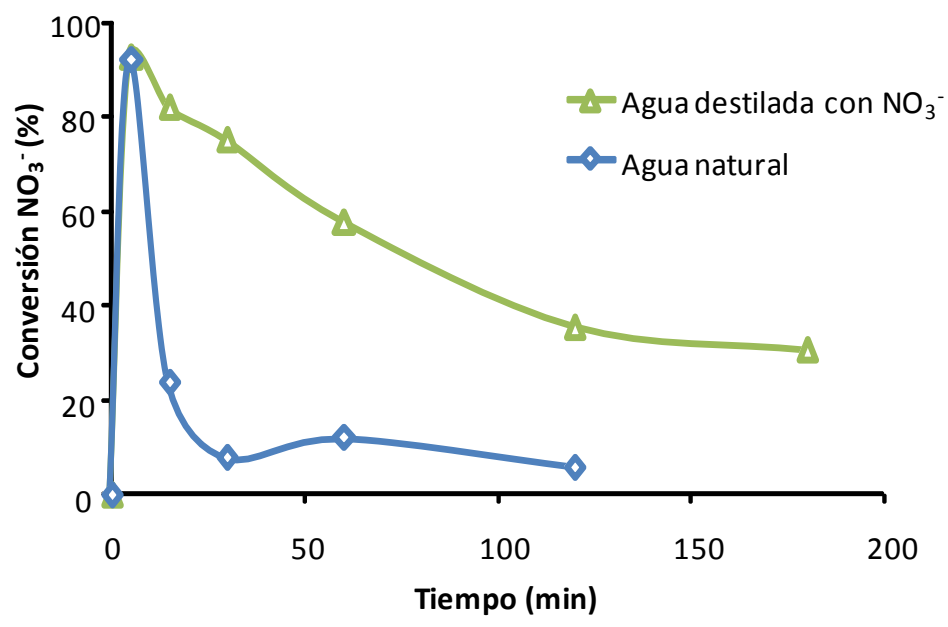

Figura 7. 10. Conversión de nitratos frente al tiempo al usar el catalizador $2 \% \mathrm{Pd} / \mathrm{HT}(\mathrm{Mg}-\mathrm{Al}-7 \% \mathrm{Cu})$ en la reducción de nitratos en agua destilada conteniendo 100 ppm de nitratos (2 g de catalizador, 20 $\mathrm{mL} / \mathrm{min}$ agua) o en agua natural (4 $\mathrm{g}$ de catalizador, $10 \mathrm{~mL} / \mathrm{min}$ ).

De hecho si se realiza un análisis elemental de los catalizadores después de reacción (tabla 7.4) se observa que, los contenidos en C y S de la muestra utilizada en la reacción con agua natural son mucho mayores que en los del catalizador usado en la reacción con agua destilada conteniendo nitratos, mientras que ocurre lo contrario con el contenido de $\mathrm{N}$ de las muestras. Esto indica que los bicarbonatos, carbonatos y sulfatos que contiene el agua natural compiten con los nitratos por su incorporación en el espacio interlaminar de la hidrotalcita [17]. Así, se comprueba que simplemente añadiendo al agua destilada con nitratos la misma cantidad de iones sulfato que contenía el agua natural (figura 7.11) la conversión disminuye en un 15\%.

Estos resultados nos llevan a concluir que no es recomendable el uso de las hidrotalcitas para la eliminación de nitratos en aguas naturales cuando éstas tienen un elevado número de especies aniónicas. 
Tabla 7. 4. Contenido en nitrógeno, carbono y azufre del catalizador $2 \% \mathrm{Pd} / \mathrm{HT}(\mathrm{Mg}-\mathrm{Al}-7 \% \mathrm{Cu})$ al realizar experimentos con agua sintética y con agua natural.

\begin{tabular}{lccc}
\hline Reacción & Contenido en N (\%) & Contenido en C (\%) & Contenido en S (\%) \\
\hline Con agua sintética & 1,917 & 1,073 & 0 \\
Con agua natural & 0,049 & 1,777 & 0,371 \\
\hline
\end{tabular}

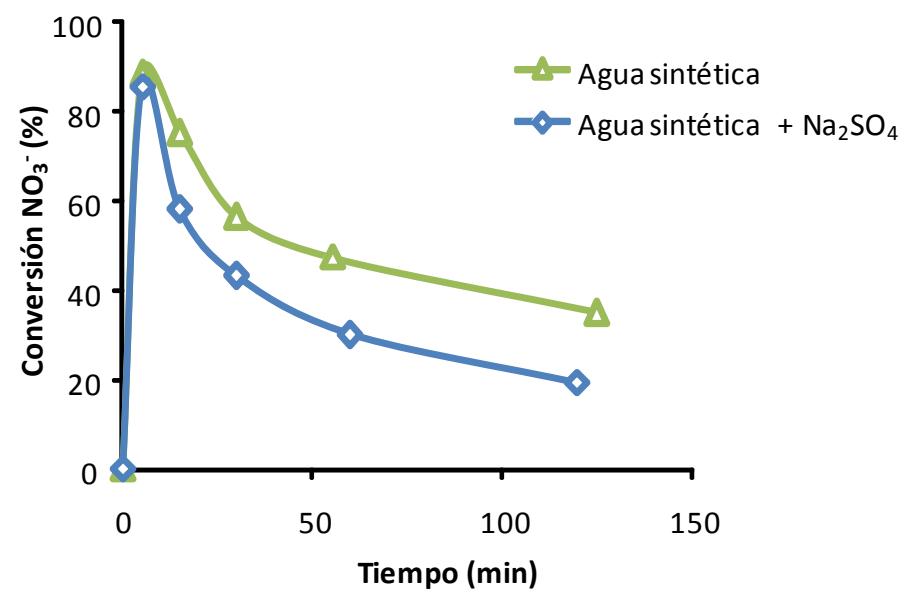

Figura 7. 11. Conversión de nitratos frente al tiempo al utilizar agua destilada con nitratos $1,5 \mathrm{~g}$ de catalizador 5\% Pd/HT(Mg-Al-1,5\%CU), $15 \mathrm{~mL} / \mathrm{min}$ agua) o con nitratos y sulfatos (4 g de catalizador, $10 \mathrm{~mL} / \mathrm{min}$ agua).

\subsection{Zeolitas}

Las zeolitas deslaminadas constituyen un nuevo tipo de materiales que han introducido un concepto diferente en el campo de los tamices moleculares utilizados como catalizadores o como soportes inorgánicos. Este tipo de sólidos son mucho más accesibles debido a que presentan estructuras más abiertas con una elevada superficie externa aprovechable, y sin ningún tipo de restricción impuesta por el tamaño de poro limitante en las zeolitas tridimensionales. Están compuestos por láminas individuales que se encuentran situadas en el espacio de forma desordenada y presentan, como característica fundamental, una elevada y perfectamente ordenada superficie externa. 
Esta característica les confiere propiedades muy ventajosas en aplicaciones en las que sean necesarios sólidos de elevada superficie que presenten centros activos completamente accesibles [1], lo que tal como se ha descrito en el apartado 5.2 es muy importante para esta reacción.

Dentro de la familia de las zeolitas deslaminadas, la zeolita ITQ-2 ha sido el primer material descrito [18]. Este material está formado por finas láminas de 2,5 nm de espesor y posee una elevada y estructuralmente bien definida área externa ( $\geq 700 \mathrm{~m}^{2} / \mathrm{g}$ ). Las láminas consisten en una serie de copas hexagonales que penetran en la lámina desde ambos lados. Estas copas tienen una apertura de 0,7 nm y están formadas por anillos de 12 miembros. Las copas se unen en el centro de la lámina formando una ventana con 6 anillos que conectan las copas desde su parte superior. Como resultado se obtiene un sistema de canales de 10 miembros entre las copas dentro de las láminas (figura 7.12).

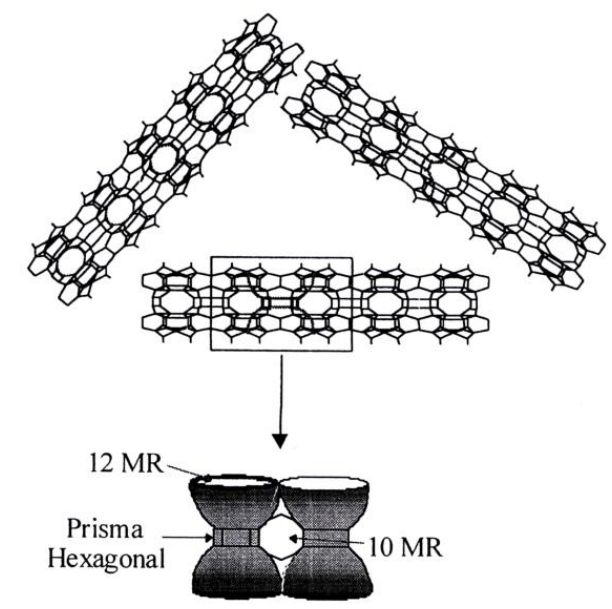

Figura 7. 12. Representación de la estructura de la zeolita deslaminada ITQ-2.

Otra de las zeolitas deslaminadas recientemente descritas es la zeolita ITQ-6. La zeolita ITQ-6 está constituida por láminas desorganizadas que tienen aproximadamente 0,9 $\mathrm{nm}$ de espesor, formadas por asociaciones de 4 anillos de 5 miembros unidos entre sí. En la superficie de las láminas, se forman unas pequeñas cavidades de $(0,28 \times 0,42) \mathrm{nm}$ abiertas al exterior, provenientes de los canales formados por anillos de 10 miembros que no llegan a formarse al no unirse las láminas entre sí [1] (figura 7.13). 


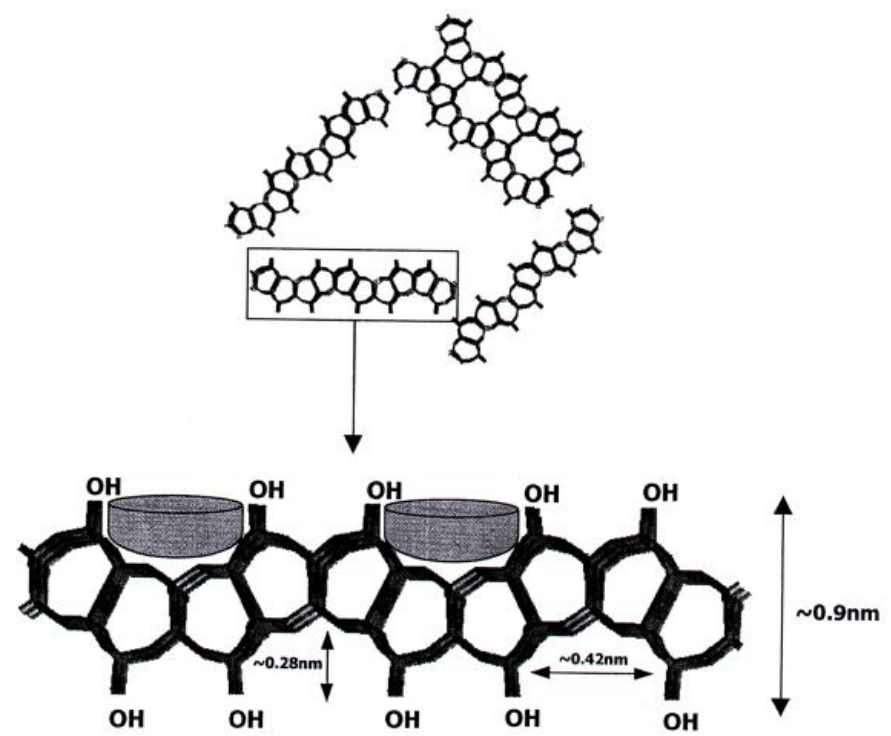

Figura 7. 13. Representación de la estructura de la zeolita deslaminada ITQ-6.

Estas dos zeolitas se han usado como soportes para catalizadores de $\mathrm{Sn} / \mathrm{Pd}$ y se ha estudiado su actividad en la reducción catalítica de nitratos en aguas naturales usando un reactor en continuo. En la figura 7.14 se muestran los resultados obtenidos con las zeolitas ITQ-2 e ITQ-6 de relación Si/Al=25 impregnadas con 2,5\%Sn y 5\%Pd. Tal como se observa, la conversión obtenida al usar el catalizador soportado sobre la zeolita ITQ-6 es del 80\%, a las 2 horas de reacción, y va disminuyendo lentamente hasta alcanzar el 60\% de conversión a las 6 horas de reacción. Por el contrario, si se utiliza la zeolita ITQ-2 como soporte catalítico se obtienen conversiones entre el 85 y el 95\% durante 6 horas de reacción. La diferente actividad obtenida con estos materiales puede deberse a su diferente morfología ya que la superficie externa de la zeolita ITQ-2 es más accesible que la de la ITQ-6. 


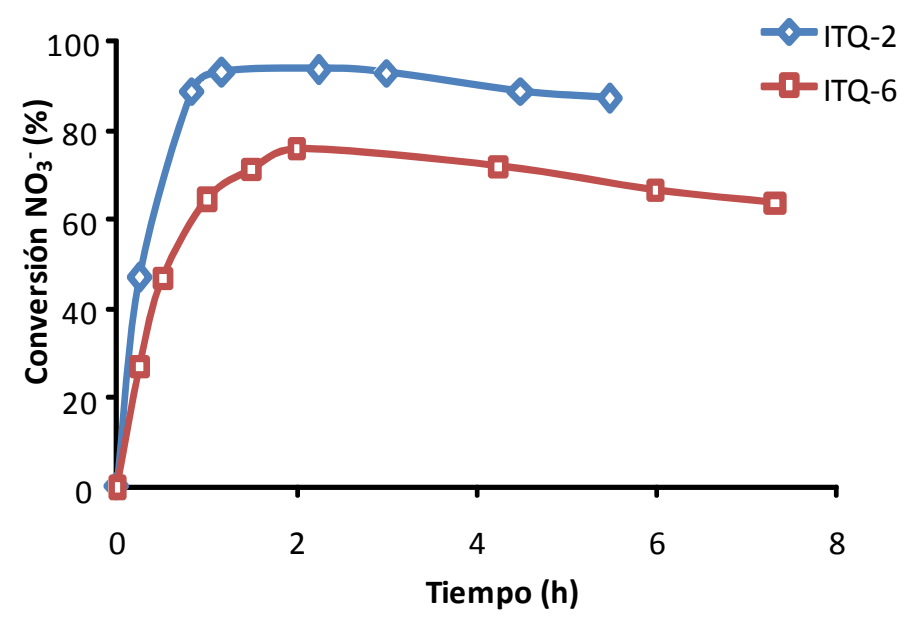

Figura 7. 14. Conversión a nitratos de los catalizadores $2,5 \% \mathrm{Sn} / 5 \% \mathrm{Pd}$ soportados sobre ITQ-6 e ITQ-2 (3 g catalizador, $5 \mathrm{~mL} / \mathrm{min}$ agua, $250 \mathrm{~mL} / \mathrm{min} \mathrm{H}_{2}, 250 \mathrm{~mL} / \mathrm{min} \mathrm{CO}_{2}$ ).

Los resultados obtenidos con el catalizador soportado sobre zeolita ITQ-2 son comparables a los obtenidos con los catalizadores Sn/Pd soportados sobre alúmina, y con este tipo de catalizadores se realizaron experimentos de eliminación de nitratos variando la relación Si/Al del soporte. Para ello se prepararon diferentes catalizadores cuyas características aparecen en las tablas 7.5 y 7.6. En estas tablas se puede apreciar cómo tanto el área BET como el área externa de los catalizadores disminuyen al aumentar el contenido en aluminio. La impregnación del material con Pd y Sn también produce una disminución del área, especialmente del área externa, que se puede deber a la formación de aglomerados de partículas de metal en la superficie del catalizador. Sin embargo, tras reacción las áreas de los catalizadores prácticamente no se modifican, lo que indica que la estructura de los mismos no se modifica en el transcurso de la reacción. 
Tabla 7. 5. Área BET de las zeolitas ITQ-2 de distinta relación $\mathrm{Si} / \mathrm{Al}\left(\mathrm{m}^{2} / \mathrm{g}\right)$.

\begin{tabular}{cccc}
\hline $\begin{array}{c}\text { Relación } \\
\text { Si/Al }\end{array}$ & $\begin{array}{c}\text { Muestra } \\
\text { original }\end{array}$ & $\begin{array}{c}\text { Muestra impregnada } \\
\text { con Pd y Sn }\end{array}$ & $\begin{array}{c}\text { Muestra después } \\
\text { de reacción }\end{array}$ \\
\hline 25 & 612 & 489 & 486 \\
50 & 757 & 459 & 433 \\
inf & 883 & 647 & 602 \\
\hline
\end{tabular}

Tabla 7. 6. Área externa de las zeolitas ITQ-2 de distinta relación Si/AI $\left(\mathrm{m}^{2} / \mathrm{g}\right)$.

\begin{tabular}{cccc}
\hline $\begin{array}{c}\text { Relación } \\
\text { Si/Al }\end{array}$ & $\begin{array}{c}\text { Muestra } \\
\text { original }\end{array}$ & $\begin{array}{c}\text { Muestra impregnada } \\
\text { con Pd y Sn }\end{array}$ & $\begin{array}{c}\text { Muestra después } \\
\text { de reacción }\end{array}$ \\
\hline 25 & 386 & 250 & 245 \\
50 & 757 & 377 & 354 \\
inf & 770 & 488 & 454 \\
\hline
\end{tabular}

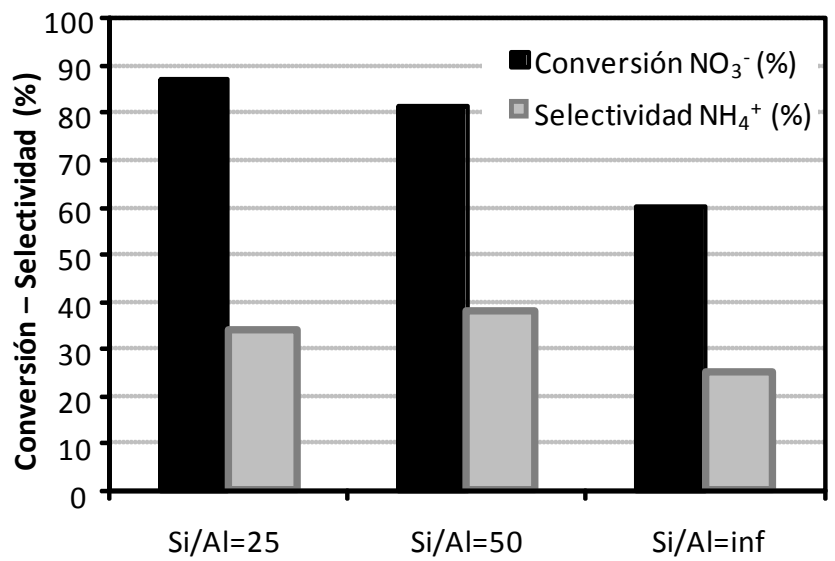

Figura 7. 15. Actividad de los catalizadores Sn/Pd soportados sobre zeolitas ITQ-2 con distinta relación Si/Al (3 g catalizador, $5 \mathrm{~mL} / \mathrm{min}$ agua, $250 \mathrm{~mL} / \mathrm{min}_{2}, 250 \mathrm{~mL} / \mathrm{min}_{\mathrm{CO}}$ ).

En la figura 7.15 se observan los resultados obtenidos con los catalizadores $\mathrm{Pd} / \mathrm{Sn}$ soportados en zeolitas ITQ-2 con distinta relación Si/AI. En dicha figura se aprecia, tal como se observaba en el caso de la zeolita MCM-41 (apartado 5.2.2), que la muestra con 
menor relación $\mathrm{Si} / \mathrm{Al}$ es la que presenta mayor actividad en este tipo de reacciones, mostrando todos ellos una selectividad similar. Esto podría deberse a que al disminuir la relación Si/Al y haber más $\mathrm{Al}$, la acidez Lewis de estas muestras es también superior, lo que lleva a que los iones hidroxilo formados durante la reacción (ecuaciones 4.1 y 4.2 ) se neutralicen de forma más rápida, disminuyendo los problemas de transferencia de materia y aumentando la actividad del catalizador.

Si se comparan estos resultados con los mejores resultados obtenidos en el apartado 5.2.4, donde se estudiaba la actividad de varios catalizadores Sn/Pd soportados sobre diversos materiales, se obtienen los resultados que se presentan en la figura 7.16. En esta figura se puede ver cómo los tres materiales estudiados como soporte muestran prácticamente la misma conversión, ya que, tal como se ha explicado en el apartado 5.2.4, los tres soportes presentan las propiedades necesarias para soportar un catalizador activo en la reducción de nitratos en aguas naturales.

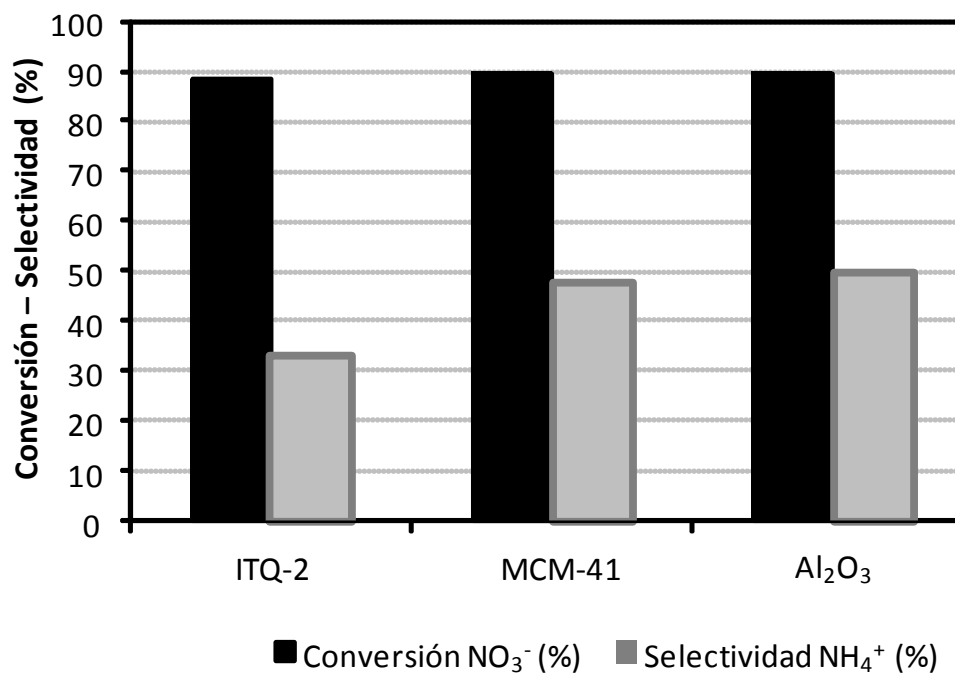

Figura 7. 16. Conversión y selectividad a amonio de los catalizadores de 2,5\%Sn y 5\%Pd soportados sobre zeolita ITQ-2, material mesoporoso MCM-41 y alúmina.

Sin embargo, la selectividad a amonio obtenida para la zeolita ITQ-2 es bastante inferior a la obtenida con la alúmina y con el material mesoporoso MCM-41. Esto podría 
explicarse en base a la diferente topología de estos materiales. Así, la mayor selectividad a nitrógeno del catalizador soportado sobre la zeolita ITQ-2 comparada con la del catalizador soportado sobre el material mesoporoso MCM-41 podría atribuirse a que éste es un material tubular compuesto por canales, lo que obliga a los reactivos y productos a difundir por su interior, dificultando su transporte y haciendo que las especies $\mathrm{N}$ estén más tiempo en contacto con el hidrógeno, lo que favorece la formación de amonio. En cambio, en la zeolita ITQ-2 la reacción transcurre en la superficie externa del material, ya que el material es laminar, lo que favorece la desorción de los productos, disminuyendo los problemas de transferencia de materia y, por tanto, la formación de amonio, tal como se ha descrito en el apartado 6.6.

Por tanto, a la vista de los resultados obtenidos en este capítulo se puede concluir que el uso de la zeolita ITQ-2 como soporte del catalizador Sn/Pd para la eliminación de nitratos en agua mejora la selectividad a nitrógeno del catalizador. Esto indica que es posible seguir avanzando con nuevos materiales que permitan superar el principal problema de esta reacción que es la selectividad a nitrógeno de los catalizadores utilizados. Al mismo tiempo, abre nuevas posibilidades para el diseño de nuevos catalizadores activos y selectivos, los cuales deben soportarse sobre materiales con elevada accesibilidad como la zeolita ITQ-2 u otros nuevos que puedan aparecer. 


\section{Referencias}

[1] U. M. Díaz Morales, PhD thesis, Universidad Politécnica de Valencia (Valencia), (2001).

[2] A. Corma, U. M. Díaz Morales, V. Fornés, Valencia Patent, P200100268.

[3] A. E. Palomares, J. G. Prato, F. Márquez, A. Corma; Applied Catalysis B: Environmental, 41 (2003) 3.

[4] A. E. Palomares, J. G. Prato, F. Rey, A. Corma; Journal of Catalysis, 221 (2004) 62.

[5] J. G. Prato Moreno, PhD thesis, Universidad Politécnica de Valencia (Valencia), (2004).

[6] F. Cavani, F. Trifirò, A. Vaccari; Catalysis Today, 11 (1991) 173.

[7] A. Vaccari; Applied Clay Science, 14 (1999) 161.

[8] F. Rey, V. Fornés, J. M. Rojo; Journal of the Chemical Society, Faraday Transactions, 88 (1992) 2233.

[9] A. Vaccari; Catalysis Today, 41 (1998) 53.

[10] S. Miyata; Clays Clay Minerals, 28 (1980) 619.

[11] S. Hörold, K. D. Vorlop, T. Tacke, M. Sell; Catalysis Today, 17 (1993) 21.

[12] F. Gauthard, F. Epron, J. Barbier; Journal of Catalysis, 220 (2003) 182.

[13] U. Prüsse, K.-D. Vorlop; Journal of Molecular Catalysis A: Chemical, 173 (2001) 313.

[14] A. Pintar; Catalysis Today, 77 (2003) 451.

[15] F. Epron, F. Gauthard, C. Pinéda, J. Barbier; Journal of Catalysis, 198 (2001) 309.

[16] Z. P. Xu, H. C. Zeng; The Journal of Physical Chemistry B, 105 (2001) 1743.

[17] Y. Wang, J. Qu, H. Liu; Journal of Molecular Catalysis A: Chemical, 272 (2007) 31.

[18] A. Corma, V. Fornés, S. B. Pergher, Valencia Patent, WO9717290A1. 

8.

CONCLUSIONES 

A la vista de los resultados obtenidos en esta tesis se han llegado a las siguientes conclusiones:

- Es posible eliminar los nitratos presentes en aguas naturales mediante la reducción catalítica con hidrógeno trabajando en continuo. Los mejores resultados se obtienen controlando el pH del medio de reacción en un valor de 6 mediante el burbujeo de $\mathrm{CO}_{2}$, lo que permite neutralizar las especies hidroxilo formadas durante la reacción, las cuales favorecen la producción de amonio y provocan la precipitación de algunas sales, como el carbonato cálcico, sobre el catalizador desactivando el mismo. La variación de temperatura entre 2 y $40^{\circ} \mathrm{C}$ no influye significativamente en la actividad del catalizador, pero trabajando a $10^{\circ} \mathrm{C}$ se observa una disminución de la selectividad a amonio del catalizador. Es necesario mantener una velocidad de agitación de 900 rpm para asegurar un buen contacto entre el sólido, el gas y el líquido y limitar los problemas de difusión interna. La presión total de trabajo no afecta a la actividad ni a la selectividad del catalizador, aunque sí que lo hace la presión parcial de hidrógeno, disminuyendo la selectividad a amonio al disminuir dicha variable.

- Existen varias combinaciones de metales activos en esta reacción, pero los mejores resultados se obtienen con un catalizador $\mathrm{Pd}$ :(Sn o $\mathrm{Cu})$ con una relación metal noble/metal no noble próximas a 2. La mejor forma de preparar el catalizador es por impregnación a volumen de poro, impregnando primero el metal no noble y luego el metal noble. La actividad del catalizador depende de la naturaleza y estructura del soporte. Se han estudiado varios soportes para los catalizadores $\mathrm{Pd} /(\mathrm{Cu}$ o Sn), obteniendo los mejores resultados al soportar los metales sobre alúmina o materiales mesoporosos, que poseen una baja conductividad eléctrica, no presentan microporos y tienen una adecuada área específica. La activación del catalizador debe realizarse con hidrógeno a temperaturas inferiores a $200^{\circ} \mathrm{C}$, debido a que a temperaturas superiores se produce una aglomeración de las partículas de metal y se forman nuevas fases que no son activas. 
- El catalizador $\mathrm{Sn} / \mathrm{Pd} / \gamma-\mathrm{Al}_{2} \mathrm{O}_{3}$ es más selectivo que el catalizador $\mathrm{Cu} / \mathrm{Pd} / \gamma-\mathrm{Al}_{2} \mathrm{O}_{3}$ y trabajando con 3 gramos de catalizador se puede tratar un caudal de agua natural de 5 $\mathrm{mL} / \mathrm{min}$ con una concentración de $100 \mathrm{mg} / \mathrm{L}$ de nitratos durante 17 días. El catalizador desactivado se puede regenerar repetidas veces mediante un lavado con agua destilada. La desactivación del catalizador se produce principalmente por la deposición de otras especies en la superficie del mismo, aunque también puede relacionarse con la oxidación parcial de las especies metálicas. La cantidad de metales presentes en el catalizador se puede disminuir, manteniendo su actividad, si se mantiene la relación $\mathrm{Pd} / \mathrm{Sn}=2$. No obstante, aunque se puede minimizar, parece inevitable la formación de amonio y se ha visto que la forma más efectiva de eliminarlo es con una zeolita natural (clinoptilolita) que actúa como intercambiador iónico.

- Se ha caracterizado el catalizador observando que sus propiedades estructurales y texturales no se modifican en el transcurso de la reacción. Tras activar el catalizador, el paladio aparece como Pd metálico y el estaño está altamente disperso. EI tamaño de partícula del paladio disminuye al disminuir la cantidad de metales en el catalizador y al disminuir la temperatura de reacción, aumentando la dispersión.

- El mecanismo de reacción propuesto para la eliminación de nitratos en aguas naturales con el catalizador $\mathrm{Sn} / \mathrm{Pd}$ se basa en la reducción del nitrato a nitrito sobre los pares $\mathrm{Pd}-\mathrm{Sn}$ y en la reducción del nitrito a nitrógeno o amonio sobre los centros $\mathrm{Pd}^{0}$. El paladio debe estar reducido y altamente disperso, mientras que el estaño no debe estar como $\mathrm{Sn}^{0} \mathrm{ni}$ formando fases $\mathrm{Pd}_{\mathrm{x}} \mathrm{Sn}_{\mathrm{y}}$. La selectividad de la reacción viene determinada por la interacción metal-soporte y la dispersión de las especies activas, de tal manera que aquellos soportes que minimicen los problemas de transferencia de materia, favorecerán la selectividad a nitrógeno del catalizador.

- Es posible utilizar otros soportes catalíticos para los catalizadores $\mathrm{Pd} /(\mathrm{Cu}$ o $\mathrm{Sn}$ ) como son los óxidos mixtos derivados de hidrotalcitas y las zeolitas laminares ITQ-2 e ITQ6. Sin embargo, los primeros no dan buenos resultados al utilizarlos en aguas naturales 
por la competencia entre los nitratos y los otros aniones del medio por situarse en el espacio interlaminar de las hidrotalcitas. En cambio, la utilización de las zeolitas ITQ-6 e ITQ-2 como soporte catalítico del catalizador Sn/Pd permite obtener buenos resultados debido a sus estructuras laminares que les confieren una elevada área externa y una gran accesibilidad. Los mejores resultados se obtienen soportando el catalizador sobre la zeolita ITQ-2 de relación $\mathrm{Si} / \mathrm{Al}=25$, la cual presenta una elevada actividad en la reacción en estudio y una elevada selectividad a nitrógeno. 

ANEXO I

ÍNDICE DE FIGURAS Y TABLAS 



\section{ÍNDICE DE FIGURAS}

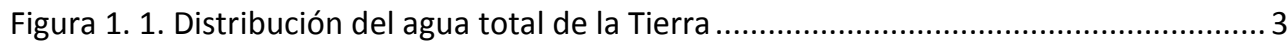

Figura 1. 2. Ciclo hidrológico del agua ........................................................................ 5

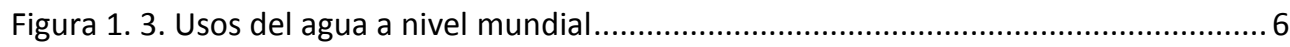

Figura 1. 4. Ciclo del nitrógeno en el suelo .................................................................... 12

Figura 1. 5. Concentraciones de nitratos en los países de la Unión Europea (2008)........... 19

Figura 1. 6. Estaciones con concentración de nitratos superior a 50 mg/L en 2007 ...........21

Figura 1. 7. Distribución del contenido en nitratos de los acuíferos de las CCAA ..............22

Figura 1. 8. Mapa de zonas vulnerables a la contaminación por nitratos ..........................23

Figura 1. 9. Esquema del proceso de electrodiálisis ....................................................... 25

Figura 1. 10. Esquema del proceso de ósmosis inversa ..................................................26

Figura 1. 11. Esquema del sistema de intercambio iónico ............................................. 27

Figura 1. 12. Mecanismo de reacción propuesto en la superficie del catalizador sobre las partículas de $\mathrm{Cu}-\mathrm{Pd}$ a $\mathrm{pH} 10,5$ 33

Figura 1. 13. Esquema representativo de la reducción de nitratos en el poro del catalizador 34

Figura 1. 14. Efecto tampón de las especies $\mathrm{COOH} / \mathrm{COO}^{-}$en las resinas acrílicas ............... 35

Figura 1. 15. Esquema de reacción propuesto por Vorlop y col. 38

Figura 1. 16. Modelos propuestos para la eliminación de nitratos en las partículas de Pd y Pd-Cu: (a) 5\%Pd, (b) 5\%Pd-0,6\%Cu, (c) 5\%Pd-3\%Cu

Figura 1. 17. Esquema de reacción propuesto para la eliminación de nitratos sobre catalizadores $\mathrm{Pd}-\mathrm{Cu} / \mathrm{TiO}_{2}$ con diferente tamaño de partícula

Figura 1. 18. Esquema de reacción propuesto al usar hidrotalcitas como soporte......

Figura 1. 19. Esquema de reacción propuesto para la reducción de nitratos usando catalizadores de Pt-Cu .....

Figura 1. 20. Esquema propuesto para la reducción catalítica de los nitritos en agua 43

Figura 3. 1. Esquema del programa de calcinación de las hidrotalcitas. 60

Figura 3. 2. Esquema del programa de calcinación de las alúminas de alta superficie. 61 
Figura 3. 3. Esquema del tratamiento térmico (I) de los catalizadores impregnados a volumen de poro 62

Figura 3. 4. Esquema del tratamiento térmico (II) de los catalizadores impregnados a volumen de poro 63

Figura 3. 5. Esquema del reactor discontinuo de tanque agitado. 72

Figura 3. 6. Esquema del reactor continuo de tanque agitado 72

Figura 3. 7. Esquema del reactor continuo de tanque agitado a presión. 73

Figura 3. 8. Esquema del reactor de flujo de pistón 74

Figura 4. 1. Variación del $\mathrm{pH}$ y de las concentraciones de nitrato, amonio y nitrito al realizar una reacción en discontinuo con aguas naturales ( 1 gramo de catalizador $2,5 \% \mathrm{Sn} / 5 \% \mathrm{Pd} / \gamma-\mathrm{Al}_{2} \mathrm{O}_{3}, 250 \mathrm{~mL} / \mathrm{min} \mathrm{H}_{2}$ ) 81

Figura 4. 2. Conversión de nitratos de los experimentos realizados con control del pH a las 4 horas de reacción (1 gramo de catalizador 2,5\%Sn/5\% Pd/ $\gamma-\mathrm{Al}_{2} \mathrm{O}_{3}, 250 \mathrm{~mL} / \mathrm{min}$ $\mathrm{H}_{2}$ ). 83

Figura 4. 3. Selectividad a nitrógeno de los experimentos realizados con control del $\mathrm{pH}$ a las 4 horas de reacción (1 gramo de catalizador 2,5\%Sn/5\% Pd/ $\gamma-\mathrm{Al}_{2} \mathrm{O}_{3}, 250$ $\mathrm{mL} / \min \mathrm{H}_{2}$ ).

Figura 4. 4. Concentraciones de nitrato, amonio y nitrito en la reducción catalítica de nitratos en discontinuo con aguas naturales al añadir $\mathrm{CO}_{2}$ como agente controlante del pH (1 gramo de catalizador 2,5\%Sn/5\% Pd $/ \gamma-\mathrm{Al}_{2} \mathrm{O}_{3}, 250 \mathrm{~mL} / \mathrm{min}$ $\mathrm{H}_{2}$ ).

Figura 4. 5. Reducción catalítica de nitratos en continuo con aguas naturales al variar la temperatura de reacción (3 gramos de catalizador 2,5\% $\mathrm{Sn} / 5 \% \mathrm{Pd} / \gamma-\mathrm{Al}_{2} \mathrm{O}_{3}, 5$ $\mathrm{mL} / \mathrm{min}$ agua, $250 \mathrm{~mL} / \mathrm{min} \mathrm{H}_{2}, 250 \mathrm{~mL} / \mathrm{min} \mathrm{CO}_{2}$ ). 86

Figura 4. 6. Selectividad a amonio en la reducción catalítica de nitratos en continuo con aguas naturales al variar la temperatura de reacción (3 gramos de catalizador 2,5\% Sn $/ 5 \% \mathrm{Pd} / \gamma-\mathrm{Al}_{2} \mathrm{O}_{3}, 5 \mathrm{~mL} / \mathrm{min}$ agua, $250 \mathrm{~mL} / \mathrm{min} \mathrm{H}_{2}, 250 \mathrm{~mL} / \mathrm{min} \mathrm{CO}_{2}$ ). ......86 
Figura 4. 7. Actividad del catalizador al modificar la velocidad de agitación (3 gramos de catalizador $2,5 \% \mathrm{Sn} / 5 \% \mathrm{Pd} / \gamma-\mathrm{Al}_{2} \mathrm{O}_{3}, 5 \mathrm{~mL} / \mathrm{min}$ agua, $250 \mathrm{~mL} / \mathrm{min} \mathrm{H}_{2}, 250 \mathrm{~mL} / \mathrm{min}$ $\mathrm{CO}_{2}$, resultados tras 4 horas de reacción). 87

Figura 4. 8. Reducción catalítica de nitratos en continuo con aguas naturales al variar la masa de catalizador $\left(2,5 \% \mathrm{Sn} / 5 \% \mathrm{Pd} / \gamma-\mathrm{Al}_{2} \mathrm{O}_{3}, 5 \mathrm{~mL} / \mathrm{min}\right.$ agua, $250 \mathrm{~mL} / \mathrm{min} \mathrm{H}_{2}, 250$ $\left.\mathrm{mL} / \mathrm{min} \mathrm{CO}_{2}\right)$.

Figura 4. 9. Reducción catalítica de nitratos en continuo con aguas naturales al variar el caudal de agua de reacción (3 gramos de catalizador 2,5\% Sn/5\% Pd $/ \gamma-\mathrm{Al}_{2} \mathrm{O}_{3}, 250$ $\mathrm{mL} / \mathrm{min} \mathrm{H}_{2}, 250 \mathrm{~mL} / \min \mathrm{CO}_{2}$ ). 90

Figura 4. 10. Variación de la actividad y selectividad al variar la presión parcial de $\mathrm{H}_{2}$ manteniendo el caudal de $\mathrm{CO}_{2}$ constante a las 4 horas de reacción (3 gramos de catalizador $2,5 \% \mathrm{Sn} / 5 \% \mathrm{Pd} / \gamma-\mathrm{Al}_{2} \mathrm{O}_{3}, 5 \mathrm{~mL} / \mathrm{min}$ agua). 91

Figura 4. 11. Actividad del catalizador $2,5 \% \mathrm{Sn} / 5 \% \mathrm{Pd} / \gamma-\mathrm{Al}_{2} \mathrm{O}_{3}$ al realizar las reacciones a las presiones de $1 ; 1,5 ; 2$ y 3 bar $\left(50 \mathrm{mg}, 1,2 \mathrm{~mL} / \mathrm{min}\right.$ agua, $5 \mathrm{~mL} / \mathrm{min}_{2}$ ). 92

Figura 4. 12. Selectividad del catalizador $2,5 \% \mathrm{Sn} / 5 \% \mathrm{Pd} / \gamma-\mathrm{Al}_{2} \mathrm{O}_{3}$ al realizar las reacciones a las presiones de 1, 1,5, 2 y 3 bar $\left(50 \mathrm{mg}, 1,2 \mathrm{~mL} / \mathrm{min}\right.$ agua, $5 \mathrm{~mL} / \mathrm{min} \mathrm{H}_{2}$ ). ...... 92

Figura 4. 13. Variación de la actividad del catalizador $2,5 \% \mathrm{Sn} / 5 \% \mathrm{Pd} / \gamma-\mathrm{Al}_{2} \mathrm{O}_{3}$ al usar un reactor de flujo de pistón (RFP) y un reactor en continuo de tanque agitado (RCTA) (3 gramos de catalizador). 93

Figura 5. 1. Actividad, selectividad a amonio y selectividad a nitrito tras 4 horas de reacción de los catalizadores preparados con distintos metales (3 g catalizador, $5 \mathrm{~mL} / \min$ agua, $250 \mathrm{~mL} / \min \mathrm{H}_{2}, 250 \mathrm{~mL} / \min \mathrm{CO}_{2}$ ). 101

Figura 5. 2. Actividad y selectividad a amonio tras 4 horas de reacción de los catalizadores preparados con distintos metales (3 g catalizador, $5 \mathrm{~mL} / \mathrm{min}$ agua, $250 \mathrm{~mL} / \mathrm{min}$ $\mathrm{H}_{2}, 250 \mathrm{~mL} / \mathrm{min} \mathrm{CO}_{2}$ ) 103

Figura 5. 3. Conversión de nitratos con catalizadores de 2,5\%Cu-5\%Pd o 2,5\%Sn-5\%Pd soportados sobre grafito ( $3 \mathrm{~g}$ catalizador, $5 \mathrm{~mL} / \mathrm{min}$ agua, $250 \mathrm{~mL} / \mathrm{min} \mathrm{H}_{2}, 250$ $\left.\mathrm{mL} / \mathrm{min} \mathrm{CO}_{2}\right)$. 104 
Figura 5. 4. Actividad y selectividad a amonio a las 4 horas de reacción del catalizador 2,5\% Sn/5\%Pd soportado sobre los distintos carbones (3 g catalizador, $5 \mathrm{~mL} / \mathrm{min}$ agua, $250 \mathrm{~mL} / \mathrm{min} \mathrm{H}_{2}, 250 \mathrm{~mL} / \mathrm{min} \mathrm{CO}_{2}$ ). 105

Figura 5. 5. Actividad y selectividad a amonio tras 4 horas de reacción del catalizador 2,5\%Sn/5\%Pd soportado sobre distintos materiales microporosos (3 g catalizador, $5 \mathrm{~mL} / \mathrm{min}$ agua, $250 \mathrm{~mL} / \mathrm{min} \mathrm{H}_{2}, 250 \mathrm{~mL} / \mathrm{min} \mathrm{CO}_{2}$ ). 108

Figura 5. 6. Actividad y selectividad a amonio tras 4 horas de reacción del catalizador 2,5\%Sn/5\%Pd soportado en zeolitas ZSM-5 con distinta relación Si/Al (3 g catalizador, $5 \mathrm{~mL} / \mathrm{min}$ agua, $\left.250 \mathrm{~mL} / \mathrm{min} \mathrm{H}_{2}, 250 \mathrm{~mL} / \mathrm{min} \mathrm{CO}_{2}\right) \ldots \ldots \ldots \ldots \ldots \ldots . . . . . .109$

Figura 5. 7. Patrón de difracción del material MCM-41. 110

Figura 5. 8. Actividad y selectividad a amonio de los catalizadores $2,5 \% \mathrm{Sn} / 5 \% \mathrm{Pd}$ soportados en el material MCM-41 de relación Si/Al 30 y pura sílice (3 g catalizador, $5 \mathrm{~mL} / \mathrm{min}$ agua, $250 \mathrm{~mL} / \mathrm{min} \mathrm{H}_{2}, 250 \mathrm{~mL} / \mathrm{min} \mathrm{CO}_{2}$ ). 112

Figura 5. 9. Actividad y selectividad a amonio del catalizador $2,5 \% \mathrm{Sn} / 5 \% \mathrm{Pd}$ soportado sobre diferentes óxidos ( $3 \mathrm{~g}$ catalizador, $5 \mathrm{~mL} / \mathrm{min}$ agua, $250 \mathrm{~mL} / \mathrm{min} \mathrm{H}_{2}, 250$ $\left.\mathrm{mL} / \mathrm{min} \mathrm{CO}_{2}\right)$ 114

Figura 5. 10. Actividad para los catalizadores de $2,5 \% \mathrm{Sn}$ y $5 \% \mathrm{Pd}$ soportados en alúmina con diferente área superficial: $(\diamond)$ conversión y $(\diamond)$ selectividad a amonio del catalizador con $355 \mathrm{~m}^{2} / \mathrm{g}$; $(\boldsymbol{\Delta})$ conversión y $(\Delta)$ selectividad a amonio del catalizador con $139 \mathrm{~m}^{2} / \mathrm{g}$ (3 g catalizador, $5 \mathrm{~mL} / \mathrm{min}$ agua, $250 \mathrm{~mL} / \mathrm{min} \mathrm{H}_{2}$, $\left.250 \mathrm{~mL} / \mathrm{min} \mathrm{CO}_{2}\right)$.

Figura 5. 11. Conversión y selectividad a amonio a las 4 horas de reacción de los catalizadores $\mathrm{Sn}-\mathrm{Pd}$ soportados con distintos tipos de materiales (3 g catalizador, $5 \mathrm{~mL} / \mathrm{min}$ agua, $250 \mathrm{~mL} / \mathrm{min} \mathrm{H}_{2}, 250 \mathrm{~mL} / \mathrm{min} \mathrm{CO}_{2}$ ). 116

Figura 5. 12. Actividad y selectividad tras 4 horas de reacción de catalizadores Cu-Pd al mantener constante la cantidad de Pd y variar la cantidad de $\mathrm{Cu}$ (porcentaje de metal en masa, $3 \mathrm{~g}$ de catalizador, $5 \mathrm{~mL} / \mathrm{min}$ agua, $250 \mathrm{~mL} / \mathrm{min}_{2}, 250 \mathrm{~mL} / \mathrm{min}$ $\mathrm{CO}_{2}$ ). 
Figura 5. 13. Actividad y selectividad tras 4 horas de reacción de catalizadores Cu-Pd con $1,5 \% \mathrm{Cu}$ y cantidades variables de Pd (porcentaje de metal en masa, $3 \mathrm{~g}$ de catalizador, $5 \mathrm{~mL} / \mathrm{min}$ agua, $250 \mathrm{~mL} / \min \mathrm{H}_{2}, 250 \mathrm{~mL} / \min \mathrm{CO}_{2}$ ). 118

Figura 5. 14. Actividad y selectividad a las 4 horas de reacción de catalizadores $\mathrm{Sn}-\mathrm{Pd}$ con $5 \% \mathrm{Pd}$ y cantidades variables de Sn (porcentaje de metal en masa, $3 \mathrm{~g}$ de catalizador, $5 \mathrm{~mL} / \mathrm{min}$ agua, $250 \mathrm{~mL} / \mathrm{min} \mathrm{H}_{2}, 250 \mathrm{~mL} / \mathrm{min} \mathrm{CO}_{2}$ ). 119

Figura 5. 15. Actividad y selectividad a las 4 horas de reacción de los catalizadores Sn-Pd con $1 \% \mathrm{Sn}$ y cantidades variables de Pd (porcentaje de metal en masa, $3 \mathrm{~g}$ de catalizador, $5 \mathrm{~mL} / \mathrm{min}$ agua, $250 \mathrm{~mL} / \mathrm{min} \mathrm{H}_{2}, 250 \mathrm{~mL} / \mathrm{min} \mathrm{CO}_{2}$ ). 120

Figura 5. 16. Comparación de la actividad de los catalizadores $2,5 \% \mathrm{Cu} / 5 \% \mathrm{Pd} / \mathrm{Al}_{2} \mathrm{O}_{3}$ y 2,5\%Sn/5\% $\mathrm{Pd} / \mathrm{Al}_{2} \mathrm{O}_{3}\left(3 \mathrm{~g}\right.$ catalizador, $5 \mathrm{~mL} / \mathrm{min}$ agua, $250 \mathrm{~mL} / \mathrm{min} \mathrm{H}_{2}, 250$ $\left.\mathrm{mL} / \mathrm{min} \mathrm{CO}_{2}\right)$.

Figura 5. 17. Comparación de la selectividad a amonio de los catalizadores $2,5 \% \mathrm{Cu} / 5 \% \mathrm{Pd} / \mathrm{Al}_{2} \mathrm{O}_{3}$ y $2,5 \% \mathrm{Sn} / 5 \% \mathrm{Pd} / \mathrm{Al}_{2} \mathrm{O}_{3}$ (3 g catalizador, $5 \mathrm{~mL} / \mathrm{min}$ agua, 250 $\mathrm{mL} / \mathrm{min} \mathrm{H}_{2}, 250 \mathrm{~mL} / \mathrm{min} \mathrm{CO}_{2}$ ). 122

Figura 5. 18. Actividad del catalizador $2,5 \% \mathrm{Sn} / 5 \% \mathrm{Pd} / \mathrm{Al}_{2} \mathrm{O}_{3}$ al depositar los metales de distinta forma sobre el soporte ( 3 g catalizador, $5 \mathrm{~mL} / \mathrm{min}$ agua, $250 \mathrm{~mL} / \mathrm{min}_{2}$, $\left.250 \mathrm{~mL} / \mathrm{min} \mathrm{CO}_{2}\right)$. 124

Figura 5. 19. Actividad y la selectividad a amonio al utilizar precursores distintos de paladio y estaño (3 g catalizador, $5 \mathrm{~mL} / \mathrm{min}$ agua, $250 \mathrm{~mL} / \mathrm{min} \mathrm{H}_{2}, 250 \mathrm{~mL} / \mathrm{min} \mathrm{CO}_{2}$ ).. 125

Figura 5. 20. Esquema del tratamiento térmico (I) de los catalizadores impregnados a volumen de poro. 126

Figura 5. 21. Esquema del tratamiento térmico (II) de los catalizadores impregnados a volumen de poro. 126

Figura 5. 22. Actividad del catalizador $2,5 \% \mathrm{Sn} / 5 \% \mathrm{Pd} / \gamma-\mathrm{Al}_{2} \mathrm{O}_{3}$ calcinado según el tratamiento térmico I o según el tratamiento térmico II (3 g catalizador, 5 $\mathrm{mL} / \mathrm{min}$ agua, $250 \mathrm{~mL} / \mathrm{min} \mathrm{H}_{2}, 250 \mathrm{~mL} / \mathrm{min} \mathrm{CO}_{2}$ ).

Figura 5. 23. Conversión frente al tiempo para distintas temperaturas de reducción (3 g 2,5\% Sn $/ 5 \% \mathrm{Pd} / \gamma-\mathrm{Al}_{2} \mathrm{O}_{3}, 5 \mathrm{~mL} / \mathrm{min}$ agua, $250 \mathrm{~mL} / \mathrm{min} \mathrm{H}_{2}, 250 \mathrm{~mL} / \mathrm{min} \mathrm{CO}_{2}$ ). .... 128 
Figura 6. 1. Estudio del tiempo de vida del catalizador $2,5 \% \mathrm{Sn} / 5 \% \mathrm{Pd} / \gamma-\mathrm{Al}_{2} \mathrm{O}_{3}$ utilizando agua natural. 136

Figura 6. 2. Recta de desactivación del catalizador $2,5 \% \mathrm{Sn} / 5 \% \mathrm{Pd} / \gamma-\mathrm{Al}_{2} \mathrm{O}_{3}$ en la reducción catalítica utilizando agua natural (concentración inicial de nitratos=95 mg/L) . . 137

Figura 6. 3. Estudio del tiempo de vida del catalizador $2,5 \% \mathrm{Sn} / 5 \% \mathrm{Pd} / \gamma-\mathrm{Al}_{2} \mathrm{O}_{3}$ utilizando agua destilada conteniendo nitratos. 138

Figura 6. 4. Recta de desactivación del catalizador $2,5 \% \mathrm{Sn} / 5 \% \mathrm{Pd} / \gamma-\mathrm{Al}_{2} \mathrm{O}_{3}$ en la reducción catalítica utilizando agua destilada conteniendo nitratos (concentración inicial de nitratos $=98 \mathrm{mg} / \mathrm{L})$. 139

Figura 6. 5. Conversión obtenida al regenerar el catalizador $2,5 \% \mathrm{Sn} / 5 \% \mathrm{Pd} / \mathrm{Al}_{2} \mathrm{O}_{3}$ utilizando distintos tratamientos.

Figura 6. 6. Comparación entre la conversión de nitratos obtenida al regenerar el catalizador $2,5 \% \mathrm{Sn} / 5 \% \mathrm{Pd} / \gamma-\mathrm{Al}_{2} \mathrm{O}_{3}$ y la obtenida con el catalizador original.

Figura 6. 7. Comparación entre la selectividad a amonio obtenida al regenerar el catalizador $2,5 \% \mathrm{Sn} / 5 \% \mathrm{Pd} / \gamma-\mathrm{Al}_{2} \mathrm{O}_{3}$ y la obtenida con el catalizador original.

Figura 6. 8. Conversión de nitratos obtenida al regenerar 3 veces 1 gramo de catalizador $2,5 \% \mathrm{Sn} / 5 \% \mathrm{Pd} / \gamma-\mathrm{Al}_{2} \mathrm{O}_{3}$ lavándolo con agua (los valores entre paréntesis indican la cantidad de catalizador en cada experimento). 143

Figura 6. 9. Selectividad a amonio obtenida al regenerar 3 veces 1 gramo de catalizador $2,5 \% \mathrm{Sn} / 5 \% \mathrm{Pd} / \gamma-\mathrm{Al}_{2} \mathrm{O}_{3}$ lavándolo con agua (los valores entre paréntesis corresponden a la cantidad de catalizador en cada experimento).

Figura 6. 10. Conversión de nitratos obtenida al regenerar 3 veces 3 gramos de catalizador $1,5 \% \mathrm{Sn} / 3 \% \mathrm{Pd} / \gamma-\mathrm{Al}_{2} \mathrm{O}_{3}$ lavándolo con agua. 145

Figura 6. 11. Selectividad a amonio obtenida al regenerar 3 veces 3 gramos de catalizador $1,5 \% \mathrm{Sn} / 3 \% \mathrm{Pd} / \gamma-\mathrm{Al}_{2} \mathrm{O}_{3}$ lavándolo con agua. 145

Figura 6. 12. Actividad del catalizador $2,5 \% \mathrm{Sn} / 5 \% \mathrm{Pd} / \gamma-\mathrm{Al}_{2} \mathrm{O}_{3}$ usando aguas de distintas procedencias. 147

Figura 6. 13. Conversión obtenida con los catalizadores $2,5 \% \mathrm{Sn} / 5 \% \mathrm{Pd} / \gamma-\mathrm{Al}_{2} \mathrm{O}_{3}$ y 1,5\%Sn/3\% Pd $/ \gamma-\mathrm{Al}_{2} \mathrm{O}_{3}\left(3 \mathrm{~g}\right.$ de catalizador, $5 \mathrm{~mL} / \mathrm{min}$ agua, $250 \mathrm{~mL} / \mathrm{min} \mathrm{H}_{2}, 250$ $\left.\mathrm{mL} / \mathrm{min} \mathrm{CO}_{2}\right)$. 148 
Figura 6. 14. Selectividad a amonio obtenida con los catalizadores $2,5 \% \mathrm{Sn} / 5 \% \mathrm{Pd} / \gamma-\mathrm{Al}_{2} \mathrm{O}_{3}$ y $1,5 \% \mathrm{Sn} / 3 \% \mathrm{Pd} / \gamma-\mathrm{Al}_{2} \mathrm{O}_{3}\left(3 \mathrm{~g}\right.$ de catalizador, $5 \mathrm{~mL} / \mathrm{min}$ agua, $250 \mathrm{~mL} / \mathrm{min} \mathrm{H}_{2}, 250$ $\left.\mathrm{mL} / \mathrm{min} \mathrm{CO}_{2}\right)$. 148

Figura 6. 15. Conversión obtenida con los catalizadores $2,5 \% \mathrm{Sn} / 5 \% \mathrm{Pd} / \gamma-\mathrm{Al}_{2} \mathrm{O}_{3}$ y 0,5\%Sn/1\%Pd/AAS (3 g de catalizador, $5 \mathrm{~mL} / \mathrm{min}$ agua, $250 \mathrm{~mL} / \mathrm{min} \mathrm{H}_{2}, 250$ $\left.\mathrm{mL} / \mathrm{min} \mathrm{CO}_{2}\right)$. 149

Figura 6. 16. Selectividad a amonio obtenida con los catalizadores $2,5 \% \mathrm{Sn} / 5 \% \mathrm{Pd} / \gamma-\mathrm{Al}_{2} \mathrm{O}_{3}$ y 0,5\%Sn/1\%Pd/AAS (3 g de catalizador, $5 \mathrm{~mL} / \mathrm{min}$ agua, $250 \mathrm{~mL} / \mathrm{min} \mathrm{H}_{2}, 250$ $\left.\mathrm{mL} / \mathrm{min} \mathrm{CO}_{2}\right)$. 150

Figura 6. 17. Eliminación de amonio por aireación forzada o por difusión de aire 151

Figura 6. 18. Conversión de amonio tras 6 horas de reacción empleando distintos catalizadores (1 gramo de catalizador, $200 \mathrm{~mL} / \mathrm{min}$ de aire). 152

Figura 6. 19. Variación de las concentraciones de amonio y nitratos con la adición de $\mathrm{H}_{2} \mathrm{O}_{2}$ 153

Figura 6. 20. Conversión de nitratos con un catalizador de $2,5 \% \mathrm{Sn} / 5 \% \mathrm{Pd} / \mathrm{Al}_{2} \mathrm{O}_{3}$ y variación de la concentración de amonio a la salida del reactor y tras el paso por una columna de intercambio conteniendo clinoptilolita (20 g). 154

Figura 6. 21. Difractogramas de rayos $X$ de las muestras: (a) $\mathrm{Al}_{2} \mathrm{O}_{3}$, (b) $2,5 \% \mathrm{Sn} / 5 \% \mathrm{Pd} / \gamma$ $\mathrm{Al}_{2} \mathrm{O}_{3}$ calcinada, (c) $2,5 \% \mathrm{Sn} / 5 \% \mathrm{Pd} / \gamma-\mathrm{Al}_{2} \mathrm{O}_{3}$ después de activación con hidrógeno a $500^{\circ} \mathrm{C}$, (d) $2,5 \% \mathrm{Sn} / 5 \% \mathrm{Pd} / \gamma-\mathrm{Al}_{2} \mathrm{O}_{3}$ después de reacción. 155

Figura 6. 22. Difractogramas de rayos $X$ de las muestras después de reacción con $5 \%$ de $\mathrm{Pd}$ y cantidad variable de Sn. 157

Figura 6. 23. Difractogramas de rayos $X$ de las muestras después de reacción con $2,5 \%$ de Pd y cantidad variable de $\mathrm{Cu}$. 158

Figura 6. 24. Perfil de $\mathrm{H}_{2}$-TPR del catalizador $2,5 \% \mathrm{Sn} / 5 \% \mathrm{Pd} / \gamma-\mathrm{Al}_{2} \mathrm{O}_{3}$. 159

Figura 6. 25. Micrografía del catalizador $2,5 \% \mathrm{Sn} / 5 \% \mathrm{Pd} / \gamma-\mathrm{Al}_{2} \mathrm{O}_{3}$ obtenida mediante microscopía electrónica de barrido. 162

Figura 6. 26. Micrografías de microscopía electrónica de transmisión de la muestra $2,5 \% \mathrm{Sn} / 5 \% \mathrm{Pd} / \gamma-\mathrm{Al}_{2} \mathrm{O}_{3}$ 163 
Figura 6. 27. Distribución de tamaño de partícula obtenida mediante microscopía electrónica de transmisión. 163

Figura 6. 28. Esquema de reacción propuesto por Vorlop y col. 165

Figura 6. 29. Actividad de los catalizadores $5 \% \mathrm{Pd} / \gamma-\mathrm{Al}_{2} \mathrm{O}_{3}, 1 \% \mathrm{Sn} / \gamma-\mathrm{Al}_{2} \mathrm{O}_{3}$ y $2,5 \% \mathrm{Sn} / 5 \% \mathrm{Pd} / \gamma$ $\mathrm{Al}_{2} \mathrm{O}_{3}$ en la eliminación de nitratos en aguas naturales 166

Figura 6. 30. Eliminación de nitritos usando el catalizador $5 \% \mathrm{Pd} / \gamma-\mathrm{Al}_{2} \mathrm{O}_{3}$ 167

Figura 6. 31. Actividad del catalizador $2,5 \% \mathrm{Sn} / 5 \% \mathrm{Pd} / \gamma-\mathrm{Al}_{2} \mathrm{O}_{3}$ sin reducir en la eliminación de nitratos en aguas naturales. 168

Figura 6. 32. Concentraciones de nitratos, nitritos y amonio al usar el catalizador $2,5 \% \mathrm{Sn} / 5 \% \mathrm{Pd} / \gamma-\mathrm{Al}_{2} \mathrm{O}_{3}$ en la eliminación de nitratos en aguas naturales 170

Figura 6. 33. Concentraciones de nitratos, nitritos y amonio al usar el catalizador $2,5 \% \mathrm{Sn} / 5 \% \mathrm{Pd} / \gamma-\mathrm{Al}_{2} \mathrm{O}_{3}$ en la eliminación de nitratos en aguas naturales 170

Figura 7. 1. Estructura de una hidrotalcita. 178

Figura 7. 2. Concentración de nitratos para experimentos realizados (a) con hidrógeno, o (b) sin hidrógeno (3,5 g de $\mathrm{HT}(\mathrm{Mg}-\mathrm{Al}-7 \% \mathrm{Cu}), 35 \mathrm{~mL} / \mathrm{min}$ de agua destilada conteniendo $80 \mathrm{mg} / \mathrm{L}$ de nitratos). 180

Figura 7. 3. Esquema de reacción propuesto para la reducción de nitratos usando catalizadores de Pt-Cu.

Figura 7. 4. Espectros de infrarrojo de las muestras utilizadas en un experimento (a) con o (b) sin hidrógeno (catalizador $\mathrm{HT}(\mathrm{Mg}-\mathrm{Al}-7 \% \mathrm{Cu})$ ). 183

Figura 7. 5. Difractogramas de rayos $X$ del catalizador $\mathrm{HT}(\mathrm{Mg}-\mathrm{Al}-7 \% \mathrm{Cu})$ : (a) antes de calcinar; (b) después de calcinar, (c) después de reducir, (d) después de reacción. 184

Figura 7. 6. Concentración de nitratos para experimentos realizados con y sin hidrógeno (2 g de $5 \% \mathrm{Pd} / \mathrm{HT}(\mathrm{Mg}-\mathrm{Al}-1,5 \% \mathrm{Cu}), 20 \mathrm{~mL} / \mathrm{min}$ de agua destilada con $80 \mathrm{mg} / \mathrm{L}$ de nitratos). 185

Figura 7. 7. Esquema propuesto para la reacción de eliminación de nitratos utilizando hidrotalcitas como catalizadores. 
Figura 7. 8. Actividad del catalizador $5 \% \mathrm{Pd} / \mathrm{HT}(\mathrm{Mg}-\mathrm{Al}-\mathrm{Cu})$ al modificar la cantidad de $\mathrm{Cu}$ en la estructura de la hidrotalcita (2 gramos de catalizador, $15 \mathrm{~mL} / \mathrm{min}$ de agua destilada con $80 \mathrm{mg} / \mathrm{L}$ de nitratos). 187

Figura 7. 9. Actividad del catalizador $\mathrm{Pd} / \mathrm{HT}(\mathrm{Mg}-\mathrm{Al} / 7 \% \mathrm{Cu})$ al modificar la cantidad de $\mathrm{Pd}$ impregnada en el catalizador (2 gramos de catalizador, $15 \mathrm{~mL} / \mathrm{min}$ de agua con $80 \mathrm{mg} / \mathrm{L}$ de nitratos). 187

Figura 7. 10. Conversión de nitratos frente al tiempo al usar el catalizador $2 \% \mathrm{Pd} / \mathrm{HT}(\mathrm{Mg}-\mathrm{Al}-$ $7 \% \mathrm{Cu}$ ) en la reducción de nitratos en agua destilada conteniendo 100 ppm de nitratos ( $2 \mathrm{~g}$ de catalizador, $20 \mathrm{~mL} / \mathrm{min}$ agua) o en agua natural (4 g de catalizador, $10 \mathrm{~mL} / \mathrm{min})$. 189

Figura 7. 11. Conversión de nitratos frente al tiempo al utilizar agua sintética con nitratos (1,5 g de catalizador 5\% Pd/HT(Mg-Al-1,5\%Cu), $15 \mathrm{~mL} / \mathrm{min}$ agua) o con nitratos y sulfatos ( $4 \mathrm{~g}$ de catalizador, $10 \mathrm{~mL} / \mathrm{min}$ agua). 190

Figura 7. 12. Representación de la estructura de la zeolita deslaminada ITQ-2 191

Figura 7. 13. Representación de la estructura de la zeolita deslaminada ITQ-6. 192

Figura 7. 14. Conversión a nitratos de los catalizadores $2,5 \% \mathrm{Sn} / 5 \% \mathrm{Pd}$ soportados sobre ITQ-6 e ITQ-2 (3 g catalizador, $5 \mathrm{~mL} / \mathrm{min}$ agua, $250 \mathrm{~mL} / \mathrm{min} \mathrm{H}_{2}, 250 \mathrm{~mL} / \mathrm{min} \mathrm{CO}_{2}$ ). 193

Figura 7. 15. Actividad de los catalizadores Sn/Pd soportados sobre zeolitas ITQ-2 con distinta relación Si/Al ( $3 \mathrm{~g}$ catalizador, $5 \mathrm{~mL} / \mathrm{min}$ agua, $250 \mathrm{~mL} / \mathrm{min} \mathrm{H}_{2}, 250$ $\left.\mathrm{mL} / \mathrm{min} \mathrm{CO}_{2}\right)$. 194

Figura 7. 16. Conversión y selectividad a amonio de los catalizadores de $2,5 \% \mathrm{Sn}$ y $5 \% \mathrm{Pd}$ soportados sobre zeolita ITQ-2, material mesoporoso MCM-41 y alúmina..... 195 


\section{ÍNDICE DE TABLAS}

Tabla 1. 1. Localización del agua en la Tierra 4

Tabla 1. 2. Porcentaje de estaciones con concentración de nitratos superior a $50 \mathrm{mg} / \mathrm{L} \ldots 20$

Tabla 1. 3. Comparación de las técnicas para la eliminación de nitratos 30

Tabla 3. 1. Composición y procedencia de las aguas contaminadas por nitratos usadas en el trabajo de tesis. 57

Tabla 5. 1. Área BET de las zeolitas ZSM-5 de distinta relación $\mathrm{Si} / \mathrm{Al}\left(\mathrm{m}^{2} / \mathrm{g}\right)$. 109

Tabla 5. 2. Área BET del material MCM-41 con distinta relación Si/AI (m²/g). 111

Tabla 5. 3. Área BET de los óxidos utilizados como soportes en la reducción catalítica de nitratos en aguas naturales.

Tabla 6. 1. Principales características del agua natural usada en las reacciones. 135

Tabla 6. 2. Condiciones de reacción para el estudio del tiempo de vida del catalizador $2,5 \% \mathrm{Sn} / 5 \% \mathrm{Pd} / \gamma-\mathrm{Al}_{2} \mathrm{O}_{3}$. 136

Tabla 6. 3. Análisis elemental del catalizador $2,5 \% \mathrm{Pd} / 5 \% \mathrm{Pd} / \gamma-\mathrm{Al}_{2} \mathrm{O}_{3}$ después de ser utilizado en una reacción con agua natural. 140

Tabla 6. 4. Composición química y procedencia de las aguas estudiadas. 146

Tabla 6. 5. Dispersión y tamaño de cristal determinados por quimisorción de CO de distintos catalizadores $\mathrm{Sn}-\mathrm{Pd} / \gamma-\mathrm{Al}_{2} \mathrm{O}_{3}$. 160

Tabla 6. 6. Resultados de quimisorción de $\mathrm{CO}$ del catalizador $2,5 \% \mathrm{Sn} / 5 \% \mathrm{Pd} / \gamma-\mathrm{Al}_{2} \mathrm{O}_{3}$ reducido a $500^{\circ} \mathrm{C}$ y a $50^{\circ} \mathrm{C}$.

Tabla 6. 7. Análisis por dispersión de rayos $\mathrm{X}$ del catalizador $\left(2,5 \% \mathrm{Sn} / 5 \% \mathrm{Pd} / \gamma-\mathrm{Al}_{2} \mathrm{O}_{3}\right) \ldots .162$

Tabla 6. 8. Propiedades texturales de la alúmina y el catalizador $2,5 \% \mathrm{Sn} / 5 \% \mathrm{Pd} / \gamma-\mathrm{Al}_{2} \mathrm{O}_{3}$ antes y después de reacción. 164

Tabla 6. 9. Dispersión de Pd, conversión a nitrato y selectividades a amonio, nitrógeno y nitrito, de los catalizadores $0,5 \% \mathrm{Sn} / 1 \% \mathrm{Pd} / \gamma-\mathrm{Al}_{2} \mathrm{O}_{3}, 1,5 \% \mathrm{Sn} / 3 \% \mathrm{Pd} / \gamma-\mathrm{Al}_{2} \mathrm{O}_{3}$ y $2,5 \% \mathrm{Sn} / 5 \% \mathrm{Pd} / \gamma-\mathrm{Al}_{2} \mathrm{O}_{3}$. 
Tabla 7. 1. Contenido en nitrógeno del catalizador $\mathrm{HT}(\mathrm{Mg}-\mathrm{Al}-7 \% \mathrm{Cu})$ tras reacción con o sin hidrógeno. 181

Tabla 7. 2. Contenido en nitrógeno del catalizador $\mathrm{HT}(\mathrm{Mg}-\mathrm{Al}-7 \% \mathrm{Cu})$ sin reducir y del catalizador $\mathrm{HT}(\mathrm{Mg}-\mathrm{Al})$. 182

Tabla 7. 3. Contenido en $\mathrm{N}$ del catalizador y $\mathrm{N}$ eliminado en la reacción al realizar experimentos con o sin hidrogenación (catalizador 5\% Pd/HT(Mg-Al-1,5\%Cu)). 183

Tabla 7. 4. Contenido en nitrógeno, carbono y azufre del catalizador $2 \% \mathrm{Pd} / \mathrm{HT}(\mathrm{Mg}-\mathrm{Al}-$ $7 \% \mathrm{Cu}$ ) al realizar experimentos con agua sintética y con agua natural............ 190

Tabla 7. 5. Área BET de las zeolitas ITQ-2 de distinta relación $\mathrm{Si} / \mathrm{Al}\left(\mathrm{m}^{2} / \mathrm{g}\right)$. 194

Tabla 7. 6. Área externa de las zeolitas ITQ-2 de distinta relación Si/AI (m²/g). 194 

ANEXO II

\section{RESUMEN-RESUM-ABSTRACT}





\section{RESUMEN}

La contaminación por nitratos de las aguas naturales es un problema que afecta a numerosas zonas en las que se desarrolla una agricultura y ganadería intensivas. Para eliminar los nitratos presentes en las aguas de estas zonas se han propuesto varias alternativas, la mejor de las cuales, desde un punto de vista medioambiental, sería la reducción catalítica de nitratos a nitrógeno.

En esta tesis se ha estudiado esta técnica para eliminar los nitratos presentes en aguas naturales contaminadas, utilizando un reactor en continuo. Para ello, se han optimizado las condiciones de reacción, estableciendo que los mejores resultados se obtienen al trabajar con un $\mathrm{pH}$ próximo a 6,5; temperatura ambiente; con una velocidad de agitación de 900 rpm; un caudal de agua de $5 \mathrm{~mL} / \mathrm{min}$; una masa de catalizador de 3 gramos y a presión atmosférica.

Una vez fijadas las condiciones de reacción se ha optimizado la composición del catalizador y su forma de preparación. Para ello, se han estudiado varias combinaciones de diferentes metales obteniendo los mejores resultados con los catalizadores de Pd-Sn con una relación metal noble/metal no noble de 2. Manteniendo esta relación y trabajando en las condiciones óptimas de reacción es posible tratar un agua natural contaminada con nitratos con un catalizador que contenga tan sólo un $1 \%$ de Pd y un $0,5 \%$ de Sn.

Se ha estudiado la influencia del soporte utilizado en la actividad del catalizador. Para ello se han preparado distintos catalizadores soportados sobre diferentes óxidos, carbones y zeolitas. La mayor actividad y la mejor selectividad a nitrógeno se han obtenido con los catalizadores soportados sobre alúmina o sobre el material mesoporoso MCM-41, ya que ambos poseen una baja conductividad eléctrica, no presentan microporos y tienen una adecuada área específica. Por tanto, se puede concluir que el mejor catalizador para la eliminación de nitratos en continuo en aguas naturales es el catalizador Sn/Pd 
soportado sobre alúmina. La forma óptima de preparar el catalizador es mediante una impregnación a volumen de poro añadiendo primero la sal de Sn y luego la sal de Pd y activando el catalizador a temperaturas inferiores a $200^{\circ} \mathrm{C}$.

Se ha estudiado el tiempo de vida y la desactivación de un catalizador con $2,5 \%$ Sn y $5 \% \mathrm{Pd}$ soportado sobre $\mathrm{Al}_{2} \mathrm{O}_{3}$ determinando que 3 gramos de catalizador pueden tratar durante 17 días $5 \mathrm{~mL} / \mathrm{min}$ de aguas naturales con una concentración de 100 ppm de nitratos. Además, es posible reutilizar varias veces el catalizador tras regenerarlo lavándolo con agua destilada, ya que su desactivación está principalmente relacionada con la deposición de especies iónicas sobre la superficie del catalizador. No obstante, hay que destacar, que es imposible evitar en la reacción de reducción de nitratos la producción de amonio, por ello se han estudiado distintas opciones para eliminar este subproducto. Tras analizar éstas, se ha determinado que la mejor manera de eliminar el amonio del medio es por intercambio aniónico usando una zeolita natural (clinoptilolita).

El catalizador $\mathrm{Sn} / \mathrm{Pd} / \mathrm{Al}_{2} \mathrm{O}_{3}$ se ha caracterizado mediante diferentes técnicas, antes y después de reacción, con el fin de determinar las fases activas del mismo, las propiedades texturales, el tamaño de partícula metálica y su dispersión. Los resultados obtenidos muestran que el catalizador es estable durante la reacción y no sufre modificaciones en su estructura ni en sus propiedades texturales.

La comparación de los resultados obtenidos al estudiar la actividad del catalizador con los resultados obtenidos en su caracterización ha permitido determinar que inicialmente los nitratos son reducidos a nitritos, siendo posteriormente los nitritos reducidos a nitrógeno o amonio. Se ha comprobado que la especie activa para la reducción de los nitratos a nitritos es el par Pd-Sn, mientras que el metal noble es el que reduce los nitritos a nitrógeno o amonio. Asimismo, se ha determinado que para que el catalizador sea activo, el paladio debe estar reducido y altamente disperso, mientras que el estaño no ha de estar como estaño metálico ni formando especies $\mathrm{Pd}_{\mathrm{x}} \mathrm{Sn}_{\mathrm{y}}$. 
Por último, se ha estudiado la actividad de nuevos catalizadores $\mathrm{Pd} /(\mathrm{Cu}$ o $\mathrm{Sn}$ ) soportados sobre otros materiales como hidrotalcitas o zeolitas deslaminadas, observando que el catalizador Pd-Sn soportado sobre la zeolita deslaminada ITQ-2 presenta una mejor actividad y selectividad si se compara con el resto de los catalizadores estudiados. Esto es probablemente debido a su elevada área externa que permite minimizar los problemas difusionales que presenta esta reacción, abriendo nuevas posibilidades para el diseño de nuevos catalizadores activos y selectivos en esta reacción. 


\section{RESUM}

La contaminació per nitrats de les aigües naturals és un problema que afecta a nombroses zones en les que es desenvolupa una agricultura i ramaderia intensives. Per tal de reduir els nitrats presents en les dites aigües s'han proposat varies alternatives, la millor de les quals, des d'un punt de vista mediambiental, seria la reducció catalítica de nitrats a nitrogen.

En esta tesi s'ha estudiat aquesta tècnica per a eliminar nitrats presents en aigües naturals contaminades, utilitzant un reactor en continu. Per a això, s'han optimitzat les condicions de reacció, establint que els millors resultats s'obtenen al treballar amb un pH pròxim a 6,5; temperatura ambient; amb una velocitat d'agitació de 900 rpm; un cabal d'aigua de $5 \mathrm{~mL} / \mathrm{min}$; una massa de catalitzador de 3 grams i a pressió atmosfèrica.

Una volta fixades les condicions de reacció s'ha optimitzat la composició del catalitzador i la seua forma de preparació. S'han estudiat diverses combinacions de diferents metalls obtenint els millors resultats amb els catalitzadors de Pd-Sn amb una relació metall noble/metall no noble de 2 . Mantenint esta relació i treballant en les condicions òptimes de reacció es possible tractar una aigua natural contaminada amb nitrats amb un catalitzador que continga tan sols un $1 \%$ de $\mathrm{Pd}$ i un $0,5 \%$ de $\mathrm{Sn}$.

S'ha estudiat la influència del suport utilitzat en l'activitat del catalitzador. Per a això s'han preparat distints catalitzadors suportats sobre diferents òxids, carbons i zeolites. La millor activitat i la millor selectivitat a nitrogen s'han obtingut amb els catalitzadors suportats sobre alúmina o sobre el material mesoporós MCM-41, ja que ambdós posseeixen una baixa conductivitat elèctrica, no presenten microporus i tenen una adequada àrea específica. Per tant, s'ha conclòs que el millor catalitzador per a la eliminació de nitrats en continu en aigües naturals és el catalitzador Sn/Pd suportat sobre alúmina. La forma òptima de preparar el catalitzador és mitjançant una impregnació a 
volum de porus afegint primer la sal de Sn i després la de Pd i activant el catalitzador a temperatures inferiors a $200^{\circ} \mathrm{C}$.

S'ha estudiat el temps de vida i la desactivació d'un catalitzador amb 2,5\%Sn i 5\%Pd suportat sobre $\mathrm{Al}_{2} \mathrm{O}_{3}$ determinant que 3 grams de catalitzador poden tractar durant 17 dies $5 \mathrm{~mL} / \mathrm{min}$ d'aigües naturals am una concentració de 100 ppm de nitrats. A més, és possible reutilitzar varies voltes el catalitzador després de regenerar-lo llavant-lo amb aigua destilllada, ja que la seua desactivació està principalment relacionada amb la deposició d'espècies iòniques sobre la superfície del catalitzador. No obstant, hi ha que destacar que és impossible evitar en la reacció de reducció dels nitrats la formació d'amoni, per això s'han estudiat distintes opcions per a eliminar aquest subproducte. Després d'analitzar estes, s'ha determinat que la millor manera d'eliminar l'amoni del medi és per intercanvi aniònic usant una zeolita natural (clinoptilolita).

El catalitzador $\mathrm{Sn} / \mathrm{Pd} / \mathrm{Al}_{2} \mathrm{O}_{3}$ s'ha caracteritzat per diferents tècniques, abans $\mathrm{i}$ després de reacció, a fi de determinar les fases actives del mateix, les propietats texturals, la grandària de la partícula metàl-lica i la seua dispersió. Els resultats obtinguts mostren que el catalitzador és estable durant la reacció i no pateix modificacions en la seua estructura ni en les seues propietats texturals.

La comparació dels resultats obtinguts al estudiar l'activitat del catalitzador amb els resultats obtinguts en la seua caracterització han permès determinar que inicialment els nitrats són reduïts a nitrits, sent posteriorment els nitrits reduïts a nitrogen o amoni. S'ha comprovat que l'espècie activa per a la reducció dels nitrats a nitrits és el par Pd-Sn, mentre que el metall noble és el que redueix els nitrits a nitrogen o amoni. Així mateix, $s^{\prime}$ ha determinat que perquè el catalitzador siga actiu, el pal-ladi ha d'estar reduït $\mathrm{i}$ altament dispers, mentre que l'estany no ha d'estar com estany metàl/lic ni formant espècies $\mathrm{Pd}_{\mathrm{x}} \mathrm{Sn}_{\mathrm{y}}$. 
Finalment, s'ha estudiat l'activitat de nous catalitzadors $\mathrm{Pd} /(\mathrm{Cu}$ ○ Sn) suportats sobre altres materials com hidrotalcites o zeolites deslaminades, concloent que el catalitzador Pd-Sn suportat sobre la zeolita deslaminada ITQ-2 presenta una millor activitat i selectivitat si se compara amb la resta de catalitzadors estudiats. Açò es déu probablement a la seua elevada àrea externa que permet disminuir els problemes difusionals que presenta esta reacció, obrint noves possibilitats per al disseny de nous catalitzadors actius i selectius en aquesta reacció. 


\section{ABSTRACT}

Nitrates contamination in natural water is a problem that affects many agricultural and livestock areas. To reduce the nitrates present in that water some techniques have been proposed being the best, from an environmental point of view, the catalytic reduction of nitrates to nitrogen.

In this thesis, that technique has been studied to remove the nitrates in natural contaminated waters, using a continuous reactor. The reaction conditions have been optimized, stating that the best results are obtained with a $\mathrm{pH}$ around 6,5; room temperature; a stirring velocity of $900 \mathrm{rpm}$; a water flow of $5 \mathrm{~mL} / \mathrm{min}$; 3grams of catalyst and atmospheric pressure.

The catalyst composition and its preparation have been optimized. Different metal combinations have been studied, achieving the best results using a Pd-Sn catalyst with a noble metal/no noble metal ratio of 2 . Maintaining this ratio and working in the optimal conditions it is possible to treat a natural water contaminated with nitrates with a catalyst containing $1 \% \mathrm{Pd}$ and $0,5 \% \mathrm{Sn}$.

The influence of the support in the catalyst activity has been studied. Some catalysts supported on oxides, carbons and zeolites have been used, and the best activity and selectivity to nitrogen has been obtained with the catalyst based in alumina or in a mesoporous material such as MCM-41, since both have low electrical conductivity, have no micropores and have adequate specific area. From these results it was concluded that the best catalyst to remove nitrates in a continuous reactor is the $\mathrm{Sn} / \mathrm{Pd}$ catalyst supported on alumina. The best results are obtained with a catalyst prepared by wetness impregnation adding first the $\mathrm{Sn}$ salt and then the $\mathrm{Pd}$ salt and activating the catalyst at temperatures below $200^{\circ} \mathrm{C}$. 
The catalyst lifetime and the deactivation of a catalyst with $2,5 \% \mathrm{Sn}$ and $5 \% \mathrm{Pd}$ supported on alumina have been studied and it was found that 3 grams of the catalyst can treat during 17 days $5 \mathrm{~mL} / \mathrm{min}$ of natural water containing $100 \mathrm{ppm}$ of nitrates. Moreover, it is possible to reuse several times the catalyst after its regeneration. The regeneration was made with distilled water because the catalyst deactivation is mainly related to the deposition of ionic species on the support surface. However, it must be stressed that it is impossible to avoid during the nitrates reduction the production of ammonium, therefore some options have been studied to remove this by-product. It has been determined that the best way to remove ammonium from the media is using a natural zeolite (clinoptilolite) as anionic exchanger.

The catalyst $\mathrm{Sn} / \mathrm{Pd} / \mathrm{Al}_{2} \mathrm{O}_{3}$ has been characterized using different techniques, before and after reaction, to determine the active phases, the textural properties, the metal particle size and the metal dispersion. The results obtained shows that the catalyst is stable during the reaction and there are not modifications of its structure or of its textural properties.

The comparison of the results obtained in the catalyst activity study with the results obtained in the characterization study show that first the nitrates are reduce to nitrites, and then the nitrites are reduced to nitrogen or ammonium. The active phase in the reduction of the nitrates to nitrites is the $\mathrm{Pd}-\mathrm{Sn}$ combination, while the noble metal is able to reduce the nitrites to nitrogen or ammonium. Also, it has been determined that in order to obtain an active catalyst the palladium has to be reduced and highly dispersed, while the tin has not to be as metallic tin or forming $\mathrm{Pd}_{\mathrm{x}} \mathrm{Sn}_{\mathrm{y}}$ species.

Finally the activity of new $\mathrm{Pd} /(\mathrm{Cu}$ or $\mathrm{Sn})$ catalysts supported on other materials such as hydrotalcites or delaminated zeolites has been determined. The conclusion is that the best activity and selectivity is obtained with the Pd-Sn catalyst supported on delaminated ITQ-2 zeolite. This is probably due to its high external surface area that decreases the 
diffusional problems. This opens new possibilities for the design of new active and selective catalysts in this reaction. 



\section{ANEXO III}

\section{CURRICULUM OBTENIDO}

DURANTE EL PERIODO DE TESIS

DOCTORAL 



\section{Participación en proyectos de investigación}

- 2007-2008

Título: Desarrollo de nuevos sistemas catalíticos para el control de gases contaminantes precursores de ozono.

Entidad financiadora: Conselleria d’Empresa, Universitat i Ciencia, Generalitat Valenciana.

Investigador principal: Dr. Antonio Eduardo Palomares Gimeno (Departamento de Ingeniería Química y Nuclear, Universitat Politècnica de Valencia).

- 2010-2012

Título: Síntesis, caracterización avanzada y empleo en procesos industriales de nuevas zeolitas obtenidas con cationes orgánicos no convencionales como agentes directores de estructura.

Entidad financiadora: Ministerio de Ciencia e Innovación.

Investigador principal: Prof. Fernando Rey García (Instituto de Tecnología Química, UPV-CSIC)

- 2010-2010

Título: Comparative catalytic XAS study of Cu-ZSM-5 and Cu-IM-5.

Entidad financiadora: European Synchrotron Radiation Facility (ESRF).

Investigador principal: Dr. Gemma Guilera

- 2009-2012

Título: Monolithic reactors structured at the nano and micro levels for catalytic water purification.

Investigador principal: Dr. Enrique García Bordejé

\section{Publicaciones}

Autores: A.E. Palomares, C. Franch, A. Corma.

Título: Nitrates removal from polluted aquifers using ( $\mathrm{Sn}$ or $\mathrm{Cu}$ )/Pd catalysts in a continuous reactor.

Revista: Catalysis Today 149 (2009) 348-351. 
Autores: A.E. Palomares, C. Franch, A. Corma.

Título: Answer to the comments made by Ruiz-Bevia et al. on "Nitrates removal from polluted aquifers using ( $\mathrm{Sn}$ or $\mathrm{Cu}) / \mathrm{Pd}$ catalysts in a continuous reactor".

Revista: Catalysis Today 160 (2011) 251.

Autores: A.E. Palomares, C. Franch, A. Corma.

Título: A study of different supports for the catalytic reduction of nitrates from natural water with a continuous reactor.

Revista: Catalysis Today 172 (2011) 90.

Autores: A.E. Palomares, C. Franch, A. Corma.

Título: Determining the characteristics of a Co-zeolite to be active for the selective catalytic reduction of NOx with hydrocarbons.

Revista: Catalysis Today in press.

Autores: X. Fan, C. Franch, A.E. Palomares, A. Lapkin.

Título: Simulation of catalytic reduction of nitrates based on a mechanistic model.

Revista: Chemical Engineering Journal In press.

Autores: C. Franch, E. Rodríguez-Castellón, A. Reyes-Carmona. A.E. Palomares

Título: Characterization of $(\mathrm{Sn}$ and $\mathrm{Cu}) / \mathrm{Pd}$ catalysts for the nitrate hydrogenation in natural water.

Revista: En preparación.

\section{Contribuciones a congresos}

Autores: A.E. Palomares, C. Franch.

Título: Catalizadores de Sn-Pd y Cu-Pd para la eliminación catalítica de nitratos en aguas subterráneas con un reactor continuo.

Tipo de contribución: Comunicación Oral

Conferencia: SECAT'07

Publicación: Actas

Lugar: Bilbao

Fecha: 2007

Autores: A.E. Palomares, C. Franch.

Título: Eliminación de nitratos en aguas naturales mediante catalizadores de $(\mathrm{Sn}-\mathrm{Cu}) / \mathrm{Pd}$ con un reactor continuo.

Tipo de contribución: Comunicación Oral

Conferencia: SICAT'08

Publicación: Actas

Lugar: Benalmádena, Málaga

Fecha: 2008 
Autores: A.E. Palomares, C Franch, A. Corma.

Título: A study on the activity and selectivity of a $\mathrm{Pd} /(\mathrm{Cu}$ or $\mathrm{Sn})$ catalyst for the denitrification of natural water in different reactor systems.

Tipo de contribución: Poster

Conferencia: XVII International Conference on Chemical Reactors

Publicación: Actas

Lugar: Malta

Fecha: 2008

Autores: A.E. Palomares, C. Franch, A. Uzcátegui, A. Corma.

Título: Catalysts based in hydrotalcites containing transition alkaline metals as active NOx storage/reduction catalysts.

Tipo de contribución: Poster

Conferencia: Eighth International Congress on Catalysis and Automotive Pollution Control.

Publicación: Actas

Lugar: Bruselas

Fecha: 2009

Autores: A.E. Palomares, C. Franch, A. Uzcátegui, A. Corma.

Título: Doped cobalt hydrotalcites as NOx storage/reduction catalysts.

Tipo de contribución: Comunicación Oral

Conferencia: $21^{\text {st }}$ North American Catalysis Society Meeting

Publicación: Actas

Lugar: San Francisco

Fecha: 2009

Autores: A.E. Palomares, C Franch, A. Corma.

Título: Utilización de soportes micro o mesoporosos en la reducción catalítica de nitratos en continuo en aguas naturales.

Tipo de contribución: Comunicación Oral

Conferencia: SECAT'09

Publicación: Actas

Lugar: Ciudad Real

Fecha: 2009

Autores: A.E. Palomares, C Franch, A. Corma.

Título: Characterizing NOx storage/reduction based on hydrotalcites containing transition and alkaline metals.

Tipo de contribución: Poster

Conferencia: IX European congress on catalysis (EUROPACAT IX)

Publicación: Actas

Lugar: Salamanca

Fecha: 2009 
Autores: A.E. Palomares, C Franch, A. Corma.

Título: New zeolitic materials for the SCR of NOx in stationary resources.

Tipo de contribución: Comunicación Oral

Conferencia: APAC2010

Publicación: Actas

lugar: Cracovia, Polonia

Fecha: 2010

Autores: A.E. Palomares, C Franch, A. Corma.

Título: Micro and mesoporous supports used for the catalytic reduction of nitrates in continuous in natural water.

Tipo de contribución: Poster

Conferencia: IZC-IMMS2010

Publicación: Actas

Lugar: Sorrento, Italia

Fecha: 2010

Autores: A.E. Palomares, C Franch, A. Corma.

Título: Reducción catalítica, en continuo, de los nitratos presentes en aguas naturales, empleando distintos soportes catalíticos.

Tipo de contribución: Poster

Conferencia: CICAT2010

Publicación: Actas

Lugar: Cón-Cón, Chile

Fecha: 2010

Autores: S. Armenise, E. García-Bordejé, E. Vanhaecke, M. Rönning, T. louranova, L. KiwiMinsker, C Franch, A.E. Palomares.

Título: Catalytic nitrate reduction using carbon nanofibers on macrostructured supports.

Tipo de contribución: Oral

Conferencia: Water \& Industry

Publicación: Actas

Lugar: Valladolid

Fecha: 2011

Autores: C Franch, A.E. Palomares, S. Armenise, E. García-Bordejé.

Título: Eliminación de nitratos con catalizadores $\mathrm{Pd}-\mathrm{Cu}$ soportados en nanofibras de carbono.

Tipo de contribución: Poster

Conferencia: SECAT2011

Publicación: Actas

Lugar: Zaragoza

Fecha: 2011 
Autores: C Franch, A.E. Palomares, A. Corma.

Título: Eliminación de nitratos en aguas naturales utilizando soportes micro y mesoporosos.

Tipo de contribución: Oral

Conferencia: SECAT2011

Publicación: Actas

Lugar: Zaragoza

Fecha: 2011

Autores: A.E. Palomares, C Franch, A. Corma.

Título: Microporous, mesoporous and delaminated supports for Pd-Sn catalysts in the water nitrates hydrogenation.

Tipo de contribución: Poster

Conferencia: FEZA2011

Publicación: Actas

Lugar: Valencia

Fecha: 2011 